\title{
THE FEEDING OF
}

CROPS AND STOCK

A. D. HA L L 


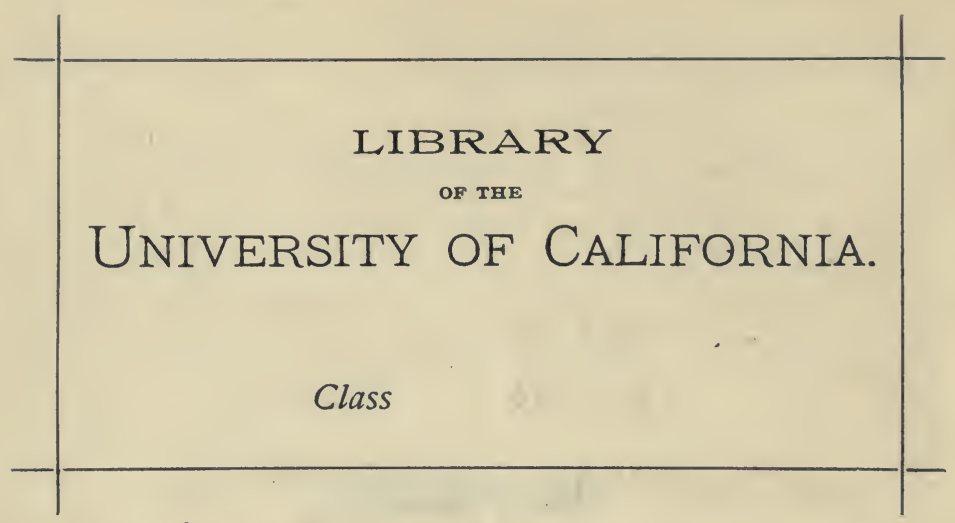




Digitized by the Internet Archive in 2008 with funding from Microsoft Corporation 

THE FEEDING OF CROPS AND STOCK 



\section{THE FEEDING OF CROPS AND STOCK}

AN INTRODUCTION 'TO THE SCIENCE OF THE NUTRITION OF .PLAN'TS AND ANIMALS

BY A. D. HALL, M.A., F.R.S.

DIRECTOR OP TBE ROTHAMSTED EXPERIMENTAL GTATION FOREION MEMBER OF THE ROYAL ACADEMY OF AORICULTURE OF SWEDEN

WITH ILLUSTRATIONS AND DIAGRAMS

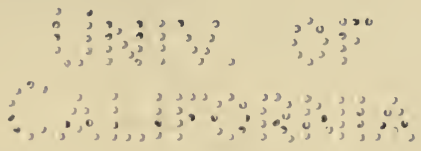

NEW YORK

E. P. DUTTON AND COMPANY 
$=-2$.

LIRARAM WH

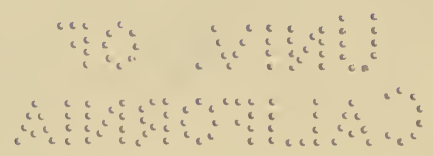




\section{INTRODUCTION}

IN this book I have endeavoured to provide a general introduction to the science of growing crops and feeding animals : an outline, in fact, of the theory of the nutrition, first of the plant and then of the animal. The book is intended on one side to give the student of agriculture a general framework of ideas, before he enters upon the more detailed study of agricultural chemistry that will be presented to him by his professor. I have found that such students often experience a difficulty in following and making the best use of their lectures because the whole trend of the subject is strange to them; they would be better able to appreciate the value of the illustrations they receive if they could at once see their bearing upon the scheme of nutrition of plant or animal. There are many students also in our schools and colleges who do not as a rule pursue the subject any further than it is carried in these pages; both on their account and for the student who is only laying a foundation, I have insisted as far as possible on the main principles governing this branch of science, hoping thereby to induce a sound way of thinking that will not prove misleading on 
further study and practical experience. The writer of an elementary book must always adopt short views and make dogmatic statements which he knows to be no more than approximations to the truth. I can only hope that the constant reference to experiment, and the whole style in which the book has been written, will keep before the reader an appreciation of how much still remains unsaid.

Even more than for the student, this book is intended for the workaday farmer who wants to get an intelligent conception of how his crops and stock make their growth. Complex and unknown as many of these processes are, the main outlines are sufficiently estab. lished to have a bearing upon practice; but the practical application can be more surely and readily made if the farmer, with his inside knowledge of the way things can be done, will learn the theory, than by any attempt of the scientific man striving from the outside to get up the working conditions.

Moreover, the subject is interesting; it should neither be difficult nor tedious for the man with an ordinary education to learn how a plant draws its nutriment from the soil, and how the animal depends in its turn upon the plant; so if this book is not readable, mine is the fault, and I have failed in the object with which I set out. To this end I have avoided technical language as much as possible, and I have assumed that the reader possesses little or no knowledge of chemistry. Of course, a book of this kind cannot be finally intelligible unless the reader possesses some ideas about the constitution of air and water and the nature of chemical 
change, but these ideas are becoming more generally diffused every day, and the unfamiliar reader may to some extent gather them as he goes along. I must express my indebtedness to Dr E. J. Russell for his advice on certain sections of the book, and to Miss W. E. Brenchley for the botanical drawings therein contained. Miss L. M. Underwood also has greatly helped me by compiling the index. As on other occasions also, I have to thank Mr G. T. Dunkley for the care he has taken in looking through the proofs, and verifying the results quoted.

A. D. HALL.

The Rothamsted Experimental Station,

June 1910. 



\section{TABLE OF CONTENTS}

\section{CHAPTER I}

\section{WHAT THE PLANT IS MADE OF}

Elements present in the Plant. The Chief Compounds forming Plant Tissues-Carbohydrates, Fats, Proteins, $a$-Proteins, and Ash. The Growth of a Plant from a Seed; the Embryo and the Food Store. Conditions necessary for Germination-Water, Warmth, Air. How Materials are moved to the Growing Parts of a Plant. Seed Testing

\section{CHAPTER II}

THE WORK OF THE LEAF

The Increase of Weight in a Growing Plant is derived from the Air. Plants split up Carbon Dioxide and give off Oxygen. Purification of the Air by Plants. Formation of Starch in the Green Leaf. Motive Power supplied by Light. All parts of the Living Plant are also breathing. Necessity of Leaves to the Growth and Ripening of the Plant. The Leaves of the Plant give off Water. How much Rainfall is required by Crops . 


\section{CHAPTER III}

\section{THE WORK OF THE ROOTS}

The Roots as anchoring the Plant. The Roots supply the Plant with Water. Roots require Air. Roots can only take in dissolved Material. Etching Action of Roots due to their Excretion of Carbon Dioxide. Elements necessary to the Nutrition of Plants. Plants require Combined Nitrogen

\section{CHAPTER IV}

\section{CHANGES OF COMPOSITION WITHIN THE PLANT}

The Manufacturing, Resting, and Spending Stages in a Plant's Development. The Course of Nutrition and Migration in the Growth of Wheat. The Ripening of the Grain. Storage and Migration in Root Crops. Removal of Food Materials from the Leaves of Trees as they Ripen. The Ripening of Fruit. Effect of Soil and Climate upon the Composition and Quality of the Crop

\section{CHAPTER V}

\section{THE ORIGIN AND NATURE OF SOILS}

The Weathering of Rocks to Soil. Solution of Rock Materials in Water containing Carbon Dioxide. Action of Frost. Transport of Soil by Rain and Running Water. Action of Worms. Approximate Analysis of Soils. Propertics of Clay and Sand. Chemical Constituents of Soils. Soils and Subsoils 


\section{CHAPTER VI}

\section{CULTIVATION AND THE MOVEMENTS OF SOIL WATER}

Nature of the Film of Liquid surrounding Wet Particles of Soil. Retention and Movements of Water due to Surface Tension. Percolation. Rise of Subsoil Water by Capillarity. Value of Autumn Ploughing. Effect of Spring Cultivations. Cooling of the Land by Evaporation. Effect of Hoeing and Rolling upon the Temperature and Water-content of the Soil. Dry Farming in Semi-arid Regions. Drainage and the Temperature of Soils. Spring Frosts. Early and Late Soils .

\section{CHAPTER VII}

\section{THE LIVING ORGANISMS OF THE SOIL}

Formation of Nitrates in the Soil. Bacteria in the Soil which decompose Organic Matter. Bacterial Loss of Nitrogen from the Soil. Formation of Humus. Fixation of Nitrogen by Bacteria associated with Leguminous Plants. Value of Clover Crops in the Rotation. Inoculation of Soil. Other Bacteria-fixing Nitrogen in the Soil. Accumulation of Nitrogen in Virgin Soils. Dependence of Soil Fertility upon Bacteria .

PAGE 100

\section{CHAPTER VIII}

THE CHEMICAL COMPOSITION OF THE SOIL

Plant Food found in Normal Soils. Dormant and Available Plant Food. Rotations and Plant Food in the Soil. Systems of Farming-Wasteful and Conservative. Requirements of Different Crops for Fertilisers. Types of Soil-Characteristic Weeds and Crops . 


\section{CHAPTER IX}

FOODS

Composition of Cattle Foods. Nature of Carbohydrates, Fat, Proteins, Fibre, Ash. Processes of Digestion in the Animal Body. Digestibility. Character of various Concentrated Foods, Cereals, Roots, Straw, and Hay. Valuation of Feeding Stuffs

PAGE

\section{CHAPTER X}

THE UTILISATION OF FOOD BY THE ANIMAL

Food as a Source of Energy. Heat Value of various Foods. Energy consumed in Digestion and Internal Work. Maintenance Rations. Feeding for Rapid Work or Increase of Weight. Amount of Food required for a given Amount of Work. Nitrogenous Materials required to repair Tissue Waste. Minimum of Protein necessary . . . . .

\section{CHAPTER XI}

FOOD REQUIRED BY THE GROWING AND FATTENING ANIMAL

Composition of Lean and Fat Animals. Food required to produce a given Increase of Live Weight. Starch Values of Foods. Albuminoid Ratio. Food Rations for various Purposes, based upon Starch Values

\section{CHAPTER XII}

\section{FARMYARD MANURE}

Composition of Animal Excretions. Litter. Changes taking place during the Making and Storage of 
Manure. Losses of Nitrogen in Manure-makingUnavoidable or due to wasteful Methods. Composition of Farmyard Manure from various Sources. Care of Farmyard Manure. Farmyard Manure as a Fertiliser. Value of Farmyard Manure. Valuation of Manure Residues derived from the Consumption of Purchased Feeding Stuffs. Cost of Farmyard Manure

\section{CHAPTER XIII}

\section{ARTIFICIAL MANURES AND FERTILISERS}

Nature of a Fertiliser. Fertilisers containing NitrogenNitrate of Soda, Sulphate of Ammonia, Soot-their Use and Value. Fertilisers containing Phosphoric Acid. Bones, Superphosphate or Acid Phosphate, Basic Slag or Phosphate Powder, Ground Rock Phosphate. Potash Fertilisers. Guanos. Industrial Residues. Tankage. Action of Fertilising Ingredients upon Crops. Expenditure on Fertilisers. Character of Fertiliser required for particular Crops. Valuation of Fertilisers .

\section{CHAPTER XIV}

\section{MILK, BUTTER, AND CHEESE}

Composition of Milk. Variations to which the Composition of Milk is subject. Effect of Individuality, Breed, Food, Time of Milking, Period of Lactation. Feeding for Milk. Composition of Butter. Nature of the Churning Process. Effect of various Foods upon the Quality of the Butter. Composition of Cheese. Changes taking place during the Cheese-making Process. The Ripening of Cheese. Importance of Cleanliness in all dealings with Milk 



\section{LIST OF ILLUSTRATIONS}

I. Germinating Seedlings of Beans - Face page 6

2. Seeds of Barley at Various Stages of Growth - "

3. Mint Plant in Water splitting up Carbon Dioxide and evolving Oxygen . . . . " "

4. Apparatus to show the Absorption of Carbon

Dioxide by Green Leaves - • " "

5. Starch Formation in the parts of an Artichoke

Leaf cxposed to Light . . . "

6. Barley Seedlings enclosed within Bottle " 30

7. Fern that has been growing inside a closed Bottle for Thirty-six Years . . . "

8. Transpiration of Water from Leaf - . "

9. Apparatus for Measuring Transpiration from Leaf "

10. Stomata on Lower Surface of Sweet Pea Leaf .

11. Root Hairs of Barley . . . " "

12. Contractile Taproot of Dandelion

13. Slab of Polished Marble etched by Roots of Bean

Plant

14. Series of Plants grown in Water Cultures

15. Diagram showing Migration of Foodstuffs with the Grain of Wheat 
16. Formation of a Sedentary Soil . . . Face page 78

17. Formation of a Drift Soil • . . " " 84

18. Experiment to show Percolation and Absorption of Water by Different Soils . . . . " $\quad 92$

19. Photograph illustrating Liquid Film round Soil Particles . . . . . " 100

20. Diagram illustrating Capillary Rise of Liquids "

2I. Distribution of Sun's Rays upon Southerly and Northerly Slope

22. Apparatus used for Experiments with Bacteria Face page 122

23. Diagram showing the Energy required from the Food by Oxen of Different Weights . • " 198

24. Diagram showing the Composition of the Carcass of Lean, Half-Fat, and Fat Oxen . . " 208 


\title{
THE FEEDING OF CROPS AND STOCK
}

\author{
CHAPTER I \\ WHAT THE PLANT IS MADE OF
}

Elements present in the Plant. The Chief Compounds forming Plant Tissues-Carbohydrates, Fats, Proteins, $a$-Proteins, and Ash. The Growth of a Plant from a Seed ; the Embryo and the Food Store. Conditions necessary for GerminationWater, Warmth, Air. How Materials are moved to the Growing Parts of a Plant. Seed Testing.

BEFORE we can obtain any idea of how a plant feeds and grows, it is necessary to find out to some extent of what it is composed, and for this purpose a few simple experiments must be made. Let us begin by taking some green leaves of any plant, a carrot or a potato to represent a root, and some wheat or maize as examples of seeds; weigh out portions of each in basins of porcelain, nickel, or (best) of platinum, and then put them on a sand bath or over a low flame with glass plates covering the tops of the basins. In a very few moments the glass plates will be dimmed over and water will begin to collect in drops, water that has been driven out of the plant material by the heat. As soon as you have satisfied yourself that the plant stuff is losing water, remove the glass coverings and put the basins in the oven to dry completely, a process which will require a day or so. On reweighing the dishes it will be found 
[CHAP.

that the contents have lost a good deal of water, amounting to 80 to 90 per cent. of the original weight of the green leaves; the roots lose nearly as much, but the seeds only io to 15 per cent.

Water is an invariable, and indeed the chief constituent of the living plant.

Take now the dry plant tissues still in their basins, and heat them more strongly over the Bunsen or Argand flame, covering the greater part of the basins with a sheet of metal. Thick gases possessing a pungent smell will be given off, and these after a time will take fire if allowed to come in contact with the lamp; after a time extinguish the flame by completely covering the basin, and cease heating until the contents are cool enough for examination. It will now be seen that the whole interior of the basin is covered with black soot, and that the plant material is charred or carbonised; there is abundant evidence that the black element, Carbon, has been set free from the original plant tissues. Now resume the heating, but without any covering, push it as rapidly as possible, and let the contents of the basins burn away until little or nothing of the black carbon is left, though to get rid of the last traces it may be necessary to put the basins in a muffle furnace and raise the contents to a bright red heat. At the end, when everything possible has been burnt away, there will still be found a little grey or white ash, which on weighing will amount to from 2 to 5 per cent. of the dry matter that was left after the water had been driven off. In the plant ash only a few elements are to be found, but these are the same whatever the plant or wherever it has been grown, with a few exceptions that are small and unimportant. By tests which need not here be detailed, we can always demonstrate in the plant's ash the presence of the elements 
phosphorus, sulphur, and to a smaller degree, chlorine. Similarly we shall always find five metallic compounds, - potash, soda, lime (oxide of calcium), magnesia, and a smaller quantity of iron; when we are dealing with cereals or grasses, there will also be a large proportion of silica in the ash, though it is absent or only found in very small quantities in the ash of other plants. Thus we distinguish in the plant, (1) water; (2) a combustible part, of which carbon is the base; and (3) a small proportion of incombustible mineral ash. There remains another element which disappeared with the combustible portion, but which belongs neither to the carbon nor to the hydrogen and oxygen with which the carbon are mainly combined. To detect it we must mix some of the dry plant material in a test-tube with lime, or better with the mixture called soda-lime, and then heat the whole; gases will soon be given off in which we can detect the familiar smell of ammonia or hartshorn. Now ammonia is a compound of the element nitrogen, and ammonia is as a rule liberated from any compound of nitrogen with carbon and its associated elements, hydrogen and oxygen, when the compound is heated with lime or other alkali. A proper analysis will show that only I to 2 per cent. of the dry matter of the plant consists of nitrogen, but it is an indispensable element and always found in the plant.

To illustrate more definitely what may be expected in the plant and in what proportions, in Table I. is set out a list of the quantities of the various elements found in the grass cut from an average acre of land at the time it was ready for mowing, this ex.mple being chosen because it gives a composite analysis representing a large variety of plants. The analys:s is set out both in pounds per acre, and as percentages of the whole plant and of the dry matter respectively. 
Table I.-Composition of Meadow Grass from One ACre.

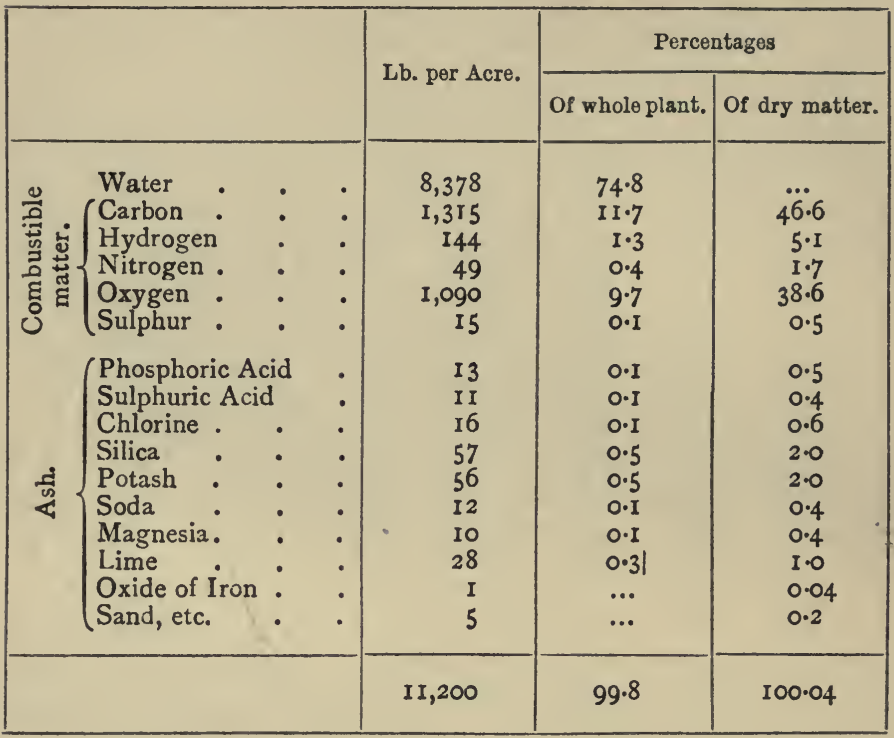

So far we have only been dealing with the elements common to all plants, which, as will be seen later, are also common to animals as well; but the elements are only the raw material-bricks, stones, beams, mortar, etc.-out of which all sorts of different edifices can be constructed. There exist in fact in the plant material certain characteristic groups of compounds, the members of each group being built up in much the same way but quite differently from the members of any other group, although only the same elements may have been used in the building of both groups. For example, the fats form a definite class of bodies common in the seeds of plants; they are easily recognisable and are distinct in every outward property from the sugars, another natural group of substances found in plants. Yet both fats and sugars contain the same elements-carbon, hydrogen, 
oxygen-and no other; the difference between them arises from certain differences in the proportions, and particularly in the manner of building up the structure. Moreover there are particular natural agencies by which one class of bodies can be transformed into the other, just as a house might be taken down and rebuilt from the same materials in a totally different style.

Among the more important of these universal constituents of plants we may place first of all the carbohydrates, a great group of substances so called because in them the elements carbon, hydrogen, and oxygen are combined together in the proportions that suggest a combination of carbon with water. The carbohydrate group includes the sugars, so easily recognisable in the sugar-cane and the beetroot, but also detectable in fruits (a raisin is most easily tested), and by special tests in the leaves and other parts of the living plant. Then come the starches, which are readily washed out of flour, potatoes, and many other storage organs of plants; also certain gums and mucilages, which are closely related to the starches. Finally, we can include the celluloses and fibres, which we obtain in a very pure state in the simple vegetable cells constituting cotton and linen, and less pure in other fibres such as hemp and jute, and in wood itself.

Rather more concentrated than the carbohydrates, i.e., containing still only carbon, hydrogen, and oxygen, but with a higher proportion of carbon, are the fats, oils, and waxes which are present in many vegetable tissues; but only in the seeds, nuts, and fruits of certain plants is there enough to be squeezed out for commercial purposes. The seed is always a very concentrated storehouse of food for the future plant, and it is in the seed that such concentrated materials as oils and fats are mainly found. 
[CHAP.

So far the compounds have only contained carbon, hydrogen, and oxygen, but in all plants there is another group of compounds built up as before with carbon as the centre, but with nitrogen also as part of the fabric. Of these compounds containing nitrogen the most important are the proteins (in older phraseology proteids or albuminoids)-complex bodies containing carbon, nitrogen, hydrogen, oxygen, and smaller proportions of sulphur and phosphorus. Perhaps the easiest of these bodies to separate is gluten from wheat flour, but by suitable tests they may be recognised in all plants and in all parts of the tissues. The proteins are very elaborately constructed bodies, and are either insoluble or not properly soluble in water; but as a sort of intermediate stage in their building up or breaking down, come certain simpler soluble compounds of carbon, hydrogen, oxygen, and nitrogen, often called amides, though the name is not very correct, and it will be simpler to call them $a$-proteins.

Of course the carbohydrates, the fats, the proteins are not the only groups of compounds occurring in plant materials: there are also bodies like the essential oils, which give scent to plants, the resins, the vegetable acids, the bitter and poisonous principles, etc., etc.; but the three groups enumerated constitute by far the greater part of every plant, and on them only depends, at least in its broad outlines, the life of the plant and in its turn of the animal.

Since the crop starts with the seed, we must begin by finding out how a seed is constructed and what conditions are necessary to make it germinate and grow into a plant capable of yielding seed in its turn. Take some conveniently large seeds-beans and maize form the best examples, though they may be supplemented or replaced by sunflowers and wheat-soak them in 
III.

I.

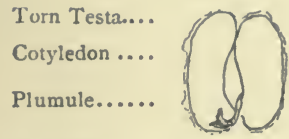

Radicle.............. I

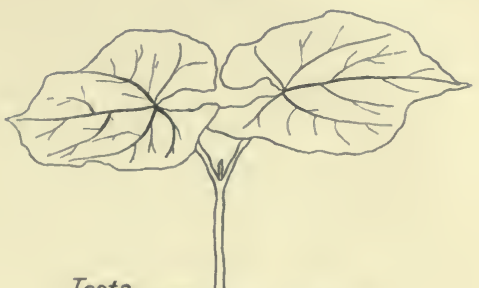

II.
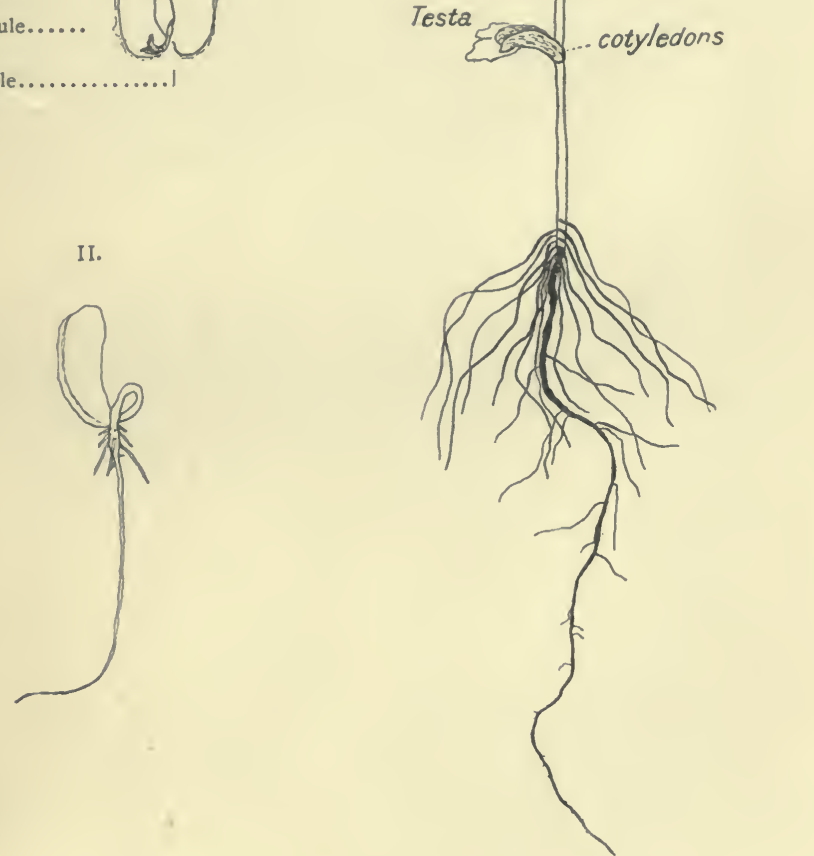

Fig. 1.-Germinating Seedlings of Beans.

I. Seed split open after germinating.

II. Root a few days old.

III. Still older seedling showing leaves and secondary roots. 

water for a few hours, surround them with damp sawdust, and then keep them in a warm place for a day or two in order to start their germination. As soon, however, as they have been well soaked they may be pulled to pieces, and the function of each part can be followed up day by day as the growth advances. Taking first the bean, we begin by finding a tough outer skin, which after soaking can be peeled off entirely; when the plant germinates under natural conditions, this skin is burst and thrown off. Under the skin we find the mass of the seed, which splits at once into two flat discs, united at one point by a small structure, that for the moment we may liken to a hinge. Notice the position of this hinge with regard to the markings in the seed coat which indicate where the bean was attached to the pod, and therefore to the parent plant. The meaning of the structure of the bean will only become plain by following up the successive stages in its growth. It will then be seen that what we have called the hinge develops into the future plant ; it puts out a root, and in the opposite direction it elongates into a shoot, from the tip of which leaves begin to unfold-it is indeed the "embryo," the seat of life in the plant. The two flat discs which are united by the embryo open apart and set themselves at right angles to the new stem, if the plant is being grown in the ordinary way; in the open air they become green, but at the same time they slowly shrink and become emptied of their contents, finally they shrivel and drop off. They are known as "cotyledons," or seed leaves. In the case of the maize the structure is somewhat different; at one end of the grain will be found, as before, the embryo from which proceed the rootlets, no longer a single one but several, and a shoot which shows a single leaf. The greater part of the grain, however, is occupied not by a pair of seed leaves, but 
[CHAP.

by a mass of material which remains attached to the side of the stem of the young plant. As the plant grows the seed material gradually disappears, until after a time only an empty husk remains, and then falls off. In the case of maize and similar seeds like wheat and barley, which begin by throwing up only a single leaf, this attached food store does the work of the seed leaves in the bean and similar plants, and is known as the endosperm. Now take some of the soaked seeds and mutilate them in various way's before setting them to germinate: cut out the embryo, cut bits off the embryo, poison it by touching it with a trace of carbolic acid or a drop of boiling water, cut off one cotyledon or half of both cotyledons, cut off a large and a small part of the endosperm.

The seeds will not grow at all if the embryo is cut out and killed or much mutilated, but the embryo itself will make a start to grow without cotyledons or endosperm, though the length of time it will subsist will depend on how much of the latter has been left to it. The embryo is in fact the seat of life in the seed, the rest (cotyledons or endosperm) is dead food material stored up by the parent plant to give sustenance to the new plant (embryo) until it can establish itself in the world. It has been found possible to grow an embryo removed from its endosperm on blotting paper or similar porous material, if it is kept moistened with an appropriate food solution containing sugars, $a$-proteins, and similar plant constituents.

We may now sum up the facts we have ascertained about the seed: it possesses a coat of one or more membranes, an embryo (which is the seat of the life of the seed), and a food store for the nutrition of the embryo until it has sufficiently developed to feed itself on the soil and the air, and this food store may take the form 


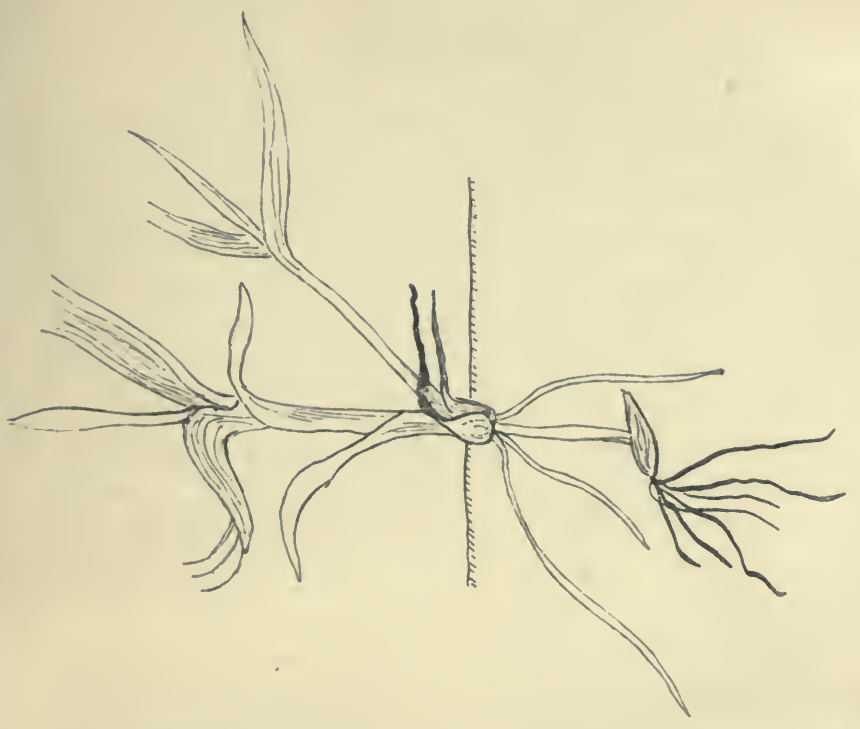

$\infty$
$\vdots$
$\tilde{\varepsilon}$
$\tilde{z}$
$\tilde{U}$
$\tilde{u}$

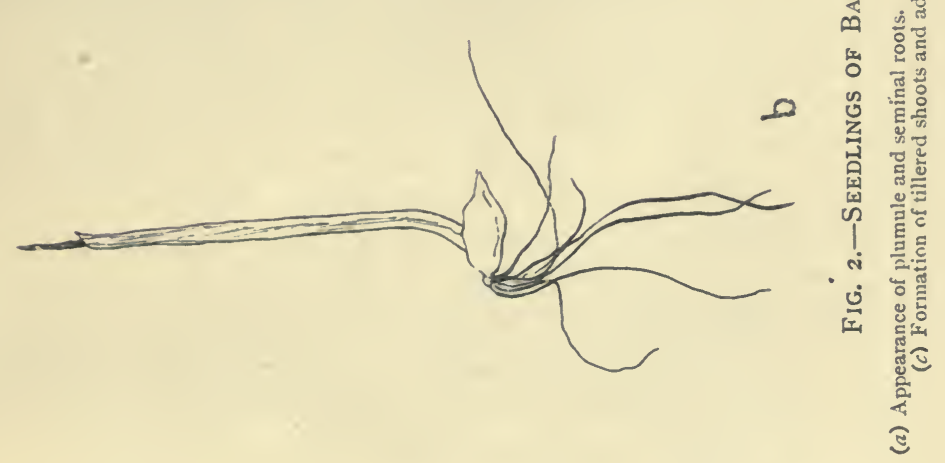

त)

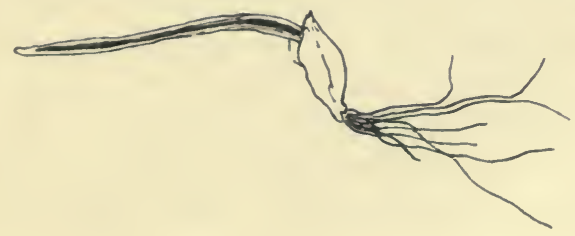



of a pair of cotyledons or a single endosperm. There are other minor differences in arrangement that need not concern us; there are also very interesting variations in the way the root develops, in the origin of secondary roots, side buds, etc., etc., and again in the character of the cotyledons and the way they develop above ground, but these points do not bear directly on nutrition, and the student must follow them up for himself.

We may now proceed to examine the conditions which favour or are necessary to the germination of the seed. In the first place, moisture is required; dry seeds can be kept a considerable time without apparent change, it is only when the embryo has absorbed sufficient water to get some of its soluble constituents into solution that growth can begin at all. Hence a seed must be sown in a sufficiently moist soil and the supply of moisture must be maintained until the plant is established ; moreover, moisture must reach the embryo inside the seed coat, yet in some cases the seed coat offers a considerable resistance to the passage of water through it. Every seed possesses a fine passage through the seed coat, called the micropyle, but in many cases soon after the seed is ripe the micropyle becomes closed by the shrinkage of the seed coat, which itself also grows impervious to water. Hence follows a great delay in germination, which may not take place indeed for a year or longer until the seed coat has wholly decayed away. With many garden plants, e.g. the auricula and the hellebore, germination will take place in a few days if the seeds are sown directly they are ripe, but if once they are dried off and stored before sowing they will probably remain dormant for a year in the seed pans and then begin to germinate slowly or at irregular intervals. In any sample of clover seed a certain number of "hard" seeds will always be found which 
[CHAP.

fail to germinate when the usual test is made, although they are perfectly formed and will eventually start into growth after a lapse of time. In some of these cases where the seed coat is obstinate the penetration of water may be hastened by various mechanical devices; the seed coat may be cut or filed through (gardeners do this with Canna seeds), or the seeds may be dipped for a moment in boiling water, or even soaked for a short time in strong sulphuric acid, which is then quickly washed away. Certain tree seeds only germinate after a forest fire has swept over the ground; heat has been necessary to break up either the nut in which the seeds were enclosed or the seed coat itself. The object is in all cases the same, to begin the breakdown of the seed coat and admit moisture to the embryo.

TABle II.-Temperatures Required by GrRminating Serds. (Fahrenheit.)

\begin{tabular}{|c|c|c|c|c|c|}
\hline & & & $\begin{array}{c}\text { Minimum } \\
\text { limit. }\end{array}$ & Optimum. & $\begin{array}{l}\text { Maximum } \\
\text { limit. }\end{array}$ \\
\hline & & : & Degrees. & Degrees. & Degrees. \\
\hline Wheat . & - & & $4 \mathrm{I}$ & $8 \mathrm{I}$ & 99 \\
\hline Barley & - & • & $4 I$ & 83 & 100 \\
\hline Mustard & - & - & 32 & 83 & 99 \\
\hline Turnips & 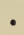 & . & 46 & 89 & 109 \\
\hline Cucumber & . & . & 56 & 93 & II 5 \\
\hline
\end{tabular}

Besides requiring a provision of moisture, seeds will only germinate within certain well-defined limits of temperature; for each species there is a minimum temperature below which no germination will take place, above that minimum the rapidity of germination increases with the temperature up to an optimum point, beyond which it declines until an upper limit is reached, which again stops germination entirely. The lower limiting or minimum temperatures for germination 
have considerable bearings upon practice; gardeners know well that certain seeds must be sown "in heat" or they will not start; amongst farm crops, the seeds of turnips and mangolds make very little progress if sown before the land has got warmed up by the spring suns and cultivation.

The next indispensable factor in the germination of seeds is the presence of air, and this may be illustrated by one or two simple experiments. Put some mustard seeds into a bottle, fill it completely with water and stopper it, then let it stand in a warm place; a few of the seeds may "chit" because there is a little dissolved air in the water, but they will stop at that and cease to grow any further. Grease the stopper of a widemouthed bottle holding about a pint, put in half an ounce of mustard seeds and enough water to wet them thoroughly, stopper up and set in a warm place as before, but this time in the dark. In a few days the seeds will germinate, and as there is some air in the bottle they will continue to push for a few days before they come to a pause and stop for lack of more air. Now see what has happened to the air inside the bottle by taking out the stopper and inserting a lighted taper. It goes out, indicating that the oxygen of the original air has been so far used up that a candle can no longer burn. Now decant some of the air into a clean bottle and shake it up with lime water: the lime water becomes milky, indicating the presence of carbon dioxide or carbonic acid. The germinating seeds have thus affected the air with which they were enclosed, just as a burning candle would do or a breathing animal; oxygen has been used up, and carbon dioxide has taken its place; something, in fact, in the seed has been burnt, i.e., combined with the oxygen of the air to form carbon dioxide and water. The identity of the process going on during germination 
with burning and breathing may be further demonstrated by showing that heat is given off during the process. To prove this, a pair of sensitive thermometers are necessary, reading to a tenth of a degree; put a mark on each and let them stand in the same jar of water for a time to note any difference in their readings. Meantime, soak about a pint of peas, or mustard, or barley in water for a few hours, drain off the water, put the peas in a jar and plunge the thermometer into their midst. Fill up another jar with water, in which insert the second thermometer, wrap both jars in flannel to reduce losses of heat, and then stand the pair in some place where they are screened from any but slow changes of temperature, as in an inner cupboard of a room without a fire. In a day or two, when germination has set in actively, the thermometer among the seeds will be standing permanently higher than the other one which indicates the normal surrounding temperature. With this further proof we may conclude that germination is a process of breathing or burning, in which some of the seed material combines with the oxygen of the air to produce carbon dioxide and water; only by this sort of burning does the infant plant get the energy to go on living and working. Indeed, even while the seed is dry and apparently dormant it is breathing very slowly, and so consuming part of its substance; being dry, the embryo cannot draw upon the materials in the endosperm, but is confined to burning up any spare material it possesses within itself. Hence seeds cannot live for ever; they vary very greatly in their powers of endurance, both with the kind of seed and the way they are stored, but very few of the ordinary farm and garden seeds remain alive after ten years. The embryo is found to perish and shrivel up, though the endosperm or cotyledons remain perfectly sound; the slow combustion 
process necessary to maintain life exhausts all the available material in the embryo, which then perishes, but long before death the vigour of the seed becomes greatly weakened by age. There seems some evidence that seeds buried in the ground may retain their vitality for much longer periods than seeds stored in the open air, perhaps because the greater supply of moisture enables the embryo to draw upon the food store to support the combustion process, instead of dying as soon as it has used up all its own stock; but the evidence that long-buried seeds do retain their vitality is still a little doubtful. Of course, germination of the so-called "mummy wheat" is a fairy tale; whenever wheat grains are found that were indubitably buried with the mummy, not only has the embryo perished but the material of the endosperm is carbonised just as if it had been charred, so that it is no longer capable of forming food for an embryo.

Since the food store of the cotyledons or endosperm exists for the purpose of maintaining the embryo until it has built up a plant capable of carrying on an independent existence, it is clear that if this latter process is too long deferred, the food store may give out and the plant perish. The larger the seed the more reserve there is, and the longer the young plant can grow on the seed store alone; for this reason the depth at which seeds can be sown is determined by their size. Provided it does not get so far down as to be cut off from the daily warmth of the sun or from the air, the deeper a seed is sown the better, because it is thereby more sure of obtaining a continuous supply of moisture. But minute seeds, like those of a poppy, do not possess enough material to give rise to more than a very short stem or leaf with which to reach up to the light: mustard seeds can hardly struggle up 3 inches, while 6 inches taxes 
all the resources of wheat and barley. A few simple experiments with seeds of various sizes, sown at different depths in pots, will show how the proper depth for each seed is conditioned by its weight, i.e. by the amount of material it has available to lift a leaf up into the light. Some covering of soil is desirable in order to keep the seed from drying out; as far as the light goes it does not much matter, for all our common seeds germinate equally well in light or darkness.

One other point in the germination of seeds requires consideration: the materials in the food store of the endosperm or cotyledons are mostly insoluble, as we can convince ourselves by a little experiment; they consist as a rule of starch and proteins, with sometimes fat and oil. Yet when the embryo begins to grow these materials have to be conveyed to the end of the shoot where leaves are unfolding, and to the growing tip of the root; that they do get transferred is proved by the eventual emptying of the endosperm or cotyledon. The transference is only possible if the food store is first of all rendered soluble in water, for liquids alone can traverse the cells of the plant. The mechanism of the process can only be rendered intelligible by another experiment or two. Soak a handful of barley in water as before, and put it aside in a warm place to germinate until the rootlets are an inch or so long; now smash the grains up in a mortar, add enough warm water (at $40^{\circ}$ to $50^{\circ} \mathrm{C}$.) to make up a sort of thin porridge, and let the whole stand for an hour or two, then filter. Meantime make some starch paste by rubbing up a few grammes of starch with cold water, and pouring on 300 to 500 c.c. of boiling water; then bring the whole up to a boil, and put it aside to cool. The starch paste will form a thick, troubled-looking liquid, and if to a little of it in a test-tube a drop of a solution of 
iodine in alcohol or potassium iodide solution be added, an intense blue colour will be produced: this is a test from starch that we shall have to use repeatedly.

When the starch paste has cooled down to $50^{\circ} \mathrm{C}$. or so, and the germinated barley extract has been filtered clear, pour about 100 c.c. of starch paste into a beaker and add to it ro c.c. of the barley extract, stirring them well together. Keep the mixture on a warm bath at $50^{\circ}$ to $60^{\circ} \mathrm{C}$., stir, and watch the result : almost instantly the starch paste will begin to get thin and limpid, and if at intervals a little is taken out and tested with iodine the blue colour will begin to give place to purple, and will finally cease to appear. When this is the case, taste the mixture; it will be faintly sweet, and on testing it will be found to contain sugar. About one-quarter fill a test-tube with Fehling's solution, add half as much of the converted starch paste, and bring to the boil: the blue colour disappears, and there is a copious precipitate of bright red oxide of copper. This is a test from sugars we shall often have occasion to use; if it is tried on the unconverted starch paste, no change takes place. Clearly, then, we have extracted from the germinated barley some soluble substance which is capable of transforming the thick starch paste into freely soluble sugar; it will do the same to solid starch grains, as may be seen under the microscope. Dab a tiny bit of cut potato on a glass slip, the little smear it leaves consists of starch grains, flood them with a drop of the barley extract, put on a cover slip, and place under the microscope. In a few hours the grains will begin to get etched, and will finally break up and disappear. Now repeat the first experiment with the starch paste, but this time boil the barley extract before adding it-no change to sugar will take place; the boiling has destroyed the substance in the barley extract 
which can convert starch into sugar. This substance in the extract of the germinated barley belongs to the class of bodies known as enzymes, or soluble ferments ; it is called diastase, and it is secreted by the active growing embryo of the barley, its function being to convert the stored-up starch of the endosperm into soluble sugar which can travel to the growing points of the plant. There are many kinds of enzymes secreted by both animals and plants; they are mostly soluble in water; they all work most rapidly at a temperature of $50^{\circ}$ to $60^{\circ} \mathrm{C}$. $\left(122^{\circ}\right.$ to $140^{\circ} \mathrm{F}$.), and are destroyed at or below the temperature of boiling water. By very similar experiments we can show that the germinating seed also contains a protease, i.e. an enzyme attacking the insoluble proteins and converting them into soluble amino and amido bodies. Pepsin and papain are commercial proteases, extracted one from an animal the other from a plant, and it is easy to show that they will dissolve insoluble proteins like fragments of boiled white of egg or gluten. Similarly, the embryos of germinating seeds of mustard or flax secrete a lipase, or fat-splitting enzyme, capable of reducing fat to soluble substances which can traverse the plant and be utilised at the growing points.

The germinated barley from which we have just been extracting diastase is nothing but incipient malt; the process of malting consists in steeping good well-ripened barley for forty-eight hours, and then spreading it in a layer 4 to $I 2$ inches thick on floors to germinate. After ten or eleven days, when the rootlets are almost twice as long as the grain, the barley is slowly and carefully dried at a temperature not exceeding $180^{\circ} \mathrm{F}$. Finally it is screened to knock off the rootlets, and put into store. The germination process develops a quantity of diastase which accumulates in the embryo and is not 
destroyed at the temperature of drying, so that when the malt is afterwards ground and extracted with water-the mashing process-there is sufficient diastase to convert quickly all the starch of the endosperm into sugar, which is afterwards fermented by the yeast into alcohol.

Having thus considered the factors that determine the germination of seeds, we are in a position to consider the application of them to practice. In the first place, the seed must be alive; it must not have begun to sprout and then been dried off again; it must not have been overheated in the stack, or harvested prematurely before the embryo had come to its full term; it should not be so old as to have declined in vitality. It is easy to make a germination test of the common farm or garden seeds; select a soft tile, and with a file score ten parallel grooves across it, then ten more crossing them at right angles, thus giving rise to 100 points of intersection. Stand the tile in a dish of water so that the scored surface is above the water but is kept damp by the porous nature of the tile, and set out 100 of the seeds taken at random, one on each intersection. Cover over with another plate or dish, set it in a warm place and examine every day, counting the number that have started, and removing them. A saucer of fine sand or even three or four thicknesses of blotting paper will do as well as the tile, though the water supply may require a little more attention. Most farm seeds will have germinated in ten days, but mangolds require a fortnight, and the majority of grass seeds three weeks. If the records are properly kept, a table is finally obtained which shows both the percentage which eventually germinate and the rapidity with which they start; with a good young vigorous sample, most of the seeds start within a day or two of one another and comparatively early.

Given good seed, it is of no use to sow it until the 
year is advanced enough to ensure sufficient warmth in the soil, or without a proper preparation of the land. Of course some seeds require artificial heat, but all will grow more quickly on a southern slope, or where the soil is not kept cold by lack of drainage or insufficient preparation. The great art of the farmer-the prime act of husbandry, in fact-lies in the preparation of a proper seed bed, and its character may in most cases be summarised in two words : fine and firm. It must be fine, to ensure that all the seed can be put in at the proper depth, because there is a proper depth for each seed depending on its size; it must be firm, to keep the seed and the infant plants properly supplied with moisture. Sometimes the seed is soaked before sowing, though on the farm this is only occasionally done with mangold seed, which has a thick, coarse husk. Occasionally the soaking may very much quicken up the germination, but it is not so easy to sow wet or even damp seed evenly, and there is some danger in sowing soaked seed in dry soil, lest a drought should follow and the seed should perish after its premature start. Lastly, as air is necessary to the germinating seed, the soil must be working freely at sowing time; if the seed is plastered into wet heavy soil or the surface is smeared over by incautious cultivation, the seed may die, or become very weakly for want of air. Certain kinds of heavy land, again, are apt to develop a tight, glazed skin on the surface, if seeding on a fine tilth is followed by heavy rain and later by drying winds and sun; a roller should be put over the land to break the crust and let the air in to the seed.

As soon as the young root has got anchored in the soil and the young shoot has spread its first leaves into the air, the function of the seed is over and the plant begins its independent existence. 


\section{CHAPTER II}

\section{THE WORK OF THE LEAF}

The Increase of Weight in a Growing Plant is derived from the Air. Plants split up Carbon Dioxide and give off Oxygen. Purification of the Air by Plants. Formation of Starch in the Green Leaf. Motive Power supplied by Light. All parts of the Living Plant are also breathing. Necessity of Leaves to the Growth and Ripening of the Plant. The Leaves of the Plant give off Water. How much Rainfall is required by Crops.

THE leaf is in many respects the most important part of the plant; it is essentially the manufacturing organ, and on it depends the whole power of the plant to grow -i.e. the fundamental process which produces fuel and food for ourselves and the rest of the animal creation.

As an understanding of the manner in which a leaf works lies at the very foundation of our science, it will be necessary to consider a number of experiments to illustrate every phase of the action.

In the first experiment weigh out a few grains of mustard seed, and if you have not previously determined what percentage of water the mustard seed contains, weigh out a second portion, and put this to dry in the oven. Then take a pot filled with the purest sand and mix some of the plant ash you have previously made with the sand at the top of the pot, add a suitable amount of water, and sow the 
mustard seeds. When they are well up and showing green leaves, add one-tenth of a gramme of nitrate of soda to the water you are giving to the pot, and let the growth continue for a few weeks longer. Finally, when the plants show signs of flowering pull them up, wash away all traces of sand from their roots, put them in the oven, and weigh them when dry. They will weigh eight to ten or twenty times as much as the seed from which they started. It is not even necessary to add to the pot of sand the plant ash or the nitrate of soda-the weighed seeds may be sown on a bed of sand or a strip of clean flannel kept moist in a soup plate, the little plants being taken off when they will grow no longer. In this case, however, the increase of weight will not be so great. Or, again, one of the water cultures to be described later may be used to afford a comparison between the weight of the seed and the weight of the plant arising from it when it has not been in contact with any soil. Now the point of all these experiments is that the increased weight of the plant is largely made of carbon (we have already seen that more than half of the dry matter of a plant is carbon), yet neither the sand, the plant ash, the nitrate of soda, nor the water used in the first experiment, nor the solution used in the water culture, contain any carbon at all. It is true that the flannel we have also suggested as a medium on which the mustard seeds could be grown is a compound of carbon, but it is such a compound as the plant cannot feed upon, and is as inert as so much sand. If, then, the plant gains carbon as it grows, and there is none in the water or the support on which it grows, where does the carbon come from? There remains only one source - the air which surrounds the plant; and later experiments will make more evident the fact that plants do derive their chief sustenance from the air. In these 
preliminary experiments we did not use ordinary soil, because it contains a certain proportion of compounds of carbon, out of which the plant's increase might possibly have been made, though we can now show that such is not the case. Suppose, instead of a laboratory experiment, we deal with a crop in the open and make out a sort of balance-sheet; there is so much carbon in the soil at starting, and so much in the seed and the manure, against which we can set off the amount of carbon in the crop at the finish together with that in the soil after harvest. Such was the balance-sheet that Boussingault drew up for the first field experiments that were ever carried out, and he showed that, despite the great amount of carbon removed in a crop, the soil contained no less of this substance at harvest than at seed time.

Hence followed the inevitable conclusion that since the carbon had not come from the soil, and could not have been derived from the rain (water contains hydrogen and oxygen only), it must have been taken from the air. We can take an example of this kind of balance-sheet from the Rothamsted wheat field, choosing a plot manured only with inorganic salts containing no carbon (superphosphate, sulphate and chloride of ammonia, sulphate of potash, etc.), the soil of which had been analysed in $188 \mathrm{r}$ and again in 1893.

Table III.-Carbon in Soll and Crops, Rothamsted Wheat.

(Plot 7.)

\begin{tabular}{|c|c|c|c|c|c|c|c|}
\hline \multicolumn{3}{|c|}{ Carbon in Soil, lb. per Acre. } & \multicolumn{2}{|c|}{$\begin{array}{c}\text { Crops. } \\
\text { Average. }\end{array}$} & \multirow{2}{*}{$\begin{array}{c}\text { Totsl } \\
\text { Carbon } \\
\text { in Crop. }\end{array}$} & \multirow{2}{*}{$\begin{array}{l}\text { Carbon } \\
\text { in Seed. }\end{array}$} & \multirow{2}{*}{$\begin{array}{c}\text { Gain in Crop } \\
\text { over Seed } \\
\text { and Loss } \\
\text { from Soil. }\end{array}$} \\
\hline 1881. & 1893. & $\begin{array}{c}\text { Gain or } \\
\text { Loss. }\end{array}$ & Grain. & Straw. & & & \\
\hline $61, \infty 00$ & 54,000 & $-7,000$ & $\begin{array}{c}\text { Bush. } \\
33.5\end{array}$ & $\begin{array}{l}\text { Cwt. } \\
3 \text { I. } 8\end{array}$ & 25,200 & 600 & I7,600 \\
\hline
\end{tabular}


Thus, though the carbon in the soil has only lost $7000 \mathrm{lb}$. during the period under examination, no less than 25,200 lb. per acre has been taken away in the crops, and the air is the only source from which it could have been derived. The air, we know, contains from 3 to 4 volumes of carbon dioxide in every 10,000, and small as the proportion may seem, it yet represents an enormous quantity of carbon dioxide upon which the plant can draw.

We will now take some experiments showing that plants have the power to split up this carbon dioxide in the air and take the carbon from it. As we are dealing with gases we shall have to put our experimental plants in water in order to see and collect the gases, and it will, therefore, be necessary to take well or river water that has had an opportunity of dissolving a little air, and especially carbon dioxide, which is rather more soluble than the rest of the air. By boiling some of the water in a preliminary experiment it is easy to show that such water contains dissolved carbon dioxide, which is expelled in heating. Take a small bunch of young green active shoots of mint or watercress and put them in a jar of water, covering them with an inverted funnel the shank of which leads into a test-tube full of water. Stand the jar in the brightest light available, and repeat the experiment with another jar placed in the dark. To complete the demonstration a third jar should be used, containing water that had been boiled to expel all gases and then cooled down; this also should be placed in the light. As the light falls on the mint in the unboiled water little bubbles of gas will begin to appear on the tips of the leaves; from time to time they will break away and ascend into the test-tube above. No such bubbles appear from the mint in the dark, or from that which is in the light but immersed in boiled water. 
After a few hours of bright daylight the test-tube will be nearly full ; remove it carefully, invert it, and bring into the mouth a chip with a glowing end-the chip bursts into a flame, proving the gas to be oxygen. Now oxygen is one constituent of carbon dioxide, and the experiment is an illustration of the fact that green leaves in the light split up the carbon dioxide with which they are in contact and set free the oxygen as gas, retaining the carbon for themselves. This continual evolution of oxygen by green plants is the great agency which is always renewing the vital part of the atmosphere; out in the country where the trees and the grass are growing, the amount of carbon dioxide in the air keeps at about 3 volumes in 10,000, being rather less in the summer, when vegetation is active, than in the winter; in towns the proportion rises to 4 , and even in dense streets to 6 and 7 per 10,000. On plants growing in water it is possible to see the bubbles of oxygen as they are produced; if you look into any ditch or pool on a bright day you will see the bubbles of oxygen entangled in the vegetation, just as you will see them dotted all over the green algal growth which covers the bottom of many streams. The surface of some streams is often covered with little masses of floating scum; this scum consists of the algal growth that has been lifted off the bottom and buoyed up to the surface by the bubbles of oxygen entangled in it. It will be noticed that the scum only begins to float up towards the afternoon and on a sunny day, i.e. after the light has had time to act and bring about a plentiful evolution of oxygen.

So far, however, we have only demonstrated that the plant adds oxygen to the atmosphere; we can now show that it will remove carbon dioxide. On a bright day in spring or early summer take a wide glass tube 5 or 6 
feet long and fill it loosely with freshly gathered leaves of grass or wheat, taking care only to use young, active leaves. Now set up the tube horizontally in the brightest daylight available, and by means of an aspirator slowly draw air, first through the tube, and then through a wash-bottle containing some baryta water. Baryta water is a very delicate test for carbon dioxide, becoming troubled and milky looking with a very small quantity of the gas, but if the light is good there will be no evidence of carbon dioxide in the air that has been drawn through the tube. Then detach the tube and let the ordinary air run through the baryta water; there is at once a milkiness, showing what must have been the state of the air before it came in contact with the green leaves. This experiment illustrates the fact that green leaves in bright light take the carbon dioxide out of the air, and, as we have seen in the previous experiment, liberate the oxygen contained therein.

By using the same apparatus with petals, bracts, and other parts of a plant which are not green, it can be shown that only the green portions of the plant have this power of absorbing and splitting up carbon dioxide; in fact, the green colouring matter-the chlorophyll, as it is called-in leaves and stems effects the first necessary step in the process, by absorbing the light which constitutes the motive power. That light is absolutely essential may easily be seen by repeating the last experiment after covering the tube containing the leaves with brown paper. As soon as this has been done the leaves will be found to add carbon dioxide to the air passing through, instead of taking it out; as we shall see later, all parts of the plant, like germinating seeds, are breathing as long as they are alive, whereby they give off carbon dioxide and absorb oxygen, though 


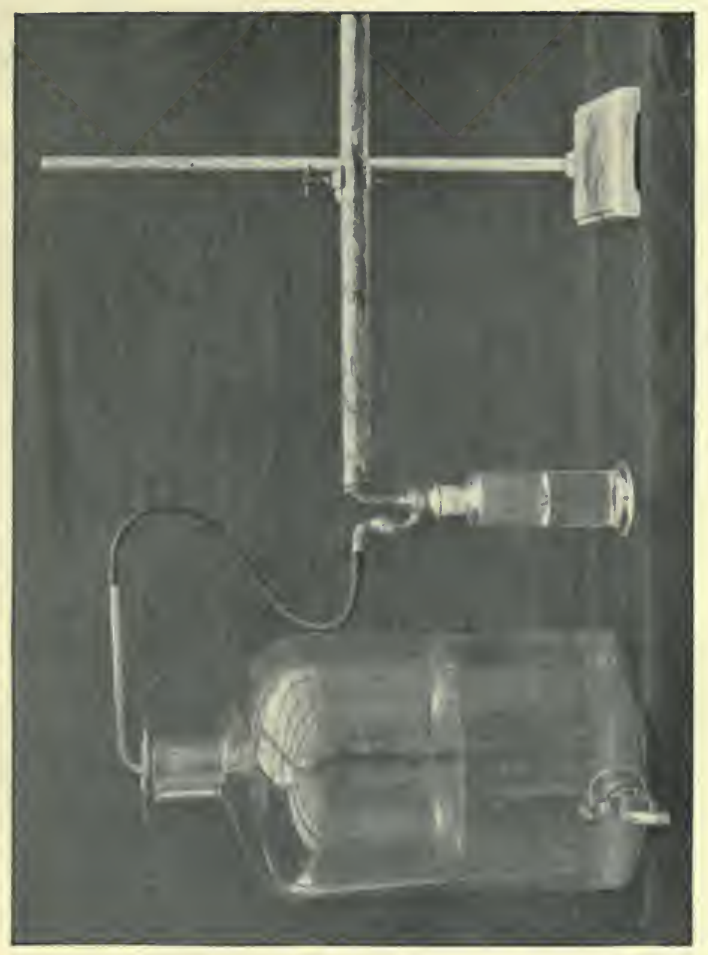

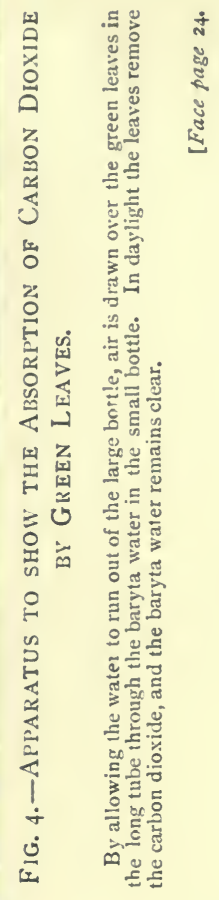
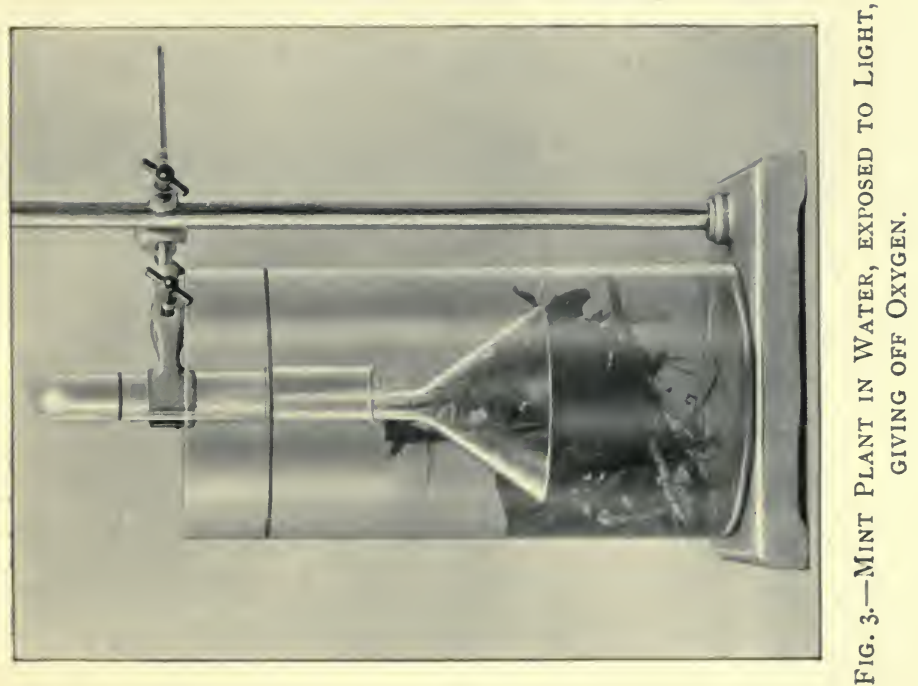

in bright light this breathing process is masked without being stopped, by the reverse process of taking in carbon which we are now considering. The method of experimenting we have just been describing has been so modified as to become a means of measuring exactly the powers of the leaf in splitting up carbon dioxide under various regulated conditions. In $\mathrm{Dr}$ Horace Brown's experiments, a leaf still attached to the plant is enclosed in a glass-sided box and a current of air is drawn through the box, the proportion of carbon dioxide being determined in the air before it reaches the leaf and again when it leaves the box. Working in this fashion, Dr Brown has shown that a square decimetre (4 inches square) of active green leaf will decompose about 0.008 gramme per hour of carbon dioxide in ordinary diffuse daylight, which amounts correspond to a formation within the leaf of about 0.006 gramme of dry matter. The light may be diminished considerably without any corresponding falling off in the power of the leaf, until a certain point is reached beyond which the action will fall off in proportion to the reduction in the light. It is easy to see how dependent plants are upon light by the failure of most of them to flourish or even to grow in anything approaching dense shade; only a few classes of green plants, like ferns and mosses and those generally of a very slow-growing character, have adapted themselves to live in comparative shade, whereas all farm crops, which are of course distinguished by the enormous quantities of dry matter they manufacture, must be exposed to the fullest possible light. The process of fixing the carbon of carbon dioxide and giving off oxygen by the green leaf in sunlight, which we shall in future call assimilation, may now be studied by a different method, depending upon the fact that the first visible product of the action in the 
[CHAP.

leaf is starch. We have already learnt that starch consists of the element carbon combined with the elements of water, from which it follows that the plants must be able to manufacture starch and oxygen out of carbon dioxide and water, just as in the reverse way starch and oxygen will burn together to produce water and carbon dioxide.

\section{Assimilation.}

$\left.\begin{array}{l}\text { Carbon } \\ \text { Oxygen }\end{array}\right\}$ Carbon dioxide + water $\left.=\begin{array}{l}\text { Carbon } \\ \text { Water }\end{array}\right\}$ Starch + Oxygen.

Of course the process of making starch is not so simple as this diagram makes out, because there must be several intermediate stages within the plant, still for our purposes we only need to recognise the relationship between the final products of the change in order to interpret the various experiments which follow. It is first of all necessary to learn to identify starch within the leaf; because the leaf is alive and strongly coloured, it disguises the blue colour which iodine usually produces with starch. The green leaf must be dipped for a moment into boiling water to kill it, and then soaked in alcohol or methylated spirit, until the green colour is dissolved out. If now the bleached leaf is dipped into a very weak solution of iodine, the colour of pale sherry, it will be turned very dark blue, practically black, because all the starch grains that are diffused throughout the leaf are intensely stained by the iodine. The leaf can then be examined under the microscope to see how the rounded grains of starch are imbedded in all the cells composing the interior tissues of the leaf.

The next step is to show the dependence of starch formation upon the exposure of the leaf to light; a dwarf tropæolum plant is very suitable for experiment, if it can be covered completely with a box so as to exclude the light. The next morning but one, remove 


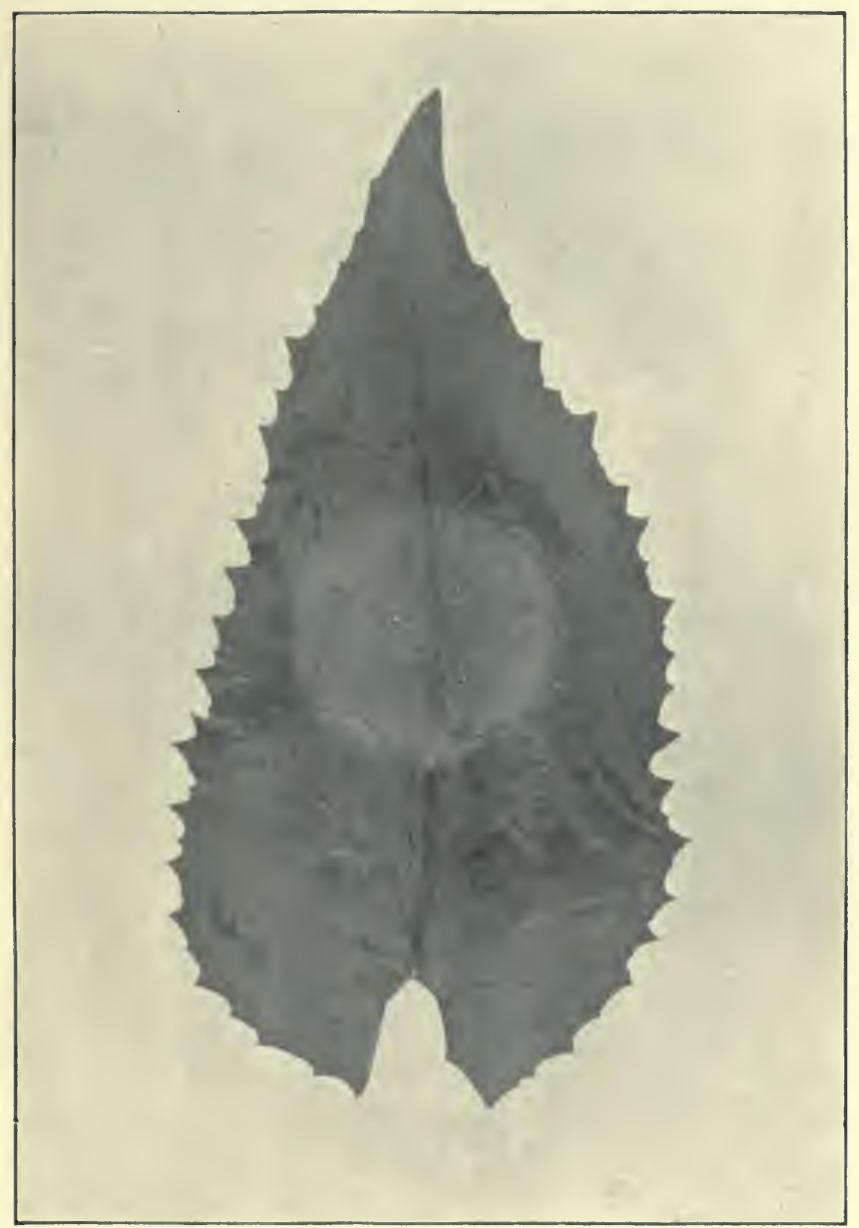

Fig. 5.-ARtichoke Leaf, on Which the Light Patch was PROTECTED FROM LigHT, THE STARCH IN THE LEAF BEING AFTERWARDS STAINED WITH IODINE. 

the box and pick off one or two leaves, which must be put away in a box until they can be brought indoors for testing; to one or two other leaves still attached to the plant fasten opaque designs covering part of the leaf, the simplest plan being to cut two discs of cork and pin them together with the leaf between. Leave the leaves thus protected in places from the light until evening, and then gather them. Follow the same routine as before in testing the leaves for starch; it will be found that the leaves which have been kept in the dark for thirty to forty hours are quite devoid of starch, from which we may conclude that any starch present in the leaf when the plant was covered up has been removed in the dark. The leaves, however, which were afterwards partially exposed to the light show a pattern; the protected portions still contain no starch, whereas the rest of the leaf on which the light has fallen has gained starch, and so will colour up when the iodine solution is applied. Further experiments depending on the test for starch can also be tried; for example, a variegated leaf, white and green, will show starch in the green parts and not in the white. Again, a small plant may be kept for a day or two under a bell-jar over water with some strong cautic soda solution standing beside it; the caustic soda will remove all the carbon dioxide from the air with which the plant is in contact, and the leaves after a day or two cease to contain any starch, though they may have been in full sunlight for some hours before they are gathered. In this way it is possible to show that the formation and presence of starch in the leaf is dependent upon (I) exposure to light; (2) upon the greenness of the leaf; and (3) upon the presence of carbon dioxide in the air with which the leaf is in contact; all of which conclusions agree with the views of assimilation that we had before obtained by other methods. 
Though starch is manufactured in the leaf it does not accumulate there, in the darkness it is moved wholly or partially away and stored in some other part of the plant: were it not so, leaves would become thick and swell with the stores of manufactured starch. The transference of the starch is effected by a similar mechanism to that which utilises the starch in a seed for the use of the distant-growing parts of the plant; the leaf cells secrete an enzyme capable of dissolving starch and transforming it into sugar, which being soluble in water can move about in the plant. To show the presence of this diastase we must gather some young and active green leaves in the early morning, or after they have been shut up from the light for some time, as in a previous experiment. Now dry these leaves very quickly but at a low temperature, best of all by exposing them over strong sulphuric acid in a desiccator from which the air has been pumped. Under these conditions the leaves will dry very rapidly and their enzymes will suffer no change; when dry, powder the leaves finely and introduce a little of the powder into a starch paste solution as before. The starch paste solution will rapidly become limpid, will lose its power of turning blue with iodine, and will finally give a reaction for sugar with Fehling's solution. Clearly the green leaf contained an enzyme which acts on the starch paste like that which was present in the extract from germinated barley-a diastase transforming starch into soluble sugar capable of diffusing out of the leaf into such parts of the plant as may require it. So fundamental is the process of assimilation that yet another experiment may be described to illustrate the action. For this purpose it is necessary to have at hand a plant or plants possessing a considerable number of large leaves: the vine, hop, or sycamore are among the most 
convenient for the purpose. Late at night, when the removal of starch has been in progress for some time, about three hundred leaves with their stalks attached should be gathered and brought indoors. From the heap of leaves pairs of approximately equal size are picked out, and as each pair is made up one member of it is placed in one heap which we will call $A$, the second on another heap, $B$. When a hundred pairs have thus been divided, the two heaps are weighed and will be found approximately equal, because the errors of matching each pair of leaves will neutralise one another with so large a number as a hundred pairs. However, there will probably be some small difference in weight which must be noted. The next step is to put one heap (A) of one hundred leaves into the oven to dry, the other hundred are set with their stalks in bottles of water in a position which will expose them to full daylight on the following morning. At the close of that day they also are put in the oven to dry. On comparing these sets of dry weights (making any necessary allowance for initial differences of green weight) the leaves that have been exposed to the air for a whole day will be found to have gained in weight, because of the starch they have formed under the action of the light.

We have already described one experiment to show that the leaf of a plant is also carrying on a second process, one of respiration or breathing, which in its result is exactly opposite to assimilation, in that it burns up some of its carbonaceous matter, combining it with the oxygen of the air by which it is surrounded to form carbon dioxide and water. It is possible to show that each part of the plant is producing carbon dioxide, merely by gathering such parts in quantity, shutting them up in a jar for an hour or so, and then testing the gas within the jar with lime water for carbon dioxide; 
though, of course, with leaves and other green parts the jar must be shielded from the light. Respiration is most active in the flower, and if the jar is filled with a lot of young, active tropæolum flowers, a very rapid evolution of carbon dioxide can be observed. Respiration is always going on, though it is reduced to a minimum at temperatures below $40^{\circ} \mathrm{F}$; it is, in fact, a process essential to the life of all the living cells that make up either plants or animals. In a leaf, however, it is never so rapid as the opposite process of assimilation is in the light; were not assimilation very much more active than respiration, the plant would never increase in weight at all. It is due to the respiration, which is a necessary accompaniment of their life, that roots, like mangolds or potatoes, gradually lose weight when they are stored, for the loss is not only of water but of dry matter also. Bulbs of tulips or daffodils are also noticeably lighter in the autumn when they are planted than in the early summer when they are first put into store, and if the planting be deferred for any reason the loss of weight becomes even more evident.

Another experiment may be carried out to illustrate further the processes of respiration and assimilation: About a hundred barley grains are soaked and placed with a little water in a stoppered bottle holding about a pint, the stopper is left out and the bottle exposed to the light until the barley has shot and made a fair amount of leaf. The stopper is then inserted, and the bottle is put away in a dark cupboard or drawer for two days; on taking it out and testing the air in the bottle by means of a lighted taper, the taper will be extinguished. In the dark only respiration has been going on, and so much carbon dioxide has been produced and so much oxygen used up that the air in the 


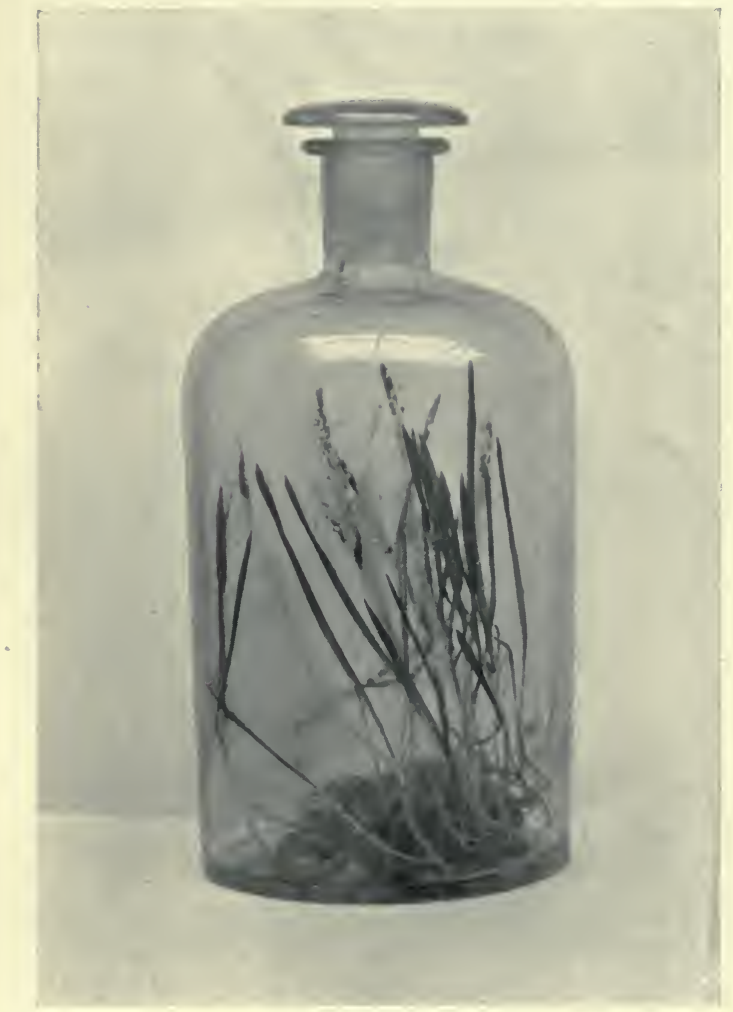

\section{Fig. 6.-Bottle enclosing Barley Seedlings.}

When kept in the dark the enclosed air puts out a lighted taper, but will allow it to burn after the bottle has been for some hours exposed to light. 

bottle is no longer capable of supporting combustion. Now stopper-up the bottle again and stand it in the light for two days; again test the air it contains with a taper, and it will be found to support combustion. In the light the green leaves of the barley have split up the carbon dioxide and replaced it by oxygen, until the air will once more support combustion. The bottle may be replaced in the dark until respiration has again loaded the air with carbon dioxide, whereupon it may again be brought into the light and the air reoxygenated by the assimilation carried out by the green leaves; these alterations may be repeated several times, until at last the barley begins to die for lack of food. Under slightly more natural conditions, however, such a cycle of respiration and assimilation can be continued for very long periods. For example, in the Rothamsted laboratory a sample of soil weighing several pounds was put away in a rather moist condition in 1874 in a gallon bottle, which it three parts filled. The bottle was corked, the cork waxed and covered with a lead capsule. A few years afterwards a fern, Asplenium nigrum, was noticed to be growing within the bottle, having developed from a spore which must have been present in the undried soil; this fern has continued to grow, and at the present time (1910) it occupies nearly the whole of the vacant upper part of the bottle. No air can either enter or leave the bottle; at first some doubts were entertained as to the impermeability of the sealed cork, but the whole of the cork and the neck of the bottle have been enclosed in a block of paraffin wax, which was melted and cast on to its present position. The bottle stands on a low shelf in a building lighted from the roof, the illumination it receives is only good for a few hours on summer days, when a little direct sunshine reaches it. This illumination in the summer is, however, enough to 
enable the green fronds of the fern to decompose sufficient carbon dioxide to maintain its slow rate of growth, and also to give rise to the oxygen required by the plant for respiration throughout the whole year. Similarly the plant is always re-creating carbon dioxide by its respiration, and this carbon dioxide must be undergoing a perpetual cycle of change-it is split up by the plant in the light summer days, its oxygen being returned to the air and the carbon held by the plant, then in the darkness and the winter this change is more slowly undone again and the carbon dioxide reconstituted. Of course, in such a fashion the fern could never become any heavier, could not in fact have reached its present size; there has also been another source of carbon dioxide within the bottle due to the slow decay of the organic matter originally present in the soil. The development of this enclosed fern with its quiet annual ebb and flow might be looked upon as a sort of perpetual motion machine, but we must not fail to recognise the fact that one external factor-the incidence of the light-is absolutely necessary to the process. It is this light, small as its amount may seem to be, which supplies the energy required to drive the machine, and this fact may lead us now to consider the assimilation process from the point of view of the exchanges of energy which go on during the life of the plant. It is clear that a plant is a storehouse of energy, of potential work; given enough of the plant-a tree, for example-we can burn it under a boiler and drive an engine which will do work for us. To come a little closer, starch will burn when ignited and supplied with air or oxygen; in burning it will give out heat, which can be made to do work. Clearly, then, starch and oxygen contain more energy than the carbon dioxide and water into which they are turned by the 


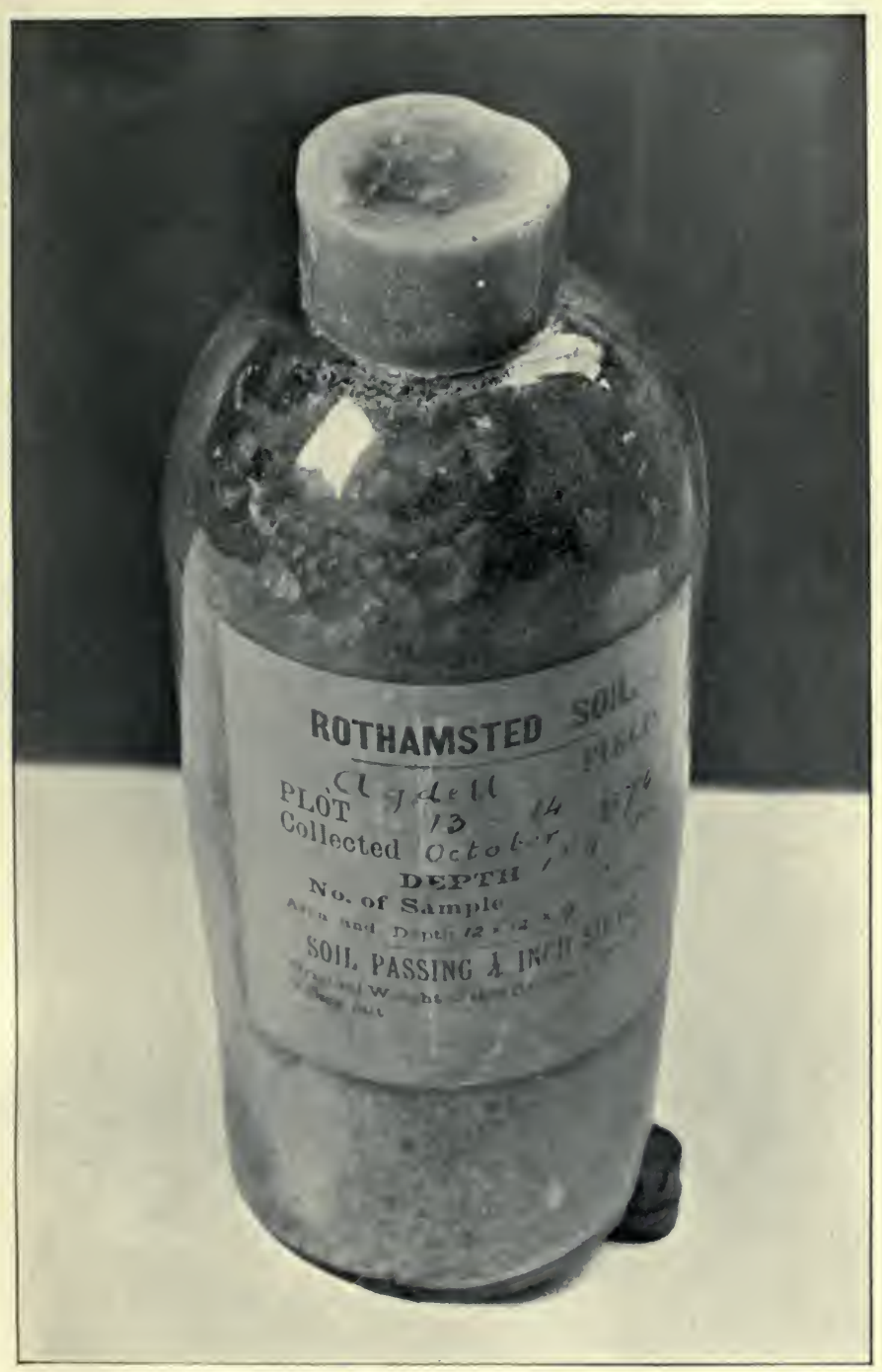

Fig. 7.-FERN THAT has BeEN GROWING INSIDE A CLOSED BOTTLE FOR THIRTY-SIX YEARS. 

burning process. In consequence, when a leaf turns carbon dioxide and water into starch and oxygen, it is, as it were, pushing something uphill, endowing the resulting product with more energy than the original material possessed, and since energy cannot be created de novo any more than matter can, this energy must have been obtained from somewhere outside the leaf. The energy required to effect the change is, in fact, obtained from the light; the green leaf simply acts as a kind of transformer of the energy coming from the sun in the form of light, into the stored-up energy possessed by vegetable material. Stephenson was absolutely right when he called coal "bottled sunlight," for the vitally important feature of the coal-its power to burn and give out heat, whereby it becomes a source of work-is all derived from the light which fell upon those early forests in which grew the vegetation that nowadays is preserved as coal. The plant is not a very efficient transformer of the energy of sunlight, because it only picks out and utilises a very small selection from the numerous rays making up the light; according to Dr Horace Brown's researches, the leaf only succeeds in utilising for the manufacture of starch about $\frac{1}{1000}$ of the energy of sunlight and $\frac{1}{60}$ of ordinary diffuse daylight. Small as this utilisation of the sun's energy may seem to be, we must not fail to realise that in the assimilation of the green leaf we see at work the only great upbuilding process, by which energy is caught and stored, that can be recognised as going on in the world. The life of an animal is a down-grade process depending upon the burning up by respiration of materials which have been previously built up by the plant, and though the animal cannot destroy the energy that was present in his food, he transforms it into low-grade forms which are not longer utilisable. Decay and 
burning are similarly destructive or down-grade processes, and just as the life of the animal is absolutely dependent on the preliminary life of the plant to build up its necessary food, so for our engine power we are largely living upon irreplaceable capital stored up in the coal and oil that were manufactured in earlier stages of the world's history.

The fact that the green leaf supplies the driving power to the whole machinery of the plant finds a good many applications in practice. It explains, for example, how it is possible to kill out perennial weeds like thistles or bearbine by persistent hoeing, which does not give the leaves an opportunity of working, although the root keeps throwing up fresh shoots from its latent buds. Every time it does so, some of the material stored up in the root is used to make the fresh shoot and get it up above the ground; if, however, the new leaves thus arising are cut off before they have had time to manufacture any surplus material and send it down to the root for storage, the original stock is somewhat exhausted, until by a repetition of the process the plant no longer possesses any reserve material wherewith to lift a shoot above ground. Persistence in the cutting-off process is, however, necessary; it is no good to spud a thistle once during the year, because it possesses sufficient reserve material in its root to get fresh leaves up to the light and they soon repair the losses.

Again, we see how unwise is the practice of many gardeners who remove the leaves of tomatoes, vines, etc., when the fruit is forming, with the idea of throwing all the strength of the plant into the fruit or of letting in the sun to ripen the plant. The removal of the leaves means that the manufacturing processes of the plant are stopped; no more carbohydrates are formed, in these cases no more sugar, and the fruits remain small and 



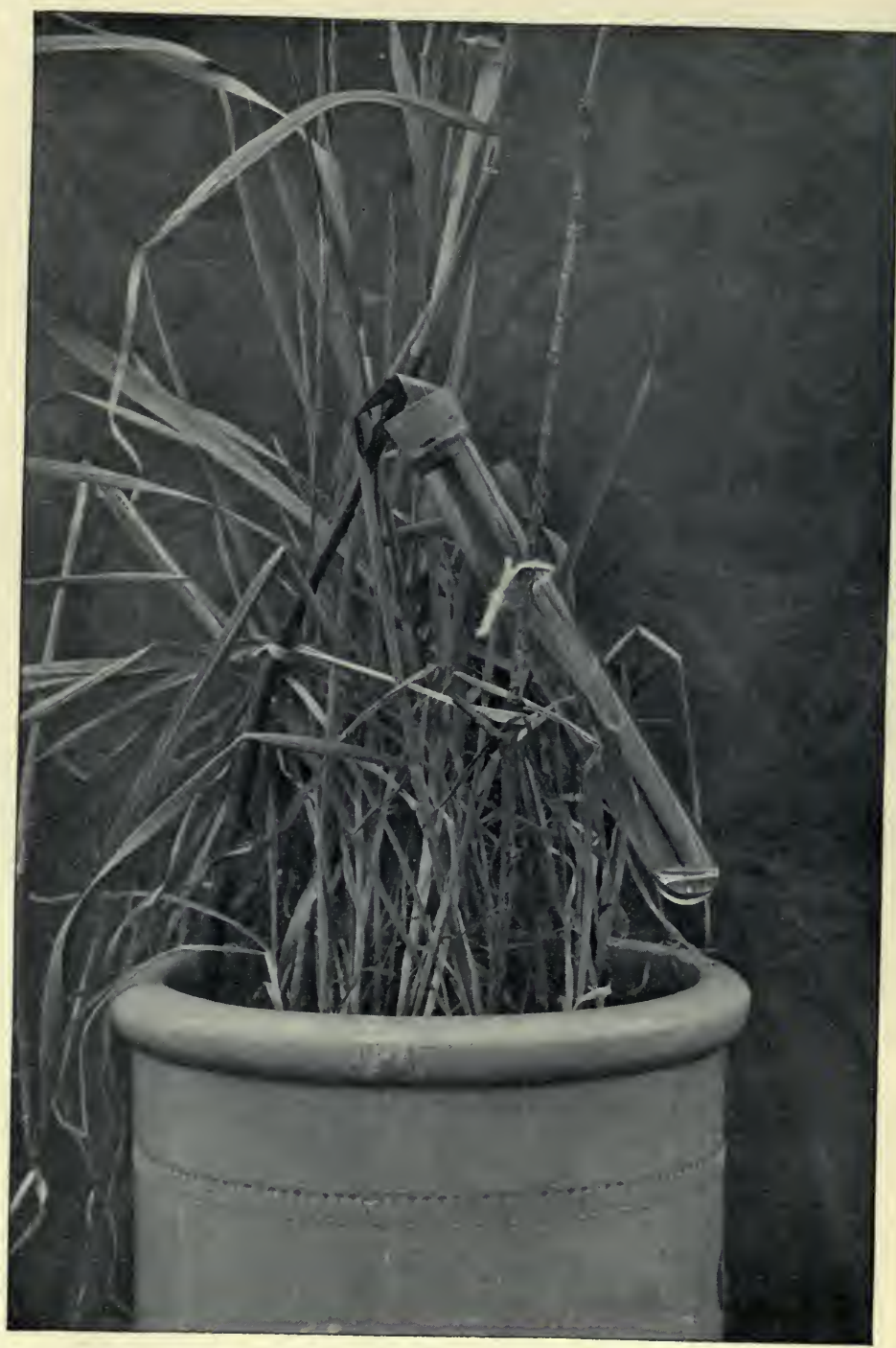

Fig. 8.-TRANSPiration of WATER from LeAF. 
without their proper sweetness because of the cuttingoff of the supply of sugar. Stopping the growing points of the plant is justifiable, because thereby the material manufactured together with whatever may be in reserve in the stems or roots will be thrown wholly into the fruit and is not wasted in making unnecessary new growth; but to the final heaping up of sugar and similar substances in the fruit the continued action of the leaf is indispensable. In the case of grapes, it has been shown that to cut off any large proportion of the leaves with the idea of more completely exposing the grapes to the sun reduces not only the size of the grapes, but their richness in sugar as well. What ripening action is caused by the direct rays of the sun is not known, but probably the increased warmth they cause induces in apples and pears a quicker change of starch and similar materials into the sugar and aromatic bodies which mark the ripe fruit. The sunny side of the fruit is never, however, very much ahead of the shaded side, so that we may conclude that the shading is not of much moment in delaying ripening, whereas the absence of leaves has a seriously detrimental effect.

Assimilation and respiration do not, however, represent the whole of the work of the leaf; it has one other fundamental piece of work to do, that is, to get rid of water from the plant. We can illustrate this action by several simple experiments; for the first, take a test-tube with a well-fitting soft cork, and slit the cork in two down its length. Then introduce a long thin leaf (a barley or a daffodil leaf will do, according to the time of year) into the tube, and cork up the tube with the leaf between the two halves of the cork. Leave the tube thus hanging on to the plant until the next day, when a plentiful deposit of water will be found inside the tube. For a second experiment, take a pot containing some actively growing 
plant possessing only a single stem, a geranium for example, and tie up the pot in waterproof paper or rubber sheet so drawn round the stem of the plant that no water can evaporate from the surface of the pot or the soil in it. Counterpoise the pot on a large balance, and note the loss of weight at intervals for the next few days, comparing the loss per hour by day or by night, and again during periods of varying temperature, etc. Instead of weighing the water lost, a form of apparatus may be devised to render visible the rate at which the plant is giving off or "transpiring" water, so that comparative measurements may be made much more quickly. An eight-ounce bottle is provided with a rubber cork pierced with three holes, through the largest of which a wooden rod passes, while a second carries a horizontal piece of capillary tubing. A young branch of a plant or the stem of a large leaf is now passed through the third opening, the bottle is filled with water, and the cork is forced in so that no bubbles of air are trapped beneath the cork. When the apparatus has been left to itself for a time, until it has become adjusted to the temperature of the room, the water in the horizontal tube will be seen to be continually receding because of the water taken up by the stem and transpired from the leaves. By means of a scale on the horizontal tube the rate at which the leaves are transpiring may be measured, and by putting the apparatus in a cooler room, by shielding it from the light, etc., the effect of various factors upon the transpiration process may be gauged. By means of the wooden rod, the water in the bottle may be forced back into the capillary tube each time a fresh measurement is required. Measurements should not be made until some little time has elapsed after each change, in order that the plant may have adjusted itself to the new condition. In this way it can be shown that a current of 


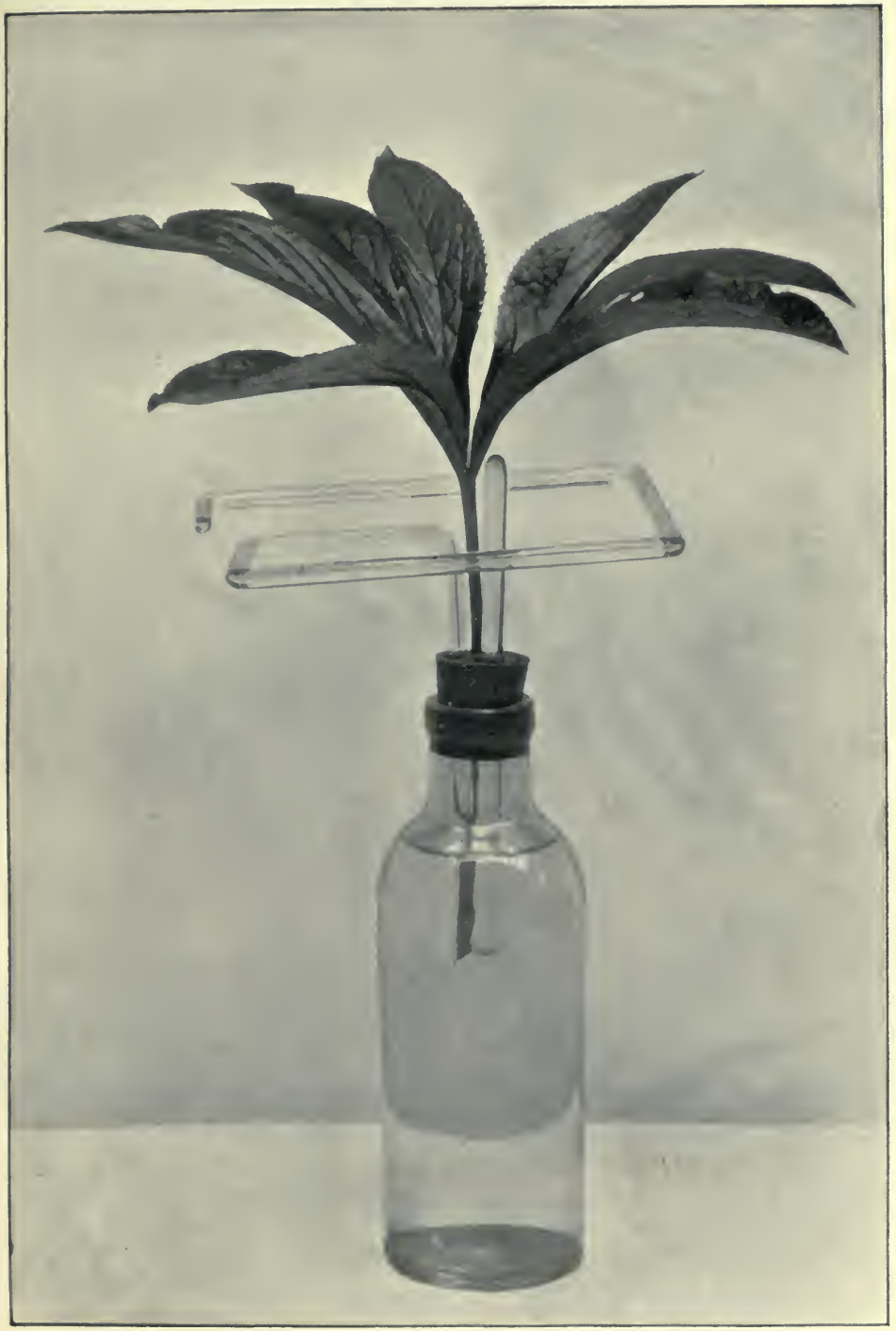

Fig. 9.-Apparatus for Measuring Rate of Transpiration FROM LEAF. 

air on the leaves, produced, for example, by a bellows, increases transpiration if it docs not lower the tempcrature too much, whereas a close saturated atmosphere obtained by surrounding the leaves with a bottle and loosely closing the mouth will reduce and almost suspend the process. Syringing the leaves, again, by inducing a saturated atmosphere next their surface, also greatly reduces transpiration. Again, by smearing with vaseline first the upper and then the under side of the leaves, we shall find that with most plants the transpiration takes place almost wholly from the under sides of the leaves. We can demonstrate this fact in another way by taking two clean but cold pieces of glass and putting a freshly gathered leaf between them; on taking them apart after a minute or two, the glass will be so dewed over as to form an image of the leaf, but the image will be very thin and faint on the glass which was in contact with the upper side of the leaf. The surfaces of a leaf should now be examined under a microscope; either the leaf can be looked at without any preparation by reflected light, or the skin on the upper and the under sides can be torn off and examined separately by transmitted light. The surface of the leaf will be seen to be studded with small mouth-like openings, called stomata, and these openings, except with a few plants, are very much more numerous on the under than on the upper side. The stomata, which open and close according to the illumination, the temperature, the degree of humidity of the air, etc., form a means of communication between the outer air and the surface of the active cells in the middle of the leaf; indeed the cuticle of the leaf, except for these openings, is composed of cells containing no chlorophyll, and simply acts as a protecting membrane practically impervious to gases. Through the stomata the plant takes in the carbon dioxide it requires for 
assimilation and in its turn exhales oxygen; through them again it exhales carbon dioxide when it is respiring, and gives off its transpiration water in the form of vapour. As a rule, the water escapes as vapour and continues to be invisible, but when the surrounding atmosphere is saturated it may condense as drops upon the tips or edge of the leaf. Thus arises the greater part of the dew which covers the grass in the early morning; were dew only water that had been condensed from the atmosphere by the ground cooled by radiation, dew would be as plentiful on a garden path or on a stone as on the grass.

Many experiments have been made to ascertain how much water a plant transpires during its growth, and this information is most easily applied to practical problems if we establish a connection between the amount of water transpired by a plant and the increase of weight (reckoned, of course, as dry matter) which takes place within the same period. At bottom there is no real connection between assimilation and transpiration; the two processes go on simultaneously, and to some extent are similarly affected by the same external conditions, but they are in so many respects independent that any ratio we may trace between them can only be a sort of average, true for the general conditions prevailing in the place of experiment. For example, in England, Lawes and Gilbert concluded that for every pound of dry matter elaborated by such plants as wheat, barley, clover, and peas, about $250 \mathrm{lb}$. of water was evaporated from the surface of the leaves. Hellriegel in Germany with a drier atmosphere obtained results about 50 per cent. higher, while Wollny in Vienna and King in Wisconsin, with still hotter and drier climates, obtained even higher ratios. In England, however, we may assume that every pound of dry matter produced 


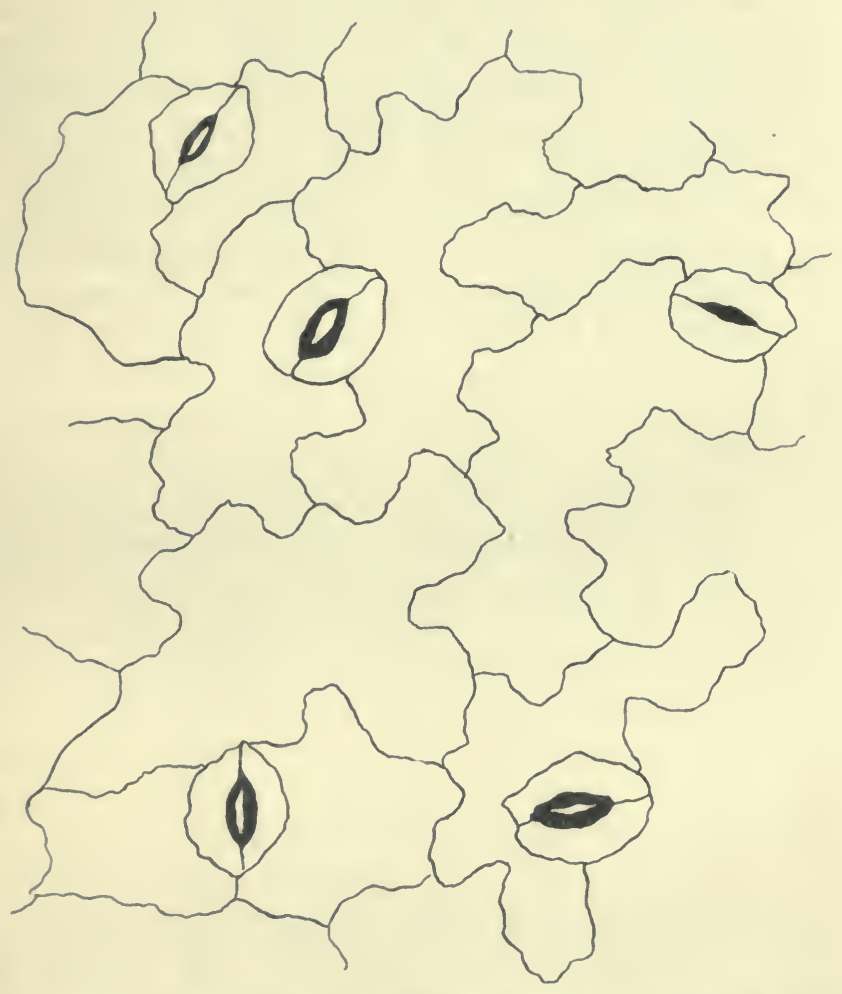

Fig. I0.-Stomata of Sweet Pea, Lower Surface. 

by a crop has entailed the supply of from 250 to $300 \mathrm{lb}$. of water, and this mounts up to a considerable quantity when the whole production per acre is considered. Of mangolds, for example, we may expect to grow with proper treatment 40 tons per acre, about 12 per cent. of which will be dry matter, i.e. 4.8 tons of dry matter per acre will be produced. This entails the evaporation of $4.8 \times 250$, or 1200 tons of water per acre; and as an inch of rain is approximately equal to 100 tons of water per acre, a mangold crop of 40 tons per acre must evaporate through its leaves as much as $\mathrm{I} 2$ inches of rain, a very considerable proportion of the annual rainfall in the districts in which mangolds are much grown. Other crops do not produce quite as much dry matter per acre as the mangold does, but still it will be found that most of our farm crops necessitate the evaporation of from 5 to 10 inches of rain. Considering that crops make their chief growth during the hotter periods of the year, when evaporation from the soil is also most active, it becomes evident why the amount of rainfall is one of the biggest factors in crop production, and why the operations of the farmer in cultivating the soil are very largely directed towards conserving for the plant whatever water reaches the land.

Because of the large amount of water evaporated by the plant, a growing crop always keeps the ground beneath it in a very dry condition; after harvest it will generally be found that the subsoil is dry to some considerable depth. For example, in June 1870 at Rothamsted after a long drought, determinations were made of the amount of water in the soil on which a barley crop was being grown, and on an adjacent piece of land which was being fallowed and kept bare. Down to a depth of 54 inches it was found that the bare fallow soil contained 900 tons per acre more water, an amount 
equivalent to 9 inches of rain. It is often impossible to lay drains in a clay soil in the autumn on land which has been cropped, because the subsoil is so dry as to be unworkable by the ordinary drainage tools. Again, the drying action of the crop explains the difficulty that is often met with in the south and east of England in attempting to secure a second catch crop by sowing on the stubbles immediately after harvest; unless there is timely and continued rain, both soil and subsoil are too dry to support any satisfactory growth. Even if a stand of vetches or crimson clover is established, it is apt to leave the land in spring so depleted of water that the succeeding crop of roots is jeopardised unless there is an abundant early summer rainfall. Another example of the drying power of a growing plant is seen in the wide circle of stunted growth which extends into a cornfield round a tree in a hedgerow, should the season have been a dry one. By its roots the tree has robbed the subsoil of water much more than it has deprived the crop of either light or nutriment. The fact that the growth of a satisfactory crop necessitates the evaporation of a certain amount of water is nowhere more distinctly recognised than in the practice of alternating one or two years of crops with a year of bare fallow which prevails in some of the western districts of North America, and also in Australia, in regions where there is but a low annual rainfall of 8 to 12 inches. This amount of rain is insufficient for more than a very small crop year after year; but by leaving the land without crop for a season and cultivating the surface of the soil so as to check evaporation, the rainfall of the fallow year can be so far accumulated that when combined with the normal rainfall of the following year a profitable crop can be grown. Over a wide area of semi-arid country farming can be made profitable without irrigation if the 
rainfall of two years can thus be stored up for a single crop, or sometimes if three seasons' rainfall can be utilised by two crops only.

It should not be supposed that all plants demand such great quantities of water for transpiration as do our ordinary field crops, because they are plants which have been selected for their rapid growth under favourable conditions. But in nature we always find that plants which have adjusted themselves to live either in very dry situations or in places where it would be injurious to take in too much water, have always modified themselves in some way so as to reduce transpiration. Whereas in temperate climates the leaves of a plant arrange themselves to wave in the air and to present as great a surface as possible to the light, the leaves of the Eucalyptus and most of the other Australian trees so dispose themselves as to present only an edge to the sun, thus reducing both the transpiration and the heating effect of its rays. Very generally, in such circumstances the plant reduces the size of its leaves or even replaces them entirely by spines, gorse or whin being a case in point; sometimes, as in the stonecrops and houseleeks or the cacti, the leaf is made very thick, so that its storage capacity is great as compared with its evaporating surface. A hairy or a waxy glaucous surface, or the presence of resins and essential oils (among the plants growing on dry banks there is a notable proportion of aromatic ones), are all regarded as mechanisms by means of which the plant has learnt to reduce transpiration.

Various other consequences also follow from the continued loss of water at the leaf surface by transpiration, such as the flow of sap in the stem; but first it will be necessary to consider at some length how the water enters the plant. 


\section{CHAPTER III}

\section{THE WORK OF THE ROOTS}

The Roots as anchoring the Plant. The Roots supply the Plant with Water. Roots require Air. Roots can only take in dissolved Material. Etching Action of Roots due to their Excretion of Carbon Dioxide. Elements necessary to the Nutrition of Plants. Plants require Combined Nitrogen.

THE root of the plant has two great functions to perform-one mechanical, in keeping the plant firmly fixed in position; the other physiological, in supplying the plant with water and the food it requires from the soil. In certain cases, notably the mangold and the carrot among farm plants, the root is also utilised as a storehouse of the reserve material that is being accumulated in readiness for the formation of flowers and seed. The books devoted specially to botany must be consulted for details regarding the many shapes taken by roots, the manner in which they grow, and the devices, such as the sensitive root-tip, which they possess in order to make their way into the ground and turn in the direction of food and water. For our purpose, the germinated bean and wheat seedlings used for the previous experiments will afford sufficient information as to structure. In the case of the bean, we find a taproot running straight down, from the side of which secondary roots are thrown off; it may further be observed, when the root has been allowed to grow into damp air, that all the slender roots near the tip are 
clothed with a down of very fine hairs, though the last quarter of an inch or so is bare. In the case of the wheat, instead of a single tap-root a number of fibrous roots, which branch as they become older, issue from the embryo; these likewise are clothed with root hairs near the tips. By day-to-day observations we shall find that the root hairs fall off as the root ages; they occur only in a region just behind the growing point of the root. By carefully digging up some young seedlings from the open ground or from a pot of earth, and washing away the soil, we shall find that the root hairs cling very obstinately to some of the fine particles of soil, with which they are evidently in intimate contact. A good deal of the holding power of roots is due to this association of the root hairs with the finest particles of the soil. It is possible to show by appropriate experiments that the primary root of a plant tends to grow straight downwards under the direction of the pull of gravity, but that it may be deflected by its attraction for such necessaries as water, air, and suitable food. The attraction exerted by the supply of air is plainly to be seen in the way roots of trees and any deep-rooting plants force their way into drains, just as their need for air is shown by the way roots will not penetrate into undrained soil, but stop short as soon as the layer is reached which is saturated with stagnant water and contains no air. It is also found that wheat develops the best root system (the foundation of a large crop later) when the winter is comparatively dry, so as to leave the soil well aerated; in a wet winter or wet soil the plant neither needs so extensive a root system in order to keep itself supplied with water, nor is it stimulated by the air to produce roots. The attraction exerted by food is seen in the way a bone or other fragment of sparingly soluble manure becomes covered and permeated 
by the roots of any crop occupying the soil in which the manure is buried.

Of the power of roots to anchor plants and hold them firmly in position little demonstration is needed, but it is interesting to see how many plants actually pull their crown closer into the ground by contracting their roots. Examine the young dandelions or plantains which have established themselves on a lawn; not only is there no stem lifting the crown of leaves out of the ground, but on the contrary this crown is pressed down tightly into the ground. As a matter of fact it has been pulled down by the contraction of the main root; and if this main root is carefully dug up in the early summer, washed and examined, it will be seen to be corrugated and to possess ridges showing where the contraction has taken place. The crocus affords another interesting example of contractile roots; each year the new crocus corm is formed on the top of the old one, so that after a few years the corm would find itself on the surface of the soil. However, the new corm develops a ring of fleshy contractile roots which draw it down again into the position occupied by the old one before its decay. The seedling tubers of the Common Arum (Cuckoo-pint, or Lords-and-ladies) possess similar contractile roots which operate each season until the tuber has been drawn down to its proper level. The habit of many plants of throwing out adventitious roots from another part of the stem than that from which the original roots start should be observed; in the case of cereals this throwing out of adventitious roots from a point close to the surface of the ground, much higher up than the original crown of roots from the embryo, is a very important factor in supporting the straw; like the formation of side shoots, or "tillering," it is promoted by free exposure to light and air. 


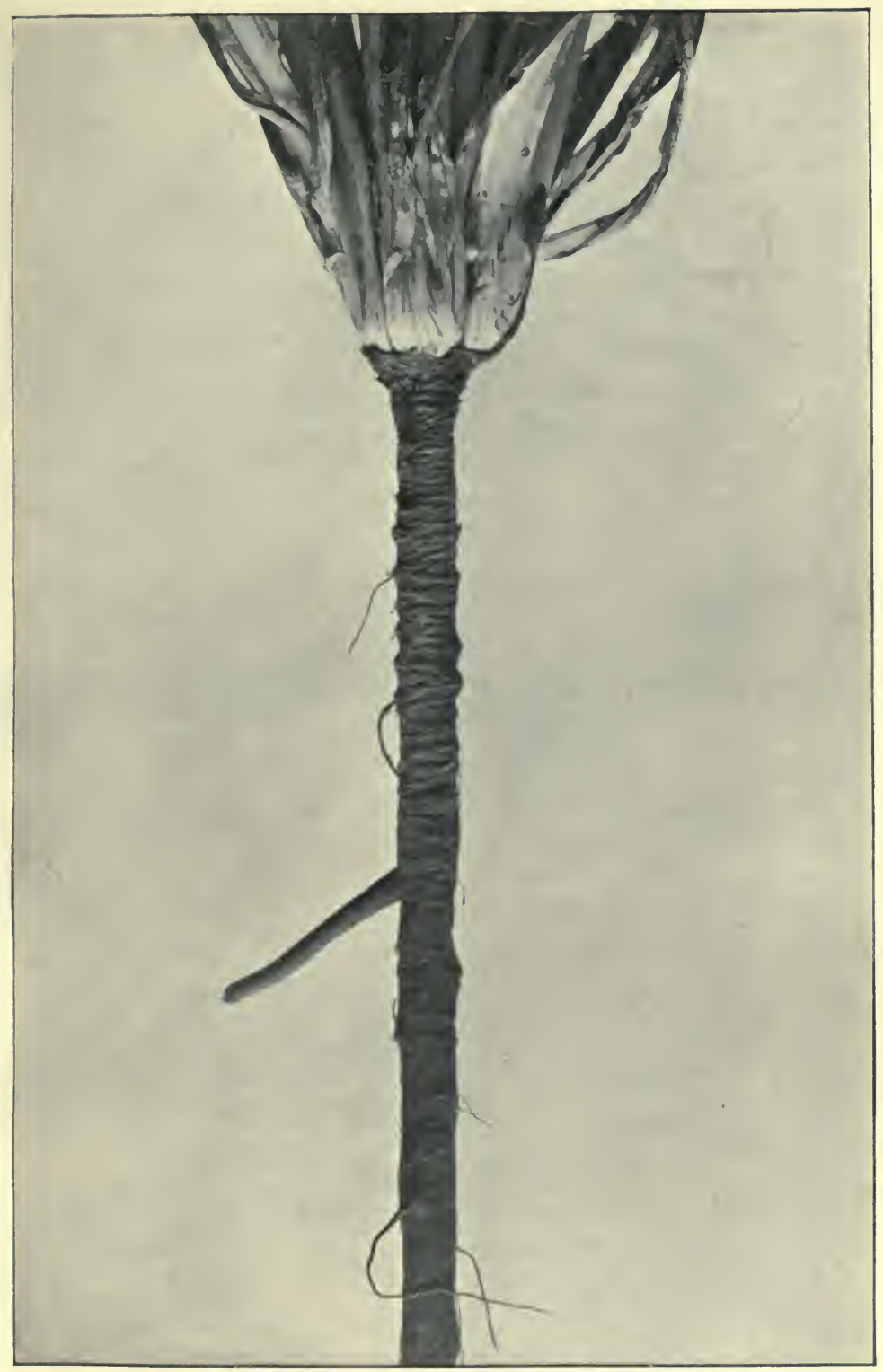

Fig. I 2.-Contractile Taproot of Dandelion.

[Face page 44. 

In order to demonstrate some of the other actions of roots, it will be as well at this stage to raise plants in water culture; barley or maize form convenient plants, so a few grains should be germinated in damp sawdust or between the folds of a roll of blotting paper standing vertically with the bottom just dipping into water. Choose some twenty-ounce bottles, fit the necks with corks, and make up a solution as follows, dissolving the ingredients separately and mixing them with the bulk of the liquid in the order given :-

\begin{tabular}{|c|c|c|c|c|}
\hline Water . . & . & & & I litre. \\
\hline Potassium Nitrate & . & & & I gramme. \\
\hline Magnesium Sulphate & . & & & $0.5 "$ \\
\hline Calcium Sulphate & . & - & & 0.5, \\
\hline Sodium Chloride & . & & & $0.5 "$ \\
\hline Monopotassium Phosp & hate & & & $0.5 "$ \\
\hline Ferric Chloride & 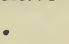 & & & trace. \\
\hline
\end{tabular}

Wrap the outside of the bottle with stout brown paper, and tie it in position so as to keep the contents in the dark. When the seedlings have grown far enough to show a little shoot and roots an inch or more long, split the corks and cut a notch in the split surface, then fix one of the grains in the notch between the two halves of the cork, and insert them into the bottle, so that the tips of the roots just dip into the liquid. If the notch is too large, a little cotton-wool may be necessary to fix the grain in position. Put the bottle in the window so that the little plant gets full light; if water is added to the bottle from time to time to restore what has been lost by evaporation, the barley or maize plant will grow in a perfectly normal manner and will ripen seed in due course. It will be obvious from the way in which the water has to be constantly renewed in the bottle when the growth is active, that the roots of a plant form the organs by which the plant takes in water, a fact which might 
indeed have been deduced from the continual loss of water by transpiration from the leaves. By weighing a bottle and its growing plant on a sensitive balance, and reweighing after a given time, the loss of water by transpiration under different conditions of temperature, illumination, etc., can be readily determined, thus checking the conclusions reached by the previous experiments upon the leaf. It is only by the root that water enters a plant: when a gardener syringes the leaves or waters the paths and stages of a greenhouse in which plants are flagging, he does not thereby add water to the leaf; by saturating the air with moisture he checks transpiration, and thus enables the intake by the roots to make up for the evaporation at the leaf surface. Anything that checks the development of root, or for a time deprives the plant of its proper amount of root, renders the plant more liable to die from lack of water; thus plants after repotting should be kept for a short time in a close atmosphere in which little transpiration can take place until fresh roots have developed, and a transplanted tree requires special attention in a dry season to maintain a moist soil round the mutilated root system. Again, crops on a well-drained soil, even though it is light and little retentive of moisture, will withstand a period of drought longer than on a heavy undrained clay, because in the former case the root system extends deeply into the soil, whereas in the latter it is cut short near the surface by the stagnant, airless water. A plant begins to wilt and will eventually die when the transpiration from the leaves is greater than the supply brought in by the root from the soil, and it will be found that roots are not able to extract the whole of the water present in the soil. If plants are grown in a pot, and as soon as they begin to wilt the soil is turned out and a sample weighed and put to dry, even a sandy soil will be found to contain 
about 3 per cent., while a clay may contain more than Io per cent. of water which the soil particles can hold against the plant, so that it therefore is useless for the support of vegetation. That the roots themselves take water from the soil, and do not merely pass on the suction exerted by the transpiring leaves, may be seen by the manner in which the supply of water to the plant ceases when any such cause as cold stops the functioning of the roots. The vital actions of the root are suspended at or near the freezing point, and water ceases to be taken up; consequently if the leaves or stem of the plant are subjected to any great drying influence while the roots are thus cold and out of action, the death of the plant by drying-out may result. Indeed, much of the destruction by frost of what are known as tender plants, e.g. tea roses, is due not to drought so much as to cold. Such destruction will always be found most severe if a spell of drying wind comes when the ground is frozen and there is no snow round the plants to maintain a slightly moist atmosphere and prevent the access of the drying wind. The shelter of a little bracken or straw, or of a few spruce boughs, is sufficient to preserve the plants from injury, not that they are thereby maintained at any higher temperature, but because of the protection from wind and evaporation that has been afforded. The morning sunshine falling upon a frozen shrub and plant is most destructive, not because the sudden thaw can exert any direct harm, but because the sun starts a considerable transpiration which cannot be met by the roots in the still frozen ground. We may also use the water cultures to demonstrate the fact that the roots, like all other parts of the plant, respire, and therefore must be supplied with oxygen, in place of which they give off carbon dioxide. In a water culture the roots obtain the oxygen they 
require from the small quantity that the water holds in solution and constantly renews from the atmosphere with which it is in contact. For this reason it is advantageous to blow a little air through the culture solution once a week, especially when the root development has become at all extensive. The result of cutting off the oxygen can be shown by replacing the culture solution in one of the bottles by some water which has been boiled, to free it from any dissolved air, and then cooled. Fill up the bottle with this water close to the neck of the plant, and then pour on it a very thin layer of olive oil, which will effectually cut off the access of air to the water in which the roots are distributed. In a day or so the plant will begin to show signs of ill-health, and will rapidly die. That the respiration of the root is accompanied by the evolution of carbon dioxide, can be seen by placing another plant's roots in distilled waternot, however, freed from dissolved air-pouring off this water on the following day, and adding to it lime water. The milkiness which ensues shows that carbon dioxide has been given off from the root, and has remained to some extent dissolved in the water. The same demonstration may be effected by letting the plant's roots themselves dip into lime water.

In addition to the water, it is the function of the root to take in the various substances required for the nutrition of the plant. These are obtained from the soil, and constitute the plant's ash. A simple experiment can be carried out to demonstrate that any substances which get into the plant must first of all be dissolved in the water in contact with the root. Colour the solution in one of the water-culture bottles a bright pink with eosin ; to another bottle add carmine or Indian ink. The eosin, being in solution, will gradually penetrate the young barley plant, and may be seen colouring the veins; but 
the carmine and Indian ink show no signs of penetration, because in their case the colouring matter is not dissolved, but consists of very fine solid particles suspended in the fluid. Flowers, especially those from bulbous plants, which readily absorb water, are occasionally dyed by thus leaving them for some little time with their stems dipping into a solution of some dyestuff which makes a true solution.

If the plant, then, can only take in materials that have been first dissolved in the water in contact with the root, how comes it that the plant can make any use either of the soil or of a great number of manure substances which are comparatively insoluble in water? This point will be more fully dealt with when we are considering the soil, but at this stage we can show that the plant itself helps towards bringing such substances into solution. For the experiment, a thin slab of polished marble will be wanted; the colour is of no moment, provided that the surface is nicely smooth and bright. This slab must be set vertically near the bottom of a pot filled with ordinary soil in which two or three dwarf beans are planted, preferably after germination, in order to save time. When the beans have grown pretty well and the pot is full of roots, shake out the contents and wash the slab free from all dirt. The polished surface will be found to be etched with a series of markings representing the places where it has been in contact with the roots, which thus evidently possess some power of dissolving the carbonate of lime composing the marble. From this experiment and the fact that the sap contained in the roots of most plants is acid to litmus paper, it has been somewhat hastily concluded that the plant's roots excrete an acid sap, or that the sap acts through the walls of the root and so attacks the solid particles of the soil. Probably, however, 
this view is erroneous; there is evidence that the acid sap can never reach anything outside the unbroken root, and all the actions, including the etchings of the marble, are quite explained by the excretion of carbon dioxide, which, we know, is always taking place from the root. As a solution of carbon dioxide in water acts like a weak acid and is much more effective than pure water in dissolving mineral matter, the roots of the plant have a distinct effect in rendering the materials in the soil available as food for the plant; this point will be considered later when dealing with the soil.

We may now proceed to make use of the method of water cultures, to determine what are the mineral substances, etc., taken by the plant from the soil, and which of them are essential to its growth. When dealing with the composition of the plant, we have already seen that a comparatively small range of elements are to be found there, and that all plants are alike in containing besides carbon, hydrogen, and oxygen, also nitrogen, sulphur, phosphorus, chlorine, and often silica, with potash, soda, magnesia, lime, and iron among bases. Only these elements can be essential to the plant: and whether all of them are necessary can be ascertained by growing a set of plants in water cultures and omitting from successive bottles each element in turn. Taking, for example, in bottle $\mathrm{I}$, the standard solution which we have already employed; in 2 the potassium nitrate may be omitted, thus giving a solution without nitrogen (the potassium will be still furnished by the potassium phosphate); in 3 the potassium phosphate is omitted, to get a solution containing no phosphoric acid; in 4 the potassium phosphate and nitrate are replaced by the corresponding sodium salts; and so on. The seedling barley or maize plants are inserted in the usual way, with the result 


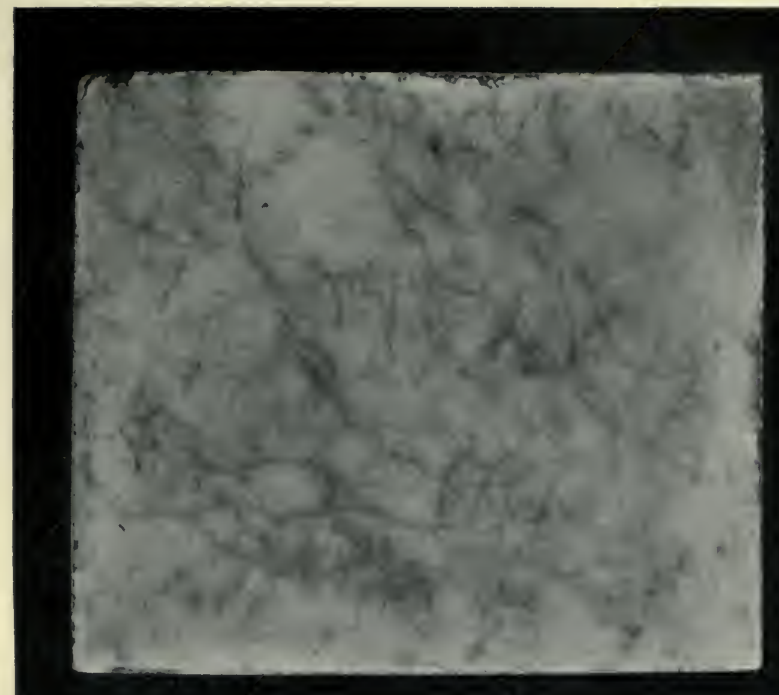

鼻

蒠

留葍

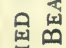

约

ํํㅇ

เ્1

$\infty$

范

!

$m$

๖.

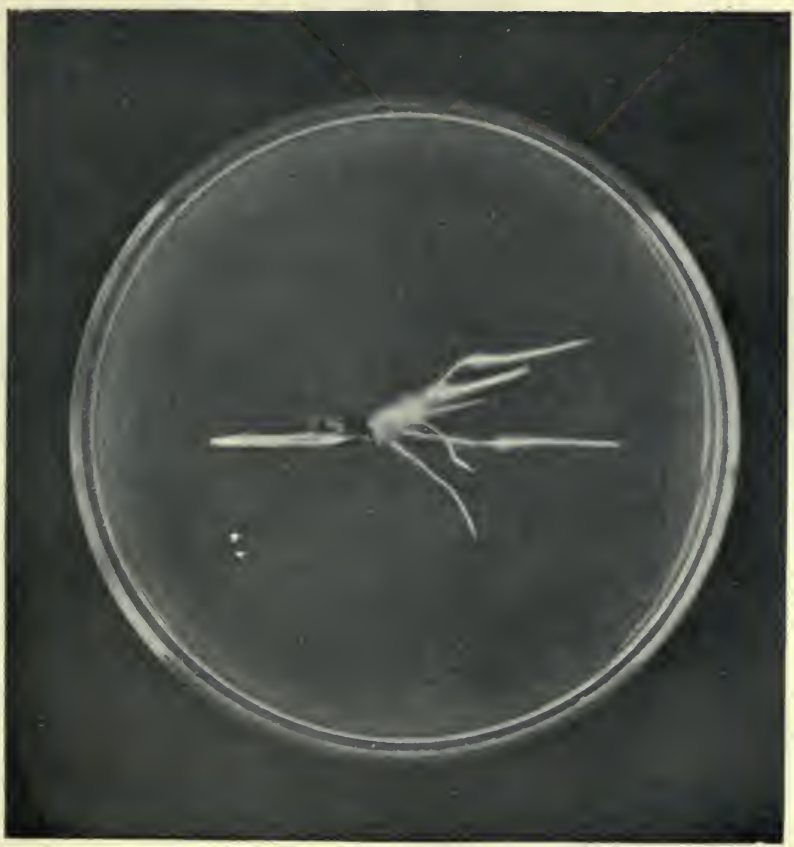

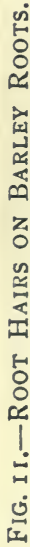



shown in the illustration, from which it will be seen that only soda and perhaps chlorine can be omitted without some injury to the plant. When either nitrogen, phosphoric acid, or potash is omitted, growth ceases as soon as the food supply in the seed is exhausted; in the absence of sulphuric acid, or magnesia, or lime, growth continues, though it becomes rather abnormal; but soda, silica, and sometimes chlorine can be left out without causing any difference to the growth. If no iron is added to the solution, the leaves of the seedling plant soon become very pale in colour; the new shoots in particular will be of a pale straw colour and possess no substance, until in a short time the whole plant perishes. But if a few drops of ferric chloride are added to the solution, on the following day the veins of the leaves will be seen to be turning green again, and the whole of the leaf will rapidly follow suit. In some way an iron salt is necessary to the formation of the chlorophyll - the green colouring matter of the leaf-without which no assimilation can take place. We may extend the method of water cultures to ascertain in what state of combination the various elementary constituents must be presented to the plant if they are to be utilised by the plant. In our experiment, for example, we have used a nitrate as the source of nitrogen, and seen that the plant can take in this compound of nitrogen and elaborate from it all the proteins and other complex nitrogenous bodies it contains; which of the numerous other compounds of nitrogen can be similarly utilised? As a matter of fact, only a very few, and those of the simplest type of construction, can be so utilised; in addition to the nitrates, plants will take in the salts of ammonia and a very few bodies like asparagin-i.e., simple amino bodies such as they build up themselves at a very early stage from the still simpler nitrates and ammonia 
salts taken from the soil. Phosphorus, again, must enter the plant as a phosphate or phosphoric acid; sulphur as a sulphate, for sulphites, sulphides, and many other compounds of sulphur are not only useless but poisonous. The bases found in the plant enter as the neutral salts of sodium, potassium, calcium, magnesium, etc. ; in fact, for all the elements except chlorine we may say that the plant prefers or even requires the ordinary most highly oxidised compound of each element. It will thus be seen that the plant behaves towards its nitrogen and its ash constituents just as it does towards its carbon compounds-i.e., it begins with a simple oxidised compound, reduces it by splitting off oxygen, and builds it up into a variety of bodies of great complexity possessing more potential energy than the initial compounds out of which they have been wrought. It is easy to understand that a plant must take up the mineral substances which are found in its ash from the soil, because it is in contact with no other source of such a constituent as phosphoric acid. The case is, however, different as regards nitrogen, because the plant when growing is surrounded by the atmosphere, four-fifths of which consists of nitrogen in a free, uncombined state. It has therefore been a question of much interest-one that has always been in dispute, and is still not regarded as settled by some people-whether the plant is not able to utilise some of this vast stock of free nitrogen and draw a part, if not the whole, of the combined nitrogen it contains from such a source. The evidence is, however, strongly against the view that plants are in any way able to "fix" or bring into combination the nitrogen gas of the air, except in one or two special cases where the process is really effected by certain bacteria living in partnership with the plants; the general run of plants are supposed to be wholly dependent on combined 


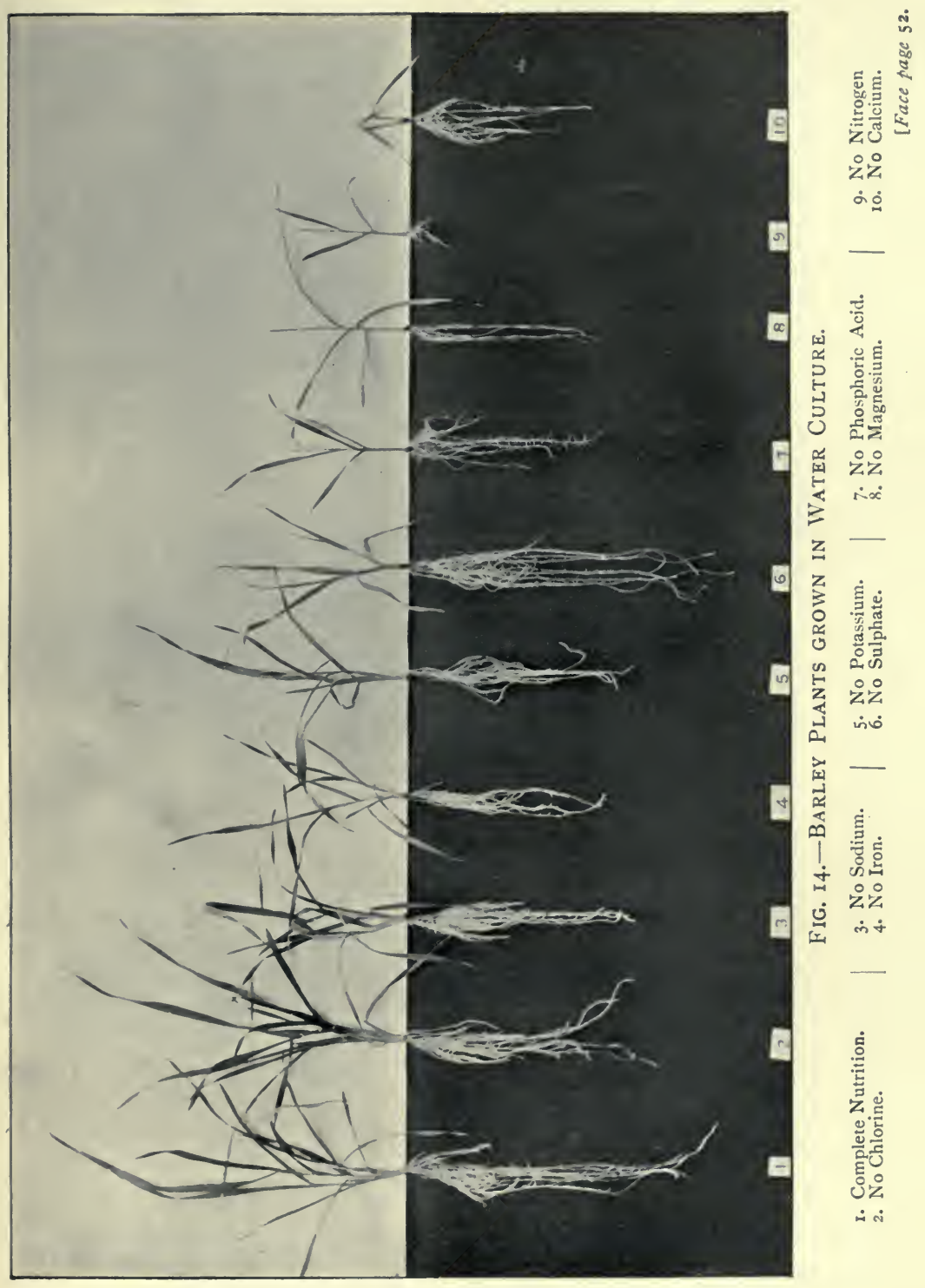



nitrogen which they derive from the soil. In the waterculture experiments, for example, we see how incapable of growing the plant becomes if the nitrate is omitted from the culture liquid; and the same thing occurs if the conditions are made more normal by growing the plants in an artificial nitrogen-free soil. Most careful experiments have also been made, in which plants are grown in prepared soil and the nitrogen present in the seed and soil at the beginning is compared with the nitrogen contained at the end in the plant and soil, with the result that no gain from the atmosphere is detectable. These experiments, however, are very difficult, and subject to a large experimental error; moreover, it has been argued that the artificial conditions result in such a diminished vigour that the plant has no longer the vitality necessary to fix the atmospheric nitrogen.

Such arguments are, however, disposed of by another type of experiment, in which a series of plants growing in sand supplied with the necessary mineral constituents are given varying amounts of nitrate, with the result that, up to a certain limit, the growth is strictly proportional to the amount of nitrogen supplied. The same kind of trial has been made in the field; for example, at Rothamsted one plot of mangolds was given a small. amount of ammonium salts to supply enough nitrogen to start the plant into full vigour; Table IV., however,

Table IV.-Produce of Mangold Roots, Rothamsted.

27 Years' Average.

\begin{tabular}{|c|c|c|}
\hline Manure. & Tons per acre. & $\begin{array}{l}\text { Return for } 11 \mathrm{lb} \text {. } \\
\text { Nitrogen. } \\
\text { Tons per acre. }\end{array}$ \\
\hline Minerals, no Nitrogen & 4.55 & \\
\hline$" \quad 7.8 \mathrm{lb} . \quad "$ & $5 \cdot 93$ & 0.18 \\
\hline $94 \mathrm{lb} . "$. & 14.60 & 0.11 \\
\hline
\end{tabular}


shows that the extra growth thus produced above that on the plot wholly without nitrogen was small, and is closely proportional to the nitrogen supply, when compared with the increase of crop produced by a much larger amount of nitrogen.

Indeed, the Rothamsted experimental results, taken collectively, are only consistent with the supposition that the ordinary farm crop obtains the whole of the nitrogen it requires from the soil; on all the plots receiving no nitrogen whatever, the crop (leguminous plants alone excepted) has been reduced to a very low level; indeed, it is only due to the large stock of nitrogen originally present in the soil and to certain recuperative actions at work there that it is maintained at all. The difficulty about this conclusion-that plants utilise only the combined nitrogen in the soil-is to understand how many of the rich virgin soils, black with organic matter down to a depth of nine or ten feet, can have accumulated the nitrogen they contain. If the plant contains only the nitrogen it has taken from the ground, there can be no gain of nitrogen when the plant falls back to the ground, however numerous the generations in which such a vegetative cycle may be repeated. Some other agencies than the mere growth and decay of plants must have been at work fixing nitrogen, and these will be discussed later.

While we are dealing with the nutrition of the plant by means of the root, one other point requires consideration: the analysis of the ash of any given plant shows a very similar composition, wherever or on whatever kind of soil the plant has been grown. For example, the ash of wheat straw (see Table V.) is characterised by a high percentage of silica and a low one of lime; this will be the case whether the wheat is grown on a sandy or a chalky soil, and is in sharp contrast to the ash of 


\begin{tabular}{|c|c|c|c|c|c|c|c|c|c|c|c|c|c|}
\hline ฮீ & $\begin{array}{l}\text { 悹 } \\
\text { 岁 }\end{array}$ & $\stackrel{m}{i}$ & 芩 & $\ddot{m}$ & $\begin{array}{c}\infty \\
\dot{\sim} \\
\sim\end{array}$ & $\stackrel{\varphi}{\mu}$ & ڤ̊ & ભ̊ & $\stackrel{\varphi}{\sim}$ & $\stackrel{\sim}{\text { m }}$ & in & o̊ & $\underset{+}{\stackrel{9}{+}}$ \\
\hline ఐ & $\begin{array}{l}\text { 品 } \\
\text { 嵌 }\end{array}$ & ֻั & $\ddot{\dot{\sim}}$ & $\stackrel{1}{1}$ & $\stackrel{\infty}{\text { in }}$ & $\ddot{o}$ & 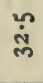 & $\stackrel{\sim}{\check{R}}$ & $\stackrel{\tilde{N}}{\text { in }}$ & : & $\ddot{m}$ & $\stackrel{\dddot{q}}{\dot{q}}$ & $\underset{\dot{m}}{\overrightarrow{0}}$ \\
\hline $\begin{array}{l}\dot{0} \\
\text { ठे } \\
\text { ठे }\end{array}$ & 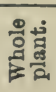 & $\stackrel{?}{\stackrel{N}{N}}$ & $\hat{0}$ & $\ddot{\text { in }}$ & ஜ̊ & $\hat{0}$ & $\stackrel{9}{\dot{+}}$ & $\stackrel{\varphi}{\sim}$ & $\stackrel{9}{\dot{m}}$ & $\ddot{\dot{H}}$ & $\stackrel{\infty}{\infty}$ & $\stackrel{+}{\dot{\sim}}$ & iิ \\
\hline$\dot{8}$ & हैं & ò & $\stackrel{N}{\text { in }}$ & $\ddot{\text { m }}$ & $\stackrel{\dddot{\leftrightarrow}}{\ddot{\sim}}$ & ֻn & $\stackrel{\text { ơ }}{\text { ơ }}$ & $\stackrel{+}{m}$ & $\hat{i}$ & o̊ & in & $\stackrel{\text { ํ }}{\text { i }}$ & 임 \\
\hline 㐘 & 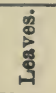 & 离 & $\stackrel{n}{4}$ & $\stackrel{\sim}{\mu}$ & $\stackrel{\leftrightarrow}{\sim}$ & $\stackrel{\varphi}{\sim}$ & $\dddot{i}$ & ᄋ̊ & à & $\stackrel{\infty}{\dot{\sim}}$ & $\stackrel{\sim}{\sim}$ & $\stackrel{?}{+}$ & $\stackrel{\tilde{m}}{m}$ \\
\hline$\frac{\pi}{7}$ & 宅 & $\stackrel{+}{\frac{\pi}{4}}$ & ழ’ & 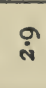 & $\stackrel{\varphi}{\dot{+}}$ & $\ddot{o}$ & ○् & $\ddot{\dot{m}}$ & $\stackrel{+}{m}$ & $\stackrel{m}{\leftrightarrow}$ & $\stackrel{0}{0}$ & $\underset{\sim}{\stackrel{\sim}{\sim}}$ & 㟧 \\
\hline 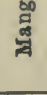 & 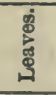 & 일 & $\stackrel{\dddot{O}}{\dot{0}}$ & $\ddot{\dot{t}}$ & $\stackrel{\infty}{\stackrel{\infty}{\sim}}$ & $\stackrel{?}{\stackrel{\leftrightarrow}{*}}$ & $\overrightarrow{\dot{m}}$ & $\ddot{\infty}$ & $\dot{+}$ & $\stackrel{+}{\dot{H}}$ & 衣 & $\begin{array}{l}\infty \\
\stackrel{\infty}{\sim}\end{array}$ & 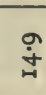 \\
\hline$\dot{\Phi}$ & 离 & 崩 & of & $\stackrel{\text { \} }{\text { N }}} &{\text { 옴 }} &{\stackrel{\infty}{\dot{0}}} &{\stackrel{n}{\text { m }}} &{\text { in }} &{\stackrel{9}{1}} &{\stackrel{\dddot{q}}{\dot{q}}} &{\stackrel{\sim}{\oplus}} &{\vdots} &{\vdots} \\
{\hline \text { 鬲 }} &{\text { 䓌 }} &{\text { ஸั่ }} &{\stackrel{\check{\sim}}{\sim}} &{\stackrel{\leftarrow}{i}} &{\text { 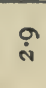 }} &{\dddot{n}} &{\text { 芦 }} &{\stackrel{\text { ஸे }}{\text { N }}} &{\stackrel{\sim}{\leftarrow}} &{\text { ợ }} &{\underset{\sim}{+}} &{\vdots} &{\vdots} \\
{\hline \text { ப் }} &{\text { 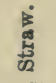 }} &{\stackrel{\sim}{\sim}} &{\vec{o}} &{\stackrel{\sim}{\sim}} &{\stackrel{+}{+}} &{\text { ò }} &{\stackrel{\rho}{\text { in }}} &{\stackrel{\infty}{\dot{m}}} &{\stackrel{\infty}{\sim}} &{\hat{\dot{0}}} &{\stackrel{5}{i}} &{\vdots} &{\vdots} \\
{\hline E} &{\text { 爮 }} &{\stackrel{m}{m}} &{\text { ơ }} &{\text { 옴 }} &{\ddot{m}} &{\stackrel{\infty}{\dot{0}}} &{\stackrel{\dddot{n}}{\dot{\alpha}}} &{\stackrel{9}{\rightarrow}} &{\text { ஸ̊ }} &{\stackrel{\infty}{\dot{0}}} &{\text { চ্ }} &{\stackrel{\overbrace{}}{\stackrel{\leftrightarrow}{H}}} &{\text { ஷู }} \\
{\hline} &{ } &{\text { • }} &{\text { • }} &{\text { • }} &{\text { - }} &{\text { - }} &{\bullet} &{\text { • }} &{\text { - }} &{\text { - }} &{\text { • }} &{\text { • }} &{\text { • }} \\
{\hline} &{ } &{\begin{array}{l}\text { त् } \\
\text { तु } \\
\text { ठ } \\
\text { م. }\end{array}} &{\text { हึ }} &{\text { 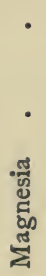 }} &{\text { : }} &{\text { 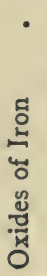 }} &{\text { 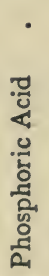 }} &{\text { 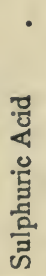 }} &{\text { • }} &{\text { • }} &{\text { 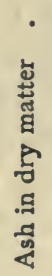 }} &{\text { 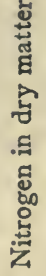 }} &{\text { 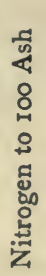 }} \\
$\hline
\end{tabular}


clover, which contains no silica but much lime, or the ash of mangolds, which, while containing a good deal of lime, is specially rich in potash and soda. These specific differences would seem to show that the roots of a plant possess a power of selection, so that they can in the one case take in silica and in the other reject it; or, again, that they can take in potash in preference to soda, or both rather than the lime which is so much more abundant in most soils. It is a mistake, however, to attribute this selective power to the roots; it really resides in the active growing cells of the plant; the root hairs (and they are the active absorptive organs of the plant, both for water and the nutrients coming in with the water) allow the passage of whatever dissolved substances are presented to them until the sap within possesses the same concentration as the water outside the plant. When this stage has been reached, no more can enter, until the living cells of the plant by withdrawing some of the material for constructive purposes lower the concentration of the sap in that particular substance. Potash, for example, accumulates in a plant rather than soda, even though there may be more soda in the soil, because the plant's cells keep utilising the potash and taking it out of the sap solution; whereas a small quantity of soda maintains the plant sap as saturated as the soil water outside, because so little of it is required by the plant's cells. But though the active agency resides in the growing cells, and not in the roots, the result is the same-the plant as a whole does exert a selective action on the elements of nutrition presented to it, so that all plants of the same kind have a certain characteristic ash composition, in which differences of soil, season, manuring, etc., do not cause wide variations. Furthermore, plants of different species possess sharply differing characteristics in the 
composition of their ash. These differences never extend to the entire absence from one plant of an element present in another : all plants contain the same elements, except silica, which is abundant in some plants and entirely absent from others, though, as far as is known, it is unessential to either.

The common idea that certain plants flourish only in particular soils because they find there some particular constituent which is elsewhere lacking, is therefore erroneous; we might almost say that all soils contain all the constituents that plants need, so that as far as food goes, where one plant can grow any other should be equally possible. It is true that the excess or deficiency of certain soils in some particular constituent renders them more or less appropriate to one crop or another, but the circumstances which determine the association of a given plant with a particular soil.are more often questions of texture, temperature, and water supply, than of absolute nutrition, as represented by the greater or less provision in a soil of a particular constituent of the plant.

Although the composition of different plants does not vary within very wide limits, and though as we shall see later the composition does not throw much light on the suitability of particular soils for certain crops, it is yet desirable to know what quantities of plant food are removed from the soil by the ordinary farm crops.

Only average figures can be given because of the variations set up by season and soil, but in Table VI. are set out the amounts of the chief nutrient constituents contained in the usual farm crops, based chiefly upon analyses at Rothamsted :- 
Table VI.-Composition of Average Crops PeR ACRE.

\begin{tabular}{|c|c|c|c|c|c|}
\hline & & $\underset{\text { Dry }}{\text { Drter. }}$ & Nitrogen. & $\begin{array}{c}\text { Phosphoric } \\
\text { Acid. }\end{array}$ & Potash. \\
\hline $\begin{array}{l}\text { Wheat Grain, } 30 \text { bushels } \\
\text { Wheat Straw, I } \frac{1}{2} \text { tons }\end{array}$ & $\dot{.}$ & $\begin{array}{l}1530 \\
2650\end{array}$ & $\begin{array}{l}34 \\
16\end{array}$ & $\begin{array}{r}14 \\
7\end{array}$ & $\begin{array}{r}9 \\
20\end{array}$ \\
\hline Total & - & 4180 & 50 & 21 & 29 \\
\hline $\begin{array}{l}\text { Barley Grain, } 40 \text { bushels } \\
\text { Barley Straw, I ton. }\end{array}$ & : & $\begin{array}{l}1750 \\
2080 \\
\end{array}$ & $\begin{array}{l}35 \\
14 \\
\end{array}$ & $\begin{array}{r}16 \\
5\end{array}$ & $\begin{array}{l}10 \\
26 \\
\end{array}$ \\
\hline Total & - & 3830 & 49 & $2 I$ & 36 \\
\hline $\begin{array}{l}\text { Oat Grain, } 45 \text { bushels } \\
\text { Oat Straw, } 21+\text { tons . }\end{array}$ & : & $\begin{array}{l}1630 \\
2350\end{array}$ & $\begin{array}{l}34 \\
18\end{array}$ & $\begin{array}{r}13 \\
6\end{array}$ & $\begin{array}{r}9 \\
37\end{array}$ \\
\hline Total & - & 3980 & 52 & 19 & 46 \\
\hline $\begin{array}{l}\text { Maize Corn, } 50 \text { bushels } \\
\text { Maize Forage, } 3 \text { tons }\end{array}$ & : & $\begin{array}{l}2500 \\
3000 \\
\end{array}$ & $\begin{array}{l}46 \\
25 \\
\end{array}$ & $\begin{array}{l}17 \\
14 \\
\end{array}$ & $\begin{array}{l}\text { II } \\
50\end{array}$ \\
\hline Total & - & 5500 & $7 I$ & $3 I$ & 61 \\
\hline Meadow Hay, I $\frac{1}{2}$ tons . & - & 2820 & 49 & 12 & $5 I$ \\
\hline Red Clover Hay, 2 tons . & - & 3760 & 100 & 25 & 83 \\
\hline Swedes, Roots, 20 tons . & - & 4700 & 100 & 23 & 90 \\
\hline Mangolds, Roots, 30 tons. & - & 7900 & I3I & 48 & 290 \\
\hline Potatoes, 8 tons & - & 4480 & 61 & 28 & 100 \\
\hline
\end{tabular}




\section{CHAPTER IV}

CHANGES OF COMPOSITION WITHIN THE PLANT

The Manufacturing, Resting, and Spending Stages in a Plant's Development. The Course of Nutrition and Migration in the Growth of Wheat. The Ripening of the Grain. Storage and Migration in Root Crops. Removal of Food Materials from the Leaves of Trees as they Ripen. The Ripening of Fruit. Effect of Soil and Climate upon the Composition and Quality of the Crop.

A REFERENCE has already been made to the fact that the starch manufactured in the chlorophyll-containing cells of the leaf is not allowed to remain there long, but is transformed into soluble sugars by the action of enzymes or ferments also present in the leaf, and is then moved on to some other part of the plant, where it is stored as sugar or as starch again until it is wanted. It is now necessary to consider such processes rather more generally from the point of view of the whole economy of the plant, in which operations of manufacture, transport, storage, and remigration take place, giving rise to the stages we call growth or resting or ripening. In some plants the various operations we have just enumerated can be seen very distinctly taking place in succession; this is particularly the case with bulbous plants, which have evolved the plan of laying 
up a large reserve store of food to carry the plant in a resting condition through periods of summer drought. Perhaps the most instructive example is afforded by the Autumn Crocus (Colchicum), which, as a wild plant, is abundant in the west country pastures, and, with its allies, is also not uncommon in gardens. The noticeable feature about the autumn crocus is that it throws up its blossoms without any leaves in the autumn, the flowers being followed sometime later by the seed pod; in March the leaves appear and grow to a considerable size without any sign of blossom. During the growth of the leaves, a corm (the equivalent of the bulb in this case) is formed, and grows to a considerable size, being packed with starch, etc., which is manufactured by the leaf and transferred for storage to the corm. Towards the end of June the leaves die down entirely and the plant goes to rest, still, however, respiring slowly in the corm, such respiration being a necessary condition of vitality. With the autumn, however, the corm renews its vigour, the flower stems are thrown up, but all the material therein, as well as that required to support the rapid respiration which attends the flowering period, is drawn from the material that had previously been stored in the corm. As far as the plant goes, this is a period of pure spending of its accumulated resources, because the plant no longer possesses any leaves or other green organs capable of assimilation; the corm itself becomes depleted, but under favourable conditions a quantity of seed is formed, capable, by its food store, of reproducing the species and giving it a start in the next generation. The corm itself also retains enough food material to carry it through the winter and start new leaves which will build up the reserve afresh in the spring, thus reproducing the same plant in the following year. With 
other bulbous plants the sequence of getting and spending is not perhaps so clearly seen as in the autumn crocus: in the common crocus, for example, the leaves are almost contemporaneous with the flowers; with the tulip and daffodil it requires closer observation in order to realise that the processes of manufacture and storage are quite distinct from those of flower and seed formation, because the two are going on almost at the same time. Just in the same way, even with annual plants like wheat, we may distinguish the processes and periods of manufacture and storage, followed by the later process of migration, when the accumulated material is stored up afresh in the seed as a reserve wherewith to give the young plant a start in life. The course of existence of a wheat plant merits particular examination from this point of view, and the changes taking place may be studied in some detail because they are typical of much of what is going on in all plants. The starting-point is the seed sown in autumn; after it germinates the blades grow 2 or 3 inches high, but there they generally remain for the rest of the winter, often indeed appearing to dwindle because of the way the leaves lie down with the first frost. But though the growth above ground is almost at a standstill, the material that is being formed by assimilation is used up for the formation of roots, which are pushing deeper into the soil all through the winter. It is at this stage that the foundation is laid for the future crop, and a wet autumn and winter, by limiting the aeration of the soil, causes a restricted root development which is always followed by a poor yield. For example, if we compare the crops upon three of the manured plots at Rothamsted, we get the following results for the ten wettest and the ten driest winters (November to January inclusive) between 1852 and 1904 :- 


\begin{tabular}{|c|c|c|c|c|c|}
\hline & \multirow{2}{*}{$\begin{array}{l}\text { Rainfall. } \\
\text { Four months, } \\
\text { Nov. to Feb. }\end{array}$} & \multicolumn{3}{|c|}{ Yield of Grain. Bushels. } & \multirow{2}{*}{ Mean. } \\
\hline & & Plot 6. & Plot 7. & Plot 8. & \\
\hline Wet winters & I 3.005 & $19 \cdot 4$ & $27 \cdot I$ & $32 \cdot 0$ & $26 \cdot 2$ \\
\hline Dry winters . & $5 \cdot 786$ & $28 \cdot 0$ & $37 \cdot I$ & 38.9 & $34 \cdot 7$ \\
\hline
\end{tabular}

Thus there was on the average a better crop by 30 per cent. after the dry than after the wet winters, and this may largely be set down to the restricted root development in the wet seasons. Of course, a wet autumn in other ways acts very prejudicially to the future crop of wheat, partly by interfering with the sowing at the proper time and partly by washing much of the soluble plant food in the soil down below the reach of the plant.

When the winter is past and the wheat begins to grow again, it enters upon its most active period of drawing nutriment from the soil and of assimilating carbon from the atmosphere; the products, as fast as they are manufactured in the leaf, are moved off and stored up in the stems of the plants. As the lower leaves age and begin to yellow off and die, the various valuable materials they contain, not only the carbohydrates that have been formed by assimilation, but the nitrogen, phosphoric acid, and potash which are bzing employed in the vital processes, are very largely withdrawn and passed on to some more active part of the plant. These substances are of too great importance to the plant to be wasted by being allowed to remain idle in dead tissue or to be lost to the plant when the leaf falls, consequently they are taken back into the active parts of the plant as far as possible before the leaf dies. Throughout the months of March to June, the processes of manufacture and storage alone are going forward; but 
as the wheat comes into flower, these processes begin to slow down : in particular, the feeding of the plant upon the soil becomes less. This may be traced in the diagram, Fig. 15, which shows the amounts of dry matter, nitrogen, and phosphoric acid contained in the whole plant and in the grain separately, from the time when the grain could first be separated-about a fortnight after flowering - up to the time of harvest. The curves show that at the starting-point the plant had reached about 90 per cent. of its ultimate dry weight, but that it had acquired only about 75 per cent. of the nitrogen and less than 70 per cent. of the phosphoric acid that were finally present in the plant. It should, however, be noted that these figures take no account of the root, which doubtless itself contained some of the nitrogen and phosphoric acid that later found their way into the above-ground parts of the plant. The earlier experiments of Pierre, conducted in the hotter and drier climate of France, would indicate that the wheat plant ceases entirely to take nutriment from the ground at a much earlier date-soon after flowering; whereas in the experiments quoted the processes of nutrition never stopped until the whole plant was ripening off for harvest. Assimilation is also shown to be going on as long as the plant possesses any green leaf tissue; during the last fortnight or so before cutting, the dry weight did not increase at all; in fact, it decreased because the burning-up of carbohydrate by respiration continued to go on and towards the end caused losses which outweighed the diminishing gains by assimilation. From the time of the formation of the grain, the most important process going forward was the migration into the seed of the material that has previously been stored in the stem. It will be seen that the gain of dry matter, and particularly of nitrogen and phosphoric acid, by the 
grain during this period was far greater than would be accounted for by what the plant had taken up meantime from either the soil or the air. In fact, at the finish, although only two-fifths of the whole dry matter of the plant was collected in the grain, yet 80 per cent. of the nitrogen and 70 per cent. of the phosphoric acid of the whole plant had been transferred to it. This, of course, is only another example of the process which we have already noted as taking place when the leaves died off one by one-the valuable materials they contained were constantly transferred to the still living and active parts of the plant. In the same way, the seed is just that part of the plant which has to carry on its life in the next generation, and it is endowed with as much as possible of the material that has been with difficulty accumulated by the parent plant.

During the formation of the grain itself, three stages may be distinguished; for about three weeks from the time of flowering the main process that is going forward is the formation of what later become the outer envelopes of the grain, in a thick and fleshy form which they lose afterwards. This "pericarp," as it is called, is richer than the ultimate grain in nitrogen and ash, though the ash does not contain so much phosphoric acid. There is, of course, no sudden break which marks the oncoming of the second stage, but towards the end of the third week the formation of the pericarp has ceased and the filling in of the endosperm begins to be the main process going forward; as this progresses, the pericarp is denuded of the material already accumulated there and becomes reduced to the series of tough, dry membranes, with which we are familiar later as the chaff and skin of the grain. The filling of the endosperm continues for nearly three weeks, and the most notable feature is that the material migrated by the plant from 
D̀ry

IMatter.

Nitrogen and $\mathrm{P}_{2} \mathrm{O}_{5}$.

-

Grammes.

130

I. 3

13

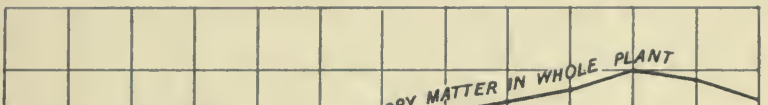

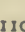

$\infty$

60

50

30

\begin{tabular}{|l|l|l|l|l|l|l}
\hline & \\
\hline & & & & & & \\
\hline
\end{tabular}
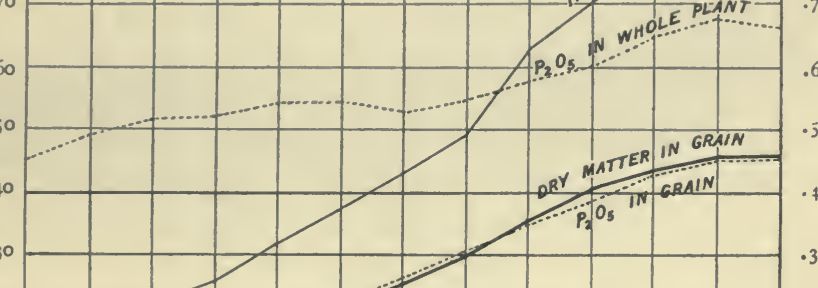

10

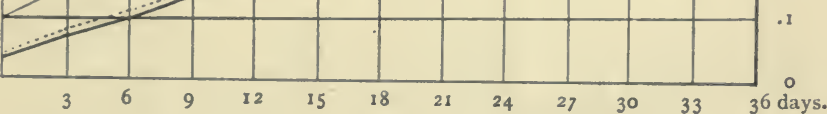

Fig. I5.-Diagram Showing the Migration of Plant Constituents INTO THE GRAIN OF WHEAT DURING THE LAST FIVE WEEKS BEFORE HARVEST.

[Face prage 64. 

day to day possesses an almost constant composition throughout the process, containing the same proportion of carbohydrates, nitrogen compounds, phosphoric acid, etc. It is a mistake to suppose that the proteins which form the gluten are filled in first, and that starch only. enters towards the later stages of filling and ripening. But though any particular lot of wheat does in this way pass on a constant mixture of materials from its reserves to the grain, there will be certain differences in the type when different varieties or the same variety grown in different climates or soils are compared. Each plant in a given field of wheat possesses, as it were, a mould wherewith to fashion the material it passes on to its grain, and the form of the mould is determined by the variety and the environment-soil, climate, season, etc. Wheats grown in certain climates, such as those prevailing in Kansas, Manitoba, or Hungary, are specially nitrogenous (glutenous or "strong" wheats), but this is not due to the hot dry climate shutting down the migration process prematurely before the later stages are reached, when starch only enters the grain, but to the fact that the environment-climate and soil, together with the varieties appropriate to such conditions-causes the wheat to make that which we have called its mould on a nitrogenous type. It should, however, be noted that though variations due to environment do occur, the composition of the grain of wheat is singularly constant. It has already been explained how all plants react against variations in the composition of the soil and select the particular constituents appropriate to their nutrition; so, similarly, when the migration process begins, the plant again effects a re-sorting of the material accumulated, and only passes on its usual constituents to the grain. Thus the straw will always vary much more in composition from 
soil to soil, climate to climate, etc., than the grain. When the filling of the endosperm has been pretty well completed-which is about a week or a fortnight before the time at which the grain would usually be regarded as fit to cut-the ripening process sets in, and this is, in the main, characterised by a drying up of what has been previously accumulated. During this last fortnight the dry matter of the grain increases little, if at all ; certainly it is stationary in amount, or even declining, during the last week, and water is being constantly removed. The main feature, then, of the ripening process is desiccation; at the same time, other rearrangements in the chemical nature of the constituents can be seen: non-protein nitrogen compounds pass over into the protein state, and the proportion of sugar falls, but these changes are not large compared with the drying up which is taking place. It would appear that it is possible to cut wheat rather earlier than the usually recognised stage of ripeness without any loss of weight in the crop, by which means losses by shedding, birds, etc., might also be reduced, the only practical question being whether the final drying process can be better effected while the wheat is standing, or after it is cut and shocked or even put into stack.

Certain other practical consequences depend upon this migration process; for example, if from any cause the crop is cut before migration is complete, then the straw will be so much richer in both fertilising and food constituents. Similarly, in bad seasons, when ripening is imperfect, the migration process is always found to be much less complete, so that a higher proportion of the accumulated material is left in the straw. Heavy manuring, again, especially manuring of a nitrogenous character, is always attended by a less complete migration, leaving the straw by so much the richer. Straw 
from the northern parts of the country, where growth is more prolonged and ripening less complete, is always of better feeding value than straw grown where drier and hotter summers prevail. Some of these points are illustrated in Table VII., which shows composition of grain and straw and the ratio between them, for the wheat grown on three of the Rothamsted plots in two sharply contrasted seasons-1852, which was cold and wet; and 1863 , which was hot and dry :-

Table ViI.-Composition of Wheat Crop in Wet and DRY SEASONS.

\begin{tabular}{|c|c|c|c|c|}
\hline & Plot. & $\begin{array}{c}3 \\
\text { Un. } \\
\text { manured. }\end{array}$ & $\begin{array}{c}2 \\
\text { Dung. }\end{array}$ & $\begin{array}{c}7 \\
\text { Artificial } \\
\text { Manures. }\end{array}$ \\
\hline Weight per bushel, lb. . & $\begin{array}{l}1852 \\
1863\end{array}$ & $\begin{array}{l}56.6 \\
62 \cdot 7\end{array}$ & $\begin{array}{l}58 \cdot 2 \\
63 \cdot 1\end{array}$ & $\begin{array}{l}56.0 \\
62.6\end{array}$ \\
\hline Grain to 100 Straw & $\begin{array}{l}1852 \\
1863\end{array}$ & $\begin{array}{l}53 \cdot 9 \\
70 \cdot 4\end{array}$ & $\begin{array}{l}49 \cdot 6 \\
67 \cdot 5\end{array}$ & $\begin{array}{l}41 \cdot 9 \\
59 \cdot 4\end{array}$ \\
\hline Nitrogen per cent. in Dry Grain & $\begin{array}{l}1852 \\
1863\end{array}$ & $\begin{array}{l}2.08 \\
1.65\end{array}$ & $\begin{array}{l}2.02 \\
1.52\end{array}$ & $\begin{array}{l}2.29 \\
1.53\end{array}$ \\
\hline Nitrogen per cent. in Dry Straw & $\begin{array}{l}1852 \\
1863\end{array}$ & $\begin{array}{l}0.57 \\
0.33\end{array}$ & $\begin{array}{l}0.46 \\
0.25\end{array}$ & $\begin{array}{l}0.87 \\
0.36\end{array}$ \\
\hline
\end{tabular}

Thus in the wet year, $I 852$, there is a smaller proportion of grain, and the straw is left much richer in nitrogen than in the dry year; the heavily manured plots 2 and 7 also show a greater proportion of straw, which is richer in nitrogen than that from the unmanured plot. If we compare the wettest season known at Rothamsted, I879, with one of the hottest and driest, I893, we find the proportion of grain to straw on the unmanured plot, which on the average is 70 per cent., varied from 43 in the wet year I879, to IIO in the dry season of 1893 .

As to the effect of heavy nitrogenous manuring, an example may be taken from some of the Rothamsted 
barley plots in 1905, where a comparison existed between an unmanured plot, a plot receiving a very large amount of nitrogenous wool waste, and a third plot which had received the same amount of wool waste a year earlier, so that it had been partially exhausted by the previous crop:-

Table VIII.-Composition of Barley Crop. Rothamsted, igo5.

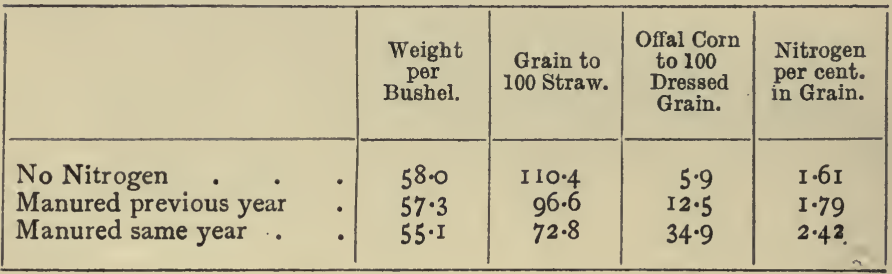

Here the heavy manuring has evidently given rise to an excessive proportion of straw, while the grain produced was so light that much of it had to be dressed out and regarded as offal.

The principles which have been illustrated in the migration of the materials forming the grain of wheat may also be applied to another case-the changes that go on during the later stages of growth and ripening of meadow hay. Although the plants composing the herbage of a meadow are in the main perennial and not annual like wheat, the process of nutrition and migration are essentially similar; carbohydrates are manufactured from the carbon dioxide in the atmosphere; nitrogen, phosphoric acid, etc., are taken from the ground and elaborated, until the flowering season is reached, when the movement of the previously formed material into the seed becomes the chief action going on. This is accompanied by an increasing change of non-protein nitrogen compounds into proteins, a loss of sugars by respiration, and a conversion of more soluble 
carbohydrates into fibre-this latter a rearrangement we did not consider in the case of wheat straw. The formation of fibre is particularly marked in the final stages when the seed of the grasses gets ripe, and as fibre is an inferior food material to starch, not only less digestible in itself but wasting much more labour in the process of digestion, there results a considerable loss of food value in the material. All this points to the desirability of cutting hay in a young state; the loss of weight in the crop will not be great, because for the bulk of the grasses the later stages of growth are not attended by much increase of dry matter, since assimilation becomes balanced off by respiration, while there will be mechanical losses through the shedding of the seed of many plants; at the same time the much smaller proportion of fibre in the early cut hay permits of a far greater utilisation of the constituents of the hay by the stock receiving it as food.

The process of storage and migration of the accumulated materials is perhaps most clearly seen in the case of the biennial root crops like turnips and mangolds (or fodder beet); the so-called bulb-an enlarged stem in the case of swede turnips, a root in the mangolds - is nothing more than a storage organ, and the whole work of the first year's growth consists in filling this with the carbohydrate assimilated by the leaves and with the proteins which are also there elaborated. In the mangold the material stored is cane sugar, which constitutes about 60 per cent. of the dry matter of the bulb; the dry matter itself varies from about 10.5 per cent. in the white-fleshed Globe variety to over I 3 per cent. in the yellow-fleshed and Long Red varieties. In the sugar-beet, a form of mangold which for more than forty years has been systematically bred and selected for its sugar content, the percentage of 
sugar in the root has been raised to eighteen or over. The sugar-content of mangold has not been similarly raised, because in its case the seed parents have been selected only on a basis of size and shape and never on the amount of sugar they contained, as determined by analysis. The figures just given for the percentage of sugar and dry matter in the mangold are of course only averages; certain variations occur due to the soil, manuring, and also season, but perhaps the largest variation is that due to size. The larger the root the more watery it becomes; mangolds weighing approximately $2 \mathrm{lb}$. apiece contain about 2 per cent. more dry matter than mangolds averaging $7 \mathrm{lb}$. apiece, above which weight the falling off in dry matter is not so marked. The age of the mangold has not much influence, it possesses much the same composition all the time it is growing; just as the wheat grain is filled up with material of approximately constant composition from the beginning until the end of grain formation, so as the mangold bulb swells it is being packed with materials of a fixed type as regards the proportions of dry matter, sugars, and nitrogenous matter, this material being manufactured in the leaf. Certain changes do occur; in the immature mangold, as in those grown with an excessive amount of manure, there is a slightly smaller proportion of dry matter, while a much larger proportion of the nitrogen contained in the root is combined in the form of nitrates and non-protein compounds. The nitrates and non-protein compounds are far from having disappeared when the mangold is ripe in the late autumn, though they are considerably reduced in amount. If the mangold is allowed to grow a second year for seed, a reverse series of changes take place; the sugar is removed from the cells of the root in order to form the flowering stem and eventually the 
seed; when the seed is ripe the former root will be found almost devoid of sugar or any other easily soluble carbohydrate or nitrogenous compound, little remains except fibre. During the storage of the mangold in the clamp under ordinary farming conditions, the ripening process proceeds during the closing months of the year; the roots are of course respiring, and losing in consequence a little sugar, the nitrates and non-protein nitrogen compounds are also being partially replaced by proteins, but the loss of material is small as long as the temperature remains low. As soon as the warmer weather of the spring sets in, respiration increases, some degradation of the cane sugar into reducing sugars takes place, and with sprouting there will also be change from the protein to non-protein nitrogenous compounds. When mangolds are kept as late as May or June, there is a very marked loss of dry matter by respiration, which may amount to as much as one-third of the original material, though the loss will be disguised by the drying-off of water which simultaneously takes place, so that the stored mangold is apparently as rich as ever in dry matter.

In swede turnips the percentage of dry matter is about the same as in mangolds, varying from about Io to I 3 or over, according to the variety, size of root, season and soil, etc. ; the sugars present are different from the cane sugars of the mangold, and there is also a considerable proportion of a class of carbohydrates known as pectins, bodies which form a mucilaginous jelly when boiled with water. The changes which the swede turnip undergoes on storage and when growing a second year for seed are strictly similar to those taking place in the mangold, the only difference being that in the formation of the seed a good deal of oil is built up from the carbohydrates in the storage material. White turnips 
resemble swedes in composition, but are more watery; while potatoes contain a much higher proportion of dry matter, about 25 per cent., and store their carbohydrates in the form of starch. When a potato set is planted in spring the starch is converted by a diastatic ferment into sugar, which is moved off to the growing shoots, where it is used for constructing the new tissues; as growth progresses the cells will be found to be progressively depleted of starch until little more than an empty husk is left. A slow conversion of starch into sugar is always going on during the storage of the potato, the sugar being burnt up in the respiration process which keep's the plant alive though resting. It is well known that a potato tastes sweet if it has been frosted or exposed for some time to a low temperature; this is because under such conditions the respiration process is almost suspended, while the enzyme action forming sugar still goes on until there is a perceptible accumulation of sugar in the root.

Among perennial plants the movements of the manufactured materials go on in exactly the same way as in annuals or biennials; these movements are, however, not so apparent, because of the great permanent store of food material which exists in a perennial plant. However, it is instructive to cut sections of the branches of trees at different times of the year and test them with iodine to show the presence of starch : in the autumn the wood, or rather that part of it which is still alive and active, is packed with starch, but this starch is moved out with the first growth of the leaves. It is due to the material thus stored that cuttings can be struck from shoots cut off in the autumn; they then contain easily available reserve material out of which the young roots and the new leaves can be manufactured until the cutting attains an independent 
existence. As a rule, cuttings cannot be struck from the young wood in the spring, because it then possesses no reserve material to draw upon. The leaves of deciduous trees afford another example of the migration of food materials; when the year's growth is over and the tree is preparing to shed its leaves for the winter, a layer of comparatively large cork cells forms between the stem of the leaf and the branch, and it is by the rupture of this dividing layer that the leaf becomes detached from the tree. But long before the leaf is detached, as it begins to get old, the valuable food materials it contains - the carbohydrates, the nitrogen, phosphoric acid, and potash - are withdrawn from the leaf and stored away in the stem, their place being taken by comparatively abundant and valueless materials like lime and silica. In consequence, dead leaves, from a manurial point of view, are much poorer than living leaves, as the following analyses (Table IX.) of the young, mature, and dead

Table IX.-Materials contained in 500 Leaves of the Plane TREE, GATHERED AT DIPFERENT DATES.

\begin{tabular}{|c|c|c|c|c|c|c|c|}
\hline & June 13. & July 15. & Aug. 22. & Sept. 7. & Oct. 8. & Oct. 24. & Nov. 5. \\
\hline Dry matter & $\begin{array}{l}\text { Grms. } \\
\text { I } 42 \cdot 5\end{array}$ & $\begin{array}{l}\text { Grms. } \\
\text { I } 84^{\circ} 7\end{array}$ & $\begin{array}{l}\text { Grms. } \\
\text { I } 82.8\end{array}$ & $\begin{array}{l}\text { Grms. } \\
\text { I } 93.8\end{array}$ & $\begin{array}{l}\text { Grms. } \\
196.2\end{array}$ & $\begin{array}{l}\text { Grms. } \\
\text { I } 48.8\end{array}$ & $\begin{array}{l}\text { Grms. } \\
\text { I } 66 . I\end{array}$ \\
\hline Nitrogen . & $5 \cdot 9$ & $5 \cdot 9$ & $4 \cdot 8$ & $5 \cdot 0$ & $3 \cdot 4$ & 1.8 & $I \cdot 4$ \\
\hline Ash : & $8 \cdot 7$ & $14 \cdot 6$ & I $7 \cdot 8$ & $20 \cdot 1$ & $2 I \cdot 3$ & $18 \cdot 0$ & $20 \cdot 3$ \\
\hline Phosphoric Acid & $I \cdot 3$ & $I \cdot 3$ & $I \cdot 2$ & $I \cdot 2$ & 0.9 & 0.5 & 0.6 \\
\hline Potash . & $I \cdot 9$ & $2 \cdot 1$ & $2 \cdot I$ & $2 \cdot 2$ & $I \cdot 6$ & $1 \cdot 0$ & 0.9 \\
\hline Lime & $2 \cdot 5$ & $5 \cdot 7$ & $7 \cdot 7$ & $9 \cdot 0$ & $9 \cdot 5$ & $8 \cdot 2$ & $9 \cdot 2$ \\
\hline Silica & 0.6 & $I \cdot 9$ & $2 \cdot 9$ & $3 \cdot 5$ & $4 \cdot 0$ & $3 \cdot 9$ & $3 \cdot 7$ \\
\hline
\end{tabular}

leaves of the plane will show. The economy of this process is obvious; such substances as the starch formed by the leaf, the nitrogen, phosphoric acid, and potash taken from the ground, are required by the active cells in order to carry out the vital processes of the plant; they 
are too valuable to be cast aside in the dead leaf, and are therefore carefully removed into the permanent storehouse of the stem and roots during the winter resting period.

In herbaceous plants, which die down to ground level each winter, the roots form the storage organs; the stem and leaves are depleted of their valuable constituents before death sets in. For example, Table X. shows the

TABLE X.-Material CONTAINed in UpPeR GRowth of HopPlant at time of Picking and after Dying Down.

Lb. per Acre.

\begin{tabular}{|c|c|c|c|c|}
\hline & $\begin{array}{l}\text { In Hops } \\
\text { Sold. }\end{array}$ & $\begin{array}{c}\text { In Green Leaf } \\
\text { and Bine at } \\
\text { Picking Time. }\end{array}$ & $\begin{array}{l}\text { In Dead Leaf } \\
\text { and Bine in } \\
\text { November. }\end{array}$ & $\begin{array}{l}\text { Returned to } \\
\text { Root. }\end{array}$ \\
\hline & Lb. & Lb. & Lb. & Lb. $\begin{array}{c}\text { Per } \\
\text { cent. }\end{array}$ \\
\hline Nitrogen & $5 I$ & 38 & 18 & $20=53$ \\
\hline $\begin{array}{l}\text { Phosphoric Acid } \\
\text { Potash }\end{array}$ & 16 & 10 & 5 & $5=50$ \\
\hline $\begin{array}{l}\text { Potash . } \\
\text { Lime }\end{array}$ & 39 & $3 I$ & & $27=87$ \\
\hline Lime & I6 & 92 & 88 & $4=4$ \\
\hline
\end{tabular}

material contained in the parts of a hop plant above ground (I) at the time of its maximum growth when the hops-i.e. the seed vessels-were fully formed; (2) after the hops had been picked and bine and leaves were dead down to ground level, and from the table it will be seen that about one-half of the nitrogen, one-half of the phosphoric acid, and nearly all of the potash contained in stem and leaf are removed and sent down to the root for storage before the winter resting period sets in.

Similar cases of economy, storage, migration, and retranslation may be traced everywhere in the lifehistories of plants, the guiding fact being the endeavour of the plant to ensure its continued life and reproduction by providing a sufficient food supply to start either the next generation (the seed) or the next phase (in the case of plants reproducing asexually by bulbs, suckers, 
etc.), until it has developed adequate roots and leaves of its own. The broad chemical changes going on in the plant, such as the migration of the starch from one part to another, preceded by its conversion into sugar, and even such changes as the desiccation and the conversion of $a$-proteins into proteins which marks the ripening of cereals, are recognisable enough; there are, however, a number of more subtle changes which we are unable in the present state of knowledge to follow, though they may often be appreciable in the bulk as constituting what the practical man calls quality. As an example we may instance the ripening of fruits such as apples and pears, which after the migration and filling of the fruit has been completed, will to a large extent go on though the fruit has been detached from the tree. We know the broad outline of the process: the fruit becomes soft and sweet, often an intense harshness of taste entirely disappears, in many cases fragrant essences and aromas develop. Chemically we can recognise that starch in the unripe fruit disappears because it is converted in sugars, that some of the tough pectin bodies are also converted into sugars, as also are the very bitter tannins, while the agreeable flavours appear to be due to ethers produced by the union of some of the vegetable acids with alcohol derived from the partial breakdown of sugar. In fact, if the respiration of fruits is deranged by putting them in a jar containing no oxygen, the sugars will not be converted into carbon dioxide and water, but will be broken down part of the way into the less oxidised form of alcohol, so that the fruit may become alcoholic without any fermentation in the ordinary sense of the word taking place. Fermentation by yeast may be regarded as a similar case of respiration in the absence of free oxygen; the yeast cells when placed in a liquid containing sugar 
grow and multiply, and in doing so they split up by the aid of an enzyme the sugar into alcohol and carbon dioxide. The yeast cells do not feed upon the sugar, but they derive energy from its splitting up, just as the ordinary plant cell derives energy from the oxidation of the sugar to carbon dioxide and water which takes place during respiration in the presence of oxygen.

In discussing the changes which take place in the composition of parts of the plant, we have already had occasion to point out that the changes due to variations of environment are not very great; the variations induced by season are much greater than those due to soil or manuring, as may be illustrated by the figures for the nitrogen-content of the grain of wheat in Table VII. In the wet season of 1852 there was about 2 per cent. of nitrogen in the wheat grain, whereas in the dry year of 1863 there was little more than $\mathrm{I} .5$ per cent. ; this season alone has caused a difference of 0.5 per cent., or 25 per cent. of the total, whereas the greatest difference in nitrogen-content between the grain grown on the wholly unmanured plot and on that which receives an annual heavy dressing of farmyard manure only amounted to 0.2 per cent. As a matter of fact, the difference in the composition of the crop brought about by different soils or different manuring may be regarded as due to the change of climate which the soil and manuring sets up for the particular plant. For example, a heavy soil will maintain not only moisture about the root but a moister atmosphere about the leaves, and so become the equivalent of a wetter season; on the other hand, a nitrogenous manure will prolong the growth of a plant and so cause the ripening process to take place under other climatic conditions than those prevailing for an earlier ripening crop. If, however, the differences of composition induced by environment-soil, manuring, 
season, etc.-are comparatively small as measured by such rough analytical factors as the percentage of nitrogen, etc., they are often of extreme importance commercially, because they may and generally do affect those more subtle items in the composition of the product summed up as quality. We are as yet rarely in a position to define from a chemical standpoint what constitutes quality in each particular case, still less to state the external factors which determine it; we may, however, be sure that it is not due to the mere presence or absence of some particular ingredient in the soil. We have seen that all plants are fundamentally made up of exactly the same things in very similar proportions, the differences arise in the style of the architecture that the plant adopts in each case; and if wheat is "stronger" when grown in one place than another, it is not because in the soil of the first place there exists some element which is absent in the soil of the second place, but because the habits of the plant are affected variously by differences in the supply of water, air, or warmth in the two places. We have, in fact, many reasons for regarding the supply of water and the prevailing temperature as the main factors in determining both the yield and the quality of all crops, and it is from this point of view that it is most profitable to regard the soil. 


\section{CHAPTER V}

\section{THE ORIGIN AND NATURE OF SOILS}

The Weathering of Rocks to Soil. Solution of Rock Materials in Water containing Carbon Dioxide. Action of Frost. Transport of Soil by Rain and Running Water. Action of Worms. Approximate Analysis of Soils. Properties of Clay and Sand. Chemical Constituents of Soils. Soils and Subsoils.

BEFORE we take up the question of the composition of the soil, it will be well to learn something of its origin, and for this purpose nothing is so instructive as a visit to a quarry where a clean face of rock can be seen passing into soil, on the surface of which vegetation may still be growing. At some distance below the surface the rock is solid and massive ; in some cases, as in limestone or sandstone, it will be stratified or divided into parallel layers, which can be distinguished by changes of colour or texture, even when there is no actual division along the planes of bedding; in other cases, as in granite or basalt, the rock will be massive and show no sign of splitting into layers. The colour of the rock will be pretty uniform, and at depth it will often be some shade of dark green or blue or grey, though of course there are numerous exceptions, such as red or yellow sandstones, white or yellow limestones, reddish granites, etc. Following the rock upwards to the surface, there comes a point when the rock begins to show signs of decay; the divisions that traverse the rock, whether bedding planes or joints, become somewhat larger and 


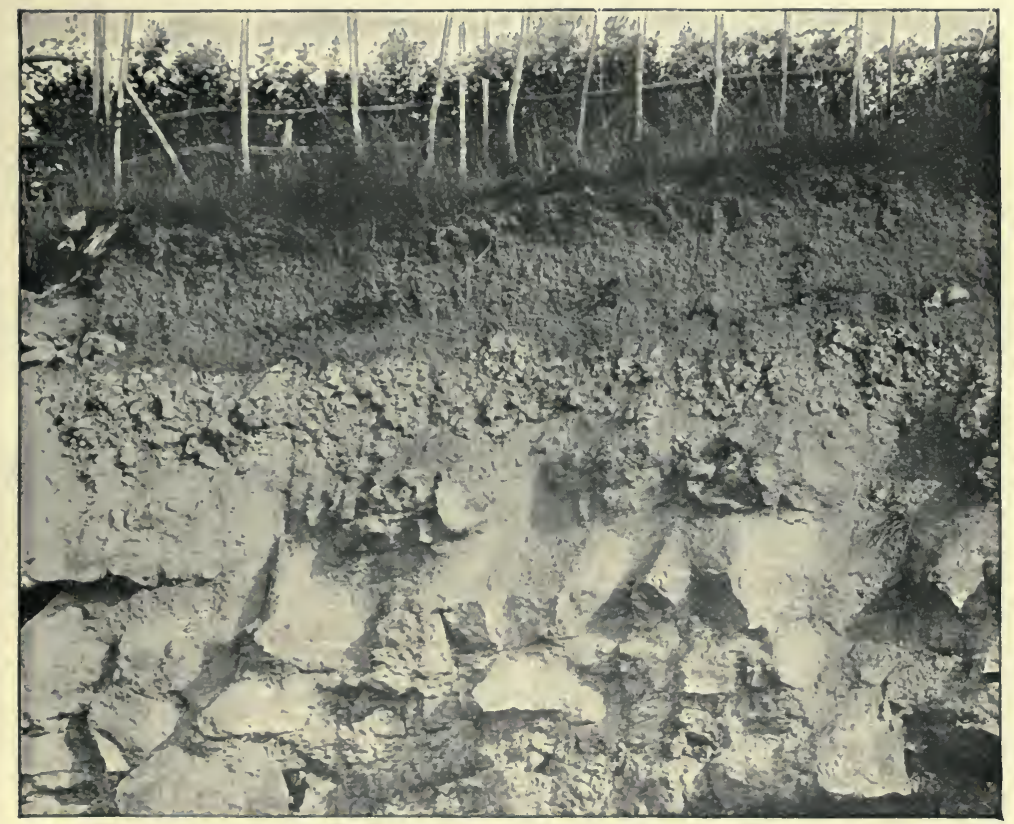

Fig. 16.-Formation of a Sedentary Soll. 

are discoloured, as though water has been oozing along them and had caused a certain amount of rusting and rotting. Higher still, the rock is obviously disintegrated ; the large fragments, which still are arranged in keeping with the structure of the unaltered rock below, are separated by layers of loose sand and stones, or by clay, and the proportion of this loose material increases the nearer one gets to the surface. Finally the rock either wholly disappears, or becomes represented only by stones in the loose material, which we may now call the subsoil. A few inches below the surface, this subsoil gives place to the soil proper, distinguished as a rule by its darker colour and its admixture with vegetable matter from the plants that have been growing upon the surface.

Such a soil passing by insensible degrees into the rock below is called a "sedentary soil," because it has grown upon the spot; but in some quarries and pits we shall not meet with the sequence described above, but one in which the surface material turning into soil is obviously quite distinct from the fundamental rock below, a sharp line of distinction marking the change from one to the other. Such cases will be considered later; it now remains to examine into the causes which have brought about the degradation of rock into soil. Water obviously plays a considerable part in the process; even the most solid rock is traversed by certain planes of weakness-bedding planes or joints, along which minute fissures water slowly percolates, and, as we have observed in the quarry, begins to degrade and discolour the edges of the cracks. In pure water itself few of the minerals constituting rocks are soluble; but the rain, as it soaks down through the upper layer of soil pervaded by plants' roots, dissolves some of the carbon dioxide that is there being produced, and then becomes a much more effective 
solvent. Such water, for example, will dissolve carbonate of lime, hence limestone and chalk rocks waste away under the weather, and leave nothing behind but the 2 or 3 per cent. of fine red clay, which is the only other material making up the rock. Wherever a railway cutting traverses chalk or limestone, the surface of the rock will be seen to be let down in places into deep and tapering pipes; these represent lines of soakage, along which the surface water has been continually travelling to a fissure below, until the rock within the influence of this gradual current has all been dissolved away. Not only does carbonate of lime occur in chalk and limestone in a more or less pure state, but it is found in other rocks acting as a cement to grains of sand, etc., and as it dissolves in the percolating rain-water the rock disintegrates. Many of the complex minerals which make up the bulk of the older primitive and volcanic rocks, are also decomposed by water charged with carbon dioxide; for instance, the felspar, which is one of the fundamental minerals in granite and in all the basaltic rocks, breaks down to clay under its influence. In Cornwall the surface of the granite is covered with a white clay thus formed, in which the still undecomposed grains of quartz and mica, the other minerals making up the granite, are lying unaltered; the basalts and trap rocks similarly yield a clay, which is red because of the oxides of iron which are simultaneously formed as the felspar decays into clay. Iron compounds are very generally diffused among the rocks; the greens and browns and blacks of the unweathered rocks are due to compounds of iron, which all break up and go into solution under the action of water and carbon dioxide, eventually becoming oxidised into something akin to iron rust, and this oxidised rusty substance is the cause of the yellows, browns, and reds which predominate in soils. Perco- 
lating water, then, acts both by pure solution and by starting more drastic chemical changes by the help of the carbon dioxide it carries; its work is often assisted by the penetration of roots into the cracks and fissures. The roots, both of the larger forms of vegetation and of trees, will travel for astonishing distances and will squeeze themselves in the pursuit of water into the closest of cracks; as they grow they exert considerable pressure to widen the cracks, and when they die and decay they leave behind a channel for percolation.

The main agency, however, in splitting rocks and reducing them to the state of soil is frost, or rather water in the act of freezing. It is well known that water expands about one-tenth of its bulk in freezing, and that it will exert enormous pressure on anything that tends to prevent such solidification and expansion. Hence the bursting of water-pipes, full bottles, and the like during a severe frost ; though, as the bursting only becomes apparent when the water thaws again, it is often supposed that the thaw does the bursting. Hence also the constant fracture of stones or bricks exposed to the weather during winter; they become saturated with water, and when this water tries to expand within them they must split to relieve the pressure, thus developing whatever lines of weakness there were within. The examination of the face of an old quarry or even an old wall of brick or stone after a frost will show the ground at the foot of the face strewn with blocks and fragments which have been wedged off by the expansion of the water within the stone or brick. We talk of the pulverising action of frost on the clods of a stiff clay soil ; frost is equally if less actively pulverising to the toughest and most closely grained of rocks. There are other minor agencies assisting, but in the main, water, roots, and frost are the tools which are always at work reducing 
rocks to soil, covering the bare surface of the former wherever it may be exposed with a slowly formed coating of its own debris. If the formation of soil ended at this stage every rock would be covered by its own appropriate "sedentary" soil, but as soon as the soil is formed it begins to move. The wind and the rain are always moving soil downhill; the wind perhaps may seem a trivial agency, but in rainless or even semiarid climates there are practically no other transporting agencies at work, and we find vast tracts covered with fine, uniform, wind-blown soil. The work of the rain is most apparent when it has been long continued enough to bring the rivers out in flood; high up the country every little gutter, every ditch that bounds the arable land, is charged with turbid, hurrying water, which is washing unseen quantities of coarser mud and sand along its course. Finally the rivers themselves are charged with sediment, as we can see by filling a large bottle with the water from one that is running in flood and allowing it to settle; along their beds also, gravel and stones of all sizes are being pushed. Wherever the velocity of the current is reduced some of the transported material will be deposited, hence as the streams descend from the heights into flatter country they discharge the coarsest part of the material they have washed from the rocks above, and so give rise to the broad expanses of gravel, sand, silt, etc., which underlie the water meadows bordering the lower levels of all rivers. Much of the suspended mud and clay, however, washes away to sea, and is thrown down when the velocity of the stream is entirely checked by the open water, where also the salts in the sea-water exert their precipitating action upon the fine particles; in consequence, beds of newly sorted soil tend to accumulate in the shallow waters just off shore, and even to block up the river mouth unless the 
tides and currents scour it free. These deposits made by the river give us a clue to the origin of that other arrangement of rock and soil that we have noted as sometimes prevailing, when a clean surface of the underlying rock is covered by gravel or sand or clay of a totally different character, without any of the gradual transition that marks the passage of a rock into a sedentary soil. The layer which thus rests upon a rock out of which it has obviously not been formed is never solid rock, but is an assemblage of divided material that is generally pretty uniform in character, wholly gravel or wholly sand, or entirely made up of a uniform silt like a brick earth. The uniformity is due to the fact that the material has been transported to its present position by running water and has undergone a sorting in the process. Gravels must have been laid down in the bed of the stream, even though the stream no longer runs in that spot, but perhaps in a course at a lower level in the valley. In such cases the gravel is generally the remains of a much larger tract of gravel which filled the valley to a higher level at a time when the stream ran in far greater volume. Similarly the sand must also have been deposited where the current still ran pretty sharply, whereas the fine-grained and uniform silts, such as constitute the brick earth patches, were either deposited in quiet backwaters and laybyes, or were dropped by slow degrees on the river meadows in flood time, just as similar stuff is accumulating to-day in the same sort of places.

In addition to these non-sedentary soils that have been moved and redeposited by running water or by wind, over considerable parts of the country, especially in the north and the midlands of Great Britain, and for a hundred miles or more south of the Great Lakes in the United States, we find the 
fundamental rocks covered, often to a considerable depth, with disintegrated rock that has been moved into its present position by the action of ice in the immediately previous geological epoch, when a glacial climate prevailed. These glacial drifts, as they are called, may be mainly clay or sand, but usually they are considerably mixed with fragments of rock of all kinds and sizesfragments which give clear evidence of the actions they have been subjected to among the moving ice by the way they have been rounded off and scored with scratches and furrows. These glacial drifts form an exception to what has already been said as to the general uniformity of the transported soil material.

All soils derived from material that has not grown up from the rock below, but has been moved by water, wind, or ice, are known as "soils of transport" or "drift soils," in contradistinction to the sedentary soils first discussed. Some idea of the constant state of motion in which soils still exist may be obtained by considering the surface of an arable field on such soils as the chalk, where there are a good many stones. The stones are always much more abundant upon the top than in the layers below; they may not be very prominent when the surface is turned over by the plough, but they work up again; they may even be picked off to sell for road-making, yet in a few years they seem as numerous as ever, so that the older farmers and labourers declare they "grow." The clue to their abundance upon the surface may be obtained by looking at any garden bed where it happens to receive the drip from the eaves of a building; the constant downpour of water washes all the soil away, and leaves the ground covered with small stones. The same action goes on in the stony mixture constituting the soil of the arable field; with every rainfall there will be some 


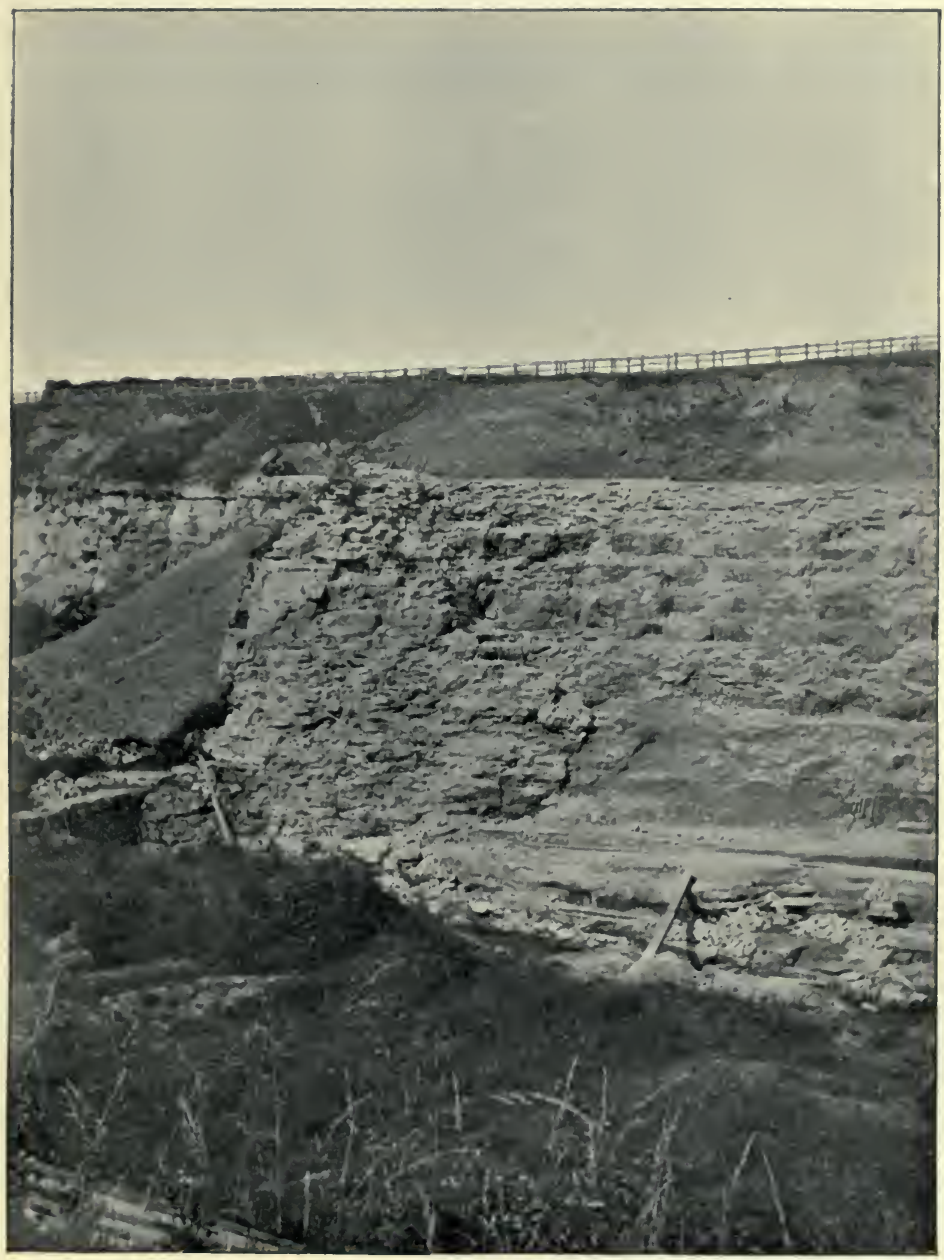

Fig. I 7.-Section showing Glacial DRIFT Lying on Magnesian LIMESTONE. 

rearrangement of the particles, some washing-down of the finest material, until the large fragments which are unmoved by the rain are left on the surface.

Nor are such inanimate agencies as the wind and rain alone effective in moving soil; animals play their part, even ants and moles are capable in time of bringing about considerable shifting of fine soil from below to the surface. That some such action does go on may be concluded from the fact that even when the soil is stony the surface of an old pasture is quite devoid of stones, to find which it may be necessary to dig down for a foot or two. This characteristic of old grass land is chiefly due to the action of worms, which are always swallowing the finest soil particles, and then ejecting them as wormcasts on the surface. At first sight such an action seems trivial, but one has only to collect and weigh on some autumn morning the wormcasts from a square yard of ground to find what a considerable shifting of earth has taken place. Darwin has shown that from this cause alone large stones, and even old buildings of the time of the Romans and later, have been completely buried; he found that in one case burnt marl, spread on the surface of grass land, had been buried 3 inches in fifteen years, and in another case that a layer of chalk had sunk 7 inches in twenty-nine years. A hole cut in an old grass field will often show at some little depth layers of chalk or ashes or burnt soil, each layer representing material which had been spread on the surface years before. Soils of transport are formed in exactly the same way as sedentary soils, they have merely travelled a little farther and been subjected to a certain amount of sorting; in all cases we have to look upon soil as the product of the weathering-the disintegration and decay-of certain fundamental minerals out of which the primitive rocks and the earth's crust 
are built up. Let us now see what these products are. It will first be necessary to obtain a certain number of typical samples of soil; properly they should be taken with an auger or other soil-sampling tool, but for the simple examination that follows they may be obtained by digging a hole, 2 feet deep, with a smooth vertical face, and taking off from that face uniform slices down to 9 inches for the soil, and from 9 to 18 inches for the subsoil. Samples should thus be obtained of both soil and subsoil, from a sand, a clay, and an alluvial pasture, also of the surface soil only from chalky and peaty land. The samples should be spread out to dry naturally on trays or sheets of paper, the lumps being gently crumbled by hand before they get quite dry; this being most necessary with the clay soils, which can only be broken down if they are caught at just the right stage of moisture. When air-dried, they must be passed through a sieve having round holes, $\frac{1}{8}$ inch or $3 \mathrm{~mm}$. in diameter, the lumps being crushed in a mortar with a wooden pestle which is not hard enough to break up the stones. The material passing the sieve forms the fine earth required for further examination; the stones are cast away, though they should first be washed in order to see of what they are composed. Now take a small quantity of the fine earth of one of the soils in a little dish, and heat it over a lamp, gently at first and then more strongly; at the outset you will notice that it begins to lose water although it was apparently dry to start with, then as it becomes hotter it smokes and gives off a smell of burning vegetable matter; finally, if heating is continued for some time, the soil will take a bright brick-red colour and undergo no further change. From this we may conclude that soils contain water and a certain amount of organic matter or humus-the debris of previous vegetation; it is most instructive to 
determine how much of each of these constituents is present in the examples that have been selected. Weigh out a series of basins, add about Io grammes of soil to each, and weigh again; put the basins in the water oven for a few hours, and reweigh to find the loss of moisture ; finally, ignite for two hours over a lamp and make a last weighing to obtain the loss on ignition, which includes a little combined water as well as the organic matter. Considerable differences will reveal themselves (see Table XI.); the moisture that is retained by the undried soil will vary from about 2 per cent. in the sandy subsoil to ro per cent. or more in the peaty soil; the loss on ignition will similarly vary from 2 to 6 , and may even run up 30 per cent. in the peaty soil. We can see clearly enough that the humus present is a compound of carbon, from the manner in which it chars and blackens on heating. The humus also contains nitrogen, as may be seen by heating a little more of the soil mixed with soda-lime, whereupon the smell of ammonia, which at once becomes palpable, may be taken as evidence of the presence of combined nitrogen in the humus, just as in the plant (p. 3). We can further show that humus, or rather the humic acid which can be set free by the action of acids on the humus, is soluble in alkalis like ammonia or caustic soda. Take about 20 grammes of the peaty or alluvial soil, and cover it with dilute ( 5 per cent.) hydrochloric acid for half an hour, then pour off the acid and get rid of it entirely by one or two washings with pure water. Finally, pour on the soil five or six times its bulk of a weak solution of ammonia and shake up from time to time; a deep brown or even black solution will result, and the remaining soil will be considerably bleached by the removal thus effected of the greater part of its organic matter. We may conclude that humus is one 
of the regular constituents of soil, and is the result of the decay of the vegetation that previously lived on the soil; it is a dark brown or black compound of carbon containing also nitrogen, and is to some considerable extent soluble in dilute alkalis. It is one of the chief colouring matters of soils, among the particles of which it also acts to some degree as a cement.

It is now necessary to make a rough mechanical analysis of the mineral part of a soil; Io grammes are weighed out into a dish, a little water is added, and the contents of the dish are rubbed up into a paste by means of a pestle made by sticking a rubber bung on to the end of a glass rod. A beaker about $8 \mathrm{~cm}$. in diameter and $9 \mathrm{~cm}$. high is now clearly marked on the side at a point $7.5 \mathrm{~cm}$. from the bottom, and the pulped-up soil is washed into this beaker through a small sieve made of brass-wire cloth of 100 meshes to the inch. The sieve and its contents are put in the oven; when dry, the material on the sieve is weighed and counted as "coarse sand." The dirty liquid in the beaker is now made up to the $7.5 \mathrm{~cm}$. mark with more water, given a good stir, and left to stand for exactly twelve and a half minutes, at which moment the upper turbid liquid is steadily but quickly poured off from the sediment below into a large jar. The sediment is now rubbed up afresh with more water, the water is brought to the mark, stirred, left to stand for twelve and a half minutes, and poured off as before into the same jar; all the processes being repeated half a dozen times or more, until at last there is nothing left floating in the clear water at the end of the twelve and a half minutes' wait. The sediment remaining in the beaker is dried and weighed; the contents of the large jar can also be evaporated down and weighed, but as this constitutes rather a long operation it will be sufficient to evaporate a little in order to examine the 
character of the deposit, and to arrive at its weight by taking the difference between the original Io grammes and the sum of the two fractions already weighed, together with the moisture which we have previously found the soil to contain. By this process, the results of which are set out in Table XI., the soil has been

TABLE XI.-A PPRoximate Mechanical ANalysis of Various Solls.

\begin{tabular}{|c|c|c|c|c|c|c|c|c|c|}
\hline & & \multicolumn{2}{|c|}{ Sand. } & \multicolumn{2}{|c|}{ Clay. } & \multicolumn{2}{|c|}{ Alluvial. } & \multirow{2}{*}{$\frac{\text { Chalk. }}{\text { Soil. }}$} & \multirow{2}{*}{$\begin{array}{c}\text { Peat. } \\
\text { Soil. }\end{array}$} \\
\hline & & Soil. & Subsoil. & Soil. & Subsoil. & Soil. & Subsoil. & & \\
\hline Moisture . & . & $2 \cdot 4$ & $1 \cdot 7$ & $4 \cdot 4$ & $5 \cdot 5$ & $2 \cdot 4$ & $4 \cdot 6$ & 2.4 & $8 \cdot 4$ \\
\hline Organic matter & . & $40^{\circ}$ & 3.0 & 6.4 & $4 \cdot 4$ & $14 \cdot 3$ & 8.1 & 6.9 & 32.8 \\
\hline Coarse Sand & 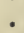 & 10.3 & $9 \cdot 7$ & 3.9 & 0.8 & $0 . I$ & 0.0 & $20 \cdot 2$ & 26.6 \\
\hline Fine Sand. & . & 670 & 68.6 & $30 \cdot I$ & 16.0 & $53 \cdot 3$ & $47 \cdot 5$ & $2 I \cdot 9$ & $14 \cdot 2$ \\
\hline Clay and Silt & . & $16 \cdot 3$ & 17.0 & $55 \cdot 2$ & $73 \cdot 3$ & $29 \cdot 7$ & 39.8 & $9 \cdot 6^{*}$ & 18.0 \\
\hline
\end{tabular}

* This soil also contained 39 per cent. of carbonate of lime.

divided into three fractions-the coarse one caught by the sieve, which casual examination and feel shows to be sand; the finer one in the beaker, which is still gritty to the touch and is seen under the lens to be made of rounded particles, so that it may be called fine sand; and the finest stuff of all that remained suspended in the water poured into the jar, material which is so fine that some of it will remain floating for days though left quite undisturbed. When we have collected a portion by evaporation or long settlement it will feel quite smooth and greasy between the fingers, and only under the higher powers of the microscope will it show the particles of which it is composed. It is clay, but not so wholly clay as a finer separation would obtain, being in fact a mixture of what the soil analyst would call clay and fine silt, but still for working purposes a very pure clay. Notice particularly that when it dries it forms a 
tough cake which requires some force to break, whereas both the coarse and fine sand fall to a powder as soon as they are dry. If we make this partial separation for all the examples of soil we shall find the greater part of each of them to be composed of sand and clay in varying proportions; however, even the coarsest soil is not free from clay, while even the heavy clay soil probably contain 50 per cent. of the sand fractions.

Before examining the nature of the sand and clay fractions there is still one other regular constituent of soil which must be identified, and this we may do by putting a few grammes of each soil in a dish and covering it with dilute hydrochloric acid. In several cases, especially with the chalky soil, there will be a visible effervescence, due to the escape of carbon dioxide from carbonate of lime in the soil, which is being decomposed by the hydrochloric acid. Even the soils which do not effervesce probably contain some carbonate of lime, small amounts of which (less than I per cent. or so) show no visible evolution of carbon dioxide gas, because it dissolves in the liquid as fast as it is set free. The peaty soil is pretty sure to show no effervescence, and as a rule this is due to the entire absence of carbonate of lime from such soils. A further test which should be applied is to put a little of each soil in a wettish condition on a strip of blue litmus paper; the peaty soil, and perhaps some of the others, will show themselves after standing to be acid, and from acid soils carbonate of lime is absent except in accidental fragments. These four substances-humus, sand, clay, carbonate of lime, constitute the solid matter of all soils; but only in the exceptional cases of peats on the one hand or chalky soils on the other do the sand and clay fail to predominate greatly over the other two constituents.

To study the properties of sand any ordinary clean 
sand will suffice, while for the clay a piece of pure tile or brick clay before it has been mixed with sand is required, or better still, a sample of modelling clay; some will be wanted in its natural moist condition, while a little should be dried and roughly powdered. Begin by taking some moist clay and some wetted sand; the clay can be moulded into shape and will hold together even when squeezed into thin sheets, the sand possesses little or no cohesion. On drying, the sand falls to pieces, the clay retains its shape and becomes hard. Mould a little brick of the clay, 6 to 7 inches long and about I inch square, make two marks on the face exactly 5 inches apart; put the clay aside to dry, and then measure the distance between the marks; the clay shrinks in drying. Clay is plastic and coherent when wet, retains its shape on drying, but shrinks and becomes very hard, none of which properties are shared by the sand. Take three funnels, plug their stems loosely with cotton-wool, and weigh out into one 50 grammes of sand, into each of the others 50 grammes of the dry powdered clay; stand each above a beaker, and pour on to the soils 100 c.c. of water. On to one of the clay soils, however, pour a little water to begin with and make it into a paste with the clay, adding water little by little until all the clay is pulped up and then pouring on what remains. Now note both how much water runs through and how long it takes to drain in each case. The water runs through the sand in a few minutes, and when measured the sand will probably not have retained more than IO c.c. of the water. Through the powdered clay the water may take an hour or more to pass, and when the drainage is complete the clay may have retained almost its own weight of water. In the third funnel, where the clay has been pulped up with water or "puddled," no water at all will have passed. As compared with clay, the sand passes water quickly 
and retains but a small proportion when thoroughly drained; puddled clay is quite impervious to water.

We may make one more experiment with clay: Work up a few grammes of clay with a gallon or so of distilled or rain water, and divide the turbid water that results among several jars. To one add a few grains of salt, to another a few cubic centimetres of lime water, to a third a little sulphate of lime dissolved in water, to a fourth a few drops of ammonia, to a fifth a few drops of acid, and leave a control without addition; put them all aside to settle down undisturbed. The liquid to which nothing has been added will take a long time to clear, with the ammonia it will take longer still, days or even weeks. The acid, on the contrary, causes the solution to clear in a comparatively short time; the lime water and the sulphate of lime also induce clearing, though not so rapidly, and the salt is still less effective. The appearance of the quickly clearing liquids gives us some clue to what takes place; the acid and the salts, especially salts of lime, induce the very fine particles of which the clay is composed to clot together and coagulate, or flocculate, as we shall prefer to call it. Since each of the compound particles thus formed must be heavier than the units of which it is composed, it falls to the bottom of the liquid more quickly, and generally behaves as though it were something of the order of a grain of sand. Clay particles will also flocculate if left to themselves and exposed to changes of temperature, wettings and dryings, freezings and thawings, and this fact has a very important bearing on the working of clay soils. On the other hand, any handling or knocking about of the clay soil when in a wet condition breaks down the flocculation and sets all the fine particles free once more, making the clay more characteristically clay than ever. 

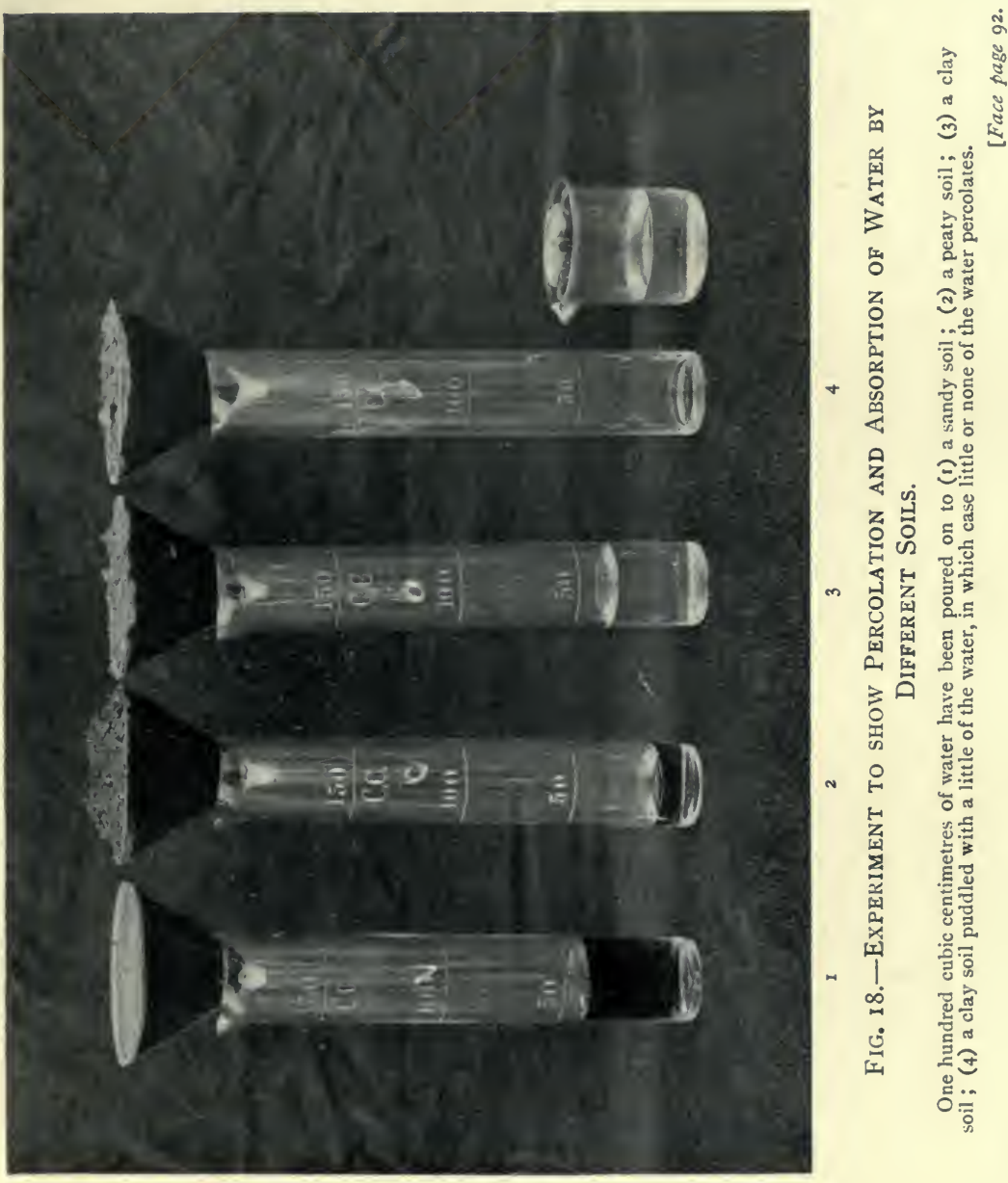

But though all soils are built up of sand and clay, humus and carbonate of lime, these materials only give rise to its physical structure; they account for the manner in which the soil works and its relations to water, but in themselves they have nothing to do with feeding the plant. In order to get information on that aspect of the soil it is necessary to try a new experiment. Take a series of funnels, plugged as before loosely with cotton-wool, and pack each with a different sample of soil, then pour on to each a small quantity of hot water and let it percolate through, an operation which will be hastened if each funnel can be led into a flask communicating with a filter pump. Take the liquid which comes through, filter if necessary, and evaporate it to dryness in a clean basin-a small residue will be left representing the material in the soil which was soluble in water. One test only need be applied to it; pour on to the residue a solution of diphenylamine in sulphuric acid and an intense blue colour will appear, indicating the presence of nitrates in the extract from the soil. In this nitrate, which is present in all soils, we have a substance which, as we have learnt before, will serve as food for plants, supplying them with the combined nitrogen that is necessary for their existence. Ammonia, the other nitrogen compound which plants can utilise, may also be detected in soil, but in such small quantities that a delicate test is necessary. The small proportion is due to the fact that ammonia in the soil is constantly being converted into nitrates by a process which will be explained later. Indeed the nitrates themselves are only present in the soil in very small amounts, from two to twenty parts per million of a dry soil; how minute a fraction of the whole soil does the soluble portion constitute, may be guessed from the residue left in the dishes after evapora- 
tion of the soil extract. It is, however, not quite sufficient to consider the soil materials that are soluble in water as alone capable of feeding the plant; we have already seen reason to suppose that the carbon dioxide excreted by the plant's roots and also present in the soil from other sources, adds greatly to the solvent action of the water, enabling it to attack substances which are usually regarded as insoluble in water. In consequence, we have come to regard any substance in the soil that is soluble in acids as a potential plant food which may, however slowly and in whatever small quantities, be brought into solution and so reach the plant.

If, then, we attack a soil with strong hydrochloric acid, which we may be sure will dissolve everything that is likely to reach the plant within the next century, we shall find some 5 to 15 per cent. of the soil going into solution, but by far the greater part of this consists of oxides of iron and alumina, to which (except for a trace of iron) the plant is indifferent. If we analyse the soluble material we shall find exactly the elements we have previously ascertained to be common to all plants, i.e., chlorine, phosphoric acid, sulphur, and some silica among non-metals, with soda, potash, magnesia, lime, iron, and alumina in excess; but the elements that are necessary to the plant rarely make up I per cent. of even the most fertile soils. This I per cent., however, is allimportant, constituting as it does a vast reservoir of potential plant food. . Nor is the quantity so small as might at first sight appear; a cubic foot of soil in situ weighs from 90 to I Io lb., clays being the lighter and coarse sands the heaviest of all; at Rothamsted, again, where the soil is a clay loam, the layer of soil, an acre in extent and 9 inches deep, weighs about two and a half million pounds, exclusive of stones, i.e. rather more than 
a thousand tons. If, then, a soil possesses as little as one-tenth per cent. of nitrogen, it still contains about a ton of nitrogen per acre down to the depth of 9 inches only; yet, as we have seen earlier (Table VI.), an ordinary crop does not remove from the soil more than 50 to $100 \mathrm{lb}$. of nitrogen per acre. There is thus material for fifty or more full crops in the poorest soils; but these questions will be discussed more in detail in a later chapter.

We may now return to the rough soil analyses we have made, to see what light they throw on the relative nature of the soils and subsoils. For purposes of illustration, Table XII. (page 96) gives more accurate and detailed analyses of such a series, in which the soils have been split up into a larger number of fractions than was attempted in our rough analysis; each of the fractions in the first case included two of the fractions into which the soil is separated in the full analysis.

Looking down this table we first notice that there is comparatively little humus in the subsoils; the humus is almost wholly confined to the 9 inches in which the roots are numerous. Exceptions to this rule are furnished by the alluvial and sometimes by the peaty soils if the soil has been taken from the top of a peat deposit of any depth, because peat is nothing more than an accumulation of former vegetation in a more or less pure state. The alluvial subsoils always show a considerable amount of humus, because down to their lowest depths they consist of old soil which has been washed off the surface into the rivers in flood time, and redeposited lower down the river. Only when the alluvial subsoil consists of coarse-grained gravel or sand will it be poor in humus; these large particles naturally carry no humus after rubbing together for a time in running water. As regards carbonate of lime, soil and 
THE ORIGIN AND NATURE OF SOILS [CHAP.

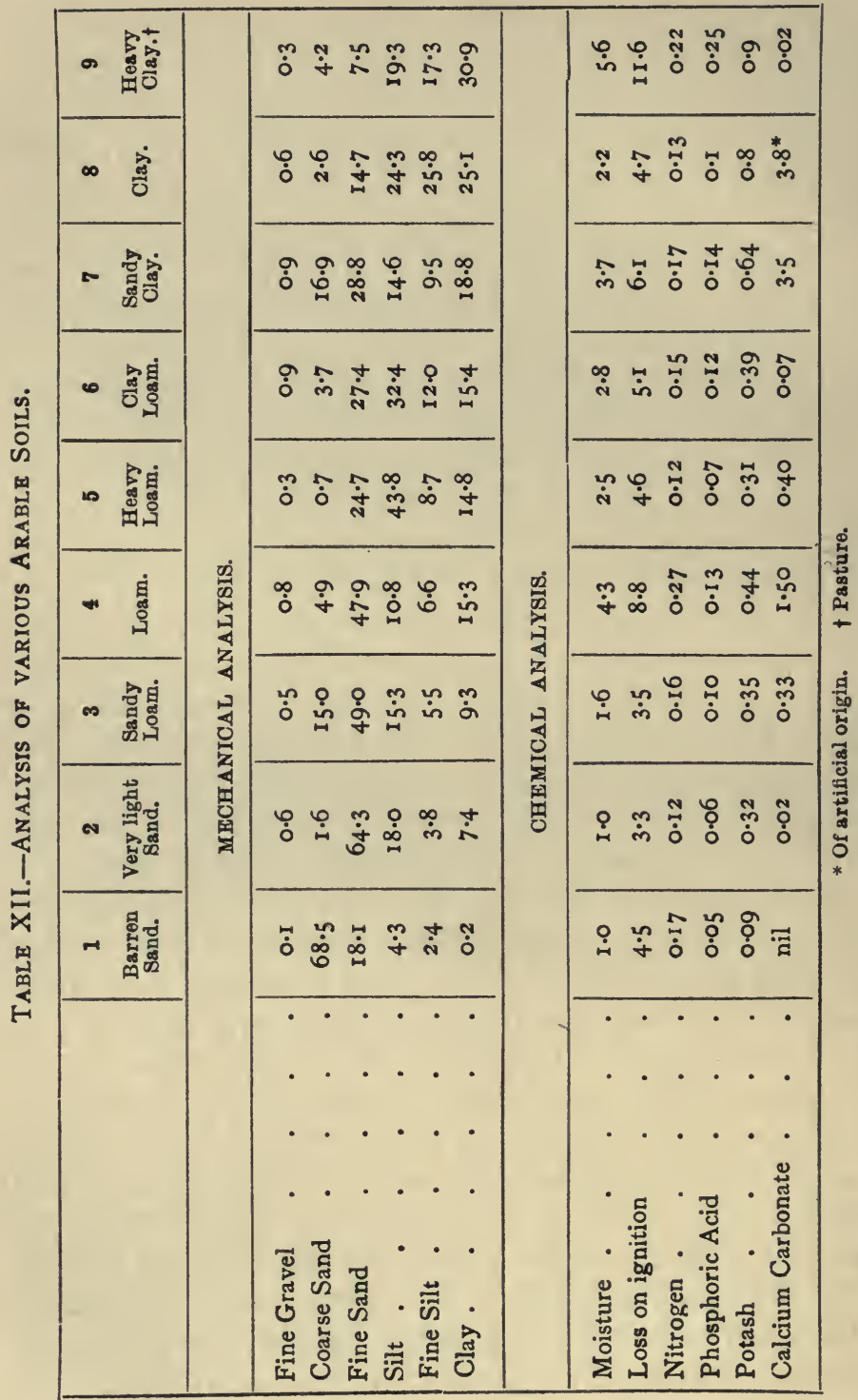


subsoil are very much alike, the soil being generally a little the poorer, because of the constant solution that is going on in the surface soil. On the other hand, the surface soil has sometimes been so regularly dressed with chalk or lime that it shows a higher percentage of carbonate of lime than the subsoil. Soils on chalk or limestone formations are often very shallow, so that the subsoil becomes nearly pure carbonate of lime, wherever a subsoil can be said to exist. As regards sands and clay, in the heavier soils-i.e., the true clays, the heavy clay loams, and most alluvial soils - the surface soil is more coarsely grained than the subsoil ; it contains more sand and less clay. This difference is due to the constant action of the rain washing down the finest particles, especially when the soil is loose after cultivation. When the rain beats upon the rough surface of the soil, some of the very finest particles become washed off and suspended in the water; sometimes they are filtered out again by the soil at a lower level, sometimes they are carried away into the ditches; in either case the coarser-grained material is left behind on the top. The subsoil, however, of a sandy soil possesses much the same composition as the soil; in this case there is both less fine material to wash down, and also the whole soil settles together when beating rain falls, instead of leaving the hollow spaces which occur in a clay soil for a long time after it has been worked. As to the comparisons between different kinds of soils, we find that all the heavy working soils (really the lightest per cubic foot) are made up of the finer particles, and contain but little sand ; especially do they contain very little of the coarsest sand, which tends to keep a soil open and friable. They are distinguished by a high proportion of clay, though of what the analyst properly calls clay-material made up of particles less than one hundred and twenty-five 
thousandth of an inch in diameter $(0.0002 \mathrm{~mm}$ ), there is rarely as much as 30 per cent. In some very wet and heavy working soils, of which No. 8 is an example, the percentage of true clay is not especially great, but it is associated with high percentages of the fractions next in fineness-the fine silt and the silt-and these, in the absence of coarse sand, are almost as retentive of water and clay-like as clay itself. Such a soil does not shrink so much on drying, but it lies wet for a long time; it is excessively greasy and sticky after rain, and when worked down to a fine tilth will run together after rain and cake on the top in a fashion special to itself. The difficulty of working all heavy soils is much mitigated if they contain an appreciable quantity of carbonate of lime, because that substance constantly dissolves in the soil water which has gathered carbon dioxide from the decaying humus, and thus forms a solution of bicarbonate of lime which keeps the clay particles flocculated. On some formations marls occur containing a considerable proportion of very fine-grained carbonate of lime mixed with clay; such soils are very sticky and work heavily, but they crumble readily when dry, and never lie so wet as the true clay soils. Lastly, the sandy soils vary very much in character; some sandy soils, in which the fine sand and the silt are the predominant fractions, are amongst the most valuable of soils for tillage purposes. They are light, and so are cheaply worked; no time is lost, because they are fit for the plough almost immediately after rain, and yet for all the quickness with which they dry, they do not lose their power of supporting the crop with water during a drought. Such soils may contain no more than Io per cent. of clay, but owe their good qualities to the general predominance of fractions of medium coarseness. The really poor sands, which are often so light (in the farmer's sense) as never to have 
been brought into cultivation but remain in open common and waste, may still contain 6 to Io per cent. of clay, but the sand fractions and particularly the coarse sand, constitute something like three-quarters of the whole soil. Such soils can retain no water for the service of the crops upon them, nor for reasons that will be seen later can they retain any plant food: they are poor in the chemical sense, but barren chiefly because of their dryness, even with the evenly distributed rainfall of Great Britain. 


\section{CHAPTER VI}

CULTIVATION AND THE MOVEMENTS OF SOIL WATER

Nature of the Film of Liquid surrounding Wet Particles of Soil. Retention and Movements of Water due to Surface Tension. Percolation. Rise of Subsoil Water by Capillarity. Value of Autumn Ploughing. Effect of Spring Cultivations. Cooling of the Land by Evaporation. Effect of Hoeing and Rolling upon the Temperature and Water-content of the Soil. Dry Farming in Semi-arid Regions. Drainage and the Temperature of Soils. Spring Frosts. Early and Late Soils.

Somewhat earlier in the book an experiment was described (p. 9l) which had for its object the determination of the relative powers of different soils to retain water, though the water was given every opportunity of draining away. It will now be necessary to ask how the soils effect this retention of water, because on this depend many of the properties of soils which are important to the farmer. It is not easy to observe what is going on in the soil itself, because the particles are so small, but we can obtain a convenient illustration by means of a model on a large scale. Procure a dozen or so large beads and thread them on three or four strings from a stick, so as to form a little rectangle of beads hanging vertically and all in contact; this may be taken to represent an imaginary section of the soil greatly magnified. Now dip the beads in oil and lift them out to drain, or better still, dip them in melted wax for a few moments, so that after lifting them 


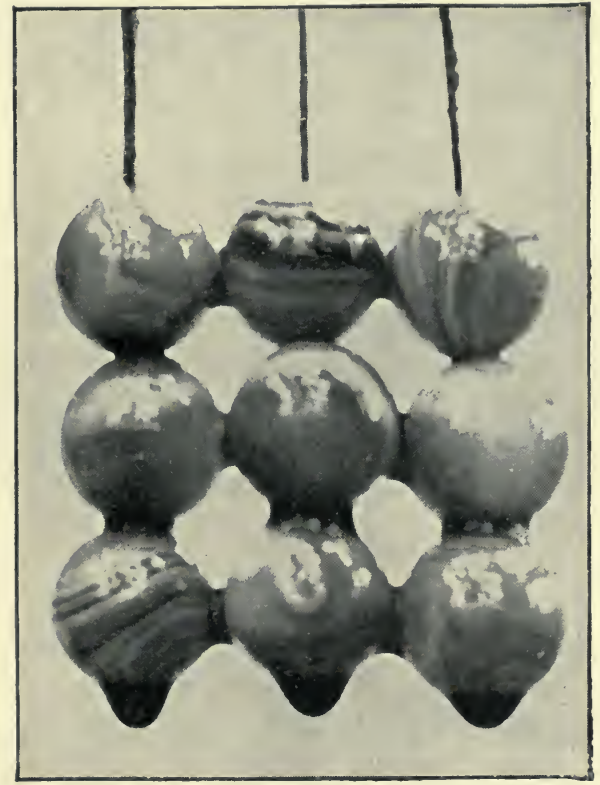

Fig. I9.-Photograph ILlUStrating LiQUid Film ROUND SOIL PARTICLES. 

out the wax will drain away for a short time before setting to a solid state. Oil or wax is only used because it exaggerates and renders more perceptible the results which would be equally given by water; the appearances presented are shown in the photograph. It will be found that all the beads are covered with a skin of oil or wax, just as they would have been "wetted" had they been dipped in water, but this skin is thinnest on the upper row of beads, and gets perceptibly thicker on each lower row. Moreover, wherever two beads are in contact there is a much thicker layer of liquid in the angle joining the two surfaces, though again the accumulations are greater the lower the row; finally, the lowest row of beads carry beneath them large drops which are just not big enough to fall off. The whole set of beads must be considered as enclosed within a film of oil, which we may regard not so much as sticking to the material of the beads but as drawn over them, because the outer surface of the film acts like an elastic skin-so that we might compare the arrangement to a set of balls tied up in a stretched sheet of thin indiarubber. This stretched skin on the surface of a liquid is always pulling inward and trying to shrink into the smallest possible area; for this reason drops of water assume a round shape whenever they reach such a small size that their weight becomes less effective than the elastic pull of the film, or the surface tension as we shall call it. To take another illustration: the hairs of a dry paint-brush stand out to form a round end; wet them, and they are dragged together to a point by the surface tension of the film of water trying to reduce itself to the smallest possible area. It is not merely the contact with the water which causes the pointed end, because when the brush is dipped below the surface it retains the rounded shape it possesses when dry, the 
point is only in evidence when the brush is partially wet. Water or other liquids cling to solid bodies which they "wet," because they enclose them within the elastic film formed by their surface, and as the liquid inside the film is free to move, the film must be equally stretched at every point when equilibrium has been attained and the liquid is at rest. When the shape of the wetted body is irregular, the film that encloses it will always adjust itself to develop its minimum of surface. Coming back to the beads in oil or wax, the film on the upper surface is stretched to the thinnest extent that is consistent with not breaking, because all the liquid inside that does not form the film itself is free to move, and sinks by gravity as low as possible. On the lowest row the film is at its thickest, all the pull of the elastic skin being employed in holding up the weight of liquid inside the skin. In the angles between the beads the layer is thicker, because the skin is, as it were, stretched across a corner in order to reduce its area to a minimum. With this idea of a stretched outside skin in our minds, let us imagine what would happen if liquid were added or taken away from any point. Suppose liquid is added at the top, the skin becomes at once more stretched, and tries to readjust matters by pressing the liquid down and establishing an equal stretching all over, and in this downward pressure it is aided by gravity. Once the liquid has arrived at the lower layer, the skin there has to carry an increased weight, too much for its elasticity, so that the skin breaks and a drop falls. It is in this way that water percolates downwards in consolidated soil where there are no actual channels through which to flow; it is handed on from particle to particle, until at last it reaches an open space into which a drop can form and break off. This open space may be a drain-pipe, which then begins to 
run. It has often been thought difficult to explain how drains come to have free water in them at all, being themselves composed of porous material which clings to water like the fine-grained soil with which it is in contact; but when any of these fine particles gets so overcharged with water that the elastic skin is stretched beyond its holding power, the skin will rupture and detach a drop of free water into any open space that may be present. Returning now to our original illustration of the set of beads dipped in oil, what will happen when liquid is taken away from the top? The skin is reduced in thickness, its stretching and therefore its pressure on the liquid inside is reduced, so that a rise of liquid takes place from below until the tension is once more equalised all over. Thus water can rise in a soil from the lower wet layers in order to replace that which has been taken away by evaporation at the surface, but it is necessary that there shall be a continuous film of water from the evaporating surface to the wet layer below. If the evaporation continues until the films become thinner and thinner and more and more stretched; at last the stretching becomes too much for the elasticity of the material, the film ruptures and shrinks up to a smaller surface with a relieved internal strain. Similarly, if liquid is taken away at the side there will be thinner films created at that point with reduced stretching, which exerts a pull on the liquid until the tension of the film is once more equalised all over. Water will move horizontally from 'a wetter to a drier area, just as it can move upwards against gravity, or still more readily downwards with gravity; as long as the film of water round the particles is continuous, this motion in order to restore equilibrium can take place. This property of water and other liquids to generate a kind of stretched skin on the 
surface is known as surface tension; it is only another way of looking at the property which is sometimes called capillarity, the power of liquids to move upwards, downwards, or sideways, along, or into any system of fine tubes. By means of a few glass tubes drawn out fine and some coloured water, one may easily see that water will rise in such tubes above the level outside, and will rise farther the finer the tube in which the experiment is tried. When one corner of a sponge or a towel is dipped into water, the whole soon becomes wetted, and the behaviour of the water may either be regarded as a creation of a stretched film from fibre to fibre, or a motion of the water along the fine channels formed by the closeness of the fibres. In the same way water may be conceived to move in the soil along the fine channels formed between particles which are touching at their salient points; it is quite easy to show that soil is never packed solid, there is always about 40 per cent. of free pore-space between the particles, like the spaces which must exist between the spheres making up a heap of shot, however closely they are packed together. But just as we have seen that, for any motion of water to take place in the soil, the film of water must be continuous from particle to particle, so from this other point of view there must be no gaps in the soil destroying the continuity of the fine tubes, because liquids can move but a small distance along a wide tube. In interpreting the relations between water and the soil particles, either way of looking at things-capillarity or surface tension - may be employed; perhaps the stretched film is the more useful, because it fixes attention on the fact that the surface exposed by the soil particles is their active and effective part in all such actions. It is easy to understand that the more extensive the total surface possessed by the soil 


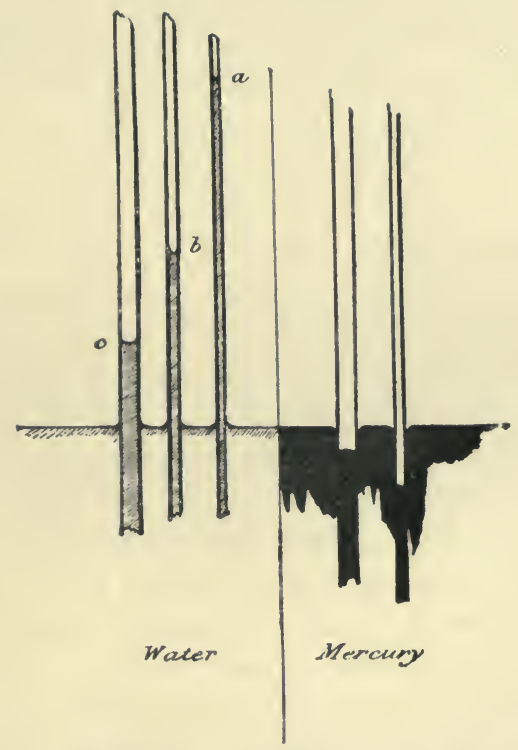

Fig. 20.-Diagram illustrating Capillary Rise OF LIQUIDS. 

particles, the bigger area there is to which water, or anything else wetting the surface, will cling; furthermore, the smaller the particles into which a given weight of soil is divided, the greater the total area of surface. Imagine a little cube, I inch on the side, divided by three cuts into eight cubes, each $\frac{1}{2}$ inch on the side; the surface exposed by the solid material has been doubled, because for one cube with six faces, each an inch square, there are now eight cubes, each with six faces a quarter of a square inch in area, or 12 square inches in all. In consequence, a really fine-grained soil possesses an enormous area and a corresponding absorbing power; it has been calculated in various ways that the particles contained in a cubic foot of an average heavy soil possess surfaces making up a total area of about an acre, while in a clay soil this is increased to about 4 acres. All surface-tension actions are, therefore, more powerful in clay and similarly fine-grained soils; they absorb a greater amount of water, and hold on to it more tightly. The rate of motion of water, however, in such soils is slower, whether it be the downward movement due to gravity and surface tension together which we call percolation, or the upward movement due to surface tension alone when the surface is losing water. The slowness of the movements is due to extreme fineness of the channels between the minute clay particles; the water in these channels cannot move freely, because it is never removed from the drag caused by the attracting surfaces of the solid. Skin friction is always at work, and there is never anything approaching free flow.

Applying these principles to the soils themselves, we see that in a coarse-grained sandy soil percolation will always be rapid, because the mere motion of water by gravity in the large spaces between the particles will be 
little impeded by skin friction. Drainage will therefore be good, but since the soil particles possess so small a surface that can be wetted, the soil will therefore retain very little moisture, sometimes no more than Io per cent. when fully saturated but drained. Similarly, the particles being large the water-films round them are not extensive, and will not possess much power of lifting water against gravity; when evaporation is going on, the water will rise quickly because it is little impeded, but to no great distance. The capillary tubes formed by the interspaces between the sand grains are large, so motion up them is quick, but for only a short distance. In the opposite way, in a very finely grained soil like a clay, percolation will be slow, because the downward motion is hindered by the clinging of the extensive surface to the water, and by the fineness of the interspaces through which it has to ooze. This extensive surface, however, retains a considerable proportion of water, up to 40 per cent., when drainage is over but losses by evaporation have not begun. Again, although the pull exerted by so great a surface is enormous, it is very ineffective in drawing up water rapidly, because of the drag exerted by the particles on the water with which they are in such close contact. When the clay has been tempered and kneaded so as to reduce it to its maximum of fine division and also to pack the particles together as closely as possible, water will not move through it at all, because the water particles are held so tightly by the clay particles with which they are in contact that to all intents and purposes they cannot move at all. For practical purposes the most valuable soils are those which are fine-grained enough to possess considerable surface, capable of retaining water against drainage, and also of lifting it from the wetter layers below when the proportion has been reduced by 
evaporation at the surface, but yet are sufficiently coarse to admit of the reasonably free movements of water either downwards or upwards. There is, in fact, a happy medium of grain which has a large and effective surface that is yet not too large to shut down the movement of the water. Such soils are found among some of the loams and fine sands in which predominate those fractions which we have previously designated as fine sand and silts.

We have already discussed the amount of water required by the growing plant, and have found that taking the experimental figure of 200 to 300 pounds of water transpired from each pound of dry matter elaborated, then the usual crops grown in this country will evaporate from 6 to 10 inches of rain, and even more in the case of a heavy crop of mangolds. Considering that this growth is all made during a portion of the year only, that evaporation from the bare soil will also dissipate much of the rainfall, a great deal of which also runs off the surface or percolates so quickly into the subsoil as to lead to its permanent loss to the land by drainage, we can easily understand that where the annual rainfall is only 30 inches or so, as is the case over the greater part of England, the crops are often likely to suffer for want of water. Humid as is the English climate, the magnitude of the crops in any given year is more often determined by lack of water than by any other single factor, and the majority of the operations of cultivation are directed towards obtaining and storing as large a water-supply as possible. Beginning in the autumn, it is desirable to get the stubbles ploughed early and left rough for the winter; much more of the winter rainfall will be absorbed by such a ploughed surface than by one which remains so firm and trampled by the harvest operations that water 
penetrates with difficulty and largely runs off to the ditches. Not only is more water collected, but the exposure of the plough slice to the weather, to the pulverising action of freezings and thawings, wettings and dryings, tends to flocculate the clay particles on heavy soils, so that later they are easily worked down to a fine tilth. This weathering action has even some effect on the chemical constituents of the soil ; the potash compounds in particular are found to become more soluble after a winter's exposure of the soil to frost and rain. The autumn ploughing is particularly valuable on really heavy soils; they are rarely dry enough during the winter or early spring to be fit for cultivation; in the process they become somewhat tempered and smeared by the plough, kneaded also by the treading of horses and man, so that they would dry into tough and difficult clods were they not afterwards exposed to a succession of spring frosts to bring them into condition again. One cultivation of a clay soil in a wet state in the spring may easily spoil its working and therefore its productivity for the rest of the year, because there are no longer any frosts to restore the tilth, whereas a mistake in the autumn becomes repaired by the action of the later frosts.

Assuming that the land has been ploughed in the autumn, it is then desirable to plough once more in the spring as soon as the land will carry horses safelythe object of this second ploughing being to conserve the main supply of water in the subsoil, and also to enable the layer on the surface to become dry and warm so as to be ready for the formation of a seed bed. After the winter rains the plough slices will have become somewhat closely beaten down and joined up once more into a compact mass with the earth forming the subsoil below; thus the film of water on the particles 
at the surface is joined up to that surrounding the particles in the subsoil below, with the result that as fast as water is evaporated from the surface the losses are repaired from the subsoil. This not only causes a loss of water to the soil-a loss which may become of importance later-but the continuous evaporation keeps the surface moist and cold. It should always be realised that an evaporating liquid withdraws heat from the objects with which it is in contact-the heat being necessary to convert the liquid into vapour. This withdrawal of heat is well seen in the cold experienced by the wetted hands or face when a dry east wind is blowing and causing rapid evaporation; it may be illustrated experimentally by wrapping the bulb of a thermometer in wet flannel or cotton-wool and whirling it rapidly round and round in the air, whereupon the temperature indicated by the thermometer may be made to fall several degrees. Again, the cooling effect of evaporation may be demonstrated by the cold experienced when a little alcohol, ether, or petrol is poured on the hands. Being all readily volatile liquids, they withdraw a considerable amount of heat from the hands in order to pass into the state of vapour. The spring cultivation of the previously ploughed land breaks up the continuity of the water films between the plough layer and the subsoil below, water thereupon travels much more slowly into the surface layer, which in consequence can become dry, and being dry can also warm up at an earlier date. The actual drying will probably take place a little more gently, because the land is not forced to wait until the parching east winds set in; when heavy wet land is dried rapidly under their influence a hard, steely crust is generally formed on the surface which is difficult to break down later. The early spring ploughing before the frosts are quite 
ended is of the greatest importance in getting a heavy clay soil to break down to a mellow crumbly seed bed. The remaining operations of early spring are mostly directed towards obtaining a good seed bed by the use of cultivators of various kinds, and on heavy soils the important thing to be observed is never to work the land when it is in the least wet, or clods of deflocculated clay must inevitably be the result, clods which dry with difficulty and then form hard tough masses which can only be worked down by the action of frost. By implements alone-cultivators, rollers, or clod-crushers - it is impossible to reduce the lumps formed by smeared and deflocculated clay into a fine tilth.

But while the farmer is reducing his soil to a crumb, so as to secure a fine seed bed in which he can deposit the seeds at an even depth, he is also careful to keep the soil consolidated, because if it becomes loose below the surface there can no longer be any continuity of liquid films between the water in the subsoil and that round the particles in contact with the roots of the young plant. After sowing, the land is generally further consolidated by rolling, and in a dry spring the rolling may be repeated just after the seeds have begun to push. The effect of rolling is to consolidate the whole soil from the surface downwards ; it brings the soil particles into more intimate contact and assists the formation of continuous water films from the wet subsoil below. As these water films are continuous to the surface there will be loss of water by evaporation, with a consequent reduction of temperature; but these disadvantages have to be faced, in view of the vital importance of keeping up the water-supply from below to the germinating seeds or infant plants in time of drought. By experiment, we can find that land which has been rolled is ( $\mathrm{I}$ ) moister at the surface but drier at 9 inches or a foot 
down ; (2) cooler at the surface than is a piece of adjoining land which has been kept loosely covered with soil. Too much stress cannot be laid on the importance of consolidating the soil round the roots of plants, especially in their earlier stages of growth; although gardeners are accustomed to tread over their beds before sowing small seeds like onions, they often allow the soil of flower-beds to become altogether loose and porous down to considerable depth, simply by doing too much trenching and deep digging.

As soon as the plant has been established the chief work of the farmer or gardener consists in maintaining a loose surface of the soil for the remainder of the season. Not only are the various processes which liberate plant food from the reserves in the soil promoted by a constant stirring of the surface, but above all things the stock of water in the soil is conserved for the uses of the plant alone. A loose surface tilth soon dries itself, but as it possesses no close connection with the layer below there is no continuous water film from the water-bearing layers to the surface at which loss is suffered by evaporation. The water is lifted by surface tension as far as the soil is consolidated, i.e. up to the roots of the plant, but it cannot get into the layer which is actually exposed to the drying wind and sun, because this layer is only lying loosely on the water-holding soil with large gaps between. The loose, friable layer of soil acts as a screen on the soil below, protecting it from evaporation: it is in fact a soil mulch, and serves just the same purpose as a layer of farmyard manure, or straw, or grass clippings -any of the materials which a gardener usually calls a mulch. By keeping it constantly renewed, the soil mulch may be completely effective in preserving all the water originally present in the soil until the only loss of water to the soil is that which the crop takes and utilises. 
An old gardener was accustomed to say that he watered his garden with his hoe; and in this connection it should be noted that a light watering or a gentle shower of rain during a drought often causes more loss than gain of moisture to the soil. The wetting of the surface soil which ensues may be only sufficient to re-establish the film of water round the soil particles at the top and make that film continuous with the permanent film reaching up from the wetted subsoil. In consequence, as soon as evaporation begins afresh at the surface, water is lifted from the lower layers to takes its place, and the process goes on with considerable loss to the stock of water in the soil unless the continuity of the film near the surface is ruptured by cultivation. Waterings should be done thoroughly or not at all, and they should be followed up by hoeing as soon as the surface is fit to work again.

The fact that the crop evaporates or transpires considerable quantities of water has already been noted, and also the consequence that the growth of a crop leaves the soil very much drier than it was before. The converse of the proportion is seen in the fact that a year of bare fallow, in which no crop is grown but the surface is kept stirred to check evaporation, will accumulate a considerable proportion of that year's rainfall in the subsoil for the benefit of subsequent crops. In semi-arid areas of deficient rainfall such as prevail in many parts of western America and Canada, in southern Russia, and in regions bordering the Australian deserts, farming is rendered possible with a rainfall of 10 to 15 inches per annum by taking advantage of bare fallows. It is customary to take only one crop in two years, or two crops in three years; in the intermediate years the soil is kept ploughed so as to establish a surface which will both collect any rain that falls and will also evaporate but little because of its looseness. The chief features of 
this "dry farming" in arid areas are the insistence on the establishment of a soil mulch-the loose dry layer of soil which will prevent evaporation-and on "subsoil packing," as it is called, i.e., the consolidation of the soil immediately below the mulch, so that it will continuously and steadily lift whatever water may have been accumulated in the subsoil as far as the roots of the plant. To generate the soil mulch, shallow, broad-tined cultivators and harrows are used, while ring rollers are used to effect the subsoil packing. These principles of "dry farming " have been before the mind of the British farmer from time immemorial, especially when farming upon some of the light sandy and chalky soils in the east and south-east of England, where the rainfall is light and the evaporation active. To grow satisfactory root crops under these conditions demands great skill in the preparation of the soil, and the whole art of the farmer is therefore concentrated on getting a good seed bed. First of all, if the soil is heavy he has to work it with judgment to get it to fall down into a crumb at all; then he strives to render this crumb deep and uniform, thoroughly consolidated, and in intimate contact with the undisturbed subsoil below, but at the same time possessing a loose, friable surface which will admit air yet protect the layer in which the roots are growing from the evaporation that follows exposure to sun and wind. It is possible to understand the principles underlying the farmer's operations and aims, but only experience can teach the moment at which a difficult soil may be moved with success so as to bring it into the desired condition. Such knowledge, however, of what to aim at in the cultivation of the soil, of the best tool to take and the right opportunity to seize for each operation, lies at the basis of all husbandry. The art of the arable farmer may be summed up as the proper preparation of 
a seed bed, for on that depends the future of the crop to a far greater extent than on the inherent fertility of the soil ur the amount of manure it receives.

The effect of the water-content of the soil upon its temperature is one of the most important factors which the cultivator of the soil has to bear in mind: it has already been explained that the evaporation of water results in a considerable lowering of temperature, so that the heat of the spring sun may be largely spent in drying a soil without raising its temperature at all. The amount of heat necessary to raise the temperature of a pound of water by one degree would heat a pound of dry soil by about seven degrees, whereas it would require about a thousand times as much heat to evaporate a pound of water and even then cause no rise of temperature. Growth does not take place below a temperature of about $4 \mathrm{I}^{\circ} \mathrm{F}$, this being also the limit below which most seeds do not start nor do the ruots of a plant function, hence before any growth can take place in the spring, it is necessary to raise the soil's temperature above this limit. Almost the only source of heat is the radiation from the sun, which is absorbed by the soil and converted into heat; but to ensure that the heat shall be effective in raising temperature, evaporation, and therefore the access of the soil moisture to the surface, must be checked by cultivation. Any method of diminishing evaporation will, of course, aid in raising the temperature of the soil ; for example, a rough surface to the ground, wind breaks, hedges, or belts of trees, which check the sweep of the wind over the ground, are very effective in early spring towards getting the soil quickly into condition for maintaining growth. In many places the producers of early vegetables on light land near the sea have learnt how desirable it is to establish wind breaks by erecting lines of thatched 
hurdles or temporary reed fences across their land. Similarly, stones upon the surface of the land both help the ground to warm up more quickly and maintain the stock of water later in the season when droughts set in.

The effects of drainage upon cultivated land afford several illustrations of the principles underlying the operations of cultivation. In the first place, the drained land is warmer and therefore earlier, because as the level of permanent water is no longer near the surface, less water will be brought up to be evaporated ; consequently, drying and warming of the surface soil can take place comparatively quickly. At the same time the temperature of the air above the soil is also found to be raised by drainage. In the second place, with the lowering of the water-level in the soil, air is introduced to greater depths, the root system of the crops can extend farther, and in consequence the plant has a greater soil layer to draw upon, and is thereby better able to resist a drought. Lastly, the introduction of air more deeply with the soil and the replacement of the old stagnant water conditions by a steady movement of water through the soil, results in the improvement of its texture; the clay particles are flocculated both by the occasional dryings and by the salts that are washed through; to a certain extent also the very finest particles of all are washed down into the drains. The improvement of the texture of the soil by drainage is of course a question of time, and only becomes apparent some years after the drains have been put in.

Just as the drainage of a heavy or a waterlogged soil, by reducing the amount of water with which it is burdened, causes the soil to warm up more quickly in the spring, and therefore to become earlier, so the question of early or late soils is largely determined by 
the quantity of water they retain. Only a light, coarsegrained soil, possessing a good natural drainage, can free itself quickly from the winter rainfall, and therefore can warm up quickly; but whether such a soil will also be an early one, depends also upon its situation, aspect, and a few minor factors like colour. The heating of a soil is practically wholly due to the sun; although, if a soil is made very rich in fresh organic matter, like farmyard manure, there will be a little heating of the soil owing to the rapid decomposition of organic matter that ensues. In this case the soil has been to some degree converted into a hot bed; but putting this rare factor aside, the colour of the soil has a certain influence upon the completeness with which the sun's rays are absorbed and converted into heat within the soil. Black soils will be the most effective, red soils come next. One practical application of this fact lies in the use of soot as a topdressing for wheat in the early spring; the soot contains a little ammonia which acts as manure, it also checks the attacks of the slugs and small snails which often do damage to the young corn, but it has a further beneficial action, because its colour enables the soil to absorb more heat, enough in fact to raise the temperature by one or two degrees on a sunshiny day. A very simple experiment will demonstrate this : a small plot of ground, a few yards square will suffice, must be brought into a state of good uniform tilth in March or April, and one-half should be lightly dusted over with soot, so as to blacken the surface, without protecting it by any such coating as would act as a mulch. Two ordinary thin-stemmed thermometers (which should be checked against one another beforehand), are then plunged in the soil, one in each portion, care being taken to bury the bulbs at exactly the same depth of 3 inches and to make the soil firm round them. On a bright day of continuous 
sunshine, the thermometer below the blackened soil will register from one to four degrees higher temperature than the other one beneath the uncoloured soil. Aspect is also a matter of considerable importance-a field sloping to the south, not only receives the sun's rays both earlier in the morning and later in the evening, than another field facing north, but also the intensity of the rays upon a given area is greater. Since the sun is never vertically overhead in this country, the area that has to be covered and warmed by a given beam of sun is smaller when it falls on ground sloping towards the

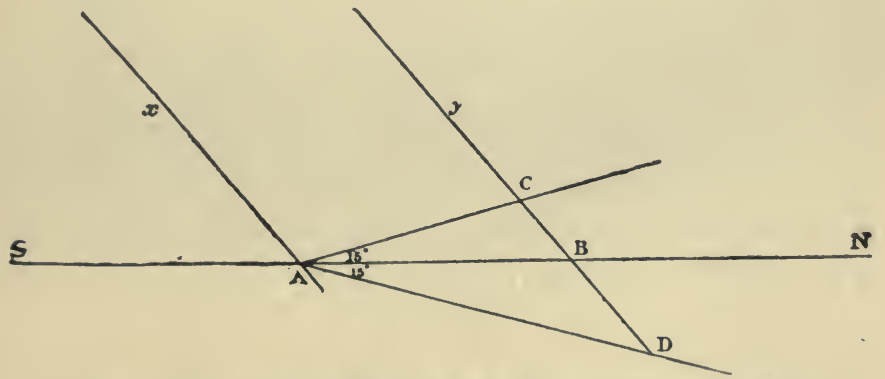

Fig. 21.-Distribution of SUn's Rays upon SOUTHERLy AND NORTHERLY SLOPE.

beam, i.e. southwards, than when it slopes the other way. The diagram, Fig. 2I, shows on to how much smaller an area the sunbeam $A B$ is concentrated when the area slopes towards instead of away from the beam. An early soil should also be a sheltered one; wind always increases the evaporation from the soil, and therefore reduces its temperature; the use of hedges and screens of any kind is of value to the raiser of early vegetables, provided he does not allow them to keep the sun off his crops. Height above sea-level is also a factor demanding consideration; putting aside 
local variations, there is a steady fall of average temperature with increasing elevation, so that nearly all the soils in Britain usually known as early and used for the productions of the first vegetable crops, are comparatively near the sea-level. At the same time, soils which lie at the bottom of valleys are subject to late frosts in the spring, and early frosts in the autumn; the frosts always come more severely and more frequently in the lowest parts of the valley, and often do not extend many feet up the sides of the valley. Such frosts arise in still weather and cloudless nights, and are due to the cooling down of the earth's surface by radiation into space, when there are no clouds to act as a blanket. If the atmosphere is also still in such radiation weather, the air in contact with the ground becomes chilled, whereupon it contracts and grows denser. Owing to its increased density it then begins to roll downhill like so much water and accumulates at the bottom of the valley until it is displaced by the still colder air which occurs later in the night. Stillness is necessary, otherwise the cooled air would not lie in the valleys, but soon become disseminated. The proximity of the sea or other large body of water, is also a considerable factor in the production of an early soil ; the water, because of its large specific heat tends to keep temperatures equable, and does much to mitigate the untimely spring or early autumn frosts which are so much dreaded by the fruit and vegetable grower. Nearly all the districts in which early potato-growing is practised in the United Kingdom are near the sea, e.g. Jersey, the neighbourhood of Penzance, Ayshire, Kerry, parts of West Lancashire, and a few places on the seaboard of Kent and Essex, etc.

A soil which is thus early because of its coarse texture, its dryness, the readiness with which it can be 
worked after rain, its aspect and situation, develops certain disadvantages later in the season. It is apt to dry out with even a short drought; it often reduces the yield of ordinary crops by thus checking the growth at critical stages, even if the crop is not forced to ripen off too early. Such soils, again, often give rise to very rapid growth in the autumn after the rains; this growth, however, is often soft and stands very badly in a severe winter. A heavy soil which is late to warm up, for the same reason often holds its temperature until well on into the autumn; and crops growing upon such heavy soils will continue their development far into the winter. On them the whole course of development is slower and more uniform, and this results in subtle differences in quality between the produce of heavy and light soils, which in the present state of our knowledge can be better appreciated by experience than explained by science. 


\section{CHAPTER VII}

THE LIVING ORGANISMS OF THE SOIL

Formation of Nitrates in the Soil. Bacteria in the Soil which decompose Organic Matter. Bacterial Loss of Nitrogen from the Soil. Formation of Humus. Fixation of Nitrogen by Bacteria associated with Leguminous Plants. Value of Clover Crops in the Rotation. Inoculation of Soil. Other Bacteriafixing Nitrogen in the Soil. Accumulation of Nitrogen in Virgin Soils. Dependence of Soil Fertility upon Bacteria.

So far, we have considered the soil as though it were a merely dead medium in which the plant can fix itself, and from which it can obtain food by processes of solution and diffusion, as though the whole behaviour of the soil towards the plant were regulated by chemical and physical actions of the kind that can be reproduced in the laboratory. Yet certain facts might serve to suggest that other changes have their seat in the soil; for example, we have ascertained by water-culture experiments that plants can only take in their necessary nitrogen in the forms of nitrates or ammonia, small amounts of which are very general constituents of cultivated soils. But though nitrate of soda and sulphate of ammonia are employed as manures, their purpose is equally and more commonly served by other compounds of nitrogen, such as the animal and vegetable residues which are found in ordinary dung. Both experiment and farming experience show that the plant will obtain nitrogen from whichever of its compounds is put into 
the ground, yet we do not know of any means by which these nitrogen compounds can be converted into nitrates in the laboratory except by most difficult and involved processes. The whole history of nitrates in the soil will, in fact, repay a little study. It has been known from time immemorial that nitre in some form or other is a product of the soil, and in India the men of a whole caste or guild make their living by gathering nitre. They scrape away the surface soil from time to time in the neighbourhood of the villages just beyond the point where the drainage finds an outlet, extract it with hot water, and then after clarification concentrate the solution thus obtained, the result being the nitrate of potash, nitre, or saltpetre of commerce. Similarly, in Egypt the native cultivator knows that the earth from deserted villages - the dust, in fact, into which the old mud-built habitations resolve themselves-forms a valuable fertiliser and will yield nitre when extracted with water. Again, nitre used to be obtained in Europe from the earth of cellars, stable floors, and other fairly dry places near habitations; in later times it was expressly manufactured by building up nitre beds-mixtures of earth with a certain amount of carbonate of lime and organic matter, over which urine and similar liquids containing compounds of nitrogen were poured from time to time. The bed was protected from the rain, was kept moist but not wet, and after a period of from three to five years it was extracted with water and yielded a solution of nitrate of lime, which could be afterwards converted into nitrate of potash for gunpowder-making. This well-known process of nitrification represents the fact that the soil is able to bring about a change in the organic compounds of nitrogen and convert them into nitrates, either nitrate of lime or nitrate of potash, according to the base which happens to be present. Long before the mechanism of 
the change was understood men had learnt that it was forwarded by a proper degree of moisture, by warmth, and by the presence of a base like carbonate of lime. Not, however, until about 1877 was it demonstrated that the agents effecting the change are certain minute organisms living in the soil and called bacteria, which are classed with the plants, though they are so lowly in type that they might almost be regarded as the common meeting-ground of the lines of plant and animal descent. At first only the fact was demonstrated that the change was due to something living, and this was done by showing that nitrification ceases when the soil is kept permeated by the vapour of chloroform, which will inhibit or destroy living organisms. Again, if the soil is heated to the temperature of boiling water it loses its power of forming nitrates. The first step having thus been taken, subsequent investigators cleared up the various steps in the process and succeeded in isolating from the soil in an unmixed state two organisms, one of which will change ammonia into nitrite and the other will complete the oxidation into nitrate. We can demonstrate their action by a few simple experiments; an ammoniacal solution that also contains the other elements necessary to the nutrition of bacteria is made up as follows:-

$\begin{array}{lll}2 \text { grammes } & \text { Ammonium Sulphate } \\ \text { O.2 " } & \text { Potassium Phosphate } \\ \text { O.I } & \text { Magnesium Sulphate } \\ \text { O.I } " & \text { Sodium Chloride }\end{array}$

are dissolved in I litre of water, and a few drops of ferric chloride solution are also added. One hundred cubic centimetres of this solution are placed in each of four flasks of about 300 c.c. capacity, the mouths of which are afterwards plugged with cotton-wool. The flasks and their contents are then sterilised by heating 


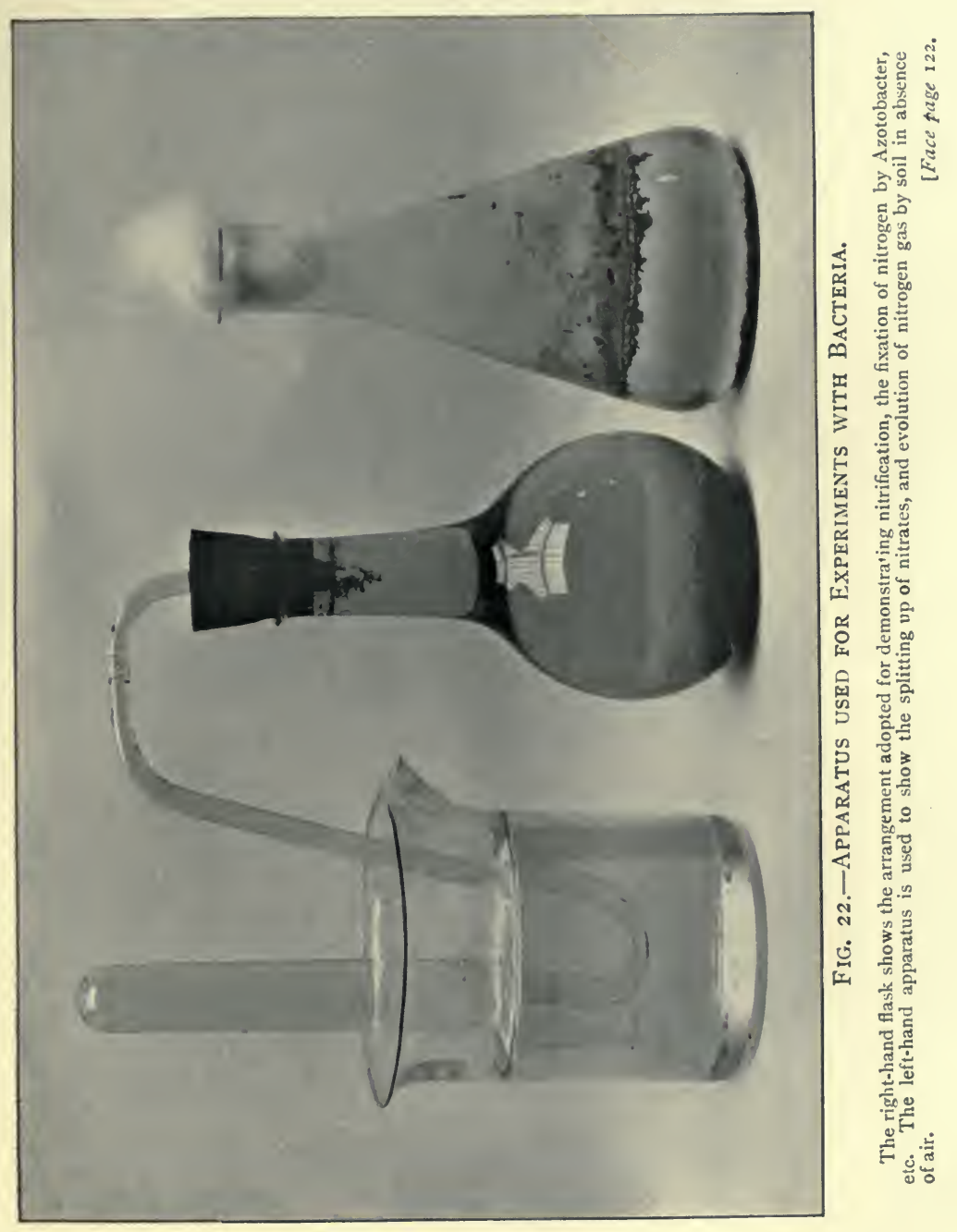



them in a steamer for an hour or so to the temperature of boiling water. One flask is retained as a check, to another about a gramme of fresh soil is added, to a third and fourth a gramme of soil each and half a gramme of carbonate of lime. One of these latter flasks is then heated up to boiling again for half an hour. The four flasks are put aside in a warm and dark place for a period of three weeks or a month, and the liquid in each is then tested for the presence of nitrates by taking out one drop of it on a loop of platinum wire and introducing it into a solution of diphenylamine in sulphuric acid. The control-the nutrient solution to which no soil has been added-will show no nitrate; sometimes the solution to which soil only has been added will also show none, but in the solution to which both soil and carbonate of lime have been added, nitrates will be found and the ammonia may have entirely disappeared. Finally, the fourth flask which had been boiled after the addition of the soil will also show no change, only the unaltered ammonia remains without nitrates. In this simple way it is possible to demonstrate that some living agency is forming nitrates in almost all cultivated soils. These agents are, however, absent from peaty and acid soils, and do not occur in subsoils taken below a depth which varies with the nature of the soil. Another instructive experiment may be made by filling a glass tube about 5 feet long and I inch in diameter with fragments of chalk, the cork which closes the bottom of the tube being supplied with one exit-tube to drain off any liquid, and another rather longer tube turned over inside, through which air can be admitted to the interior. The tube is first of all seeded with the nitrifying bacteria by running some well-water through it, or by putting a little soil on the top of the chalk, then a dilute ammoniacal solution or even a liquid 
like diluted urine or liquid manure or sewage is allowed to drip very slowly on to the top of the chalk, so slowly that the liquid takes several days to work its way from piece to piece of the chalk before it finds its way out at the exit. When the tube has grown into good working order the ammoniacal liquid will undergo pretty complete nitrification as it soaks down the chalk, and only nitrates will be found leaving the tube, but the introduction of a little chloroform into the tube will soon put a stop to the action.

Though it was the first to be investigated, nitrification is only one of the many changes going on in the soil that are due to bacteria, and some of these changes are of the utmost moment to the nutrition of the plant and to the maintenance of the fertility of the soil. As regards changes in the nitrogenous compounds, another experiment can be performed which will illustrate the main features of the cycle that is perpetually being worked through. A flask is made up as before with roo c.c. of nutrient solution, in which, however, the sulphate of ammonia is replaced by an equal weight of peptone, this being a complex carbon compound of nitrogen closely related to flesh, albumen, etc., but more convenient in this connection because it is soluble. Half a gramme of carbonate of lime is placed in the flask, which is then sterilised as before in the steamer; when cold, about I gramme of soil is added. The flask is put away in the dark as before, and at the end of a week it is examined. It will be found that the first change to take place has been putrefaction; the liquid possesses a strong and offensive smell and is turbid with swarms of organisms it contains, some of which are easily visible if a little of the liquid is placed under the higher powers of the microscope. The liquid is then restored to the dark for another fortnight or so, when the putrefactive 
smell will have disappeared and been replaced by a faint smell of ammonia, the next step in the cycle of transformations. Another month in the dark will show the third and, as a rule, the final stage well on its waythe previously formed ammonia is now being converted into nitrate. Lastly, the fate of the nitrate may be illustrated by leaving the flask in the light for a few weeks, whereupon a bright green growth of algæ will appear from spores introduced with the original soil. In sunlight the algæ will form a scum buoyed up by the bubbles of oxygen set free, because the algæ are green plants which possess chlorophyll and split up carbon dioxide like other higher plants. After the algal growth has made some headway the liquid may be tested, and will no longer show either nitrate or ammonia; these substances have been absorbed by the growing algæ and reconverted into proteins by being drawn into combination with the carbon compounds which the algæ have assimilated from the atmospheric carbon dioxide. Thus in the flask has been illustrated the whole cycle of the breakdown by bacteria and the reconstruction in the living plant of the protein bodies which are fundamental to both plants and animals. This all-important set of changes is brought about by at least three distinct sets of bacteria. The first comprises numerous forms or species of the so-called putrefactive bacteria, which seize upon the complex nitrogenous bodies like the proteins and break them down into simpler substances, among which are certain compounds containing sulphur and possessing characteristic disagreeable smells, the unpleasantness of the smell being probably nothing more than a physiological memory of the fact that intestinal disorders have always followed the consumption of food possessing such a smell and therefore swarming with bacteria. After this first 
[CHAP.

putrefactive breakdown another set of bacteria takes up the resulting nitrogenous compounds and breaks them down still further into ammonia, whereupon the nitrifying bacteria can begin to exercise their function. Compounds in the soil are, however, subject to other kinds of change, as we can show by a further experiment. A flask of about IoO c.c. capacity is fitted with a good cork and a single exit-tube leading downwards and then bent up at the extremity: into this flask about 10 grammes of soil and a $\frac{1}{2}$ gramme of sugar are placed, then the flask is completely filled with a solution containing I per thousand of potassium nitrate. After the contents of the flask have been shaken a little to get the sugar dissolved, the cork and exit-tube are inserted; the latter is completely filled with water and set up so that it dips into water and is directed into the open end of an inverted test-tube, also filled with water. The apparatus is then put away in a dark, warm place, and examined from time to time; after some days bubbles of gas will begin to appear and will collect in the test-tube. When enough of the gas has been collected it may be examined with a lighted taper, and by shaking up with lime water it will prove to consist in the main of nitrogen gas. If at the same time the liquid remaining in the flask be tested it will no longer show any reaction for nitrate; this salt has been decomposed by certain organisms in the soil with the liberation of nitrogen gas. Obviously this is a very wasteful process, because nitrates and all forms of combined nitrogen are valuable, whereas four-fifths of the atmosphere is made up of nitrogen gas. Any such change in cultivated soils ought so be checked as much as possible, and this can only be done by avoiding the conditions which give rise to the decomposition. Now the essential conditions of the experiment were the 
presence of organic matter like sugar, which is easily oxidised, and the exclusion of all air, so that the soil bacteria in want of oxygen are driven to take it out of the nitrate which is present. In nature the soil does lose nitrogen because of bacterial changes of this kind; we call the process denitrification, but the losses will only be large when there is much easily oxidisable organic matter present in the soil, and when the soil gets short of air by waterlogging or some similar accident. That the losses, however, may be considerable can be deduced from one of the experimental plots on the wheat field at Rothamsted, where the large quantity of 14 tons per acre of farmyard manure are applied every year for the wheat crop. Despite all this application of manure the yield of wheat has not continued to increase; indeed, for the last forty years it has been almost stationary, except for seasonal fluctuations. The amount of nitrogen, however, that is obtained in the wheat crop is only about one-quarter of the $200 \mathrm{lb}$. per acre that was applied in the manure. Of the remaining three-quarters of the annual supply of nitrogen, about one-quarter still remains in the soil, as an unexhausted residue which will very slowly be converted into plant food. But one-half of the immense amount of manurial nitrogen applied has been lost entirely; it has been dissipated as nitrogen gas by the bacteria in the soil causing what we have called denitrification, and the loss has been so great because of the enormous accumulation of organic matter in the soil. Denitrification causing loss of soil capital must be added, then, to the list of bacterial actions always going on in the soil, or ready to take place whenever the conditions become favourable to that particular form of activity.

So far, however, we have only been considering 
changes brought about by bacteria in the nitrogenous compounds present in or added to the soil, but non-nitrogenous materials undergo equally marked decompositions, often of great practical importance. To illustrate the nature of these changes, two experiments may be performed. A tall bottle, which has an inlet at the bottom, is filled with dry soil, mixed with a small quantity of finely powdered sugar, about 2 grammes of sugar per kilogram of soil. The action is the same with all carbohydrates, but it will take place more rapidly with sugar, so that it is the preferable substance to use. Sufficient water is slowly poured in to moisten the soil, then the bottle is put aside in a warm place, and once a day the gas it contains is pumped out through a wash-bottle containing lime water, air being allowed to enter in its place. It will be found that quantities of carbon dioxide are given off by the soil, and in a week or two if the soil be washed and the solution filtered and tested no trace of sugar will be detected. It has all been oxidised by the bacteria of the soil into carbon dioxide, air of course having been also necessary to the process. In the other experiment a corked-up flask with an exit-tube, such as was employed in the denitrification experiment, is required. The flask is partly filled with a solution of nutrient salts, such as was used for water cultures, and a number of strips of clean filter paper, which is nearly pure cellulose, is introduced together with a small quantity of soil, or better still, of pond mud. The flask and tube are filled up with water, and made to lead into an inverted test-tube over water as before, then the whole apparatus is put aside in a warm place in the dark. It may be some days before any action sets in, but eventually bubbles of gas will arise and will collect in the test-tube, which can be removed for their examination from time to 
time. Carbon dioxide will always be found, but if that is removed by shaking up the contents of the tube with lime water or a little caustic soda, some other gas will also remain, and this gas will take fire if a light be brought to the mouth of the test-tube. The inflammable gas is generally marsh-gas, sometimes hydrogen, or a mixture of the two. At the same time, it will be seen that the filter paper is being attacked; the strips get thinner and begin to break up in places; finally they disappear entirely, or give place to a dark brown, structureless mass. On testing the liquid it will be found to be acid. In this type of fermentation, which takes place without any contact with the air, cellulose and other carbohydrates become split up into carbon dioxide and either marsh-gas or hydrogen, a certain amount of humus being formed at the same time. It should be noted that all the changes described in this and the preceding experiments will not take place if the action of bacteria is suspended at starting by introducing chloroform into the mixture, or by sterilising the whole by boiling; they are all processes due to living agencies, and in most cases we cannot reproduce them in the laboratory by purely inanimate means. These two modes of breaking down carbohydrates illustrate processes which are widespread in nature. The first, in which the carbon compounds are oxidised in the presence of air to carbon dioxide, represents the slow decay which overtakes all organic matter when freely exposed. A leaf, a branch, even a tree itself, which falls to the ground in a wood is eventually dissipated into gas, and leaves behind nothing more solid than the ash which would have resulted if it had been burnt. The process of aerial decay is, in fact, neither more nor less than a slow burning brought about by living organisms; not only bacteria effect such actions, but many fungi, 
and even insects, worms, and other lowly creatures help to produce the same change. The other change, which takes place in the absence of air, is seen when a branch of a tree falls into a pond or a deep ditch and becomes buried in the mud. Thus cut off from the air it changes much more slowly, but it does lose carbonic acid, marshgas, and sometimes hydrogen. Thereby it also becomes gradually black, and on analysis proves to be richer in carbon than the original wood, because it has been giving off in the gases that arise from it more of its hydrogen and oxygen than of its carboll. This process of an anaerobic (out of contact of air) change is seen most markedly in the formation of peat from vegetable matter on waterlogged land, but it has its share in the production of the humus of all cultivated soils.

We have now reviewed the main types of change brought about by bacteria in the organic matter of the soil; the carbon compounds are being broken down into simpler bodies and in nearly all cases eventually become carbon dioxide, the regeneration of which into the complex organic matter of the carbohydrates, etc., is effected by the living plant. The nitrogen compounds are also broken down into successively simpler bodies, finally into ammonia and nitrates, which the living plant can again utilise and reconstruct into the more complex protein forms. Some nitrogen also is always being thrown out of combination, and passed into the air in the comparatively useless state of nitrogen gas. It will be noticed that we have seen no agency at work to reconvert nitrogen gas into any form of combination, nothing in fact to account for the original stock of combined nitrogen in the world. Plants can only make use of nitrogen when it is already combined as ammonia or nitrates; they build up successively more complex bodies from these substances, but not from nitrogen gas 
itself. The soil bacteria we have been discussing similarly only cause the circulation of nitrogen from one form of combination to another; one type sets nitrogen free, but none that we have yet examined do anything to bring it back into combination. But if the combined nitrogen of the world had only been suffering loss by change into nitrogen gas ever since the beginning of things, however small those losses may appear to be, we should probably have arrived at some evidence of a diminution of the stock and signs of its ultimate exhaustion. No indications of the sort, however, exist, from which it might be concluded that some agency must be at work replenishing the stock by "fixing" nitrogen gas and bringing it back into combination.

The discovery of such an agency arose out of the long-debated question of whether our ordinary plants, which are always in contact with a boundless store of nitrogen gas, do not possess in their leaves the power of thus "fixing" the nitrogen they require. Many of the earlier investigators were firmly convinced that plants had such a power, arguing from the difficulty of understanding how there could be combined nitrogen in the world from any other source. Moreover, great refinement of experiment is necessary to demonstrate that the nitrogen gained by a plant is exactly balanced by the amount lost by the soil, hence the controversy lasted for a considerable time, even if it can be regarded as ended now. However, the weight of evidence, and notably a series of experiments carried out by $\mathrm{Dr}$ Evan Pugh of Pennsylvania at Rothamsted in 1857-8, coupled with the experience gained by field trials of the great value to the crop of a supply of manurial nitrogen, have led people ever since the middle of last century to accept as a general principle the opinion that plants do not fix nitrogen. In I886, however, two German investigators, 
Hellriegel and Wilfarth, who had been growing different kinds of plants in pots containing pure sand supplied with nutrient salts in solution, and particularly with varying quantities of nitrogen, noticed that certain plants which were being nitrogen-starved suddenly recovered their vigour and began to grow as though they were freely supplied with the missing element, nitrogen. Such plants were always of the leguminous family-peas, beans, clovers, lupins, etc.; when grown in the sand with little or no combined nitrogen, they began by reaching a stage when they had used up all the nitrogen contained in the seed, after which they became stunted or took on rather a light yellowish colour. Some of them, however, would sudderily recover from this debilitated condition, turn green again, and begin to flourish as before. When such plants were shaken out of the sand in which they were growing, their roots were always found to be studded with small warty nodules, which varied in size from that of a pin's head on clover to something as large as a walnut on the larger perennial leguminous plants. The investigators at last made certain that the presence of these nodules upon the roots was accompanied by an increase in the amount of combined nitrogen in the plant, an increase that could only have been obtained by the fixation of some of the atmospheric nitrogen. The nodules were found to be colonies of a peculiar form of bacterium, which must have originally come from the soil, because when leguminous plants were grown on sterile sand with suitable precautions, no formation of nodules nor fixation of nitrogen took place until there had been infection of the plant's roots either by the introduction of a trace of soil or of an infusion of a nodule that had grown on another plant. Once, however, inoculation had been effected, nodules began to appear on the root and fixation 
of nitrogen took place in the plant as a whole. The seat of this fixation was then demonstrated to lie in the bacteria themselves-these bacteria in fact live in partnership (symbiosis) with the clover or other plants. They receive from its leaves a certain amount of sugar which they oxidise in order to obtain the energy necessary to effect the combination of free nitrogen; in their turn they give up to the plant the nitrogen compounds it requires for its life cycle. It has since been found possible to cultivate these bacteria apart from the leguminous plant with which they are usually associated and to get them to fix nitrogen when fed with sugar, but the amount so fixed is small compared with that obtainable by them for the living plant. The organism has also been shown to exist in several different forms; in the soil it takes a motile form very much smaller than the rod-shaped and even branched forms which may be seen in the nodules, and in this state it is capable of passing through the fine root hairs of a seedling leguminous plant, an infection which soon becomes evident in the growth of a nodule swarming with the transition forms of the bacterium. The laboratory evidence for the fixation of nitrogen by these bacteria was thus rendered very complete; indeed it is a simple matter to arrange an experiment to demonstrate the process. All that is necessary is a series of small pots, preferably of glazed earthenware, filled with sand mixed with I per cent. of calcium carbonate, the pots and their contents being sterilised before starting by heating in an oven for an hour or so. The seeds of some leguminous plant-vetches, sweet peas, or lupins are convenient for the purpose-are sterilised by washing in alcohol and recently heated distilled water, and are then germinated on sterile sand or filter paper until the seedlings are large enough to handle. Meantime the 
[CHAP.

pots of sand are watered nearly up to saturation with a culture solution made up as on p. 45 , but omitting the sodium nitrate, and the seedling plants are carefully introduced. The pots must now be either kept in a case well protected from dust, or the surface of the sand must be covered over by a thin layer of cotton-wool, in order to keep away dust which may contain the organism. After a week or so of growth all the plants will begin to show the want of nitrogen by a cessation of growth and the sickly yellow colour of the leaves. To one pot is then added a few cubic centimetres of a soil extract made by shaking up soil with rather more than an equal bulk of water, and filtering; to a check pot is added the same quantity of infusion that has been boiled. Similarly, another pot is watered with an infusion of a nodule taken from a leguminuus plant of the kind growing in the pot, and as before the check pot is given the same infusion, boiled. The checks will continue to get more sickly looking and will shortly die, whereupon it can be ascertained that they possess no nodules on their roots; but the plants inoculated either from soil or another nodule develop nodules, recover their health, and will grow into perfect plants if the supply of mineral constituents be sufficiently renewed. The experiment should be duplicated, because the check pots are liable to get accidently inoculated unless dust is most rigorously excluded.

This discovery of the fixation of nitrogen by the bacteria associated with leguminous plants at once threw light on a number of facts which had been difficult of explanation before. For example, farmers had always known that in some way the growth of clover and similar plants was beneficial to the soil ; even in the time of the Romans, Pliny, Virgil, and other writers on agriculture had instructed the husbandman to prepare his land for 
wheat by first growing crops of vetches or lupins or beans. In English agriculture the same idea was enshrined in the Norfolk four-course rotation, in which red clover or beans are followed by wheat; and it was well known to the practical man that the wheat always flourished best where the clover had been good in the previous year. Boussingault, who was the first scientific man to make field experiments, drew up a kind of balance-sheet in which the carbon and nitrogen supplied to the land over a term of years was compared with the amounts of the same elements taken away in the crops. Of course, in all cases the carbon removed was enormously in excess of that supplied, because of the assimilation that had taken place, but when the land was alternately bare fallowed and cropped with wheat, there was no more nitrogen obtained in the crop than had been put on in the manure. But with other rotations including clover and beans, there was always more nitrogen harvested than was applied; and when the land was occupied by lucerne or alfalfa, more than a hundred pounds of nitrogen were taken away annually for five years, and yet the soil showed no sign of impoverishment, rather the contrary. Another example of the same kind was obtained at Rothamsted : in 1873 a piece of land was divided, one part being cropped with barley, the other with clover which had been sown the year before; the nitrogen was determined in the two crops, and showed that in the barley $37 \mathrm{lb}$. of nitrogen was removed, in the clover I $5 \mathrm{I}$ lb. In the following year the whole of the land was sown with barley, and the crop where barley followed barley contained $39 \mathrm{lb}$. of nitrogen per acre, whereas that which followed clover contained $69 \mathrm{lb}$. per acre. An analysis was also made of the soil in 1873 , after the first barley and clover crops had been removed, and the soil after 
clover, down to a depth of 9 inches, was found to contain $3915 \mathrm{lb}$. per acre of nitrogen, against $3540 \mathrm{lb}$. after barley. Table XIII. sets out the figures.

Table XIII.-EFfect of Growth of Clover on Succeeding Crop.

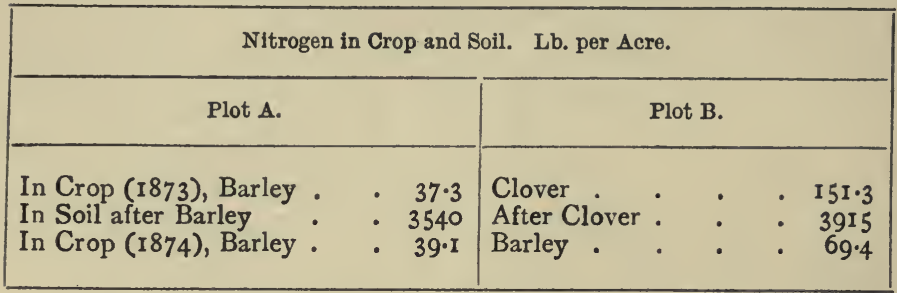

This last experiment illustrates a fact of great practical importance-that a good crop of clover not only produces a lot of highly nitrogenous fodder, in which most of the nitrogen has been won from the air, but also leaves behind in the roots and stubble such an additional amount of nitrogen as will be of considerable benefit to future crops. Another example from Rothamsted will illustrate this point: on the Agdell rotation field, which is farmed on the Norfolk four-course shift, one-half of the field carries no crop during the year preceding the wheat, whereas the other half grows clover or beans. Thus an opportunity is afforded of estimating the effect of the clover or beans on the succeeding crops of the rotation. If we take for our example the years following a specially good clover crop, and compare the two plots which are manured once in the rotation, we obtain the figures in table.

TABle XIV.-Total Produce PER ACre after Clover or Bare FALLOW.

\begin{tabular}{|l|c|c|c|c|}
\hline & Clover, 1894. & Wheat, 1895. & Swedes, 1896. & Barley, 1897. \\
\hline $\begin{array}{l}\text { Clover Plot Piot } \\
\text { Bare Fallow Plot }\end{array}$ & $\begin{array}{c}76.7 \mathrm{cwt} . \\
\ldots\end{array}$ & $\begin{array}{c}5209 \mathrm{lb} . \\
4547,\end{array}$ & $\begin{array}{c}389 \mathrm{cwt} . \\
380, "\end{array}$ & $\begin{array}{c}49 \mathrm{I} 3 \mathrm{lb} . \\
3595 \%\end{array}$ \\
\hline
\end{tabular}


Thus we see that the clover crop not only produced nearly 4 tons of hay, which was removed from the land, but left behind residues which increased the next wheat crop from 4 to 5 quarters, and even caused a large increase in the barley crop which came two years later, in spite of the fact that a considerable amount of nitrogenous manure had been applied to the intermediate crop of swede turnips. It is, in fact, possible by growing clover once during the rotation, to maintain the soil at a moderate level of fertility without bringing in any external source of nitrogen such as purchased fertilisers or feeding stuffs, notwithstanding the continual removal of nitrogen from the farm in the corn and the meat that are sold away. The following example from the same Agdell field will illustrate the point:-

On one of the plots, which receives phosphoric acid and potash but no nitrogenous fertiliser, clover is grown once in the four years' rotation, and the swede turnip crop is chopped up and ploughed in, thus returning to the land the fertilising materials contained in the plant, in the same way as is done when the turnips are fed off with sheep. The following table (XV.) shows

TABLe XV.-Conservation of SoIl Fertility DURing ROTATION WHEN NO NITROGEN IS SUPPLIED. (ROTHAMSTED.)

\begin{tabular}{|c|c|c|c|}
\hline $\begin{array}{c}\text { Nitrogen in So } \\
" \\
"\end{array}$ & $\begin{array}{c}\text { 1, per cent. } \\
" \\
"\end{array}$ & $\begin{array}{l}1867 \\
. \quad 1874 \\
. \quad 1883 \\
. \quad 1909\end{array}$ & $\begin{array}{l}0.138 \\
0.132 \\
0.138 \\
0.150\end{array}$ \\
\hline $\begin{array}{l}\text { Average yield, } \\
1852 \text { to } 1903\end{array}$ & $\begin{array}{l}\text { Wheat } \\
\text { Clover Hay } \\
\text { Swedes : } \\
\text { Barley }\end{array}$ & $: \quad:$ & $\begin{array}{l}35 \cdot I \text { bushels } \\
47 \cdot 7 \text { cwt. } \\
9 \cdot 3 \text { tons } \\
34 \cdot 5 \text { bushels }\end{array}$ \\
\hline
\end{tabular}

that the nitrogen in the soil is not experiencing any measurable loss, while the crop returns indicate that a 
fair level of fertility is being maintained through the nitrogen collected by the growth of clover once during each four-year cycle.

All these illustrations serve to emphasise the point, that by the growth of leguminous plants as frequently as possible the farmer possesses a means of maintaining and even increasing the stock of nitrogen in his land without expense, because the crop of valuable fodder produced in itself pays for the year's farming. Of the crops commonly grown, lucerne (or alfalfa) seems to be the most effective in fixing nitrogen; it is particularly valuable on poor chalky and sandy soils where it can be left down for several years, when it will with a minimum of expense both yield a paying amount of fodder and prepare the land to carry a short succession of arable crops with no extraneous nitrogen supply. Lucerne has proved more difficult to establish on the poor clays, but even there its benefits are very marked. Sainfoin is probably as valuable a nitrogen collector, but it has been less rigorously tested; while the clovers, particularly red clover, are especially effective considering the short time they occupy the soil. Red clover is most valuable to the soil if it is kept grazed after the first cut; a second cut leaves less nitrogen behind, because in the late summer the nodules on the roots become considerably depleted of the nitrogen previously gathered from the atmosphere in order to make the second growth, while a crop of clover seed is even more exhaustive of anything that may have been stored in the root. The annual leguminous plants-beans and vetches-gather less nitrogen from the atmosphere, and are therefore less valuable as preparations for succeeding crops; indeed, on the rotation field at Rothamsted, a bean crop has proved no better preparation for wheat than a summer of bare fallow. At Rothamsted, however, the beans are 
pulled and not cut, thus depriving the soil of a considerable residue of root and stubble. Of course it should not be forgotten that leguminous plants can, and do to a large extent, in nature feed upon the combined nitrogen in the soil, and it is probable that a plant like a bean utilises the nitrogen of the soil until it is driven by starvation to make the nitrogen of the nodules its source of supply.

In view of the enormous importance to practical agriculture of the nitrogen-collecting power of the leguminous nodule bacteria, a number of experiments have been made all over the world to see if anything could be gained by introducing an increased or possibly a more vigorous supply of these organisms into the soil. It has been shown, in fact, that although there is only one species, as it may be called, of bacterium associated with leguminous plants, yet that species possesses a certain amount of racial adaptation, so that clover which has been infected from a clover nodule grows better than if it had been infected from a bean nodule. In some cases this specialisation has gone so far that the particular leguminous plant can only be infected from another plant of the same kind or by soil in which it has been grown; it responds very indifferently to the neutral form of organism that is present in cultivated soils and adapts itself to most of the leguminous crops it meets. Moreover, from time to time, particularly in new countries or where heath or bog or salted alkali land is being reclaimed for the first time, soils are met with which do not contain any nodule organisms, so that when leguminous plants are sown they neither develop nodules nor fix nitrogen. These considerations have led to the artificial inoculation of the soil with the organism appropriate to the desired crop, either by spreading over the land a small 
[CHAP.

quantity, half a ton per acre or so, of soil taken from a field in which the crop in question had before grown successfully, or by sprinkling on the seed an artificial culture of the organism. A number of artificial cultures of the organisms appropriate to such crops as clover, lucerne, sainfoin, beans, peas, etc., have been prepared and can now be purchased commercially in an active state. The practice recommended has been to add the small pure culture that is purchased to a fair bulk of water containing sugar and nutrient salts, or to diluted separated milk, and to keep the mixture for a day or two in order to allow the bacteria to increase, then the seeds are dipped in the liquid for a moment immediately before sowing. The results of such inoculation trials have, however, been disappointing from a practical point of view ; in most cases the soil is already so well stocked with the usual nodule bacteria that the introduction of a few more in the inoculating liquid does not affect the growth of the leguminous plant. In the much rarer cases where the soil is entirely without the organism, its artificial introduction may prove of enormous benefit and enable the crop to grow where it would otherwise have starved. But very often the absence of the organism is only a sign that the soil is in some way unfit to carry it, and some improvements must be effected in the soil before either organism or leguminous plant can be established. Even when the soil is not actually in a condition to prevent the organism growing, the introduction of a particular bacterium, such as that associated with lucerne, cannot be done all at once, or with the rapidity and certainty of growth that is seen when even a single bacterium is added to a sterile medium. The strongest inoculation that is practical only introduces a minute new element into an active flora already in possession of the soil; 
to make good their footing they have to compete with the already overcrowded population of the soil, the numbers of which are only maintained at a certain level by the limited extent of the food supply. It has thus been found necessary to make several inoculations and renewed sowings before lucerne can be regularly established in soils to which it was entirely new, though when one successful crop has been grown there is never any difficulty later in establishing a second. At present, however, the practical applications of pure cultures of the nodule bacteria to the inoculation of soil are distinctly limited, and the enormous returns that have been promised for them can only be realised in very special cases.

Since the discovery of the nitrogen-fixing organisms associated with the nodules of leguminous plants several other bacteria have come to light which can fix nitrogen without any such partnership with a higher plant. For example, among the typical organisms bringing about the decay of organic matter in such places as the mud of ponds and marshes, there occurs a bacterium possessing a limited power of fixing nitrogen, but which we have reason to suppose does play some part in keeping up the stock of nitrogen in soils. But the most actively fixing organism that has heen isolated is a comparatively large bacterium, called Azotobacter, which has been identified in virgin soils from all parts of the world. Certain characteristic features possessed by $A$ zotobacter enable it to be readily detected, and the following experiments may be performed to illustrate its action. A non-nitrogenous culture medium must be prepared as on p. I22, omitting the ammonium sulphate, and portions of 100 c.c. are placed in flasks, I gramme of glucose and half a gramme of carbonate of lime are added to each, after which the flasks are plugged and sterilised in the usual way. From 
[CHAP.

one or two of the flasks the carbonate of lime is omitted. If such a non-nitrogenous medium is inoculated with a mixture of organisms, only those which are able to draw upon the atmospheric nitrogen can live and multiply, because all the usual bacteria depending on a supply of combined nitrogen are starved out and must remain dormant until their necessary food comes along. The series of prepared flasks are then inoculated with about a gramme of soil each, and put away in a warm dark place to incubate as usual. After a week or ten days' time the flasks are examined; wherever the Azotobacter was present in the soil the liquid in the flask will be covered with a dark brown skin, held up on the surface by a number of bubbles of some gas which is evidently being freely developed. The flasks containing no carbonate of lime will often show no brown scum nor formation of gas, unless the soil sample added is itself rich in carbonate of lime. An analysis of the contents of the flasks will show that nitrogen has been gathered -often as much as 8 milligrams of nitrogen are fixed for each gramme of sugar in the original solution. The glucose that has been added is necessary, not merely as food for the Azotobacter, but as material which can be oxidised or burnt up to supply the energy required to bring the nitrogen into combination. Almost any carbohydrate will serve the purpose, but glucose and mannite appear to be most readily oxidised. The Azotobacter is really a very powerful oxidising agent; the gas which is given off during the first growth in the culture flasks is carbon dioxide produced in this way. During, or by means of the rapid process of oxidation, some of the nitrogen which is present is also drawn into combination. Perhaps an even more satisfactory method of demonstrating the fixation-more satisfactory because it follows the sequence of changes taking place in the 
soil in nature-is to put some of the flasks back in the incubator and leave them there for one or two months. The other groups of bacteria introduced in the soil sample resume their activity as soon as they can obtain some of the combined nitrogen that has been introduced by the Azotobacter, and a portion of the compounds that have been so elaborated is broken down and successively oxidised into ammonia and nitrates. On eventually testing the contents of the flask no glucose will be found, but the presence of nitrates can be shown by diphenylamine in the usual way. Finally, if the flasks are put in the light, green algæ will begin to make their appearance, the spores having been introduced with the soil, and thus a growth of green vegetable matter is seen which has derived the whole of the nitrogen it contains from the atmosphere through the agency of the Azotobacter.

It will easily be seen that so widely distributed and so active an organism as Azotobacter may have played a considerable part in maintaining and even in creating the stock of combined nitrogen possessed by the world. The one factor necessary for fixation is that the soil shall be kept supplied with the purely carbonaceous material formed by plants from the atmosphere by the assimilation process. In the Rothamsted wheat field it has been shown that little fixation has taken place in the soil of the unmanured plot -only enough to replace the small losses by drainage, weeds, etc., the amount removed in the crop being balanced exactly by the reduction in the stock of nitrogen in the soil during the period under investigatlon. The crop being wheat after wheat every year, a very small residue of roots and stubble are left as material which the Azotobacter can oxidise. When more carbonaccous residues are left behind, as on grass land, 
particularly where the natural herbage is allowed to fall and decay, there is abundant material for the purposes of the organism, and fixation in consequence can become a marked feature in the history of the soil. Two small portions of land at Rothamsted have been allowed to run down from arable into a mass of rough grass and weeds, nothing having been done to the land for more than a quarter of a century. The coarse derelict herbage that has sprung up-natural prairie-falls back to the soil every year, and an analysis of these soils before and after the growth of the wild vegetation show a notable fixation of nitrogen, over $90 \mathrm{lb}$. per acre per annum for the twenty-five years during which the land has been left to itself. This experiment also helps us to understand how forest soils get enriched with nitrogen; the autumnal fall of leaf adds a large amount of carbonaceous matter to the soil and thus enables the Azotobacter to go to work. The enormous accumulations of nitrogen in the deep black soils of the prairies, the steppes, and similar areas, probably also owe their origin to Azotobacter; for in these soils the requisite conditions are fulfilled-carbonate of lime exists in the soil, and there is a steady addition of carbonaceous matter as each year's growth dies down in the autumn.

We are now in a position to get some general conception of the work of the bacteria in the soil; the actual numbers are very great, as many as forty millions have been estimated in a gramme of a garden soil fairly rich in organic matter, and the number of species that can be distinguished is considerable. It is, however, better to consider them by groups according to their function, than by species, and the main features of the chief groups have been set out above. All these different groups are at work together in the soil, but which will predominate and what degree of activity it 
assumes will depend very greatly on external conditions, such as the cultivation the land receives. Perhaps the most important are the organisms concerned with preparing the food for plants; in the first place the putrefactive organisms break down proteins and kindred nitrogenous material into successively simpler compounds, which are then taken in hand by another group of bacteria and converted into ammonia, though it is impossible to draw any hard and fast distinction between these two sets of organisms. The work of the ammonia-makers is concluded by the nitrifying organisms, which complete the final stage of oxidation of the nitrogen compounds and produce the nitrates forming the chief source of nitrogen for our crop plants. The nitrifying organisms are on the whole so much more active than the ammonia-makers that there is rarely more than a trace of ammonia to be extracted from the soil; the rate at which nitrates are ready for the plant is mostly determined by the rate at which the ammonia-makers can produce ammonia to be nitrified. The work of all this group of organisms is promoted by the same factors as forward the growth of other living creatures, i.e., a proper degree of warmth and moisture and a due amount of soluble food (in this case the mineral salts found in plant ashes). It is also stimulated by such special conditions as an abundant supply of air, a sufficiency of carbonate of lime, and cultivation to distribute the bacteria in the soil. On the other hand, under certain conditions, as when sulphate of ammonia or nitrate of soda is applied to the soil, many organisms will seize upon these soluble nitrogen compounds for their own nutrition and multiply in such numbers that an appreciable fraction of the nitrogen in the fertiliser is withdrawn in order to build up the bodies of the bacteria, which becoming thereby con- 
verted into proteins or substances akin to them, require to go through the routine of decay and oxidation before they can reach the plant. Next come the group of denitrifying organisms which deal wastefully with the nitrogenous reserves of the soil, converting them into nitrogen gas, which possesses no value. These become active when the soil is waterlogged and the supply of oxygen cut off; their action is also promoted by an abundance of organic matter. Then we have groups of organisms working in a contrary sense by fixing nitrogen gas and so enriching the soil; some of these organisms live free in the soil, others enter into symbiotic partnership with the leguminous and a few other kinds of plants. Similarly, for the non-nitrogenous organic matter we have one group of oxidising or decay bacteria, which burn up the carbohydrates to carbon dioxide and water in the presence of air, and another group working under anaerobic conditions, which produce carbon dioxide and marsh-gas or hydrogen; both groups, but especially the latter, giving rise to humus as an intermediary product. The tendency of these various organisms, which are in many cases working in opposite directions, is to arrive at some state of equilibrium appropriate to each given soil and to the treatment it receives; for example, in an exhausted soil such as prevails on the unmanured plot on the Rothamsted wheat field, the activity of the ammonia-making organisms has been reduced to the point that the nitrogen thus rendered available for the crop is practically balanced by the nitrogen gained by the fixation organisms. On the other hand, on the plot receiving farmyard manure every year, to which about four times as much nitrogen is being applied as is being removed in the crop, there is no longer any increase of nitrogen in the soil; the activity of the denitrifying 
group has been so increased by the excess of organic matter that it maintains the balance by getting rid of all the surplus of nitrogen.

The "condition" of the soil in the farmer's sense of the word-its capacity to keep the orop steadily and fully nourished-is in the main determined by the activity of the ammonia-makers, and this, temperature and moisture conditions being equal, depends wholly upon their numbers. The numbers are in the first place conditioned by the food supply of the soil, and secondly by another wholly different class of living creatures which have recently been ascertained to play an important part in the soil. These are various protozoa - distinctly animal organisms a thousand times larger than the bacteria upon which they prey, the numbers of which they keep down to a certain limit. It is possible on a small scale to kill off these protozoa and yet leave the bacteria active, in which case the productivity of the soil is raised, even to the extent of being doubled, without any additions of manure: whether these small-scale processes can be adapted to our fields yet remains to be seen.

Within the soil there are also numerous microfungi and moulds of all kinds, many of which are breakersdown of protein and carbohydrate matter like some of the bacteria, while others are more harmful, because they compete with the higher plants for food, or even give rise to diseases like "finger-and-toe" or "club root" in turnips and cabbages. In a general way it may be said that bacteria predominate in soils which are kept neutral by a sufficiency of carbonate of lime, but that fungi become abundant and harmful as soon as the soil is allowed to get acid, their activity being promoted by the use of acid manures like superphosphates and sulphate of ammonia. While we are very 
far from being able to control the bacteria and other organisms of the soil, we are beginning to realise both the fundamental importance of the part they play in the nutrition of the crop and the manner in which they can be affected by processes and materials which can be applied to the soil; and though so far we have only succeeded in explaining results that the practical farmer had arrived at by experience, our knowledge must in time lead to deliberate and conscious advances in the way of utilising their powers to better effect. 


\section{CHAPTER VIII}

THE CHEMICAL COMPOSITION OF THE SOIL

Plant Food found in Normal Soils. Dormant and Available Plant Food. Rotations and Plant Food in the Soil. Systems of Farming-Wasteful and Conservative. Requirements of Different Crops for Fertilisers. Types of Soil-Characteristic Weeds and Crops.

IT has already been stated that while the greater part of the soil consists of sand and clay, materials that are of no service as food for the plants, there are also present much smaller quantities of the elementary substances-nitrogen, phosphoric acid, potash, lime, magnesia, etc.-elements which we have found in plants and learnt to be necessary to their nutrition. In Table XII. a series of chemical analyses of characteristic English soils are set out, and though the number of soils represented is not great, the examples show almost as wide variations in composition as may be expected anywhere in the United Kingdom. The first things that may be noticed in these analyses is that the range of variation in composition is not great, in few of the soils does the nitrogen fall below 0.1 per cent., in very few arable soils, on the other hand, does it rise above 0.3 per cent.; phosphoric acid may be as low as 0.06 per cent. in exceptional cases, but very rarely will it be higher than 0.2 per cent.; potash perhaps shows the greatest variations, ranging between 0.1 per cent. to 1.0 per cent. These comparatively small variations hardly seem to 
account for the great differences in fertility which we know to exist between one soil and another, differences which are reflected in a rent of $5 \mathrm{~s}$. an acre in one case and $£_{5}$ in another. The next point that requires consideration is the comparatively large quantities of plant food present in even the poorest soils, a quantity which is enormous in comparison with the amount required by ordinary crops. For example, Table VI. shows that few crops take more than $100 \mathrm{lb}$. of nitrogen per acre from the soil, or $50 \mathrm{lb}$. of phosphoric acid, or I $50 \mathrm{lb}$. of potash; only heavy root crops will remove as much as this, crops of cereals require about one-half. As the layer of soil 9 inches deep over an acre weighs about two and a half million pounds, the one-tenth per cent. of nitrogen which is to be found in all but the very poorest of soils would still represent as much as $2500 \mathrm{lb}$. per acre, or sufficient for twenty-five full crops of roots or fifty full crops of corn.

Yet at Rothamsted, where an attempt has been made to grow both roots and corn continuously without manure, in a very few years the crop of wheat fell to about I 3 bushels per acre of corn and Io cwt. of straw, while the mangold crop averaged no more than 4 tons per acre. Nor does growing crops in a rotation instead of continuously help matters much: on the Agdell field at Rothamsted, where the Norfolk four-course system is followed, the average production of the unmanured plot has been $16 \mathrm{cwt}$. swedes, 16 bushels of barley, $9 \mathrm{cwt}$. of clover hay, and 26 bushels of wheat. When grown in a rotation, the cereal crops have maintained their yield at a much better level than when grown continously on the same land, but the preceding crops of clover or swedes are so poor that the land is practically lying fallow for the year before the corn. Some clue to the explanation of the difficulty is afforded by the facts which have been 
considered in the previous chapter, as to the changes which the nitrogen compounds in the soil have to go through before they can feed the crop. Proteins and similar compounds of nitrogen are of no service to the plant until they have been transformed by bacteria into ammonia and nitrates; hence the amount of nitrogen available for the plant in the soil at any moment may be but a small fraction of the whole. Just in the same way, phosphoric acid and potash must be brought into solution before they can enter the plant, and the rate at which the compounds of these constituents in the soil will become dissolved depends greatly on their nature and physical condition. For rough practical purposes we may divide the plant food in the soil into a dormant and an available portion, though it would probably be nearer the truth to consider the whole as potentially available, yet differing greatly in its degree of activity. It is indeed impossible to draw any absolute line of distinction between the dormant and the available-only an absolute division can be made among the nitrogen compounds, of which nitrates and ammonia might be classed as available and the rest as dormant, but even then some of the dormant materials might be rendered available a few days or even hours later. Again, among the compounds of phosphoric acid we might regard dicalcium phosphate in the soil as available and iron phosphate as dormant, but really this only means that the calcium phosphate would yield a solution containing perhaps a hundred times as mich phosphoric acid as would the phosphate of iron. This shows how vain it is to hope to separate the available from the dormant plant food by means of a solvent which will extract the one and leave the other undissolved; in any solvent, however weak, both dissolve up to a point, and the differences are only of degree and not of kind. The 
point to realise is, that plants feed on the solutions in the soil water, and when the compounds in the soil can renew this solution quickly and maintain it at a comparatively high concentration, they may be described as "available" plant foods, whereas the "dormant" plant foods give rise to soil solutions of low concentration, which are not speedily repaired when the plant has extracted the constituent in question. In the case of nitrogen, the renewal of the solution depends upon the attack of bacteria upon the nitrogen compounds in the soil; as regards phosphoric acid and potash, more purely physical and chemical actions regulate the rate of solution. The formation of the soil solutions has already been discussed, and it was stated that the carbon dioxide excreted by the roots of the plant has a considerable effect in aiding the attack of the soil water upon the mineral constituents of the soil. It is easy to show in the laboratory that a solution of carbon dioxide in water is a better solvent of such phosphates and potash compounds as occur in the soil than pure water is-almost in proportion to the amount of carbon dioxide dissolved-and that such a solution must exist in the soil is evident from the composition of the gases in the soil. In most soils the actual solid particles only occupy about 60 per cent. of the total space, the rest being filled up by water and air. When the soil is saturated with water the air is expelled, but complete expulsion is only possible when the soil is saturated very carefully from below, so as gradually to displace all bubbles. Under ordinary conditions some air is always entangled even when the soil is soaking, and as soon as drainage gets established there will be 20 per cent. or more of air, even though the soil is apparently very wet. The air in the soil, however, does not long retain its original composition; by the respiration of the roots and the 
oxidising action of the decaying bacteria, oxygen is always being replaced by carbon dioxide, until, as the various determinations of the composition of the air extracted from an alluvial pasture soil indicate, there may be Io per cent. of carbon dioxide present, despite the exchanges that are always going on at the surface where the soil becomes open to the air. Now the carbon dioxide will dissolve in the soil water in proportion to its concentration in the air with which it is in contact, hence a solution with a fair amount of power to attack minerals is formed as soon as the rain-water has been lying for some little time in the soil and has taken up its proper proportion from the soil air with which it is in contact. In a few cases, as with peaty soil, it is possible that the organic matter may yield certain acids to the soil water which give it an extra solvent power, and the bleaching of stones and sand in peaty soils is sometimes taken as a proof that this happens; but it is doubtful whether carbon dioxide would not equally effect the solution, aided perhaps by reducing actions caused by the organic matter. In the same way it has already been stated that the supposed solvent action of roots may be put down to the carbon dioxide they excrete, rather than to any fixed sap acids that exude from the roots and then attack the soil particles with which they are in contact. That roots have a powerful solvent effect, may be learnt from various direct experiments ; in one case it was shown that plants growing in a mixture of sand and ground rock phosphate could get a good supply of phosphoric acid, whereas similar plants starved when growing in the sand alone, though they were supplied with water that had previously filtered through a second plot of sand and phosphate. In another experiment plants were grown in powdered granite, and when this was washed after growth was 
over, a certain proportion of it was found to have been converted into clay. The solvent action, however, in both these cases can be put down to the carbon dioxide excreted by the roots.

Many attempts have been made to devise processes of analysis which should discriminate between the available and the total plant food present in the soil : it has already been pointed out that an ordinary straightforward analysis which determines all the nitrogen in the soil and all the phosphoric acid and potash which can be dissolved out by strong hydrochloric acid, shows enough food material for fifty and even one hundred ordinary crops. Consequently, when such an excess is revealed it is difficult to interpret the analysis, or to base upon it any recommendations to the farmer regarding the kind of manures he requires. Very dilute acids have, therefore, been suggested-a solution of citric acid that shall be comparable to the acid sap of the root, or a solution of carbon dioxide that shall be like the soil water-with the idea that all of the phosphoric and potash which these liquids would dissolve might be regarded as available. It cannot be said that these methods of analysis have provided infallible information; it is not possible, for example, to say that if a soil contains less than a certain limited amount of phosphoric acid determined by this method it follows that a phosphatic manuring is required. The limit to be adopted will vary with the texture of the soil, the water usually present, the amount of carbonate of lime, the crop under consideration, and other independent factors. For example, a sandy soil may contain much less phosphoric acid than a clay soil and yet feed the plant equally well, simply because the open, aerated soil induces a much greater root development. Again, a crop like wheat, with its long period of growth and deep roots, is much 
less dependent upon mineral manures than are the shallow-rooted crops like turnips and barley. Soil analysis, even by the most refined methods, is chiefly of value when the analysis of the particular soil under consideration can be compared with a number of analyses of similar soils on the same type of land; so as to ascertain its relative deficiencies or excesses, and interpret them in the light of what has been ascertained beforehand about this type of soil by experience or by field trials. If, for example, the average percentage of phosphoric acid in soils of a given type, defined perhaps by a particular geological formation, is 0.15 , and it is also known that phosphatic manures usually meet with a fair response on such land, then if the soil of a particular field on that formation only shows 0.12 per cent. of phosphoric acid, it will be safe to predict the necessity for phosphatic manures on that field, though on other soils 0.12 of phosphoric acid might indicate such richness in that constituent as to remove the need for phosphatic manures.

One other point is brought out in a series of soil analyses: besides a considerable uniformity in the proportions of nitrogen, phosphoric acid, and potash, all soils contain very much the same substances. It is extremely rare to find that any one of the regular constituents is missing, i.e., soda, potash, lime, magnesia, iron, manganese, alumina, chlorine, silica, phosphoric and sulphuric acids; and it is almost as rare to find an appreciable quantity of any other element, though one or two occur occasionally in small quantities. Now this fact puts an end to the very common idea that differences in character or quality in the crops grown on a given soil are due to specific deficiencies in the soil which may be made up artificially. Of course, there are cases where a crop shows certain special features 
brought about by lack of phosphoric acid or lack of potash, because these substances affect the whole course of development of the plant; yet when the apples grown on a particular field are always very red or the wheat is very strong, it is useless to expect to find some substance in the soil to which the redness or the strength is due. It seems so straightforward to analyse the "strong" wheat and ascertain the substance which causes the strength, and then proceed to find the same substance in the soil giving rise to strength. Unfortunately, things do not happen in this simple way: the differences in quality are usually due to very subtle differences in the construction of the plants' constituents, and not in the materials-carbon, hydrogen, nitrogen, oxygen, etc. -out of which the structures are made. In nearly all cases, also, the structure is mainly determined not by the plant food or the manure available, but by the climate, the water-supply, the temperature, and other physical conditions of the soil. Just in the same way the old theory must be erroneous which explained the value of a rotation of crops by supposing that each plant in turn extracted one particular substance from the soil, and so temporarily exhausted the land for itself but not for other crops requiring a different nutrient. We see that no single crop can exhaust the soil of any of its essential constituents, we see also that all crops take out very much the same elements and in similar quantities-therefore the value of a rotation depends on a quite different set of factors. Putting aside the economic arrangement of the labour which a rotation permits, its great value lies in the facility it affords for cleaning the land without any special labour. Whenever one crop is grown continuously on the same land, as is done on the Rothamsted experimental plots, certain weeds which are favoured by the particular crop 
always get an extremely strong hold on the land and become very expensive to keep under. Diseases and insect pests special to the crop tend to accumulate until they may unfit the land to carry the crop. The tilth of the land often suffers when the same crop is grown continuously on it; for example, when wheat follows wheat there is very little time to prepare the land between the crops; again, if swede turnips are repeated for the second crop the land would miss the autumn ploughing, which on many lands is a very necessary element in the preparation of a seed bed for turnips. And though soil exhaustion in any strict sense is impossible, yet when any particular crop is repeated there will always be one particular layer of soil in which the roots of the plant chiefly reside, and this layer is somewhat affected either by the removal of its plant food, or possibly by the addition of some injurious substance due to the plant. At any rate it is the deeprooted plants, wheat and mangolds, which seem to flourish best when grown repeatedly on the same soil ; whereas shallow-rooted plants like turnips, barley, and specially clover, soon begin to fall off in yield if grown continuously on the same land. The theory that plants excrete some substances specifically poisonous to themselves and that a rotation is necessary to give it time to decay, has been revived of late years, but the evidence in its favour seems inconclusive, nor is it necessary to set up so remote a hypothesis to explain the main factors in the virtues of a rotation.

Before we can leave the question of rotations and the amount of plant food in the soil, it is desirable to arrive at some idea of what is removed from the land during an ordinary course of cropping, for on that will, to some extent, depend the nature and quantities of the materials which must be returned as manure if the 
fertility of the soil is to be maintained. As we shall see later, we cannot wholly gauge the requirements of a given crop by first ascertaining what it takes away from the soil, but we can sum up the effect of a given rotation and learn whether it is likely to leave the land richer or poorer. We may consider arable land first, and assume that when farmed on the Norfolk four-course rotation it is of such fertility as to yield, on the average, $4 \frac{1}{2}$ quarters of wheat and 5 quarters of barley, 2 tons of clover hay and 20 tons of roots. We may also assume that only corn and meat are sold off the farm, the straw being trampled down, and some of it fed with the roots in order to make the dung which comes back. When farmyard manure is made in the yards we may expect, for reasons which will be set out later, that only one-half of the nitrogen contained in the food will find its way back to the land in the dung, though when roots are fed off by sheep folded on the land about nine-tenths will be returned. About three-quarters of the phosphoric acid and practically the whole of the potash may be expected to come back in the dung. On this basis we should get figures somewhat as shown in Table XVI.- the annual loss to the land per acre would amount to about $3 \mathrm{I} \mathrm{lb}$. of nitrogen, $9 \mathrm{lb}$. of phosphoric acid, and $5 \mathrm{lb}$. of potash.

As regards phosphoric acid and potash, there can be no possible compensating agents at work other than feeding stuffs or fertilisers brought on to the farm from some external source; it will, therefore, be necessary to use about $240 \mathrm{lb}$. per acre of superphosphate (33 per cent. acid phosphate) once during the rotation, say for the swedes, in order to maintain the fertility of the land. The draft on the potash is not so great, and on the stronger soils we may expect that the weathering of soil particles will render available a sufficient proportion of 
the dormant stock of potash to obviate the necessity of any specific potash manuring: on the light soils $200 \mathrm{lb}$. of kainit per acre once during the rotation would repair all losses. As regards the nitrogen, however, the figure we have obtained possesses very little value as a guide to practice, because it ignores the whole group of gains and losses of nitrogen which are due to bacteria in the soil. For example, we have assumed that the nitrogen contained in the clover crop has all been derived from the atmosphere, so that this crop has

TABLe XVI,-Fertilising Constituents PER ACRe Removed DURING FOUR-COURSE ROTATION.

\begin{tabular}{|c|c|c|c|}
\hline & Nitrogen. & $\begin{array}{c}\text { Phosphoric } \\
\text { Acid. }\end{array}$ & Potash. \\
\hline $\begin{array}{l}\text { Wheat, } 36 \text { bushels, less } 2 \frac{1}{2} \text { for seed } \\
\text { Wheat Straw, } \frac{1}{2} \text { ton fed, rest in dung } \\
\text { Swede Turnips, } 20 \text { tons fed } \\
\text { Barley, } 40 \text { bushels, less } 3 \text { for seed } \\
\text { Barley Straw trampled into dung } \\
\text { Clover, } 2 \text { tons Hay, fed }\end{array}$ & $\begin{array}{l}\text { Lb. } \\
37 \\
0.7 \\
56 \\
32 \\
54^{*}\end{array}$ & $\begin{array}{r}\text { Lb. } \\
14.8 \\
0.5 \\
3.6 \\
14 \cdot 0 \\
3.8\end{array}$ & $\begin{array}{r}\text { Lb. } \\
\text { IO.8 } \\
0.1 \\
0.4 \\
9 \cdot 0 \\
0.4\end{array}$ \\
\hline Total for four years & $125 \cdot 7$ & $35 \cdot 7$ & $20 \cdot 7$ \\
\hline Average loss per acre per annum . & $3 \mathrm{I} \cdot 4$ & 8.9 & $5 \cdot 2$ \\
\hline
\end{tabular}

* Nitrogen drawn from atmosphere and not added in.

entailed no loss to the soil; but we have very sound evidence that the soil will have gained nitrogen after the growth and removal of the clover crop. Moreover, half the nitrogen in the clover-hay fodder is returned to the soil in the dung, whereby the farm will have been still further enriched by the growth and consumption of clover. On the other hand, the soil suffers losses of nitrogen which cannot be estimated-losses both by drainage and by bacterial action-and these losses grow larger the higher the level of richness at which the land 
is maintained. A better idea of the requirements of land under ordinary farming conditions may be obtained from a study of certain of the Rothamsted plots, for which a balance-sheet showing the gains and losses of nitrogen over a period of years can be drawn up.

Taking first the unmanured wheat plot as an example of land reduced to a very low level of fertility, we learn that during the years 1852 to 1902 it yielded on an average a crop of I3.I bushels of wheat, which contained in both grain and straw $18 \mathrm{lb}$. of nitrogen. During this period the percentage of nitrogen in the soil had fallen, and the nitrogen lost by the soil is approximately equivalent to that removed in the crop. At this low level of fertility, then, the nitrogen that had also been removed by drainage and bacterial action (and such losses must exist) had been replaced by recuperative actions, doubtless due to Azotobacter and kindred organisms in the soil. But for the plot receiving farmyard manure every year, the nitrogen removed in the crop together with what has been stored up in the soil only accounts for about one-half of the nitrogen applied as manure. The wasteful actions due to drainage or bacteria must have enormously increased and have removed the balance, any recuperative actions being swamped in such great losses. Turning now to one of the rotation plots on Agdell, we find that when clover or beans were grown once in each four years, and where also the root crop was returned to the land (see Table $X V$.), the nitrogen in the soil remained stationary despite its removal in the crops of wheat, barley, and clover, or beans. In this case, then, the recuperative actions (which include the growing of a leguminous crop) were able to balance the wasteful processes in the soil and the removal of the grain and clover crops, without any additions of nitrogen from outside the farm. The level of production was not, how- 
ever, high, being only 35 bushels of wheat and 34 bushels of barley, and though it might have been increased had the straw and clover hay been made into manure and returned to the soil, only a level of production below the average can be maintained if the land is left to natural recuperative actions. As soon as larger crops are aimed at and the soil is brought into higher condition to produce them, the wasteful actions are increased in a higher ratio, as may be seen from the example of the wheat plot dunged every year. Consequently, to get the land up to the level of 5 qrs. of wheat, not only the extra nitrogen contained in 5 qrs. above 4 qrs. must be added, but a great deal more must be brought in, in order to make up for the increased rate of loss taking place in land in higher condition.

We thus find it impossible to construct a balancesheet for the land that sets off the removal of plant food in the crop against the original stock in the soil and the additions in the manures, because any such summary is upset by the unknown gains and losses suffered by the nitrogen in the soil, nitrogen being the most important element of plant food. As we began by dismissing the idea that we could decide upon the manuring of a given field by finding out by analysis some particular substance lacking in the soil which could be supplied as manure, so now we must dismiss in its turn the theory that for the proper manure we have only to provide what the crop will take away from the soil. The first theory made too much of the soil, since it assumed that different soils possess radical differences which do not exist ; the second theory fails because it takes no account of the soil at all, and neglects the enormous reserves of plant food therein contained. In fact, no general theory of manuring can be drawn up which will predict the appropriate treatment for every plant beforehand-we 
must ascertain by experiment the specific requirements of each crop, and adjust the manure to them, taking also into account the character of the soil and the style of farming, whether high or low.

According to their habits of growth, different crops possess very different powers of feeding themselves upon the stock of plant food in the soil-the specific requirements of each is generally the particular element the crop finds some difficulty in obtaining for itself. For instance, wheat is sown without much previous preparation of the soil, and makes the greater part of its growth during the cooler portion of the year when bacterial activity in the soil is low; as a consequence, the stock of nitrogen compounds in the soil is being but slowly converted into ammonia and nitrates available to the plant, and this particular crop becomes specially dependent on a supply of some active form of nitrogen as manure. On the other hand, the wheat plant possesses a very extensive root system and has a long period of growth, so that it searches the soil pretty thoroughly and is well able to pick up the mineral plant foods-potash, phosphoric acid, etc.-which it requires. Hence, on the normally fertile soil, wheat requires no mineral manures, but will respond to active nitrogenous manure should the land not be in very high condition. Barley supplies an instructive contrast-it is a springsown crop, and for it the land gets a more thorough preparation than for wheat. Nitrification and other bacterial processes rendering available the nitrogenous compounds of the soil are active in the recently stirred land as it is warming up in April, May, or early June, so that the barley crop requires little manurial nitrogen, though it takes away from the soil as much of this element as does the wheat crop. Being, however, shallow-rooted and possessing but a short period of 
growth, it is very dependent on a manuring of phosphates, potash being less necessary, because it is fairly abundant on any but the lightest soils. Swede turnips afford another illustration: they are sown late, when spring is well advanced, and after a very extensive working of the soil; during growth there is also a good deal of intertillage, which promotes bacterial activity, with the result that the crop requires very little nitrogen in its manure though it takes away two or three times as much as the wheat crop does. But with its shallow root system the swede crop is greatly in need of phosphates, and also of potash-perhaps more frequently than is suspected. The specific requirements of crops will be dealt with more particularly in a later chapter; but soils show certain real differences, partly chemical and partly physical, which affect their manuring and management and may be now considered.

Sandy soils are made up, as we have said before, of the coarser grades of particles, and contain as a rule but a small proportion of clay; it follows that they are easily and rapidly permeable by water, and as they do not retain much water they warm up quickly in the spring and are early soils. Possessing but little clay, they not only dry quickly, but they can be worked when wet without any danger of destroying their texture; this, again, helps towards early cropping. Their coarseness of grain, however, prevents them from lifting subsoil water readily to the surface, so that crops on them suffer from even short periods of drought, and it is necessary to keep them as consolidated as possible by folding with sheep, rolling, etc., in order to help the capillary uplift of water. Being so warm and well aerated, all bacterial actions go on rapidly in light soils, and humus and other organic materials decay quickly: such soils, therefore, are not retentive of manure but 
must be dressed frequently and heavily if they are to be made fertile. From the chemical point of view, they often show certain special deficiencies; very generally they are lacking in carbonate of lime, with the result that turnips and similar cruciferous crops are found to suffer from finger-and-toe or club root. Lacking clay, they are also apt to be deficient in potash, and crops like mangolds, potatoes, clover, and tobacco, which require plenty of potash, should always receive potash manures on sandy soils. All sandy soils, from their warmth and friability, are apt to be very weedy; the characteristic weeds are often those associated with lack of lime rather than with the dryness of the soil. Good examples of this type of weed are the Spurreys (Spergula arvensis and Spergularia rubra), Sheep's Sorrel (Rumex acetosella), and Corn Marigold (Chrysanthemum segetum), all common on light sandy soils, but indicating also great lack of lime if not actual acidity. The Knawels (Scleranthus annuus and perennis), Knot Grass (Polygonum aviculare), and some of the wild Poppies (Papaver dubium) and the small Bindweed (Convolvulus arvensis), are among the most troublesome weeds of sandy arable land; sometimes also a form of Bent Grass (Agrostis alba) is very abundant. On the grass land various tufted species, Cock's-foot (Dactylis glomerata), the Oat Grasses (Arrenathemum avenescens, Avena flexuosa), and the Soft Brome (Bromus mollis), are characteristic. Leguminous plants, except Bird's-foot Trefoil (Lotus corniculatus), and more occasionally some of the Vetches like Vicia cracca, are not abundant; though various weeds-Hardhead (Centaurea cyanus), Buttercup (Ranunculus bulbosus), Rattle (Rhinanthus crista-galli) and Silver Weed (Potentilla anserina) are common. On the wastes, Gorse (Ulex europaus and nanus) Broom (Cutisus scoparius), Heather and the Heaths, the 
Bracken Fern (Pteris aquilina), and the Foxglove (Digitalis purpurea) are typical, all of them being associated with lack of lime also; while the characteristic trees are the Spanish Chestnut, the Silver Birch, the Holly, and many Conifers, particularly Pinus pinaster.

The sandy soils pass by insensible stages into the loams-indeed many of the most fertile loams are really sands in which the finer silt fractions predominate. Properly a loam is marked by an equable distribution of the various grades of particles, with enough clay and fine silt to render it retentive of moisture and manure, but with sufficient sand to keep it open and well drained. Chemically, also, the loams might be described as well found, without any specific deficiencies or excesses; particularly the proportion of carbonate of lime, though it may be small, is sufficient to maintain the neutrality of the soil. The loams might, on the one hand, be said to have no specific flora; on the other hand, certain plants are only found on good, free-working soil in fair condition, so that they may be taken as indicative of fertile loams. Among trees the Elm is characteristic, as are clean, well-grown Thorn hedges, and an abundance of Nettles (Urtica dioica) in the hedgerows and waste places. On the arable land, Chickweed (Stellaria media), Groundsel (Senecio vulgaris), Fat Hen (Chenopodium album), Annual Nettle (Urtica urens), and Sow Thistle (Sonchus oleraceus) are weeds indicative of good land. Goose Grass (Galium aperine), the Speedwells (Veronica, sp.), Pimpernel (Anagallis arvensis), Henbit (Lamium amplexicaule), and various Spurges (Euphorbia peplus) etc., are also common. On the pastures, Perennial Rye will generally be the most characteristic grass, and its smooth leaf gives a characteristic shine to some of the best grazing land; White Clover is also abundant, and 
the herbage is generally very varied and forms a thick close sole. Buttercups are very common on some of the alluvial pastures, and are sometimes taken as a sign of overmuch cake feeding; many Oxeye Daisies (Chrysanthemum leucanthemum), on the contrary, indicate that the land has been allowed to get too poor.

Just as the sands pass insensibly into the loams, the latter grade by degrees into the clays, the most pronounced examples of which are the soils resting upon some of the formation developed in the East Midlands and in the east and south-east of England-the Oxford and Kimmeridge Clays, the London and Weald Clays, being the most marked. A true clay soil is cold and late, very retentive of moisture yet suffering severely from a drought of any duration, not only because of the cracks it develops, but because of the slowness of the capillary movement of water from below and the restricted root development of all crops upon clay, especially when the land has not been drained. Clays are difficult to work, the draught of all tools being heavy, and great care must be taken to catch them at the right moment of working; especially in spring it is ruinous to their tilth to put horses on them when they are in the least wet. It is most important to plough heavy soils in the autumn and leave them rough through the winter, so as to get the beneficial pulverising and flocculating action of repeated frosts and thaws; on the heaviest soils an occasional bare summer fallow is desirable because of the value of the weathering to the tilth. Being cool and moist, clay soils are retentive of manure; long straw and other bulky manures are of value to open up the texture of the soil ; it is often indeed of service to burn, or rather char, some of the clay and incorporate it with the rest of the soil. Clay soils are very often deficient in carbonate of lime, so that dressings of lime are of 
special value both in supplying this needed constituent and in bringing about the flocculation of the finest particles, thus improving the texture and rendering the soil drier and warmer. Phosphoric acid is also deficient in many clays, and as plants become naturally somewhat shallow-rooted on such soils a good supply of phosphate manure is often extremely effective; potash, on the contrary, is usually abundant on clay soils. The typical crops of clay soils are wheat, mangolds, beans, and permanent pasture, though the latter may be very bad unless it is properly managed. Weeds are not so abundant as on other soils, but a few are specially troublesome, especially Black Bent Grass (Alopecurus agrestis) and Field Mint (Mentha arvensis); the Rest Harrow (Ononis arvensis) is often a bad weed on the poor pastures; the Wild Carrot (Daucus carota), the Teazel (Dipsacus sylvestris), and the Primrose (Primula vulgaris) are characteristic. The Oak is the typical tree of clay land, with Ash in wetter places, and Hornbeam in the underwood and hedges. Clay land pastures are often characterised by a very shallowrooting vegetation, which may even become largely stoloniferous (creeping rooting), with such difficulty do the roots penetrate the stiff, unaerated soil; a form of Bent Grass (Agrostis alba) often constitutes the bulk of herbage; Sweet Vernal Grass (Anthoxanthemum odoratum) and Crested Dog's-tail (Cynosurus cristatus) are also common.

Calcareous soils may be either light, as when derived from the Upper Chalk, or heavy and sticky, when they contain much admixture of clay as they do on the Chalk Marl and several of the argillaceous limestones in the Midlands; but in all cases they possess a very special and characteristic flora. The wild plants are very full of flowers, and the copses and hedgerows contain a 
number of flowering shrubs that are seen on few other kinds of land-the Traveller's Joy (Clematis vitalba), the Mealy Guelder Rose (Viburnum lantana), the White Beam Tree (Pyrus aria), the Dogwood (Cornus sanguinea) being most characteristic; while of the trees, the Beech, the Yew, and the Cherry are particularly associated with chalk and limestone soils. Leguminous plants are abundant both in the pastures and the waste places, the Horseshoe Vetch (Hippocrepis comosa) being a very sure indicator of a calcareous soil, while the natural home of Sainfoin and Lucerne (Alfalfa) is on the warm, chalky soils of the south and east of England. The lighter chalky soils are notoriously weedy, Fumitory (Fumaria officinialis), Dove's-foot Cranesbill (Geranium molle), and Field Buttercup (Ranunculus arvensis) being among the most abundant.

Peaty and waterlogged soils also develop a special vegetation which need hardly be considered in detail, since the farmer merely wants to recognise certain plants and other indications that show the need for drainage either in spots or over the whole field. Patches of rushes always indicate stagnant water near the surface, as also the various sedges known to the farmer as Carnation Grass (Luzula, sp.). The occurrence of tufts of Aira caspitosa also indicates wetness ; and a stagnant, waterlogged condition of the soil is shown by the presence of brown rusty deposits in the ditches, accompanied by an iridescent scum on the surface of the water. On digging into such land a layer of peat is generally found below the surface vegetation, and below that a layer of rusty oxides of iron upon the surface of the true soil. The treatment required in such cases is drainage and liming. 


\section{CHAPTER IX}

FOODS

Composition of Cattle Foods. Nature of Carbohydrates, Fat, Proteins, Fibre, Ash. Processes of Digestion in the Animal Body. Digestibility. Character of various Concentrated Foods, Cereals, Roots, Straw, and Hay. Valuation of Feeding Stuffs.

WE have already discussed the constituents of plants ; these constituents in their turn make up the foods, and have to be considered from a fresh point of view in dealing with the rutrition of animals. As a rule, the composition of any given cattle food is expressed as follows :-Decorticated cotton-seed cake contains-

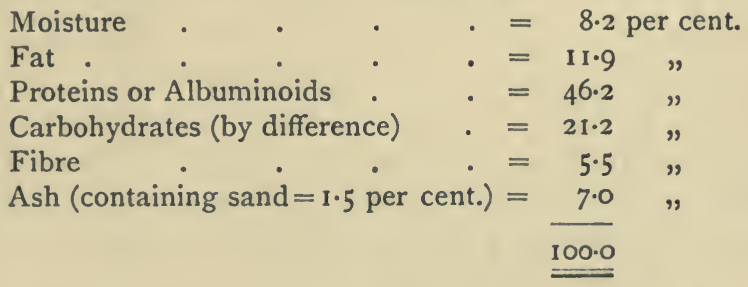

The fat really represents the material which is soluble in ether; when dealing with oilcakes and similar ripe foods it will consist almost wholly of pure fat, but in the case of green fodders various other materials, e.g. chlorophyll, are dissolved by the ether in the process of analysis and counted as fat. Crude fat would be a more correct title. The proteins (albuminoids of the older 
books and in trade documents), again, should be called crude proteins or some equivalent term, because the figure expressing them is only obtained by multiplying by 6.25 the total nitrogen contained in the food, thus including as proteins various non-protein nitrogenous compounds such as the amides, amino-acids, and other bodies intermediate between nitrates and proteins. All green fodders contain a considerable proportion of their nitrogen in this "amide" or non-protein form, and in their case the true proteins are sometimes determined separately. Crude fibre is again a purely conventional term for whatever remains undissolved when the food has been digested for some time, first with dilute acid and then with alkali : it represents very approximately a part of the food which can only be very imperfectly digested by the animal, and is therefore of much smaller value as food. The ash is a figure of value to the analyst, while the "sand" (that portion of the ash which will not dissolve in weak acids) provides an index of how far the food is contaminated with dirt, mud, sand, etc. Finally, all the rest of the food is reckoned as soluble carbohydrates; obviously the figure expressing their percentage contains the accumulated errors of the analysis, and is of value only for comparison with other foods. Indeed in the United Kingdom the seller of feeding stuffs is under no obligations to state the amount of carbohydrates in the food he is selling, though he must state the percentage of moisture, nitrogen, and fat. In all foods we find these constituents-fats, proteins, carbohydrates, fibre-and though great differences exist between the various materials thus classed together, according to the food in which they occur, our knowledge is still too imperfect to make it worth while discriminating between them in an ordinary analysis.

We must now consider the processes of digestion 
which these foods undergo in the body in order to become available for the nutrition of the animal. They have to reach the blood, this being the circulating medium which conveys them to every part of the body, and in consequence they must either be soluble or become converted into such a state of solubility as will permit them to pass through the walls of the stomach and intestines. These organs form the alimentary canal, from which there is no direct opening into any other part of the body. The process of digestion takes place as the food is passing along this alimentary canal; whatever is not absorbed by its walls forms the undigested part of the food, which is excreted as the fæces. The solution of each of the constituents of food is effected by one or more of a series of enzymes which are secreted by the animal; these enzymes being exactly comparable in their action and nature to the diastase, etc., which have previously been described under plants. Considering first the fat, its digestion is not accomplished until the food has left the stomach; at this stage the food materials, which had previously been rendered acid by the gastric juice, are brought into an alkaline condition by mixture with the bile and the pancreatic juice. Amongst other enzymes the pancreatic juice, which is also mixed with the food at this stage, gives rise to a lipase or fat-splitting ferment, which resolves the fats into their component fatty acids, and glycerin. These later bodies are capable of passing through the walls of the intestine, and by means of the blood and of the lymphatic system they are distributed about the body. It is found that fat stored up by an animal, or excreted as milk, does to some extent partake of the nature of the fats contained in its food, showing that the fatty acids (the basal material of the fats) are not entirely broken down before the fat is reconstructed in 
the animal. On the other hand, there is plenty of evidence that the fat of the food never passes into the body or into the milk without some change. Once digested, all fat that is not stored is used by the animal as fuel in order to maintain its heat and provide it with the energy by which it is enabled to work. In this process the fat is completely burnt up, and its elements leave the body again in the form of carbon dioxide and water, having undergone just the same change as would have taken place had the fat been set on fire. The fat is truly burnt, and has been proved to give out the same amount of heat inside the animal as if it had been burnt in a lamp.

The carbohydrates contained in the food also become soluble as a result of enzyme action; the sugars are, of course, soluble to begin with, but starch is first attacked by a diastase which occurs in the secretion of the saliva. In consequence, the digestion of starch is active in the first stomach and during the "chewing of the cud" in ruminant animals. This salivary digestion is, however, suspended in the stomach proper, because of the acid reaction there set up ; but the starch is attacked again in the small intestine, after the influx of the alkaline bile and the pancreatic juice, which gives rise to a second diastatic enzyme. The digestion of cellulose and the more soluble portions of the fibre is less easy to follow. All seeds themselves contain an enzyme capable of attacking cellulose, and this would become active in the alimentary canal, especially in the long digestive tract of ruminants, in which the food remains for four or five days. There is little evidence that animals themselves secrete any cytase or cellulose-dissolving enzyme. The intestinal tract, however, contains bacteria, which multiply greatly in the food, and are able to break down the cellulose and fibre into various simpler bodies, 
such as sugars and fatty acids that are capable of absorption by the blood, together with gases like methane, and to these bacteria is ascribed the main part of the work of digesting cellulose and similar carbohydrates.

All carbohydrates-sugars, starches, or soluble celluloses-acts as fuel for the body: having reached the blood, they are passed on to the living cells, and there burnt to carbon dioxide and water in order to supply energy. When more carbohydrates are supplied than the animal requires, they can be built up into fats either for storage or for milk production, carbohydrates themselves being never stored in the animal body except in the liver, which contains one special body of this nature -glycogen. The combustion of the carbohydrates is not, however, always so complete as that of the fats; a certain proportion, especially of the cellulose and fibre, is excreted in a unoxidised form as methane or marshgas, and to this extent the value of the carbohydrate as fuel has been reduced.

The digestion of the proteins is a more complex process. The stomach secretes a gastric juice which is acid and also contains an enzyme called pepsin, by which the proteins are first attacked. Then in the small intestine the partly digested food is mixed with the pancreatic juice, which possesses an alkaline reaction and generates a second enzyme called trypsin, which also attacks the proteins. Both of these enzymes break down the proteins into peptones, albumoses, and successively more soluble amino-acids, which are able to diffuse through the walls of the intestine. There the simple nitrogen compounds are once more built up into proteins, and in that form are passed into the blood and led to the different parts of the body; though another view is that the soluble nitrogen compounds enter the 
blood, and are only re-formed into proteins by the cells which remove them from the blood. The greater part of the nitrogen compounds thus digested is oxidised into carbonic acid and water, the nitrogen part of the compound being eliminated from the blood by the kidneys, chiefly as the urea which is excreted in the urine. A part, however, of the digested protein-and this is really the indispensable part to the animalis used up for repairing nitrogenous waste in the tissues. In growing animals some of the proteins of the blood are stored up as lean meat; also, when there is an excess of protein in the diet, some of the carbon will be stored in the animal as fat, the nitrogen being again excreted as urea. When an animal is not putting on weight at all, the whole of the nitrogen that is digested is excreted again as urea and kindred bodies in the urine; the amount of protein required to repair the daily waste is comparatively small, and the excess is simply treated by the animal as fuel.

The fibre in the food analysis does not truly represent the indigestible portions of the food, for all natural foods except pure oil, sugar, and starch are only imperfectly digested; some part of the food resists the intestinal enzymes and bacterial processes and is excreted from the body in the fæces. As regards the nitrogenous compounds of food, it is important to remember that whatever is digested is afterwards excreted as soluble urea in the urine, while the undigested portions remain in an insoluble state in the dung. The non-protein nitrogenous bodies possess a much smaller food value than the proteins; as fuel they are not so valuable, while it is still a matter of debate to what extent they can replace proteins in repairing tissue waste. Apparently they can at least save waste of the proteins, and in 
ruminant animals they can become converted into proteins by the action of the bacteria in the intestinal tract. Little need be said about the mineral constituents of the food-the ash-though it is essential to build up the bones of the animal, and to supply the salts circulating in the blood. As with the other constituents, some of the contents of the ash are digested and excreted in the urine, some are excreted unchanged in the dung. Salt is one of the most important food constituents, since from it has to be made the hydrochloric acid which is secreted in the stomach, and is required for the digesting processes there proceeding. Phosphate of lime is also absolutely necessary; from it is built up the framework of the bones as well as the phosphorus compounds which occur in all parts of the body. Young animals soon become diseased if fed upon foods in which this constituent is deficient. Of course, besides these main constituents which run the machinery of the body - the fat, carbohydrates, proteins-foods contain a variety of other bodies which give flavour, and affect the disposition of the animal towards its food, although, as far as is known, they do not actually alter its digestibility. The question of flavour is as yet beyond scientific treatment, its influence must be left to the observation and judgment of the skilled feeder of cattle.

When the value of different foods comes to be considered, especially with the object of compounding rations for feeding stock, it is not sufficient to know the percentage of fat, proteins, etc., which the food contains, we must also know how much of each is digestible. For example, pure fat is completely digestible by the animal so that it is wholly burnt up within the body, yet the same fat when disseminated through the mass of a hard seed may, to a greater or less degree, escape the 
attack of the digestive ferments in its passage through the alimentary tract, and so be in part excreted unchanged. Obviously the test of non-digestibility is the occurrence of the material in the fæces, hence if we wish to determine the digestibility of a given food we must maintain an animal on a diet consisting of the food in question over a particular period. During this period the weight of the food given and the fæces excreted is exactly observed. Both food and fæces are analysed by the similar methods; the difference between the fat that has been fed and the fat contained in the fæces gives the proportion of this constituent that has been digested, similarly for the protein and the carbohydrates. When concentrated foods which cannot be fed by themselves are in question, e.g. linseed cake, a preliminary diet of hay alone is given and the fæces analysed, then for a certain period a known amount of linseed cake is added to the hay diet, and the change in the composition of the fæces is determined. Certain errors are inherent in this process; in the first place, it is impossible to mark off exactly when the fæces corresponding to a given diet begin and cease to be excreted. Then a certain amount of waste tissue containing nitrogen which had previously been stored in the body is always excreted into the intestine, and so gets reckoned as undigested protein. Again, the bile and other secretions provide matter which is soluble in ether but is not fat. Still the results obtained are close enough to the processes going on in digestion to be of real value. Greater discrepancies are introduced by the fact that the digestive power of one animal differs considerably from that of another, and besides this personal idiosyncrasy one kind of animal possesses greater digestive powers than another, especially for the cellulose and fibre portions of the food. It has already been mentioned 
how much more capable are sheep and cattle, with their complex stomachs, ruminating habits, and lengthy intestines, to deal with fibrous foods than are horses or even pigs, in the intestine of which animals the food remains for a much shorter period. Hence the digestibility of many foods depends upon the animal to which it has been fed, but these variations occur much more in dealing with such bulky foods as hay or straw than with the concentrated feeding stuffs. Of course, variations occur in the food itself; for example, hay cut before it is dead ripe is the most digestible, and the nitrogenous matter of hay is better digested when the food is rich in this constituent. In fact, we may say generally that rich foods are better utilised than poor ones, without regard to the fact that they contain initially a higher proportion of valuable constituents. Only when an excess of food is given does its digestibility decrease, a starving animal cannot get more than the normal amount of nutriment out of a given food. Again, the work that the animal is doing has little or no effect upon the digestibility of the food given to it. Cooking does not appear to increase the digestibility of any of the usual cattle foods; in fact, the digestibility of the proteins is reduced. Drying the food, as in making hay from grass or in curing maize forage, does not diminish the digestibility if the process is properly carried out. Making the grass into silage, so far from increasing, actually reduces the digestibility of such proteins as escape reduction to $a$-proteins by the process; it is a mistake to suppose that silage-making will convert worthless grass and similar waste products into valuable food. It has also been shown that while the addition of fats or proteins to a comparatively poor diet of hay and straw and roots causes no reduction in the digestibility of either the original diet or the additions, 
yet if carbohydrates are added to a hay or straw diet the digestibility of the proteins in the original diet is reduced when the added carbohydrates amount to more than ro per cent. of the fodder. Thus, roots should not be added to a hay and straw diet in greater proportion than 15 per cent. (reckoning both as dry matter), unless some concentrated protein food be given at the same time in order to maintain the ratio between nitrogenous and non-nitrogenous constituents of the food at a higher level than $\mathrm{I}$ to 8 .

Table XVII. (page 179), which is copied from a table compiled by Dr Crowther, of Leeds University, sets out the average composition of a number of the foods most commonly in use, together with the percentages of the same constituents that are in a digestible condition and one or two other factors which will be explained later.

The most concentrated of all foods are the meals and cakes, the latter being the residues left after crushing various oil-bearing seeds in order to extract as much oil as will come out by pressure alone. The composition of such cakes will vary with the nature of the seed and its origin, but the amount of oil in the cake can also be greatly modified by the extent of pressure put on and the temperature at which the crushing is conducted. With linseed cake in particular it is customary not to extract the oil as fully as would be possible, whereby the cake is enriched and at the same time rendered softer and easier of digestion. In some cases the oil is extracted by chemical means, but the seed residue is then generally used for manure; as a rule, rape seed is treated in this fashion because it is rarely pure enough to be used afterwards as cattle food, being often mixed with a considerable proportion of mustard seed. In the United Kingdom few cakes are used beyond those derived from linseed and cotton seed, and of 


\begin{tabular}{|c|c|c|c|}
\hline \multicolumn{3}{|c|}{ 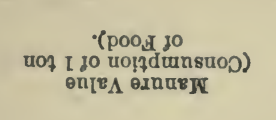 } & 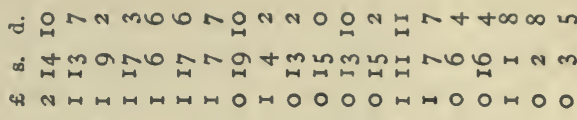 \\
\hline \multirow{10}{*}{ 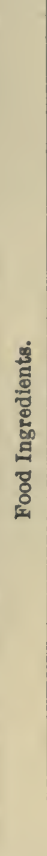 } & \multicolumn{2}{|c|}{ 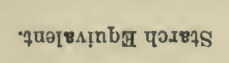 } & 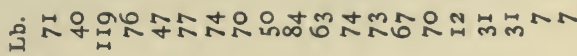 \\
\hline & \multicolumn{2}{|c|}{ 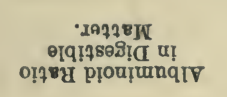 } & 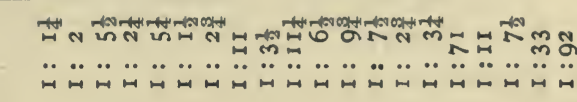 \\
\hline & \multirow{3}{*}{ 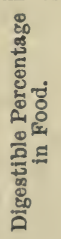 } & 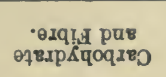 & 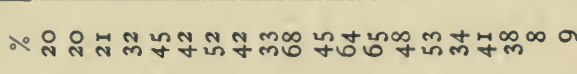 \\
\hline & & ‘!อ & শ゚ \\
\hline & & 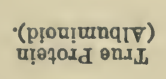 & 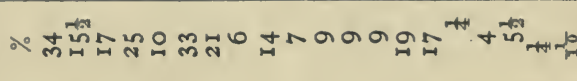 \\
\hline & \multirow{5}{*}{ 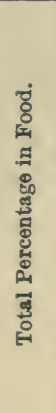 } & •өxq!, өpnID & 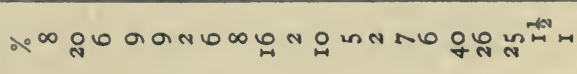 \\
\hline & & 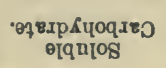 & 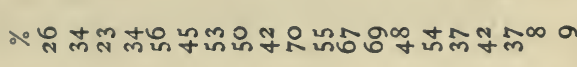 \\
\hline & & •I!O & 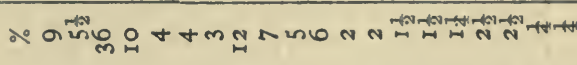 \\
\hline & & 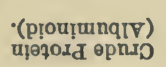 & 유 \\
\hline & & 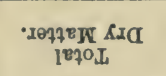 & 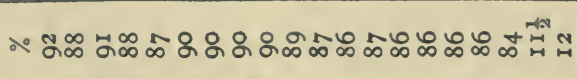 \\
\hline$y$ & $=$ & 1 & 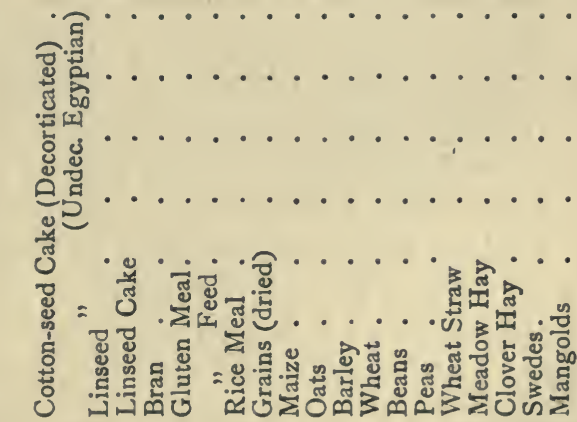 \\
\hline
\end{tabular}


recent years from soya beans; but earth-nut and palmnut cakes are sometimes obtainable and many other kinds of seeds are crushed, though the residues are usually worked into some of the compound proprietary mixtures which are so widely sold as oilcakes. Farmers are recommended to buy pure cakes made from one kind of seed only. As a rule, such cakes are cheaper intrinsically even though their price is higher, and they are much less subject to adulteration. Their greatest value, however, lies in the fact that the farmer knows exactly what he is using, and can come to definite conclusions for the guidance of his future practice.

These oilcakes constitute the richest and most concentrated of all cattle foods, in most cases also their digestibility is very high. At the head stands decorticated cotton cake, since cotton-seed meal still containing its oil unextracted is rarely seen in the United Kingdom, though it is commonly employed. for fattening cattle in the United States. The cake is made from cotton seed from which the husks have previously been removed, the undecorticated cake being made from the whole seed after the cotton fibre has been ginned off. Decorticated cotton cake is extremely rich in proteins and oil, and contains but little fibre; while it is an excellent food for bullocks fattening and for dairy cows, it must not be given to the latter anywhere near the time of calving, nor should it be fed to calves. There is evidence that it contains some substance which is at times disturbing or even poisonous to cattle, so that cotton cake must always be used with discretion. Undecorticated cotton cake is the favourite adjunct to the food of cattle fattening upon grass, especially in the early spring : it has certain astringent properties which correct the action of the young grass. When fed to milch cows cotton cake tends to harden and raise the 
melting-point of the butter made from their milk. In buying undecorticated cotton cake, care should be taken to see that it has not got heated or become mouldy-the smell and taste give fair evidence in this direction; of course an analysis is of great importance, to see that it contains no undue proportion of husk. The same precautions must be taken over undecorticated cake, of which many very inferior samples are made containing an excess of husk, sometimes ground to a powder to disguise it; an excess of cotton fibre also occurs, and is undesirable.

Linseed cake is the most highly esteemed of all the feeding stuffs; it is always relished by stock and never disturbs their health in any way, though if fed in large quantities to milch cows it is apt to render the butter too soft and oily. Linseed cake is particularly valued by graziers at the end of the fattening process, because nothing else will confer the sleek, shining appearance and kindly feel of the skin which comes to an animal "finished" on linseed cake. Linseed cake should be analysed and examined for purity; it should show no reaction when tested for starch, which would only be present as an impurity due to the seeds of weeds, for linseed itself contains no starch. Very hard cakes also are undesirable, because they are low in oil. There is evidence, however, that the very high content in oil which is often attained- 2 per cent. or over-is rather an expensive luxury, for just as good results can be obtained with poorer cakes supplemented by a corresponding amount of carbohydrate.

Soya-bean cake is so recent an introduction that little can yet be said of its specific actions or character, but it appears to be an extremely valuable food for all classes of stock. Gluten meal and gluten feed are residues obtained in the manufacture of various maize 
products, such as starch; they are in consequence foods specially rich in proteins, and have proved valuable in feeding milch cows and for young stock growing or in the early stages of fattening.

Of the cereals, oats are the richest, containing the highest proportions of both proteins and fat; they are valuable for all classes of stock, and always wholesome. Wheat requires more careful feeding, but barley again forms a very safe general food, containing a large proportion of carbohydrates. Experience has shown that the deficiency of barley in protein is best corrected by the use of cotton cake. Maize is chiefly a carbohydrate-containing food, and however valuable for work and for fattening, as regards its proteins it must be considered as rather a low-grade type of food. Beans and peas are both rich in proteins; they are amongst the most valuable of foods for either young growing stock, horses, pigs, or sheep ; an admixture of bean meal is also good in a ration for milch cows.

Oat straw is generally a little richer than either barley or wheat straw, but the variations in composition between oat straw from different fields or different varieties is greater than the differences between oat and barley or wheat straw. Only one analysis of straw has consequently been given in the table. The composition of hay is also very variable, because differences due to the making are also added to the differences induced by the nature of the herbage, the soil, or the season. Of the different roots, potatoes contain by far the most dry matter, (25 per cent.), then mangolds with about 12 per cent., swedes with a little less, and turnips with less than Io per cent. They are all in the main carbohydrate foods: the potato contains starch, the mangold sugar, while swedes and turnips contain various pectic bodies as well as sugars. A large proportion of their nitrogen 
is present in the form of non-protein compounds, as it is also in cabbage and all other green foods.

It is impossible to value feeding stuffs with the same measure of precision which attaches to comparisons of fertilisers, but certain estimates may be drawn up which are useful in considering the purchase of foods of the same class. Fats and carbohydrates may clearly be compared together, since both sets of bodies are used solely as fuel. Experiments which will be discussed later show that fats give rise to about $2 \cdot 3$ times as much heat as carbohydrates, whether compared in the calorimeter or in the body, so that we may value $\mathbf{I} \mathbf{l b}$. of fat at 2.3 times the value of $\mathrm{I} \mathrm{lb}$. of carbohydrate. Proteins besides their value as fuel are also necessary to repair waste; while no relation depending upon principle can be fixed between them and the carbohydrates, for commercial purposes they may be taken as equal to fats, i.e. at 2.3 times the value of carbohydrates. Thus if we wish to compare the values of decorticated cotton cake and of gluten meal, we can proceed as follows:-

\begin{tabular}{|c|c|c|c|c|c|}
\hline \multicolumn{2}{|c|}{ Constituent. } & \multicolumn{2}{|c|}{$\begin{array}{l}\text { Decorticated Cotton } \\
\text { Cake. }\end{array}$} & \multicolumn{2}{|c|}{ Gluten Meal. } \\
\hline $\begin{array}{l}\text { Fat } \\
\text { Protein } \\
\text { Carbohydrate }\end{array}$ & $\begin{array}{l}\cdot \\
\cdot \quad \\
.\end{array}$ & $\begin{array}{c}\text { Percentage. } \\
9 \times 2 \cdot 3 \\
41 \times 2 \cdot 3 \\
26\end{array}$ & $\begin{array}{l}\text { Food Units. } \\
\begin{array}{l}20.7 \\
94 \cdot 3 \\
26.0\end{array}\end{array}$ & $\begin{array}{c}\text { Percentage. } \\
4 \times 2 \cdot 3 \\
38 \times 2 \cdot 3 \\
45\end{array}$ & $\begin{array}{c}\text { Food Units. } \\
\begin{array}{c}9 \cdot 2 \\
87 \cdot 4 \\
45 \cdot 0\end{array}\end{array}$ \\
\hline 14 & & & $14 I \cdot 0$ & & I 4 I 6 \\
\hline
\end{tabular}

It would be far more correct to consider the digestible constituents only in such a valuation, in which case the feeding stuffs set out above would show II 8 and I26 units respectively, figures which ought not to be too widely departed from in the relative prices given for the foods. In the market, 
however, it will be found that the prices depend upon very different conditions, mainly of a commercial character, hence the grazier who values out the feeding stuffs on offer before purchase can generally obtain a substantial advantage. In a subsequent chapter, however, it will be shown that such a basis of comparison is only of value when dealing with concentrated foods; a more accurate basis of judgment is afforded by the starch equivalents which will then be explained. 


\section{CHAPTER $\mathrm{X}$}

THE UTILISATION OF FOOD BY THE ANIMAL

Food as a Source of Energy. Heat Value of various Foods. Energy consumed in Digestion and Internal Work. Maintenance Rations. Feeding for Rapid Work or Increase of Weight. Amount of Food required for a given Amount of Work. Nitrogenous Materials required to repair Tissue Waste. Minimum of Protein necessary.

So far, we have only discussed the composition of various foods and the process of digestion by which they reach the body; it is now necessary to consider the purposes which these foods serve, and their utilisation within the body. We will begin by looking at foods from the standpoint of energy: we have already indicated that an animal is an organisation which has to be continually fed with some external supply of energy in order to maintain its warmth and its power of doing work. It resembles water running downhill, in that when once started it runs on of itself; the transformation of energy continues as long as the material containing the energy is supplied, and during the transformation there is a certain wastage through change into low-grade, unusable forms of energy. The food and the oxygen together contain stored-up energy; like a reservoir of water at the top of a hill, they will run down into carbon dioxide and water, the energy being liberated as heat, just as the water will have parted with 
its energy as heat by the time it is at rest again at the foot of the hill. During the running-down process, also, in both cases a certain proportion of the stored-up energy can be converted into work or other forms of valuable energy; moreover, both processes will run of themselves if the sluice-gate be opened in one case, or the mixture be ignited in the other. The energy of all bodies, i.e. their capacity for doing work, is best measured in terms of heat, the unit usually employed in this sort of work being the large calorie, which is the amount of heat required to raise the temperature of I kilogram of water by I degree. This calorie has been valued against other kinds of energy; for instance, if the heat contained in the calorie were transformed into work, it would lift 425 kilograms I metre (or I.4 tons I foot); similarly, electricity or light can also be measured in terms of calories. To take an example, we can say that a given weight of coal possesses a certain amount of energy, which would be developed and measured as heat if the coal were burnt and the heat communicated to a known weight of water. But if the coal is burnt in a steam boiler, and the steam made to drive an engine, less than the whole of the energy of the coal will be found in the waste heat from the boiler and steam, because a certain proportion has been transformed into work. A dynamo will transform this moving energy into electricity with but a small loss by friction (i.e. with but a small reconversion into heat), and the electricity may be changed again into work, light, chemical energy, or other forms-the ultimate result being a running down into low-grade heat. The original stock of energy is never lost or destroyed, the sum total of the different forms developed being always that originally present in the coal; even when finally degraded into heat, there are still the original number 
of calories present. The difference is that such lowgrade heat has lost its effectiveness, and can no longer be transformed into work, light, or electricity. As another illustration we may take a watch: in the act of winding a certain amount of energy is communicated to it, and remains stored in the energy of the coiled-up spring. Gradually this energy is transformed into the energy of motion of the parts of the watch, which is just as continuously rubbed down by friction into heat which leaks away. There is no loss of energy; the world when the watch runs down contains a little more evenly distributed heat, exactly balancing the energy communicated to the coiled spring at the outset.

The total energy possessed by any food-that which is often called its fuel value-can be measured in the simplest fashion by actually burning in oxygen a given weight of the food in a vessel surrounded by a known quantity of water and observing the rise of temperature that ensues. This gives the maximum amount of energy available from the food, but the animal does not realise the whole of it except in the case of a pure fat or oil which is as completely burnt in the body as it is in the calorimeter. Most foods are not completely digested, hence the excreta contain some energy and must also be burnt separately in the calorimeter, the heat evolved being deducted from the total energy of the food in order to estimate what is available for the animal. The nitrogen of proteins, again, is excreted as urea, which is combustible and contains energy; this also must be burnt and the heat deducted from the fuel value of the food; also from all carbohydrates, and particularly from fibre a certain proportion of methane and hydrogen is produced in the intestine, and these unburnt gases represent losses of energy to the animal. For example, with oxen, 
Kellner obtained the following fuel values and heat values for certain typical foods, expressed in calories per gramme of food:-

TABLe XVIII.-Energy Developed by Various Foods.

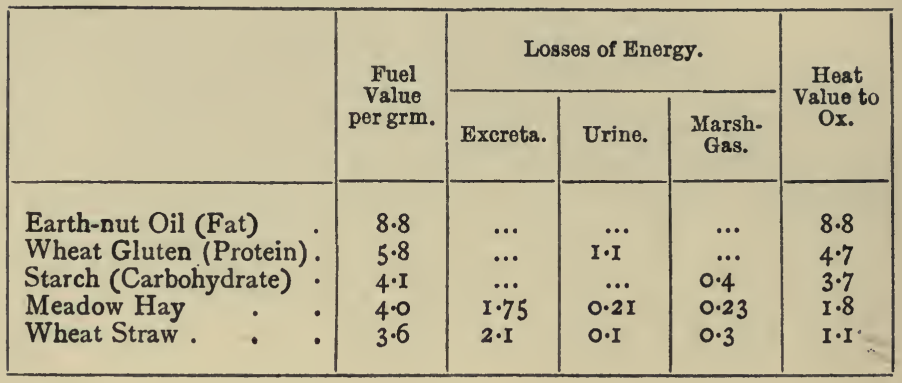

This table shows us that though in the calorimeter fat will develop $\frac{8 \cdot 8}{4 \cdot I}=2 \cdot 15$ times as much heat as starch, yet in the ox it will develop $\frac{8 \cdot 8}{3 \cdot 7}=2.4$ times as much, because in the digestion of the starch some of the material is excreted as methane which is still combustible and contains energy. Similarly proteins, which in the calorimeter have a heat value $\frac{5 \cdot 8}{4 \cdot \mathrm{I}}=\mathrm{I} \cdot 4$ times that of starch in the animal, possess $\frac{4 \cdot 7}{3 \cdot 7}=\mathrm{I} \cdot 25$ times the value of starch, because of the comparatively large proportion of undeveloped energy still contained in the excreted urea. We can then take as a basis these experimentally ascertained facts, that the heat value to the animal of a pure digested fat is 2.4 times that of starch, and that of digested protein is $\mathrm{I} \cdot 25$ times that of starch, and proceed to calculate the heat value of 
mixed feeding stuff in terms of starch. For example, roo lb. of meadow hay (Table XVII.) contains :-

\begin{tabular}{|c|c|c|c|}
\hline Constituent. & $\begin{array}{l}\text { Percentage } \\
\text { Digestible. }\end{array}$ & $\begin{array}{l}\text { Heat Value to } \\
\text { Animal } \\
\text { compared with } \\
\text { Starch. }\end{array}$ & $\begin{array}{l}\text { Total Starch } \\
\text { Units. }\end{array}$ \\
\hline $\begin{array}{l}\text { Fat } \\
\text { Protein } \\
\text { Carbohydrates and Fibre }\end{array}$ & $\begin{array}{rr}I & X \\
4 & X \\
4 I & X\end{array}$ & $\begin{array}{l}2 \cdot 4 \\
1.25 \\
1.0\end{array}$ & $\begin{array}{r}2 \cdot 4 \\
5 \cdot 0 \\
41 \cdot 0\end{array}$ \\
\hline & & & 48.4 \\
\hline
\end{tabular}

Thus, $100 \mathrm{lb}$. of meadow hay are equivalent to $48 \cdot 4 \mathrm{lb}$. of starch by calculation from the constituents, whereas Kellner found by experiment, as shown above, that when I of starch gave 3.7 calories, I of meadow hay gave I. 8 calories, or 100 of meadow hay give as much heat as $\frac{100 \times 1.8}{3.7}=48.7$ of starch, a sufficiently close agreement. If the animal is at rest, either fattening or on a mere maintenance diet (i.e. the minimum diet which will keep it stationary in weight), then the whole of the heat values of the foods expressed in the last column, less what is stored as fat and flesh, will be developed in the animal's body, and will go to keep it warm. If, however, the animal is at work, then the amount of energy thus developed will not appear as heat inside the animal. It is, of course, true that even when at rest in the stall the animal is doing a certain amount of internal work, but this internal work being done inside the body is there reconverted into heat without loss; it is only work outside the body, as in drawing a cart or turning a mill, that is lost as animal heat, because it is converted into some other form of energy that can be stored outside the body. But as regards the internal work of the 
body, we must make a distinction between the work done in carrying on such movements as breathing, the circulation of the blood, etc., which are bound up with the life of the animal, and the other work of digestionmastication, swallowing, the motions of the stomach and intestines-which will vary in amount with the nature of the food supplied. Pure fats and carbohydrates like sugar can be digested with a minimum of exertion, but when the same substances are found in food-stuffs entangled among the fibres of tough materials like hay and straw, the animal may have to do a good deal of work in breaking down the food before the enzymes can get at the digestible constituents, and this work has to be derived from the combustion of some previously digested food stored up in the body, i.e. eventually from the energy contained in the food itself. If, then, for any food-stuff we begin by estimating a certain number of calories as its heat value, which heat value is the measure of the energy it can liberate in the body, we shall have to make a deduction for the energy used up in digestion before we can get at the energy remaining that is available for work or for such purposes as putting on fat. If, incleed, the work spent in the digestion of a given food is very large, it may approach or even exceed its total heat value, and so leave no margin for either the internal or external work of the body. Of course, the energy thus spent either in digestion or internal work is still transformed into heat, whereby the animal is kept warm; hence an animal at rest on a maintenance diet, the heat value of which just supplies enough energy for both digestion and internal work, will still maintain its animal heat, and will even be able to increase it by a greater consumption of food if it is forced to make up for greater losses of heat by being put to live under colder conditions. But 
if all the energy derivable from the food is spent in effecting digestion and internal work, there will be no margin left either for external work or the production of increased weight, hence, however much food the animal ate, it can never do any work nor grow any heavier. This condition, when the energy derived from the food is wholly or even more than balanced by the energy required for digestion, is realised in the case of a horse feeding upon straw, which is very fibrous, so that the work required is great and a large proportion remains undigested, while of the digested carbohydrate about one-fifth is lost as methane. Zuntz found that the horse actually consumes more energy in digesting straw than is contained in the portion digested, and this is confirmed by an experiment of Müntz, who fed a horse on straw alone. Although the horse was allowed an unlimited amount of straw it died at the end of about two months, thoroughly exhausted because it had been compelled to draw upon its body. Again, Kellner, in experiments with oxen, which are better able than horses to deal with foods like straw, found that more than four-fifths of the energy contained in the digested part of the straw was consumed in the digestion processes, leaving less than one-fifth available for work or increase. When, however, the straw was made into a pulp by the processes employed by papermakers, who disintegrate the cellulose by boiling with an alkali under pressure, as much as 88 per cent. of the straw was digested, and of this digestible matter a little more than a third only was consumed in effecting digestion.

So fundamental are these considerations regarding the total and available energy of foods, that we may recapitulate: the total energy resident in any food is measured by the heat it will evolve on burning, and is called its fuel value. From this fuel value must be 
deducted the fuel value of the undigested excreta, and also of the incompletely oxidised urea and the gases evolved in the intestine, in order to obtain the energy available for the animal-the heat value of the food. All this energy is available for the maintenance of the heat of the animal, but a certain proportion is spent in the work of digestion, and it is only the surplus that is available for the internal and external work performed by the animal or for the increase of weight that it may be putting on. If the food is being added to the maintenance ration, all the surplus will be available for external work or for increased weight. We can now define the surplus energy which a food will give out over and above the work required for its own digestion, as the "dynamic" energy of the food, and it is this dynamic energy alone which is available for performing work or for giving rise to increased weight. Thus we distinguish the total energy or fuel value of the food, the heat value or thermal energy, and now the dynamic energy or value for work and production.

One or two examples may perhaps make this more clear.

Taking decorticated cotton cake we may on its analysis calculate the "fuel value" from the experimentally determined facts that I gramme of oil (in such seed cakes) produces 9.2 calories on combustion, I gramme of protein and $I$ of carbohydrate producing 5.8 and 4. I calories respectively. From 100 grammes of decorticated cotton cake we therefore obtain a fuel value of 460 calories as follows :-

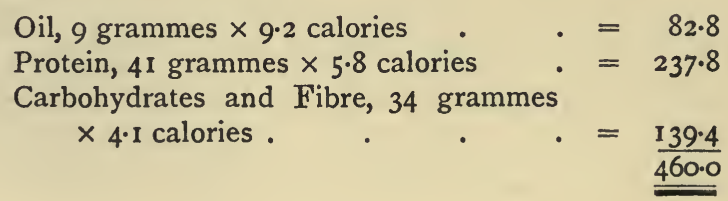


Deductions must now be made for the undigested part of the food, for the urea and the methane excreted, as follows :-

Undigested Oil, 0.5 grammes at $9 \cdot 2$ cals. $\quad .=4.6$

Undigested Protein, 7 grammes at 5.8 cals..$=40.6$

Undigested Fibre, 14 grammes at 4.1 cals. $=57.4$

Urea from 34 grammes digested protein at

I.I calories . . . $=37.4$

Methane from 20 grammes digested carbo-

hydrates, etc., at 0.4 calories

$\cdot=\frac{8 \cdot 0}{\underline{148 \cdot 0}}$

Deducting these 148 calories from the fuel value, 460 calories, we get 312 calories as the heat value of the cotton cake. We have now to make a further deduction of 3 per cent. (or 9 calories) as the internal work spent in digestion, leaving $3 \mathrm{O} 3$ calories as the dynamic energy of 100 grammes of decorticated cotton cake available for transformation into work or storage as fat in the animal; though, as will be seen later, only a certain fraction of this can be so converted or stored.

Let us now compare meadow hay, calculating on the same lines:-

2.5 grammes fat at 8.2 calories . $\quad=20.5$

ro grammes protein at 5.8 calories . $\quad=58.0$

68 grammes carbohydrates and fibre at 4.I cals. $=278.8$

Calories, fuel value $\underline{\underline{357 \cdot 3}}$

Deductions :-

Undigested Fat, 1.5 grammes at 8.2 calories . $=12.3$

Undigested Protein, 6 grammes at 5.8 cals. . $=34.8$

Undigested Fibre, 27 grammes at 4.1 cals..$=110.7$

Urea from 4 grammes digested protein, at

I.I calories

Methane from $4 \mathrm{I}$ grammes digested carbohydrates, etc., at 0.4 calories

. $=4 \cdot 4$

$==\frac{16 \cdot 4}{178 \cdot 6}$ 
Deducting this from the fuel value we get $357 \cdot 3-$ I 78.6 $=178.7$ calories as the heat value of 100 grammes of meadow hay. But from this we have to deduct 40 per cent. for internal work spent in digestion, or 71.5 calories, leaving only 107.2 calories as the dynamic energy of 100 grammes of meadow hay. Thus the meadow hay, while it possesses more than half (I78 compared with 312 ) the heat value of the cotton cake-i.e. is more than one-half as effective in keeping up the heat of the animal on a maintenance ration-has yet only about one-third of the value of cotton cake (107 as against 303) towards doing work or putting on increased weight.

Bearing these principles in mind, we may trace certain simple practical consequences. Rough, coarse fodders like hay or straw, poor grass, roots, etc., serve perfectly well for keeping animals in store condition, for though they require a considerable expenditure of energy for their digestion there is enough margin to carry on the internal work of the body and the whole energy is afterwards available as heat, while the animal has only to be kept warm and is neither working nor increasing in weight. Similarly, animals that are at slow work and are never called upon for any great output of energy in proportion to their weight, can be fed upon bulky lowgrade fodders which do not develop any great surplus of energy. But when animals are growing rapidly or are performing heavy and rapid work, then comparatively rich and concentrated foods are necessary, foods which develop a large surplus of energy over that which is required for their digestion. A horse standing in the stable may be fed on nothing but hay, just as a horse out at grass needs only a little hay besides the old grass even in severe winters, but as soon as the horse is worked, instead of more hay it must be given corn of some kind; and a racehorse, on which great calls are 
made for a sudden and excessive output of energy, must have the most concentrated and digestible foods that can be obtained. No increase in the amount of the lower-grade foods will compensate for their lack of concentration, because so much time would be spent by the animal in heaping up the necessary surplus energy. To take another example, cattle or sheep will never grow fat in one season on the grass growing on the majority of fields, however great an area they may be given to graze; it is only on certain choice fattening pastures that the increase is rapid enough to prepare an animal for market without artificial assistance. On the ordinary grass lands the animal spends so much of the energy obtained from its food in digesting it that the surplus left for production does not permit of rapid growth; on the fattening fields the grass possesses a smaller proportion of fibre, and therefore less of its heat value is wasted in the digestion processes.

Similarly, in the last stages of fattening animals in stalls carbohydrates are of much less value than they are at an earlier period, because they call for an expenditure of energy in digestion which is disproportionate to the increase they produce at that stage, when the increase bears a very small ratio to the food consumed, whereas much less of the energy of fats and proteins is wasted in the digestion process.

Treating food from this point of view as supplying energy to the animal, we may now proceed to consider the animal's requirements under different conditions. The simplest case is, of course, that of the animal at rest on a maintenance diet, so that it is neither increasing nor diminishing in weight. As the temperature of the animal is always higher than the surrounding atmosphere (from $100^{\circ}$ to $104^{\circ} \mathrm{F}$., varying with the animal), a constant loss of heat is going on from the surface of 
the body, and the food supply must be sufficient to repair this loss or the animal will be forced to consume some of its previously stored-up fat or flesh. All internal work, including that done during digestion, reappears as heat, so that as long as the food is above the grade of straw and contains more available energy than is required for the digestive process, the food is only called upon to repair the losses of heat and maintain the body temperature; the work required for digestion, respiration, and other bodily processes being performed by the way without interfering with the final production of heat, because it is work done inside the animal. In other words, the maintenance diet contains just enough energy to drive the machine when it is running idly with the animal at rest, and in the running of the machine the food energy is transformed into heat which keeps up the body temperature. Actually on most diets, even maintenance rations, the energy required by the resting animal to maintain its temperature is greater than that required for internal work; some of the food is burnt simply and solely as fuel for warming, and the amount of food required will be determined only by the heat lost by the animal. The magnitude of this factor will vary with the size of the animal, or rather with the surface it possesses, because heat is lost only from the surface. Now the smaller the animal the greater is its surface in proportion to its weight (a cubic foot of water weighs $62.5 \mathrm{lb}$. and has a surface of 6 square feet; a cube 2 feet on the side would weigh eight times as much, but only have a surface of 24 square feet, i.e. four times as much as before); hence small animals will require for maintenance more food in proportion to their weight than large ones. Of course, the greater the difference in temperature between the animal and its surrounding air the greater will be the loss of heat and 
the consumption of food to repair the loss; hence the truth of the old saying that shelter is as good as a meal. Heat may also be required, and, therefore, food consumed in raising the temperature of the food and water to the body temperature, and this may be considerable when large quantities of very cold water, or roots which contain nearly 90 per cent. of water are consumed at a freezing temperature. This, however, would only affect animals on a maintenance ration when the food is reduced to the minimum necessary to keep the animals warm; on fattening rations there is always a surplus of heat that cannot be utilised in any other way. Leaving, however, such cases out of account, Kellner has drawn up the table from which the diagram, Fig. 23 , has been constructed, showing the heat value of the food required for the maintenance of store bullocks of various weights when they are kept at rest at a temperature of about $60^{\circ} \mathrm{F}$. The solid line expresses the number of calories which the digestible part of the food must give out per day in order to keep the animal in a stationary condition; these calories can be converted into terms of food by calculating that I lb. of digestible organic matter in an ordinary ration will evolve about I 600 calories, and I $\mathrm{lb}$. of starch about I 700 calories; the dotted line gives the equivalent in starch of the solid line. A fat bullock weighing about $1750 \mathrm{lb}$. requires about 20,000 calories heat value in its daily food in order to keep it going. The maintenance requirements of a horse are very similar to those of a bullock ; according to Zuntz, the maintenance ration of a horse at rest must evolve about 12,100 calories per diem, and not more than two-thirds of this energy must be expended in the work of digestion. Sheep have rather greater requirements in proportion to their weight, because of their smaller size and therefore larger proportional 
surface, and also because of their higher temperature; a sheep weighing Ioo $\mathrm{lb}$. requires digestible food which will develop about 2000 calories, i.e. $1000 \mathrm{lb}$. of sheep requires 20,000 calories, whereas $1000 \mathrm{lb}$. of lean cattle only require about II,000 calories. All these figures, however, refer only to maintenance diets, when the animal is doing no work and not putting on flesh. As soon as work has to be performed the number of calories required jumps up : for example, a horse weighing I IOO $\mathrm{lb}$., and carrying harness weighing about $20 \mathrm{lb}$., will perform about II 50 foot-tons of work in walking Io miles at a pace of $2 \frac{1}{2}$ miles an hour; this will be increased to about 1440 foot-tons at $3 \frac{1}{2}$ miles an hour, and to about 2200 foot-tons when trotting at 7 miles an hour. Foot-tons can be transformed into calories directly on the basis that $\mathrm{I} \cdot 4$ foot-tons of work will yield I calorie when degraded into heat by friction, but the converse change cannot be made so readily, because a large proportion of the heat must always be left unutilised in its conversion into work. A steam engine, for example, is a machine for transforming heat energy into mechanical energy, yet at its utmost efficiency we can barely get out in work one-seventh of the energy contained in the coal, the rest being evolved in waste, low-grade heat. From this point of view the animal is a much more efficient machine than a steam engine, for it is able to convert into mechanical work about one-third of the available energy it derives from its food, i.e. of the "dynamic" energy of the food. According to Zuntz's experiments, a horse can turn out about 770 foot-tons of work for each pound of available food, reckoned as usual as starch, given in addition to the animal's maintenance diet-the available food being, however, the equivalent of what we have hitherto called dynamic energy, or the value of the food for work, i.e. 
Heat

Starch

Value

of Food

Equiva-

Calories.

lent.

ILb.

20,000

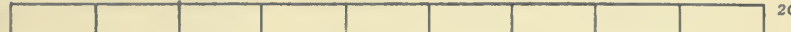

Live weight,

Ib.

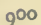

1000

1100

1200

STARCH EQUIVALEN

Fig. 23.-DIAGRAM SHOWING THE ENERGY REQUIRED FROM THE FOOD BY OXEN OF DIFFERENT WeIghtS. 

after deductions have been made for energy spent in digestion, etc. As different foods possess different amounts of available energy, Zuntz has constructed the following table for the horse :-

Table XIX.-Available Energy of Various Foods.

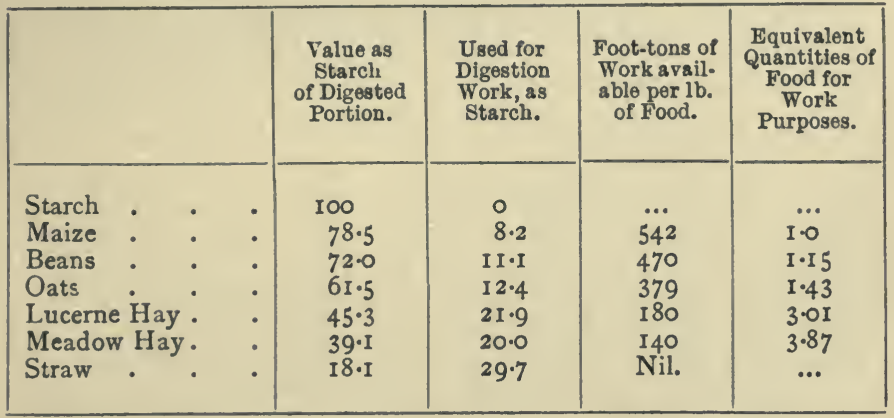

This table means that the digestible portion of a pound of maize has a heat value to the horse equal to that of rather more than three-quarters of a pound of starch; nearly ro per cent. of this heat value is used up in the work of digesting the maize, but from the available energy remaining the horse can put out 542 foot-tons of work. On meadow hay, however, although it contains just half the quantity of digestible food, yet so much energy is consumed in digestion that the balance only enables the horse to put out 140 foot-tons of work, or only one-quarter the work that can be done on the maize, though the food yields half as much digestible matter. In the case of straw there is no margin at all left for work. We also see that if the addition of $\mathrm{I} \mathrm{lb}$. of maize to a horse's diet enables him to do a certain amount of work, I.43 lb. of oats or $3 \mathrm{lb}$. of lucerne hay would be necessary to replace the maize and turn out the same amount of work. Similarly, it was found that when a horse walked $12 \frac{1}{2}$ miles a day, $20 \mathrm{lb}$. 
of hay would keep it in condition; if it drew a load that added 1943 foot-tons to its work, $26.4 \mathrm{lb}$. of hay were needed; while $24 \mathrm{lb}$. were insufficient if the horse trotted without a load. The load meant $6.4 \mathrm{lb}$. extra of hay, and according to our table a better effect would have been produced by substituting $2 \mathrm{lb}$. of maize.

It is difficult as yet to apply these kind of calculations to practice because of the impossibility of estimating with exactitude the amount of work performed by a horse in any operation, but we may assume that at ordinary heavy work like ploughing, a horse will be doing about 1000 to I IOO foot-tons of work per hour. To do this work, $2 \mathrm{lb}$. of maize, $2 \frac{1}{4} \mathrm{lb}$. of beans, or nearly $3 \mathrm{lb}$. of oats will be required; or for an eight-hour day's work, about $20 \mathrm{lb}$. of mixed corn. 'To this must be added, not the whole maintenance requirement of the horse, because his heat requirements will be satisfied by the development of heat from the muscular work spent in the body and in digestion, but instead about a third of the whole amount in order to do the work of respiration and circulation, i.e. about $3 \mathrm{lb}$. more of corn. If some of this corn is replaced by its equivalent in hay we get a fair approximation to the ordinary working rations of a farm horse, and these can be adjusted on the principle that every hour's work is equivalent to between $2 \mathrm{lb}$. and $3 \mathrm{lb}$. of corn. These figures are contained more exactly in the following table, derived from Kellner, where the horse is made to work under experimental conditions, walking at the rate of about $2 \frac{1}{2}$ miles per hour, against the draught indicated, for eight hours a day.

The concentrated foods like oats, beans, or maize yield very nearly their full value in starch equivalents for all the digestible constituents of the food, i.e. nearly all the digestible constituents are available for work. But, as 
we have explained before, with the coarse fodders much of the energy is spent in the work of digestion, so that only a portion is available for work, though all the heat value is available for maintenance. In the ordinary horse ration, we may deduct about Io per cent. from the digestible food constituents reckoned as starch in order to obtain figures comparable to those given in the bottom line of the table. In a later chapter more exact figures will be given for the starch equivalent.

TABLE XX.-Energy ReQuirements of Working Horses.

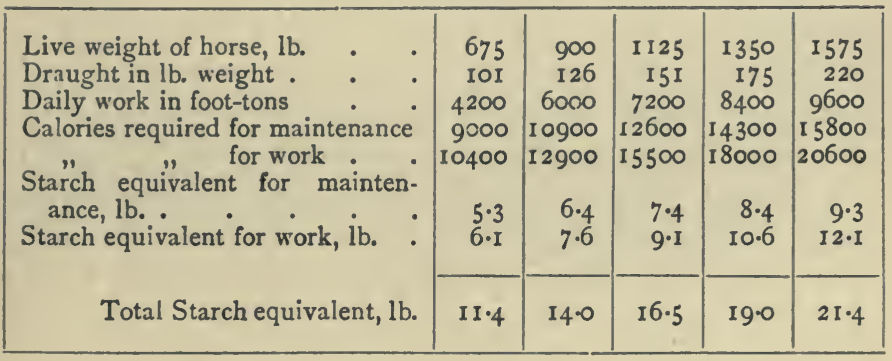

So far, the food has only been considered as a source of energy, and this is much its most important function, so that the best measure of the value of a food is the amount of available energy it possesses. Food, however, has also to effect the renewal of the tissues of the body, and this function must be considered independently of the supply of energy.

An animal cannot be maintained without a certain minimal supply of protein containing nitrogen, and though the protein can supply energy and when in excess can even give rise to fat, its prime purpose is to repair the nitrogenous waste of the tissues, and for this no other nutrient will suffice. Proteins give off heat when burnt in the body and so can take the place of fats or carbohydrates, but as these two latter con- 
tain no nitrogen they cannot do the special work of the proteins. We have already briefly indicated the metabolism suffered by the proteins in the diet; they are broken down by the enzymes of the stomach and the intestine into comparatively simple amino-acids and amides, and in this form are absorbed by the walls of the stomach and intestines. It is still in doubt whether they are there reconverted into proteins which pass into the blood, or whether the blood is given the simple split products resulting from the enzyme action. The end result is the same in either case, the nitrogenous compounds are carried always in the blood-stream and so reach successively every cell in the body where such materials.are absorbed as are required to maintain the structure of the cell; at the same time the cell hands over to the blood the waste nitrogen products excreted by the cells. The amount of nitrogen compounds thus taken up for tissue repairs and renewals is only a small portion of the nitrogenous compounds entering the blood from the food, unless the animal has been placed on a minimal ration which barely maintains a nitrogen equilibrium. As a rule, the animal is receiving more protein than is absolutely necessary, but when the blood containing the digested protein products passes through the kidneys the nitrogen part is split off in the form of urea and only non-nitrogenous compounds are passed on, to be used for generating energy or forming fat as need may be. This accounts for the rapid excretion of urea after a meal, when it cannot be supposed that time enough has elapsed to give rise to an amount of tissue waste equivalent to the urea excreted. Thus we must distinguish between the excreted nitrogen compounds, which are due to tissue waste and represent the indispensable nitrogen requirements of the body if 
its equilibrium is to be maintained, and the other nitrogen compounds (urea only, probably) split off from proteins which are being used as mere sources of energy, though both kinds are excreted together in the urine. The former quantity of nitrogen, the minimum required to repair tissue waste, can be measured either by putting the animal on a purely nonnitrogenous diet and seeing how much nitrogen is excreted under such conditions of nitrogen starvation, or, more accurately, by gradually reducing the protein in a ration supplying the proper amount of energy until a limiting condition of nitrogen equilibrium is reached when any further diminution in the protein fed results in the excretion remaining greater than the intake, after the first disturbance due to the change of diet has passed away. In this way the minimum requirements of protein for oxen or horses on a maintenance diet appear to be about $\frac{1}{2} \mathrm{lb}$. per day per $1000 \mathrm{lb}$. live weight ; for sheep this quantity must be nearly doubled, because of the comparatively large draught on protein for the growth of wool, which cannot be brought to a standstill like the formation of flesh. It is, however, never safe in feeding animals to get down to this minimal limit ; the digestibility of the carbohydrates in the ration is reduced if the proteins are low, especially when the rations are large, because the animal is then called upon to secrete an increased amount of enzymes which are themselves nitrogenous bodies. Moreover, it has been shown that respiration is quickened, the circulation is more vigorous, and the temperature is raised a trifle, if the supply of proteins is above the absolute minimum. There is another point of view also to be considered : though the proteins form a great natural group of substances having many characters in common, which can be further grouped into smaller 
classes of still more similar substances, yet it is probable that each species of animal and plant builds up a protein special to itself and differing somewhat from all others. In order to build up its special body protein an animal must be supplied with the right units, i.e., the simple amino-acids, amides, etc., which are produced by the splitting-up of proteins by enzymes, and those units which the animal does not require will be useless to it as nitrogenous food, though they will be burnt as usual to supply energy. Some food proteins also may be without a unit that is essential to the building-up of the body protein; thus it has been shown that zein, the particular protein of maize, will not maintain the nitrogen equilibrium of rats or mice. However, much of it is fed, they eventually die of nitrogen starvation, because the zein molecule lacks a particular constituent which is an essential part of the body protein of these animals. If, however, a very small quantity of this particular substance is also supplied, then the animal begins to utilise the zein split products and form its necessary body protein, because it has also obtained the necessary keystone of the structure. Thus we see that the animal must have more products of protein digestion presented to it than it actually uses, because it has to pick them over in order to select the indispensables in the right proportions; moreover, the diet should contain some variety in the proteins supplied, in order to make certain that no essential constituent is deficient.

The food of an animal not increasing in weight should therefore be considered from two points of view-it must supply sufficient energy for the calls upon the animal for work, and at the same time it must contain sufficient protein to repair the tissue waste that an animal always experiences even during. starvation. Energy is supplied by all kinds of food that are com- 
bustible-most by fat, less by proteins, less still by carbohydrates and crude fibre as far as it is digestibleand the amount of energy that must be supplied by the food depends simply upon the amount of work done by the animal. In animals at rest energy is only required to perform the operations of mastication and digestion, internal work like breathing, and to maintain the temperature of the body, though the heat developed in performing the former functions may be sufficient to keep up the bodily heat. When an animal is at work combustion is going on so rapidly that far more heat is developed than is necessary to the maintaintence of the normal temperature, and the excess is got rid of by an increased evaporation of water from the lungs and the skin, for the animal's temperature never rises sensibly as long as it is healthy. In addition to food supplying the necessary energy, the animal must also receive at least a minimal amount of protein which it can utilise for tissue formation; any excess is rapidly reduced to non-nitrogenous combinations and then burnt up for the development of energy like any other food.

From the point of view of the food, we must consider that it contains first of all a certain store of energy measured by its value as fuel, from which to begin with we must deduct the energy of the indigestible portions, and the energy still possessed by excreta like urea and marsh-gas, in order to get the heat value of the food to the animal. Further still, we must deduct from this value the work spent by the animal in masticating and digesting the food if we are to obtain the energy value of the food to the animal-i.e. the surplus remaining out of which it can do work. We now want an expression for the protein value of the food, and to do this we are accustomed to calculate the ratio between the nonnitrogenous food constituents and the protein. To make 
the comparison fair, the non-nitrogenous food constituents must be reckoned in terms of carbohydrates by multiplying the fat by 2.3 and adding it to the carbohydrates and digestible fibre; the ratio of the sum of these constituents to the digestible protein is known as the albuminoid ratio. If the albuminoid ratio is to be a figure of the slightest value in judging of a food ration, it must be calculated on the digestible constituents only and not on the analytical composition simply, as is so often done. An albuminoid ratio of $5: \mathrm{I}$ or less is said to be narrow; when it approaches 10: I or I $2:$ I it is called wide. The ratio is of comparatively little importance in connection with the cases we have just been discussing-animals at work and not increasing in weight; but when we are dealing with animals which are growing and increasing in weight, which, therefore, especially in the younger stages, are adding to the amount of body protein they contain, or again with animals which are secreting milk, the albuminoid ratio becomes of more value in forming a judgment of a ration. This most important side of feeding will be considered in the following chapter. 


\section{CHAPTER XI \\ FOOD REQUIRED BY THE GROWING AND}

FATTENING ANIMAL

Composition of Lean and Fat Animals. Food required to Produce a given Increase of Live Weight. Starch Values of Foods. Albuminoid Ratio. Food Rations for various Purposes based upon Starch Values.

IN the previous chapter we have only considered food as a source of energy to the animal, maintaining its temperature, and then supplying it with energy by which it may carry out its bodily functions and perform work. But the farmer is usually concerned with animals which are growing and increasing in weight, and we have now to ask ourselves to what extent the food is utilised in these processes. The foundation of our conclusions must rest upon the knowledge of the composition of the animal's carcass in different stages of its life, and this knowledge was obtained at Rothamsted, where Lawes and Gilbert had a number of animals slaughtered in different stages of fatness, and determined stage by stage the composition of the body of each. The following animals were selected :- $a$ fat calf, a halffat and a fat ox; a fat lamb, a store sheep, three other sheep in a half-fat, fat, and very fat condition; a store and a fat pig. The animals after slaughter were carefully divided, and the weights of the different parts of the carcass and the offal were determined; afterwards 
the proportions of water, fat, protein, and ash in each part were determined, with the results set out in Table XXI. and further illustrated in Diagram No. 24. On

TAble XXI.-Percentage Composition of Carcasses of Animals in Different Stages of Fattening.

\begin{tabular}{|c|c|c|c|c|c|c|}
\hline & 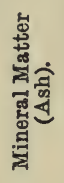 & 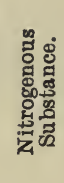 & 密 & 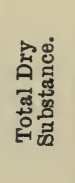 & 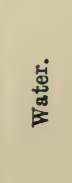 & 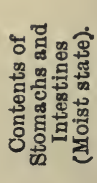 \\
\hline Fat Cal & 3.80 & I 5.2 & 14.8 & 33.8 & 63.0 & $3 \cdot 17$ \\
\hline Half-fat & 4.66 & I6.6 & $19 \cdot I$ & $40 \cdot 3$ & $5 I \cdot 5$ & 8.19 \\
\hline Fat $O x$ & 3.92 & 14.5 & & $4^{8.5}$ & $45 \cdot 5$ & 5.98 \\
\hline Fat Lan & 2.94 & I $2 \cdot 3$ & 28.5 & $43 \cdot 7$ & $47 \cdot 8$ & 8.54 \\
\hline Store Sh & $3 \cdot 16$ & I4.8 & 18.7 & 36.7 & $57 \cdot 3$ & 6.00 \\
\hline Half-fat & $3 \cdot 17$ & 14.0 & 23.5 & 40.7 & $50 \cdot 2$ & 9.05 \\
\hline Fat She & $2.8 \mathrm{I}$ & I $2 \cdot 2$ & $35 \cdot 6$ & $50 \cdot 6$ & $43 \cdot 4$ & 6.02 \\
\hline Extra F & $2 \cdot 90$ & 10.9 & $45 \cdot 8$ & $59 \cdot 6$ & $35 \cdot 2$ & $5 \cdot 18$ \\
\hline $\begin{array}{l}\text { Store Pi } \\
\text { Fat Pig }\end{array}$ & 2.67 & 13.7 & $23 \cdot 3$ & $39 \cdot 7$ & $55 \cdot I$ & $5 \cdot 22$ \\
\hline Fat Pig & I. 65 & & $42 \cdot 2$ & $54 \cdot 7$ & $4 \mathrm{I} \cdot 3$ & 3.97 \\
\hline & 3.17 & 13.5 & $28 \cdot 2$ & $44 \cdot 9$ & $49 \cdot 0$ & 6.13 \\
\hline & 111 & UF & PT & IN $\mathrm{I}$ & TTEN & \\
\hline Oxen & 1.67 & $9 \cdot 16$ & $75 \cdot 36$ & $86 \cdot 19$ & I $3.8 \mathrm{I}$ & ... \\
\hline Sheep & $2 \cdot 34$ & $9 \cdot 47$ & $79 \cdot 87$ & $91 \cdot 68$ & $8 \cdot 32$ & $\ldots$ \\
\hline Pigs & 0.06 & $6 \cdot 50$ & 78.00 & $84 \cdot 56$ & 15.44 & $\cdots$ \\
\hline
\end{tabular}

looking at these results, it will be seen that the process of fattening is very much what its name implies. As the animal puts on weight, there is little or no increase in the proportion of either the ash or the protein, but the fat gains steadily at the expense of the water. Of course, as an animal is increasing in weight during the fattening, the actual amount of protein matter it 


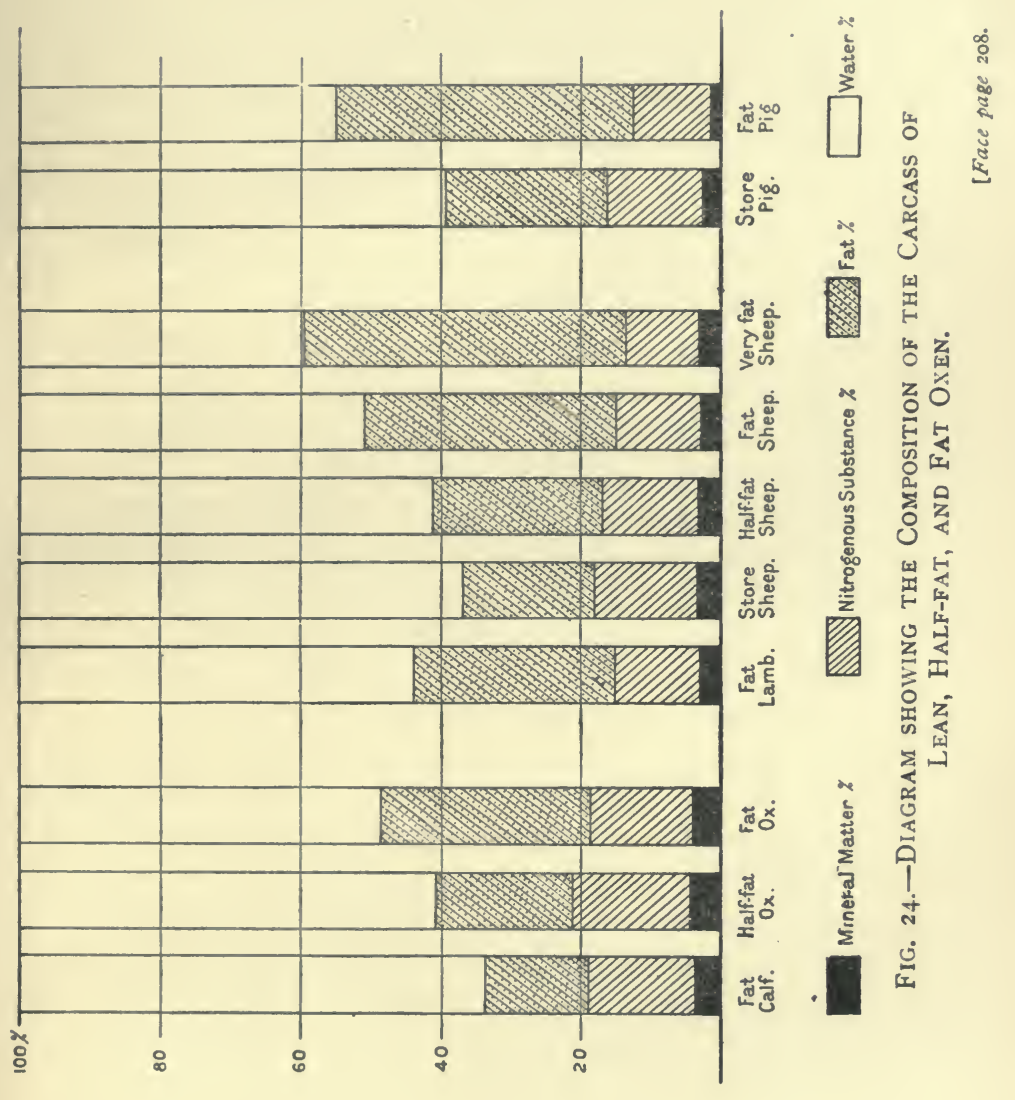



contains does also increase, but not so rapidly as the fat, so that its percentage of the total weight actually falls off. It should also be noticed that the fat animal contains a smaller proportion of water than the same animal in a store condition, lean meat is a much more watery substance than fat, so that the accumulation of fat tends to reduce the proportion of water in the whole body. If we can assume that the different animals slaughtered in the various stages of fatness fairly represent the kind of changes that the single animal would have gone through while it was being fattened, we can use these figures of Lawes and Gilbert to ascertain the composition of the increase in live weight which the animals put on in passing from the store to the half-fat, and from the half-fat to the fat condition. It will then be found that in the case of oxen which are being steadily fattened from the time they are young, the increase of weight will consist of about one-third water and two-thirds dry substance, about three-fourths of the latter consisting of fat. In the final finishing stage, when the animal is fully grown, about three-fourths of the increase will be dry matter, 90 per cent. of which will consist of fat. In the case of sheep, there is more mineral matter in the increase because of the amount of alkaline salts in the wool; but despite the nitrogenous nature of the wool, the live weight increase of sheep is even less nitrogenous and more fatty than that of oxen. In fact, about 75 per cent. of the increase of weight in fattening sheep is made up of fat itself. In the case of heavy fat pigs the increase put on is still less nitrogenous and more fatty, there being about 80 per cent. of fat and only 7 per cent. of nitrogenous matter in the increase. While these figures give us a pretty clear idea of the nature of the changes that are going on when the animal is fattened, they do not tell us how the 
food gets utilised nor what proportion of it is stored up within the animal. It is obvious that the animal by no means adds to itself the whole of its food, or even the whole of what it digests. We have already seen that a considerable proportion of food is required simply for maintenance, being burnt as fuel to keep up the heat of the body and carry on the internal work of the organs. But even if we make deductions of the matter used for maintenance, we shall not find that the rest of the digestible food is stored up in the body of the fattening animal. Lawes and Gilbert put together a large number of statistics relating to animals being fattened in the ordinary way upon the farm; determining their weight from time to time, and the weight and composition of the food which they had been receiving. From these results Table XXII. was constructed, which shows

\section{Table XXII.-Relation of Food consumed to Live WEIGHT INCREASE.}

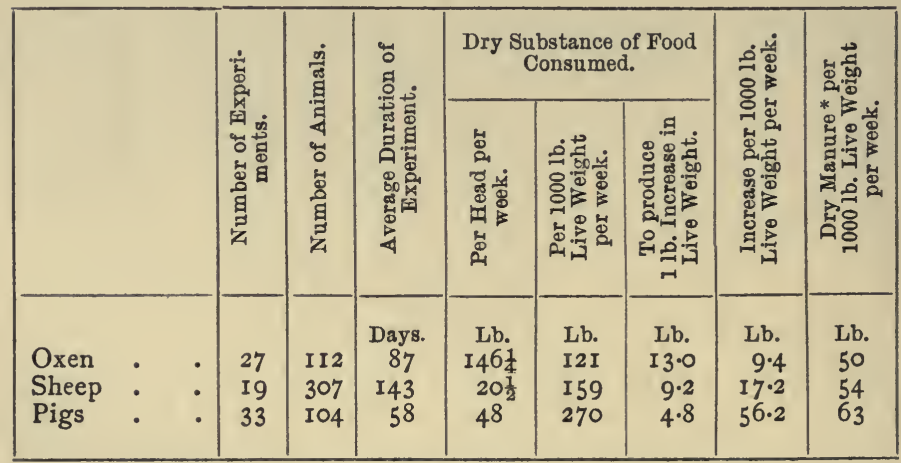

* Dry matter of solid excrement and urine, exclusive of litter.

that to make $\mathrm{I} \mathrm{lb}$. of increase in the live weight of oxen, $13 \mathrm{lb}$. of dry food material was necessary, while about $9 \mathrm{lb}$. were wanted in the case of sheep and 
$5 \mathrm{lb}$. in the case of pigs to produce the same increase of $\mathrm{I} \mathrm{lb}$. in the live weight. Of course, these results are only very approximate, particularly as they do not take into account the nature of the food, but express the kind of results which may be expected on the very mixed diet prevailing in England. We have already seen that not only do foods differ very greatly in composition, but that much more of the digestible part of the food is available for the service of the animal in the case of concentrated foods than with coarse fodders, which require a large expenditure of energy for their digestion. Moreover, these figures by Lawes and Gilbert are average figures spread over the whole period of fattening, and if we examine more closely the rate of increase, we shall find that a given weight of food is much more effective in producing live weight in the earlier than in the later stages of fattening. "This was well brought out in some other experiments of Lawes and Gilbert, in which pigs were fattened for a period of ten weeks. In the first month, less than $4 \mathrm{lb}$. of food produced an increase of $\mathrm{I} \mathrm{lb}$. in the live weight; during the second month, $5 \mathrm{lb}$. of food were required to produce the same increase; while in the last fortnight, as much as $6 \frac{1}{4} \mathrm{lb}$. of food were consumed for each pound of weight put on. Thus a farmer who is fattening animals for market should always remember that it is the last few pounds which are the most expensive to produce, and that he may easily spend very much more than he obtains in getting up the final finish of the animal.

The exact value of the various constituents of fattening stuffs in producing increased live weight has been worked out, since the experiments of Lawes and Gilbert, by the much more elaborate investigations which demand the use of a respiration chamber. By these means an exact balance-sheet is obtained for the period 
during which the animal is under investigation, the composition of the food is known, the composition of the excreta is determined, and also the amount of carbon dioxide and methane given off by the animal. The difference between the carbon in the food and the excreta will represent the carbon stored up in the body as fat and lean meat, and as the amount of nitrogen stored is similarly determined, we can further calculate how much of the carbon has been stored in the form of fat. From this kind of experiment it has been determined that of $\mathrm{I} \mathrm{lb}$. of pure digested fat about $\frac{1}{2} \mathrm{lb}$. is stored in the body, supposing that the fat is given in addition to a maintenance ration and none of it is needed by the animal for general purposes. The proportion varies somewhat with the nature of the fat, the range being from about 47 per cent. to about 60 per cent. as a maximum. Of pure digested protein about 23 per cent. could be stored as fat. Digested starch and crude fibre can give rise to about 25 per cent. of their weight as fat, while sugar gives rise to less than I9 per cent. These proportions, however, refer only to the pure food constituents in their digested form. In many feeding stuffs the digestible constituents do not attain these full values, a large and varying proportion being spent in the work of digestion. Roughly speaking, in the various cakes and meals the digestible constituents possess their full value for making fat, such as is shown by the pure constituents themselves. It is in the case of the coarse fodders, such as bran, hay, and roots like mangolds, that a deduction must be made from the full value to express the value to the animal in producing increase. We can, in fact, attach to each feeding stuff which has been under investigation a factor showing the percentage of their full value which the digestible constituents will possess in that particular feeding stuff. 
For example, the factor for meadow hay is about 70 per cent., which means that the digestible protein in the meadow hay, instead of being capable of yielding 23 per cent. of its weight of fat stored up in the animal (supposing the hay is added to the diet required for maintenance so that it can all be utilised for making increase), will only yield 70 per cent. of its full value of 23 per cent., i.e. the digestible protein of the meadow hay will only be converted into 16 per cent. of its weight of stored up fat. In the calculations in the preceding chapter (p. 193) we deducted 3 per cent. of the energy contained in the digested part of cotton cake, but 40 per cent. of the energy contained in digested meadow hay, in order to find the dynamic energy available for work or increase.

We can make use of the values which have been deduced for the digestible constituents in the feeding stuffs so as to obtain a single figure which sums up the relative value of the feeding stuff. We have already attempted to do this in a somewhat imperfect fashion when discussing the analysis of the feeding stuffs. We have taken as a kind of guide the fact that the fats are about two and a quarter times as valuable for fuel purposes as the carbohydrates, and have also made the assumption that the proteins are worth about as much as fats (a commercial assumption which takes into account the value of its nitrogen as well as the fuel value of the protein). Thus, we can add to the percentages of carbohydrates the percentages of fat and protein multiplied by $2 \cdot 3$, and so obtain the number of units which represent the value of the food in terms of carbohydrates. Such a valuation, which is all or more than the market takes account of, possesses little exact value, because it neglects the digestibility of the various constituents. But if we base our calculations upon the 
digestible portions only of the food, the results are still vitiated by failing to take into account the work that is spent in the digestion of the food. Such a unit system is not greatly in error when we can confine it to comparisons between the highly concentrated foods that possess nearly full value (p. 183), but breaks down when the comparison is made between a concentrated and a comparatively low-grade fodder.

For example, working from Table XVII. the crude analysis shows for decorticated cotton cake $4 \mathrm{I}$ per cent. of protein and 9 of oil, 50 in all, which, multiplicd by $2 \cdot 3$, give II 5. Add 26 per cent. of carbohydrates, and the total food units amount to I4I. Meadow hay, with Io of protein and 2.5 of fat, to be multiplied by $2 \cdot 3$, give 28 units, which, added to 42 of carbohydrates, give 70 food units; making the hay just about half as valuable as the cotton cake. If we consider the digestible constituents only, the cotton cake shows 34 per cent. of protein and 8.5 of oil, which, multiplied by $2 \cdot 3$, give 98 , to which must be added 20 of carbohydrates and fibre, making a total of I I 8 digestible food units. Meadow hay contains 4 of digestible proteins and I of fat, $4+\mathrm{I} \times 2.3=\mathrm{II}$; adding $4 \mathrm{I}$ digestible carbohydrates and fibre we get 52 total food units, considerably less than half the figure for cotton cake. The soundest method of comparison which we have now to explain would give figures of $7 \mathrm{I}$ and $3 \mathrm{I}$ respectively, bringing the meadow hay still further below the cotton cake.

The basis of comparison is derived from considerations-(I) of the digestible constituents of the food; (2) of the facts we have just stated, that a pound of fat in the food will be stored to the extent of about 50 per cent., whereas a pound of protein only gives rise to less than a quarter of a pound of fat, and a pound of starch to about the same; and (3) of the value that these 
constituents possess in each food when deduction has been made for the work spent in digestion. In order to arrive at a convenient number for our comparisons, we shall take starch as a basis and reduce the digestible constituents of the other foods into terms of their equivalents of starch. For example, we have just seen that a pound of digested fat in the food will give rise to half a pound of fat in the increase, whereas a pound of starch only gives rise to a quarter pound of fat in the increase; so that if we call 100 the value of starch, then we should have to express the value of fat by 200 . Similarly, pure protein has a fat-making value about 90 per cent. of that of starch, so that the equivalent in starch of 100 of protein would be 90 . In this case we are dealing with pure food constituents, but exactly the same principle may be followed for each feeding stuff as a whole. We can obtain a single number which represents the number of pounds of starch which would have the same fattening effect as $100 \mathrm{lb}$. of the food in question. This starch equivalent represents the summing up of the value of the fat, protein, carbohydrates, and fibre respectively in the food, after the deduction brought about by the work spent in digestion. Table XVII., with its list of food compositions and digestible constituents, also gives the starch equivalents, which range from as high as 120 for linseed to as low as I I for wheat straw. Such a table of starch equivalents forms the only sound basis for the comparison of the value of feeding stuffs, and though there are many other factors to be taken into account in making up rations for farm animals, these figures should be considered in deciding which are the cheaper of the concentrated feeding stuffs which can be purchased, and also in what quantities they should be used to replace one another in a ration. Of course they refer only to the fattening 
increase, and they are based upon experiments with ruminant animals-sheep and oxen. They do not hold exactly for fattening pigs, nor do they refer to the production of energy in working horses. However, the energy which becomes available for work purposes is derived from the digestible constituents after deduction of the work spent in digestion in just the same way as the materials available for increase, so that no considerable error is introduced if we take the starch equivalent of a food as representing the energy that would be available for work purposes as well as the surplus that will be available for making increase of live weight.

One other point, however, we must bear in mind. The starch equivalent takes into account only the fat-making power of the food, and pays no attention to the nitrogen it contains nor the requirements of the animal for nitrogen. Suppose we have arranged a certain ration that will supply the requirements of the animal as regards energy or fat production, basing the ration upon the starch equivalent of the foods; we have then also to make a second calculation of the albuminoid ratio of the ration in order to make sure that the animal is getting the proper amount of nitrogen. But with all the knowledge that has been derived from the experiments upon feeding animals, knowledge which is summed up in the starch equivalents, it would be extremely unwise to begin to construct rations for farm animals on a priori principles, considering that they require a certain number of starch equivalents per diem and a particular albuminoid ratio, and assuming that it is a matter of indifference how these units are arrived at. The better plan is to take as our starting-point certain wellrecognised rations which have been justified in practice for the particular purpose in view, and see how they can be modified to secure equal efficiency but greater 
cheapness. Sometimes also we find that animals are being grossly overfed, and this we can detect by finding that the total number of starch equivalents fed is greatly in excess of the number in a standard ration.

This system of starch equivalents to represent the relative value of the different feeding stuffs is really the return to one of the earliest methods by which it was proposed to bring these substances into comparison. Early in the nineteenth century Thaer, one of the first of the German agriculturists to apply science to the feeding of animals, attempted to draw up a table of what he called "hay values" for the different foods then available, these hay values being the equivalents in good hay of $100 \mathrm{lb}$. of the food in question. Thaer's hay values, however, were almost entirely based upon the amount of nitrogen contained in food, and it is rather characteristic of the change that has passed over the science of feeding stuffs to find that the new starch equivalents upon which we now base our comparisons of foods take no account of the nitrogen the food contains.

A few examples may now be given of the use of the starch equivalents in compounding rations.

The following ration was given to heavy dray horses working long journeys :-

Lb.

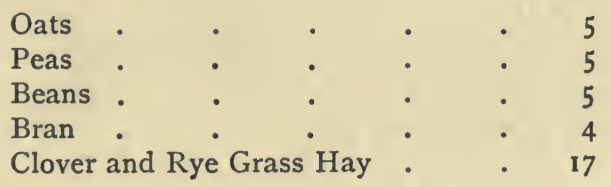

and it became desirable to replace the peas, which were no longer obtainable cheaply. From Table XVII. we learn that peas possess a starch equivalent of 70 and an albuminoid ratio of $1: 3 \frac{1}{4}$. Now maize possesses a starch equivalent of 68 , so that they could be substituted 
for peas without any serious loss in the supply of energy ; to be exact, $5 \mathrm{lb} .2 \frac{1}{2} \mathrm{oz}$. of maize would be equivalent to $5 \mathrm{lb}$. of peas. But the albuminoid ratio of maize is much lower than that of peas, so it is necessary to know if the albuminoid ratio of the new ration is below what might be considered safe. This may be calculated as follows, still using Table XVII. :-

Digestible Constituents.

\begin{tabular}{|c|c|c|c|c|c|c|c|c|}
\hline \multirow[b]{2}{*}{ Food. } & & \multirow[b]{2}{*}{ Weight. } & \multicolumn{2}{|c|}{ Protein. } & \multicolumn{2}{|c|}{ Oil. } & \multicolumn{2}{|c|}{ Carbohydrates. } \\
\hline & & & $\begin{array}{c}\text { Per } \\
\text { Cent. }\end{array}$ & $\begin{array}{l}\text { Food } \\
\text { Units. }\end{array}$ & $\begin{array}{c}\text { Per } \\
\text { Cent. }\end{array}$ & $\begin{array}{c}\text { Food } \\
\text { Units } \\
(\times 2 \cdot 3) .\end{array}$ & $\begin{array}{c}\text { Per } \\
\text { Cent. }\end{array}$ & $\begin{array}{l}\text { Food } \\
\text { Units. }\end{array}$ \\
\hline $\begin{array}{l}\text { Oats } \\
\text { Maize : } \\
\text { Beans : } \\
\text { Bran : } \\
\text { Meadow Hay } \\
\text { Clover Hay }\end{array}$ & $\begin{array}{l}\cdot \\
\cdot\end{array}$ & $\begin{array}{l}\text { Lb. } \\
5 \\
5 \\
5 \\
4 \\
8 \cdot 5 \\
8 \cdot 5\end{array}$ & $\begin{array}{c}9 \\
7 \\
19 \\
10 \\
4 \\
5.5\end{array}$ & $\begin{array}{l}45 \\
35 \\
95 \\
40 \\
34 \\
47\end{array}$ & $\begin{array}{l}5 \cdot 2 \\
4 \cdot 5 \\
I \cdot 2 \\
3 \\
I \\
I \cdot 5\end{array}$ & $\begin{array}{l}60 \\
52 \\
14 \\
28 \\
20 \\
29\end{array}$ & $\begin{array}{l}45 \\
68 \\
48 \\
45 \\
41 \\
35\end{array}$ & $\begin{array}{l}225 \\
340 \\
240 \\
180 \\
348 \\
323 \\
\end{array}$ \\
\hline \multirow{2}{*}{ Clover Hay. } & & & & 296 & & 203 & & 1656 \\
\hline & & & & & & & 1859 & \\
\hline
\end{tabular}

By multiplying the percentages of digestible protein by the weight of each food we obtain in the third column a total of 296 digestible protein food units in the ration. To obtain the number of digestible non-protein units we must similarly multiply their percentages by the weight of food, but the oil percentages must be further multiplied by 2.3 to make them equivalent to the carbohydrates. Thus we get a total of 203 food units from the oil in the ration and 1656 from the carbohydrates, making I859 non-protein food units in all. This total must be divided by 296 , the number of protein units, in order to obtain the albuminoid ratio of the whole. As in the case in question, this is still as narrow as $I: 6$, we 
may assume that the ration is well above the safety limit, and that the maize can be substituted for the peas without affecting the horses. Instead of calculating out the albuminoid ratio of the whole, we might have found how much digestible protein the new ration contained, as follows:-

\begin{tabular}{|c|c|c|c|}
\hline Oats, 5 lb. at 9 per cent. & . & - & $=$ \\
\hline Maize, 5 lb. at 7 , & - & . & $=$ \\
\hline Beans, 5 lb. at 19 & - & - & $=$ \\
\hline Bran, 4 lb. at ro ", & & - & $=$ \\
\hline \multicolumn{3}{|c|}{ Meadow Hay, $8 \frac{1}{2}$ lb. at 4 per cent. } & . $=$ \\
\hline Clover Hay, $8 \frac{1}{2}$ lb. at $5 \frac{1}{2}$ & $"$ & - & - $=$ \\
\hline
\end{tabular}

Thus the horse would be getting nearly $3 \mathrm{lb}$. of digestible protein per diem, and Table XXIII. shows that a horse in heavy work requires $2 \mathrm{lb}$. per diem per $1000 \mathrm{lb}$. live weight. Thus, $3 \mathrm{lb}$. would be sufficient if the horses in question did not weigh more than $1500 \mathrm{lb}$. To take another case, a fattening ration for cattle contained :-

$\begin{array}{llllr}\text { Swedes } & & & & \text { Lb. } \\ \text { Hay } & \cdot & \cdot & \text {. } & 84 \\ \text { Linseed Cake } & \text {. } & \text {. } & \text {. } & 12 \\ \end{array}$

and it was desired to substitute cotton cake and barley meal for the linseed cake. Five pounds of linseed cake is equivalent to $5 \times 76 \div 100=3.8 \mathrm{lb}$. starch; it also contains $5 \times 25 \div 100=\mathrm{I} \cdot 25 \mathrm{lb}$. protein. Barley has a starch equivalent of 74 and 9 per cent. of digestible protein, so that $2 \frac{1}{2} \mathrm{lb}$. of barley meal would be equivalent to $2 \frac{1}{2} \times \cdot 74=1 \cdot 65 \mathrm{lb}$. starch, and would contain $\cdot 22 \mathrm{lb}$. of digestible protein. Three pounds of decorticated cotton cake with a starch equivalent of $7 \mathrm{I}$ and 34 per cent. of digestible protein would have a starch equivalent of 
$2.13 \mathrm{lb}$, and would contain $\mathrm{I} .02 \mathrm{lb}$. protein. Thus the two would together have a starch equivalent of $\mathrm{I} \cdot 85+2 \cdot \mathrm{I} 3=3 \cdot 98$, and would contain $\cdot 22+\mathrm{I} \cdot 02=\mathrm{I} \cdot 24 \mathrm{lb}$. protein, or the fattening value of the ration has been increased a trifle, while the amount of protein remains the same, so that probably $\frac{1}{4} \mathrm{lb}$. could be taken off the barley meal, as the amount of protein is already pretty high.

Dairy cows were receiving :-

\begin{tabular}{|c|c|c|c|}
\hline Beans & . & & . \\
\hline Oats & . & . & . \\
\hline Linseed Cake & . & . & . \\
\hline Bran & . & . & . \\
\hline Straw Chaff & . & . & . \\
\hline Hay & . & . & • \\
\hline Straw & . & 。 & . \\
\hline
\end{tabular}

and it was desirable to substitute gluten meal and maize as much as possible for the other concentrated foods, which had become dear. We may calculate as follows :-

\begin{tabular}{|c|c|c|c|c|}
\hline & \multicolumn{2}{|c|}{ Starch Equivalent. } & \multicolumn{2}{|c|}{ Protein. } \\
\hline $\begin{array}{l}\text { Beans, } 4 \mathrm{lb} . \\
\text { Oats, } 3 \mathrm{lb} . \\
\text { Linseed Cake, } 2 \text { lb. }\end{array}$ & $\begin{array}{c}\text { Per cent. } \\
67 \\
63 \\
76\end{array}$ & $\begin{array}{l}\text { Lub. } \\
2.68 \\
1.89 \\
1.52\end{array}$ & $\begin{array}{c}\text { Per cent. } \\
\text { I9 } \\
9 \\
25\end{array}$ & $\begin{array}{l}\text { Lb. } \\
.76 \\
.27 \\
.50\end{array}$ \\
\hline Total . . & $\ldots$ & 6.09 & $\ldots$ & $I .53$ \\
\hline
\end{tabular}

Thus we have to make up 6.I lb. of starch equivalent and $\mathrm{I} .5 \mathrm{lb}$. of protein. Gluten meal has a starch equivalent of 77 and 33 per cent. of digestible protein; maize has a starch equivalent of 84 , but only 7 per cent. of digestible protein; thus rather a smaller weight of 
these foods will serve, but the gluten meal must predominate in order to keep up the protein. We may try :-

\begin{tabular}{|c|c|c|c|c|}
\hline \multirow[b]{2}{*}{$\begin{array}{l}4 \text { lb. Gluten Feed } \\
\text { gives } \\
4 \text { lb. Maize gives }\end{array}$} & \multicolumn{2}{|c|}{ Starch Equivalent. } & \multicolumn{2}{|c|}{ Protein. } \\
\hline & $\begin{array}{c}\text { Per cent. } \\
77 \\
84\end{array}$ & $\begin{array}{l}\mathrm{Lb} . \\
3.08 \\
3 \cdot 36\end{array}$ & $\begin{array}{c}\text { Per cent. } \\
\qquad \begin{array}{r}33 \\
7\end{array}\end{array}$ & $\begin{array}{l}\text { Lb. } \\
I \cdot 32 \\
0.28\end{array}$ \\
\hline Total & ... & 6.44 & $\ldots$ & 1.60 \\
\hline
\end{tabular}

and obtain rather more both of starch equivalent and of protein. It would now be wise to replace $2 \mathrm{lb}$. of the gluten feed by decorticated cotton cake, both to give variety and impart consistency to the butter fat.

We then have-

\begin{tabular}{|c|c|c|c|c|}
\hline & \multicolumn{2}{|c|}{ Starch Equivalent. } & \multicolumn{2}{|c|}{ Protein. } \\
\hline $\begin{array}{l}2 \text { lb. Decorticated } \\
\text { Cotton Cake } \\
2 \text { lb. Gluten Feed. } \\
4 \text { lb. Maize . }\end{array}$ & $\begin{array}{l}\text { Per cent. } \\
\qquad \begin{array}{l}71 \\
77 \\
84\end{array}\end{array}$ & $\begin{array}{l}\text { Lb. } \\
I .42 \\
I .54 \\
3.36\end{array}$ & $\begin{array}{c}\text { Per cent. } \\
34 \\
33 \\
7\end{array}$ & $\begin{array}{l}\text { Lb. } \\
\\
0.68 \\
0.66 \\
0.28\end{array}$ \\
\hline Total & $\ldots$ & $6 \cdot 32$ & $\ldots$ & 1.62 \\
\hline
\end{tabular}

so that we could reduce the amount of the mixture by about $\frac{1}{4} \mathrm{lb}$. per head in order to obtain an almost exact equivalent to the original ration both in the supply of energy and of protein.

One more example will suffice to illustrate the method; fatting pigs per roo lb. live weight received :-

Barley Meal Pea Meal . 
which have to be replaced by maize and decorticated cotton cake. Four pounds barley meal will supply $2.96 \mathrm{lb}$. starch equivalent and $0.36 \mathrm{lb}$. digestible protein; $\mathrm{I} \mathrm{lb}$. pea meal will add $0.70 \mathrm{lb}$. starch equivalent and $0 . \mathrm{I} 7 \mathrm{lb}$. protein : total, $3.7 \mathrm{lb}$. starch and $0.53 \mathrm{lb}$. protein. Four pounds maize will supply 3.36 starch and 0.28 protein, to which $\frac{1}{2} \mathrm{lb}$. of cotton cake will add 0.35 of starch and O.I 7 protein, making a total of $3.7 \mathrm{I}$ lb. starch equivalent and 0.45 digestible protein. The protein is a little lower in this ration than in that which it was intended to replace, but the albuminoid ratio is still narrow enough for pigs that have made a good deal of growth and are chiefly putting on fat. Another ounce or two of cotton cake and a little less maize would make the ration almost exactly equivalent to the old one.

Such are the uses to which the following tables can be put by a practical farmer. In Table XXIII. are given certain standard rations which have been worked out by Kellner from the results of a very large number of exact experiments ; from these he may learn the weight of starch equivalent and protein that is appropriate to various farm animals. By the aid of Table XVII. the farmer can calculate the starch equivalents and digestible protein in the rations he is using, and correct them if they depart widely from the quantities given by Kellner. Finally, if, to suit the fluctuations of the market or the materials available on the farm, he wishes to modify his current ration, he can from this same table calculate the quantities of other foods necessary to replace those to which he has hitherto been accustomed. 
TABLE XXIII.-STANDARd Rations (Kellner), per $1000 \mathrm{lb}$. live weight per day.

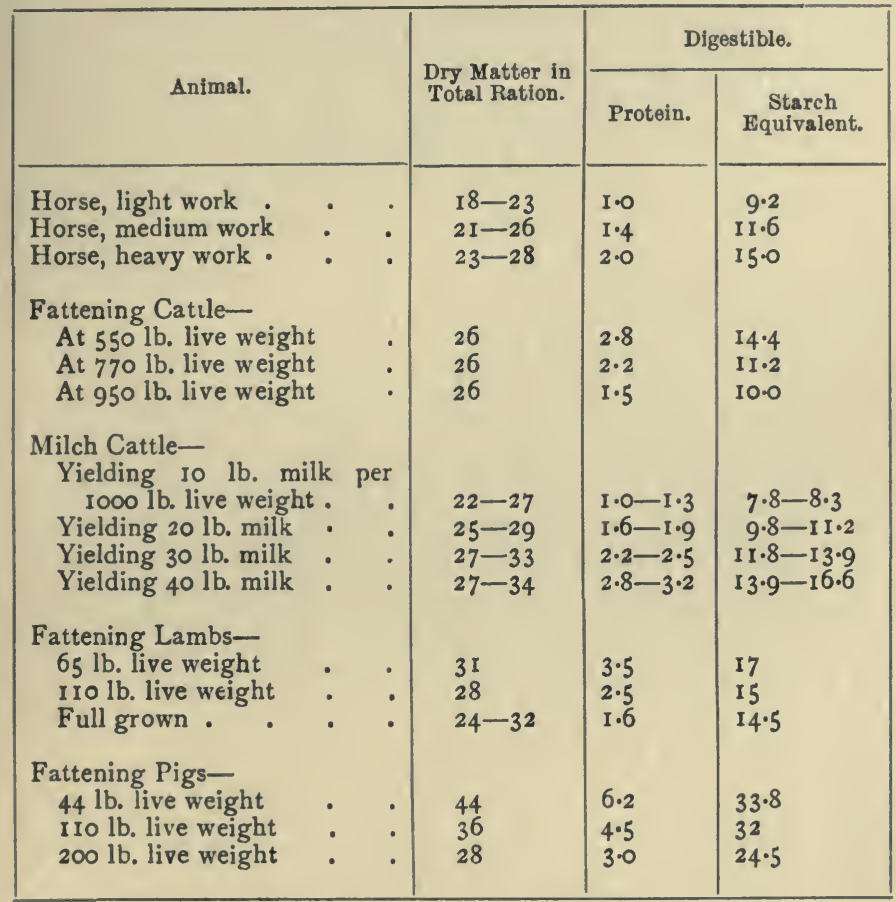




\section{CHAPTER XII}

FARMYARD MANURE

Composition of Animal Excretions. Litter. Changes taking place during the Making and Storage of Manure. Losses of Nitrogen in Manure-making - Unavoidable or due to wasteful Methods. Composition of Farmyard Manure from various Sources. Care of Farmyard Manure. Farmyard Manure as a Fertiliser. Value of Farmyard Manure. Valuation of Manure Residues derived from the Consumption of Purchased Feeding Stuffs. Cost of Farmyard Manure.

IN the preceding chapter we have learned that the food of animals contains various substances which are also food for plants. The fat, the fibre, and the carbohydrates in a feeding stuff are useless, because being only compounds of carbon, hydrogen, and oxygen, they are as far as they are digested resolved into carbon dioxide and water, and even their indigestible portions when they reach the soil cannot feed the plant. The nitrogen, however, that the feeding stuff contains is of the first importance to the plant, and the phosphoric acid and the potash which are also present in the ash are equally indispensable elements of the plant food. We have further learnt that the animal only retains in its body a comparatively small proportion of the nitrogen and other valuable constituents of the food. The actual proportion retained depends upon the age of the animal; a young animal putting on flesh, or a cow in full milk, take from the food more of the nitrogen 
and the phosphoric acid than animals which are stationary in weight, while animals in the last stages of fattening hardly retain anything at all. It is because the animal thus keeps back so little of the plant food which was, in the first place, taken from the soil for the production of the vegetable feeding stuff, that the excrements of animals has always been regarded as the most valuable of fertilisers since any settled agriculture began. In fact, it is only comparatively recently that any other fertiliser has been known, for though various industrial residues, such as woollen rags, clippings of hoofs and horns, bones, and malt dust have been utilised as manures for the last two or three hundred years, their efficacy was very limited, and the business of cropraising centred round the proper use of farmyard manure. The great range of artificial manures now available, which are either derived from industrial processes or represent the accumulated fertility of some other country, have all come into use since about 1840 .

Farmyard manure consists essentially of the excreta of the various animals, horses, cattle, and pigs kept in the farmyards, mixed with the litter-straw or otherwise-which is used to absorb the urine and keep the animals clean. Very slight consideration shows us, however, that in the farmyard manure that goes on the land we are dealing with a very different product from the fresh mixture of straw and excreta. The mixture, in fact, undergoes great changes during the time it is under the feet of the animals, and these changes are mainly brought about by bacteria. The first change taking place while the manure is being "made," as a farmer would say, is continued to a greater or less extent when the manure is afterwards removed from the yards or the boxes and made up into heaps. At first the straw of the manure shows little alteration, but 
as the making process proceeds it is partly broken down by the hoofs of the animals and partly by bacterial decay, which latter change proceeds still further during the storage process until no trace of the straw structure may remain, but the whole material has passed into a uniform brown or black mass. The farmer is accustomed to speak of the fresh straw in manure as "long," while the old fermented material he calls "short."

Before considering in detail the changes which go on during the processes of making and storage, we must refer back to what we have already learnt concerning the fate of the valuable materials in the feeding stuffs, fixing our attention for the time being upon the nitrogen. It will be remembered that portions of the nitrogenous compounds in the food are indigestible, and are excreted by the animal in the fæces; that part, however, which is digested is excreted in the form of urea in the urine, except for a small portion which the animal may retain in the body. This division of the nitrogen in the food represents a great difference in its value as a fertiliser. The nitrogen compounds in the fæces, since they have resisted the attack of the digestion processes, will be very slowly attacked in the soil by the bacteria which have to break down and convert them into ammonia and nitrates before they can feed the plant. Such materials, then, are slow in their action as fertilisers, and remain for a very long time unchanged in the soil. The nitrogen, however, in the liquid portion of the manure in which it is present in the shape of urea, will change very rapidly into ammonia, so that it is an extremely active fertiliser, and far more valuable than the solid parts of the manure which would contain the same amount of nitrogen. The same considerations apply equally to the phosphoric acid and potash; whatever part of these constituents in the food is 
digested gets excreted in a liquid and soluble form, and is therefore in an available state for the plant, whereas the same constituents in the frces are insoluble, and only reach the plant after the lapse of some considerable time. We have also learnt in the previous chapter that the richer and more concentrated a food is, the greater is the proportion of its nitrogen that is digested. For example, decorticated cotton cake contains nearly 7 per cent. of nitrogen, and about nine-tenths of that nitrogen is digested and reappears in the soluble active form of urea; whereas hay only contains about $\mathrm{I}_{2} \frac{1}{2}$ per cent. of nitrogen, of which barely half is digestible, while the other half is excreted in a solid form and will form but a slow-acting fertiliser. Thus an animal which is fed with concentrated cakes and meals, such as a bullock during the fattening process, will be giving rise to much richer manure than animals which are being kept in a store condition and only receiving such low-grade foods as hay, straw, and roots, even though the same amount of nitrogen is being consumed in the two cases. We have thus a number of factors affecting the composition of farmyard manure. Young growing stock take nitrogen from the food in order to make flesh, and phosphoric acid in order to make bone; milch cows take both phosphoric acid and nitrogen for their milk; store stock and working horses do not receive very concentrated food, and in their turn give rise to comparatively poor manure. The animals themselves induce a certain amount of difference, and though the composition of the excreta varies so much with the age and food that analyses are not of much information unless large numbers are given, it will be found that the urine of sheep and horses is more concentrated than that of cattle and pigs, and similarly, that the solid excreta of the two former are also drier. It is this greater 
dryness and richness which causes the gardener to describe horse manure as "hotter" than that produced by cattle and pigs. Bacterial changes take place in it more rapidly, and both a greater amount of ammonia and a greater rise of temperature are produced by the fermentation. The composition of the resulting farmyard manure also varies, to a certain extent, with the litter employed. Straw is, of course, most general, and though there are differences in composition between wheat, oat, and barley straw, these differences are not great, and are indeed less than the variation in the composition of any one of them in different seasons. Speaking generally, the straw is richer in cool seasons and in more northern climates. The only other substance at all widely used for litter is peat moss; it is both somewhat richer in itself in nitrogen than is straw, and possesses a greater absorbing capacity for the liquid portions of the manure. It is doubtful, however, whether the extra nitrogen in the peat moss is of much service to the plant, nor do the bacterial changes in making the manure go on so readily as with straw.

The changes we shall now discuss refer to ordinary farmyard manure made with straw, and these changes may be divided into two groups-those taking place in the carbon and the nitrogen compounds respectively. So far as the carbon compounds-the fibre and other carbohydrates in straw-are concerned, the chief change that takes place is the anaerobic fermentation which we have discussed when dealing with soils. A number of organisms are present in the air and in dust, which at once attack the carbohydrate material of the straw and begin to burn it up, with the production of carbon dioxide. The organisms, however, soon use up all the oxygen that is contained in the air entangled in the manure, whereupon the work is taken up by the 
anaerobic organisms, which give rise on the one hand to carbon dioxide and marsh-gas or hydrogen, and on the other hand to the dark brown substance of indefinite composition which we call humus. Analysis of the gas derived from a newly made dunghill showed that at first a good deal of hydrogen was being produced, but when the dunghill was kept tight and moist the most characteristic fermentation was that giving rise to carbon dioxide and marsh-gas. Only when the mass was allowed to get dry, so that air could enter, did the aerobic fermentation, giving rise to carbon dioxide alone, begin to take place. It will be seen, however, that a considerable loss of dry material must take place, because whether the fermentation takes place in the presence or absence of air, solid carbohydrates are being converted into gases like carbon dioxide and marsh-gas. We find, as a matter of fact, that during the making of dung, something like a quarter of the original dry matter is burnt up, and that by the time the dung has been made and stored, this loss of dry matter has been increased to one-half, and may easily become greater with very old short manure.

Turning now to the nitrogenous compounds which form the chief fertilising elements of the manure, we have already said that the most important is the soluble urea contained in the urine. This substance is at once attacked by bacteria which are always present in cattle stalls, stablès, etc., and by a very slight chemical change is converted into carbonate of ammonia. Carbonate of ammonia is a substance which spontaneously splits up into the two gases carbon dioxide and ammonia, so that when any liquid containing carbonate of ammonia is exposed to the air and dried up at all, the valuable ammonia is at once converted into gas, and escapes. In this way a great loss of fertilising material can easily 
arise, and we find as a matter of practice that, despite the utmost care that can be taken in making dung, there will always be a loss of nitrogen due to the volatilisation of the ammonia derived from the fermentation of the urea. This loss, furthermore, falls upon the most valuable of the nitrogen compounds, i.e. upon those which are soluble in water and readily available as food for plants. A large number of experiments have been made in which the amount of nitrogen supplied to the animals was carefully determined and compared with the amount which was afterwards found in the dung that had been made, and under the most favourable conditions of practice the loss amounted to about 15 per cent. during the making of the manure. The best conditions are found to be attained by keeping the straw and manure tightly trodden down beneath the feet of the animals, and in a fairly moist condition so as to exclude the action of air. If the straw was allowed to remain in the yard or box in a loose, open condition, or if the litter was cleared from under the animals and simply thrown into a heap day by day, then the losses of ammonia were very much increased, and often rose to half of the nitrogen that had been given in the food. All disturbances of the manure should be avoided, because they result in very active fermentation, with a corresponding increase in the evaporation of ammonia. For example, when fresh strawy manure is repeatedly turned, it is well known that the temperature of the whole mass rises to $70^{\circ}$ or $80^{\circ}$ through the fermentation that sets in, and quantities of ammonia are given off during the turning, as may be detected by the smell. The heat that is generated by the active bacterial fermentation is utilised by gardeners in the preparation of a hotbed, and it is well known that only fresh strawy manure, which contains plenty of easily fermentable 
urea and soluble carbohydrates in the straw, will get up heat quickly and serve as material for a good hotbed. A gardener is also accustomed to let manure in this way get hot and turn it repeatedly before using it for such purposes as the growing of mushrooms. Such a process the gardener calls "taking the fire out" of the manure, whereby he means that he has got rid of, in fact burnt up, the easily fermentable material, and at the same time he has reduced the amount of ammonia, which otherwise might easily have become injurious to the roots of tender plants. The fermentation of urea is not, however, the only change in the nitrogenous compounds that takes place. The undigested proteins in the frecs and similar bodies contained in the litter are attacked by the putrefactive bacteria; they are resolved into simpler substances, and may eventually break down as far as ammonia. At the same time, however, certain reverse changes take place; the bacteria which develop in the dung are so enormous in. number that they take for themselves an appreciable percentage of the soluble compounds of nitrogen there present and convert them into insoluble proteins forming part of their own tissue. The various changes, which we have thus indicated as taking place during the making of farmyard manure while it is still under the feet of the animals, are also continued during the storage process. After the manure has been made up into a mixen or dung-heap, the changes become much slower, and the loss of nitrogen is comparatively small if the heap is kept moist and tightly packed. Losses of nitrogen, however, are constantly occurring, and under ordinary working conditions we must expect that only about half of the nitrogen originally contained in the food finds its way back to the land in the farmyard manure; of the other half some will have been retained 
by the animal, but the greater part will have been evaporated as ammonia during the making of the manure and any turning it may have received, while some will have been set free as nitrogen gas. At the same time the more fermented the manure becomes, and the shorter and more rotten its condition, the less of the nitrogen will be present in soluble form, and the more of it will have been reconverted into substances akin to a protein.

In making farmyard manure, the loss of valuable nitrogen is therefore inevitable, but it is possible to keep the loss down by taking suitable precautions. In the first place, it is desirable to keep the manure as long as possible under the feet of the animals. The least loss occurs when the manure is made in deep boxes in which the cattle are fed, and the manure is not removed until it is ready to go straight out on the land. The turning of the manure, which must be done when it is carted out of the yard in order to form the mixen, always results in loss. Of course, another source of loss in manuremaking arises through washing or leakage of the liquid manure away. We have already stated that the most valuable nitrogen compounds are those contained in the liquid portions of the manure, which is also rich in potash, so that if this material is allowed to drain away, the solids that are left behind possess but little value. The dark brown liquid which we often see oozing from the dung-heap or leaking from the drains of a badly kept yard constitutes one of the finest of fertilisers, and in the management of a yard or cattle stalls the utmost care should be taken to keep this material soaked up in the litter. For this reason a partly covered yard is desirable, so that too much rain is not allowed to wash through the manure. On the other hand, the wholly covered yard may easily let the manure get too dry, and 
so result in a large evaporation of ammonia. With an entirely covered yard it is often necessary to pump the liquid over the litter again in order to maintain it in a proper condition. Various materials have been suggested to reduce the loss of ammonia. Gypsum, superphosphate, kainit, and other substances are sometimes strewn about the cattle stalls and over the litter with the idea of absorbing the ammonia whenever it is set free. All these substances, however, possess but little practical value; either they are too expensive, or they set up some secondary injurious action which renders them unsuitable. The only practical method is to keep the manure tight and move it as little as possible during either the making or the storage. It has been shown that the loss on storage can be reduced by making a foundation to the new dung-heap of a few inches of old and well-rotted manure.

It will thus be seen that the changes during the making of farmyard manure are of a very complex character. In the first place, we have the purely carbon compounds of the litter turning into humus-this change being accompanied by a loss of nearly half of the dry matter. Secondly, the nitrogenous compounds are being broken down in one or several stages into the form of ammonia, some of which escapes. Lastly, other bacterial changes under certain conditions of free aeration causes part of the nitrogen to be lost by conversion into gas, while at all times a certain amount of reverse change from the soluble to the insoluble protein state is taking place through the multiplication of the bacteria themselves. No preservatives are of any avail, but the loss of nitrogen can be best reduced by moving the manure as little as possible and getting it on to the land at the earliest available time. With these general principles in mind we may now consider a little the 
composition of farmyard manure as met with in practice. It is naturally extremely variable according to the nature of the animal, and of the food, and again according to the method of making adopted, and the age of the product. The average of a large number of analyses at Rothamsted would show that ordinary farmyard manure contains about three-quarters of its weight of water, about 6 parts per thousand of nitrogen, 2 to 3 of phosphoric acid, and 3 to 4 of potash, or about I $5 \mathrm{lb}$. of nitrogen, $5 \mathrm{lb}$. of phosphoric acid, and $7 \mathrm{lb}$. of potash per ton. Thus, farmyard manure is in the main a nitrogenous fertiliser, and as an all-round manure it is somewhat deficient in phosphoric acid for the majority of crops. The effect of feeding and management is well seen in the first four analyses given in Table XXIV.

TABLE XXIV.-COMPOSITION OF FaRMYARD MANURE.

\begin{tabular}{|c|c|c|c|c|c|c|}
\hline & \multirow{2}{*}{ Water. } & \multicolumn{3}{|c|}{ Nitrogen. } & \multirow{2}{*}{$\begin{array}{l}\text { Phos. } \\
\text { phoric } \\
\text { Acid. }\end{array}$} & \multirow{2}{*}{ Potash. } \\
\hline & & Total. & Soluble. & $\begin{array}{c}\text { In- } \\
\text { soluble. }\end{array}$ & & \\
\hline 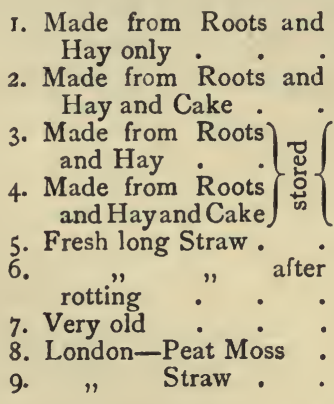 & $\begin{array}{l}74 \cdot 7 \\
74 \cdot 5 \\
78 \cdot 0 \\
75 \cdot 7 \\
66 \cdot 2 \\
75 \cdot 4 \\
53 \cdot 1 \\
77 \cdot 8 \\
70 \cdot 0\end{array}$ & $\begin{array}{l}0.59 \\
0.82 \\
0.47 \\
0.69 \\
0.54 \\
0.60 \\
0.80 \\
0.88 \\
0.62\end{array}$ & $\begin{array}{c}0.15 \\
\ldots \\
\ldots \\
\ldots .5 \\
0.51 \\
0.10\end{array}$ & $\begin{array}{c}0.4 \text { I } \\
0.4 \text { I } \\
0.4 I \\
0.54 \\
\ldots\end{array}$ & $\begin{array}{c}\cdots \\
\cdots \\
0.20 \\
0.52 \\
0.32 \\
0.45 \\
0.63 \\
0.37 \\
0.48\end{array}$ & $\begin{array}{c}\ldots \\
\ldots \\
0.37 \\
0.48 \\
0.67 \\
0.49 \\
0.67 \\
1.02 \\
0.59\end{array}$ \\
\hline
\end{tabular}

No. I shows that fresh manure taken from under the feet of the animals contained about 0.59 per cent. of 
nitrogen, of which 70 per cent. was in an insoluble condition, when the animals had been fed upon roots and hay only. When, however, linseed and cotton cake had been used in addition, the percentage of nitrogen had risen to 0.82 per cent., of which less than half was in the insoluble state. These two analyses refer to manure taken straight from the boxes; the next two refer to manure made in exactly the same way, but thrown out into the mixen and stored for a month to six weeks before being analysed. It will be seen that where roots and hay only had been fed, the manure then contained much less total nitrogen, only 0.46 per cent., though the amount of insoluble nitrogen is about the same as before, thus showing that the losses had been falling chiefly upon the soluble nitrogen. Where cake has been fed the total loss of nitrogen due to storage had also been great, and had again fallen upon the soluble portions of the manure; for whereas, in the fresh manure more than 50 per cent. of the nitrogen was in the soluble state, in the stored manure little more than 20 per cent. existed in that state. Thus the difference betwcen manure made by animals receiving concentrated foods and those getting only roots and hay, lies chiefly in the amount of ammonia and other soluble nitrogenous substances the dung contains. This difference is well seen in the effect of the manure upon the crops grown with it. For example, it was found in the field experiments made with the manures of which the analyses have just been quoted, that whereas the manure from the poorly fed animals brought about an increase of crop amounting to about 30 per cent., the manure from the richly fed animals gave an increase of over 80 per cent. In the second year after the application, however, both lots of manure gave much the same return, the manure made from the animals receiving 
cake only showing a superiority of 7 per cent. over the other. In slow-acting nitrogenous constituents the two lots of manure were alike; the difference chiefly lay in the ammonia, which had its effect in the first year, but was not effective afterwards.

Analyses Nos. 5, 6, and 7 show the change of composition that dung undergoes on storage. There is a gradual increase in the percentage of nitrogen, because the original material has lost carbon compounds more rapidly than nitrogen, so that the percentage of nitrogen in the remaining material shows an increase. At the same time, from other analyses we learn that in very old short dung but little of the nitrogen remains in a soluble form or combined as ammonia. Analyses 8 and 9 show the composition of the manure that is obtainable from London, in the one case made with peat-moss litter and in the other with straw. The peat-moss manure is not only richer in nitrogen because of the nitrogen in the peat moss itself, but it retains a much higher proportion of the nitrogen in an ammoniacal state because of the absorptive power of the peat for ammonia.

From a consideration of the origin of the losses of nitrogen which take place during the making of dung, and of the above analyses, a good deal of guidance can be obtained as to the practical management of farmyard manure, which remains the fundamental fertiliser in the ordinary course of farming in this country. In the first place, since it is clear that the most valuable part of the manure resides in the liquid, far more care should be taken to preserve this than is usually the case. Whether the dung is made in boxes or in yards, there should be sufficient depth to allow the manure to accumulate under the animal for the whole winter if need be, and the floors should be rammed with clay to 
render them watertight. Yards, in particular, should be so constructed that the accumulated manure is not above the general ground line outside, in which case there will always be a gradual soaking away of the liquid. On the other hand, yards made thus below the general ground level are apt to flood in heavy rain, so that the excess of liquid containing the soluble part of the manure has to be run off to waste by means of a drain; this can, however, be avoided by cutting drains outside to keep land water from running into the yard, and by seeing that all the surrounding sheds are properly provided with guttering. For real economy of litter, part at least of the yard should be covered; if the whole yard is covered, a certain amount of care is necessary to prevent the dung from getting at times too dry. Only just enough litter should be used to soak up the urine, and in order to prevent the liquid working up to the surface with the trampling, the floor of the yard should run down to a slight hollow, filled at first with something stiff like bean haulm or coarse peat moss, in which the excess of liquid may collect. Above all, the manure should be kept tightly trampled; the greatest amount of loss takes place when the urine falls on a thin layer of loose strawy litter. The yards and boxes should be deep enough to carry the animals through the whole winter, so that they need not be cleaned out except when dung is wanted to go straight on the land. A box, for example, 8 feet by Io feet in area, with an available depth of 3 feet, would hold about 9 cubic yards, or 8 tons of dung when well trodden down. This would accommodate two beasts, each receiving io $\mathrm{lb}$. of straw in food and $12 \mathrm{lb}$. in litter per diem, for four months. As far as possible, manure in the spring should be left undisturbed until the autumn, it may then be carted out on to the stubbles and ploughed in where potatoes or 
[CHAP.

roots are to be taken in the following spring. Even on the lightest soils the land will be more benefited thus, than if the manure is made up into a mixen and only put on immediately before the roots are grown. Sometimes, of course, a potato grower must have a supply of well-rooted manure to put in the drills immediately before planting; this can often be got from the lower layers of the earliest used boxes or yards, since a mixen should be avoided as much as possible. The principle to keep in mind is that every disturbance of farmyard manure results in loss, and that the shorter the time which elapses between the dropping of the dung and its application to the land, the less this loss of fertilising material will become.

In considering the value of farmyard manure as a fertiliser, one has to keep in mind that it is an essential product of the farm, and that it must constitute the main source of manure for the land under the conditions of ordinary mixed farming, where artificial manures will only be used as supplements and not as rivals. It is only in certain special cases, such as potato or hop growing, where the ordinary course of farming does not supply as much farmyard manure as is wanted, that the question has to be decided whether artificial manures or dung from the towns shall be purchased, or again, whether stock shall be fattened solely with the view of making manure.

As a fertiliser, the chief value of farmyard manure lies in the fact that it contains all the elements of a plant's nutrition-nitrogen, phosphoric acid, and potash -though for a well-balanced manure the phosphoric acid is comparatively deficient. Moreover, the nitrogen is present in various forms of combination, varying from the rapidly acting ammonia compounds, down to some of the undigested residues, which will remain for a very 
long period in the soil before becoming available for the plant. In consequence, dung is a lasting manure, which accumulates in the soil to build up what a farmer calls "high condition"- the state of affairs which prevails when the reserves of manure in the soil are steadily and continuously passing into the available condition in sufficient amount for the needs of the crop, so that there is no necessity for freshly applied active manurea mode of nutrition which results in healthy growth and good quality. But however marked the farmer's preference is for such lasting manures, the delay in realising the capital they represent means a certain amount of loss; besides which, some of the constituents of farmyard manure are so slowly acting as to be hardly recoverable during the lifetime of the tenant.

An examination of the records at Rothamsted shows that when farmyard manure was put on at the rate of I4 tons per acre every year for the wheat crop, at the end of fifty years only 26 per cent, of the nitrogen applied had been recovered in the crop, and less than 20 per cent. remained stored up in the soil; more than half had been wasted either by bactcrial processes giving rise to nitrogen gas in the soil, or by the washing out of nitrates into the drains. This, of course, is a very extreme case, both because wheat is a plant taking a comparatively small amount of nitrogen out of the soil, and also because the land had become so laden with farmyard manure, that all the processes of bacterial decay and destruction of the nitrogenous compounds had been increased far beyond the normal. On the mangold plot, about 32 per cent. of the nitrogen in the dung has been recovered when the dung had been put on year by year, but when the manure was only put on once in four years, about three-quarters of the total nitrogen applied was recovered in the four crops grown with that manure and 
no other fertiliser. Other experiments at Rothamsted show how lasting is the effect of farmyard manure, i.e. how very slowly some of the nitrogenous compounds get oxidised by bacteria and converted into a form available for the plant. In two cases, on the grass field and on the barley field, farmyard manure at the rate of I4 tons to the acre was applied for eight years and then discontinued. The effect of that application can still be traced more than forty years later, in the higher crop given by these manured plots than by the plots which had remained unmanured the whole time. Of course, these long-continued effects of farmyard manure are not great in themselves, and will only be perceptible when the land has been reduced to the lowest ebb of fertility by continual cropping without manure. Since the greater part of the nitrogen contained in farmyard manure is not in a condition to be utilised by the plant until it has first been attacked by bacteria and converted into ammonia or nitrates, it may happen that the plant, though it has been well supplied with farmyard manure, cannot obtain the nitrogen therein quickly enough, when the season is otherwise favourable to growth. For example, we see from the Rot'namsted experiment with mangolds that in years of large crop the plant which receives some active source of nitrogen like nitrate of soda will grow heavier crops than those which receive farmyard manure alone; although the amount of nitrogen in the manure applied to the latter, in addition to that which is already stored up in the soil, may be far in excess of the plant's requirements. From many experiments it can be demonstrated that when the grower is aiming at a very large crop, for example of potatoes or mangolds, it is more economical to obtain this by using a mixture of dung and active fertilisers than by increasing the amount of dung alone. The 
slowness with which dung can yield up its contents of nitrogen is particularly noticeable in the early spring, when the land is cold and bacterial actions in consequence go on very slowly. However rich the soil may be in farmyard manure and its residues, the gardener who is in a hurry to push on early production, finds it very necessary to use an immediately active nitrogenous manure like nitrate of soda.

The value of farmyard manure to the land is by no means confined to its fertilising action; its physical effects upon the texture and water-holding powers of the soil are equally important ; indeed, for some crops, and particularly in droughty seasons, these factors count for more than fertilisers towards ensuring a good yield. The farmyard manure, as it rots down in the soil, goes to restore the stock of humus, which otherwise is always tending to oxidise and diminish, and the humus, considered merely from the physical side, contributes largely to the fertility of the soil. In the first place, it improves the texture of all soils; to sands it gives cohesion and water-retaining power, while by loosely binding together the finest particles of clay soils it renders them more porous and friable. When a piece of old grass land, even on the stiffest of soils, has been ploughed up, it is easy to see the beneficial effect of the humus that has been accumulated; after the winter the plough slice will crumble naturally so as to harrow down at once to a mellow seed bed, whereas a neighbouring piece of the same soil that has long been under arable cultivation will only show a number of harsh, intractable clods. The importance of a good seed bed to the future well-being and ultimate yield of the crop can hardly be exaggerated; it is the basis of all good farming, so that even when the fertilising properties of farmyard manure have been replaced by artificial manures, some other 
means, such as the ploughing-in of green crops, must be employed in order to maintain the stock of humus. The effect of dung upon the soil is seen in two ways. In the first place, it will cause the surface soil to absorb more of the rainfall and to hold it up near the surface, so that cases may be found in which the subsoil is actually drier where farmyard manure has been used, because the rain has been held near the surface and therefore within reach of evaporation. But the chief value of the humus which the farmyard manure contributes to the soil lies in the better texture that it induces. It is particularly noticeable in the number of plants that are obtained when growing turnips and other root crops. When soils have long been farmed without organic manure, however rich they may be in the constituents of plant food, there will be great difficulties and even total failures in obtaining a proper stand should the weather conditions have been unsuitable soon after sowing.

In ordinary mixed farming, undoubtedly the best way of utilising farmyard manure is to apply it to the root crops, and especially to mangolds and potatoes. Swedes require much less nitrogen than do the other root crops. They also require a firm but fine tilth; in consequence, not more than 10 to 12 tons of dung per acre should be given for swedes, and it should be applied in the autumn, in order that it may become well rotted down before the spring cultivation begins. But up to 20 tons of dung per acre can be profitably employed for mangolds and potatoes, and it can, if necessary, be applied immediately before sowing. In America where corn (maize) takes the place of root crops, the farmyard manure may most profitably be applied to that crop. Any surplus dung, after the requirements of the root crops have been satisfied, is probably best given to the young 
seeds in the early winter, to act both as a fertiliser and as a mulch. The seeds benefit greatly, and at the same time much of the added fertility is retained for the corn crop that follows; manuring the young seeds is certainly preferable to the very general custom of manuring the old ley before it is ploughed up for wheat or oats. A certain amount of the farmyard manure made on the farm should, however, always be reserved for the meadow land, especially on light soils and on land comparatively newly laid down to grass. Of course, dung would be wasted on rich grazing land; it is the thin light soils that are cut for hay, or grass land that has only been laid down for a few years and has had no time to accumulate a stock of humus, which are most benefited by an occasional dressing of farmyard manure -once in every four or five years.

In Great Britain many farmers use but little fertiliser for their land beyond the farmyard manure that they make, but this farmyard manure contains not only the fertilising constituents which have been drawn from the soil of the farm and are contained in the roots and hay fed to the stock and the straw that has been trampled down as litter, but they also enrich the dung by the consumption of imported feeding stuffs, such as oilcakes, maize, and feeding meals, etc. It therefore becomes a question of some importance to determine what extra value is imparted to the manure by these purchased feeding stuffs. Specially is this important when the tenant is about to leave a farm, when the dung that has been made during the last year of his tenancy still remains in the yard and has not produced a crop. If purchased linseed cake, cotton cake, maize, and similar foods have been fed to the stock which made the manure, there will be left on the farm nitrogen and other valuable constituents which are just as much 
unused fertilisers as if they were contained in bags still unopened from the manufacturer. We have seen in the analysis that the manure made from rich feeding stuffs is very superior to that made from low-grade materials like roots and hay alone. From the records of the experiments upon fattening animals, we can obtain some idea of how much nitrogen contained in the food eventually reaches the soil. We have seen, for example, that the animal only retains perhaps ro per cent. of that which was given to it in the food, but that in making the manure, considerable losses set in even under the best conditions-losses due to the volatilisation of ammonia and to the setting free of nitrogen gas by bacteria. Though these losses are variable, and depend both upon the nature of the stock and the care taken in managing the manure, we can assume as a working compromise that half of the nitrogen contained in the food fed to the different classes of animals upon the farm will eventually reach the land again. Of the nitrogen and phosphoric acid, the losses are confined to the proportion retained by the animal and whatever may be lost by drainage, but we may again assume that about three-quarters of the phosphoric acid and all of the potash contained in the food will come back to the land. Acting upon these assumptions, we may proceed to calculate the value of the materials which the consumption of a ton of any given food-stuff will add to the manure made during its consumption. To take a concrete example-the decorticated cotton-seed cake contains about 6.9 per cent. of nitrogen, and we assume that half of this ( 3.45 per cent.) finds its way into the manure. If, on the principle explained before, we reckon that the unit, i.e. I per cent. of nitrogen, is worth I2S., then the value of the nitrogen added to the dung by the ton of cake will be $£ 2$, Is. $6 d$. The cake 
also contains 3.I per cent. of phosphoric acid, threequarters of this at $3 \mathrm{~s}$. a unit would amount to $7 \mathrm{~s}$. ; lastly, there is 2 per cent. of potash, which at $4 \mathrm{~s}$. a unit would add $8 \mathrm{~s}$. to the value of the manure. The total value, then, that the consumption of a ton of decorticated cotton cake adds to the manure is $£ 2$, Is. 6 d. $+7 \mathrm{~s} .+8 \mathrm{~s}$. $=£ 2,16 \mathrm{~s} .6 \mathrm{~d}$. Again, in the case of maize there is only I. 7 per cent. of nitrogen in the food, the value of half of which at I2s. a unit would be IOS. ; there is 0.6 of phosphoric acid, three-quarters of which would add Is. $6 \mathrm{~d}$., and there is 0.37 per cent. of potash, which would add a further Is. 6d., making I3s. in all as the value added to the manure by the consumption of a ton of maize. It will be seen that these two foods differ very greatly in the value of the manurial residues they leave behind when they have been consumed by stock, the maize being a food rich chiefly in oil and carbohydrates, which possess no fertilising value. The value of these foods for manure-making purposes again bears no relation to their cost, which is determined by the oil and carbohydrates present as much as by the proteins. The figures that we have thus deduced for the addition of fertilising material to the dung due to the consumption of purchased foods, represent what is sometimes called the compensation values to be attached to these foods, because they represent the price which should be paid to a tenant leaving the farm for the purchased foodstuffs which had been consumed during the last year of his tenancy, from the manure made by which, of course, he has as yet reaped no benefit. They are, however, we have said before, only rough approximations to the real truth. On many farms the farmyard manure is so neglected that the loss of nitrogen becomes much more than the 50 per cent. that we have assumed, and the longer the manure remains out of the land and 
lies about in the yard, the greater will this loss become. On the other hand, when food is fed upon the land and is not used for making manure in yards or stalls, as, for example, when the sheep are folded on the land or cattle are given cotton cake while they are grazing, the losses of nitrogen would be much reduced, because the urine which contains the valuable part of the nitrogen is at once absorbed by the soil, and none of the usual wasteful actions are set up. On the other hand, a farm producing much milk takes rather more, both of phosphoric acid and nitrogen, out of the food than the proportions we have been assuming, so that dung made by milch cows is never very rich. But taking all these things into account, we shall not be far wrong in assuming a loss of half of the nitrogen under the ordinary conditions of mixed farming, and in thereby deducing compensation values in the manner we have set up above.

We can apply the same principles to obtain the value of a ton of farmyard manure. Of course, as a rule, the farmyard manure is a normal product of the farm, and the only problem is to make it as carefully as possible, and apply it to the best purpose afterwards. But there are occasions, especially in growing of crops like market garden produce, potatoes, hops, when it becomes a question of whether it is more profitable to buy farmyard manure or artificial fertilisers, or to keep stock in order to make the farmyard manure that is required. It will be found that if the farmyard manure account is charged with the litter, and the compensation values of the foods calculated in the fashion described above, on the assumption that half of the nitrogen, three-quarters of the phosphoric acid, and all the potash contained in the food found its way into the manure, then the farmyard manure will cost from $8 \mathrm{~s}$. $6 \mathrm{~d}$. to I $2 \mathrm{~s}$. 
the ton by the time it is ready to go on the land; the difference in price representing a real difference in value, according to whether much concentrated food has been consumed during its manufacture or not. The farmer, then, who is faced with the problem of specially making farmyard manure, or on the other hand, buying artificial fertilisers or town dung, ought to reckon that such manure of fair quality will cost about IOs. a ton to make. In experiments dealing with fertilisers, this figure should be taken as an average valuation of wellmade farmyard manure. It is noticeable also that if we proceed to a valuation of farmyard manure on the basis of the fertilising constituents it contains at the usual unit rates, its price would work out to about the same figure of Ios. a ton. 


\section{CHAPTER XIII}

\section{ARTIFICIAL MANURES AND FERTILISERS}

Nature of a Fertiliser. Fertilisers containing Nitrogen-Nitrate of Soda, Sulphate of Ammonia, Soot-their Use and Value. Fertilisers containing Phosphoric Acid. Bones, Superphosphate or Acid Phosphate, Basic Slag or Phosphate Powder, Ground Rock Phosphate. Potash Fertilisers. Guanos. Industrial Residues. Tankage. Action of Fertilising Ingredients upon Crops. Expenditure on Fertilisers. Character of Fertiliser required for particular Crops. Valuation of Fertilisers.

IT has already been explained that of the elements found in a plant, a certain number are absolutely essential to its development, but that most of these are ordinarily to be found in the soil in sufficient quantities for the plant's requirements. There are, in fact, only three of these substances in which the soil shows any deficiency, and the bodies which we call manures or fertilisers are substances containing one or more of these three elements-nitrogen, phosphorus, or potash. At the present time the terms artificial manure and fertiliser are used indifferently to indicate such commercial materials as are of value to the plant, whatever their origin; from the farmer's point of view an artificial manure is any concentrated plant food which he purchases and receives in bags. In reviewing these substances we must begin by drawing a distinction between the fertilisers which contain only one ingredient 
of value to the plant-the single manures, as we may call them-and the compound manures which contain two or more fertilising ingredients. We may again divide these materials into nitrogenous, phosphoric, and potassic manures, according to the elements which predominate in them. The next most important factor to be taken into account is the actual percentage of fertilising material which the manure contains. With certain exceptions to be dealt with later, I lb. of nitrogen possesses the same value in whatever fertiliser it may be contained, so that we must compare all nitrogenous manures on the basis of the amount only of nitrogen they contain. Thus, if sulphate of ammonia contains 20 per cent. of nitrogen, and soot only 4 per cent., then sulphate of ammonia is five times as valuable as the soot, if we leave out of account certain other considerations which may give an extra value to one or other of these substances. In the case of sulphate of ammonia, only the 20 per cent. of nitrogen possesses any value to the soil or plant, the remaining four-fifths, however indispensable to the constitution of the manure, must be regarded as surplusage. It should not, however, be considered that there is any necessary waste, though the manure does only contain a proportion of the pure fertilising constituent, for these bodies must be combined to be of any use. Pure nitrogen gas, for example, as we have already stated, exists in air in enormous quantities, but is of no value to the plant until it has been brought into combination. Pure phosphoric acid, again, though it does exist and would act as a fertiliser, is a very scarce material, of interest only in the laboratory. Thus the surplusage which may be present in a manure, in addition to its percentage of nitrogen or phosphoric acid, must be regarded as the vehicle necessary to carry these valuable constituents. 
Among the fertilising constituents nitrogen must be given the first place. Not only is combined nitrogen much more expensive than either potash or phosphoric acid, I lb. costing about $6 \mathrm{~d}$. (I 2 cents), but as a fertiliser it seems to have a much more direct and immediate action upon a plant than the other two substances, which are at bottom equally indispensable. We find that nitrogen pushes on the first vegetative development of the plant, promotes its growth in fact, thus enabling it to search the ground more thoroughly for phosphoric acid and potash which may there be present. For some little time, indeed, crops may be grown by the aid of nitrogenous fertilisers alone, and there is always some tendency to use an excess of these substances in comparison with manures containing phosphoric acid and potash, which make less immediate show. Of the purely nitrogenous fertilisers there are five which are commonly employed; sulphate of ammonia, the most concentrated, contains about 20 per cent. of nitrogen, and nitrate of soda contains about $15 \frac{1}{2}$ per cent. To these concentrated fertilisers two new rivals have recently arisen in the shape of calcium cyanamide or nitrolim, containing about 18 per cent. of nitrogen, and nitrate of lime, containing about I 3 per cent. Theselatter materials are manufactured artificially, the nitrogen they contain being derived from the atmosphere. Lastly comes soot, a waste material which contains a small quantity of ammonia, showing from I to 5 per cent. of nitrogen according to its purity and the nature of the material from which it has been derived.

Sulphate of ammonia is a product recovered in the manufacture of coal-gas, coke, and other industries involving the destruction of coal. It is a pale grey, crystalline substance that is freely soluble in water, though it remains dry, and does not naturally run down 
into a liquid by absorption of water from the air. Although it is so soluble in water, it can be applied to the soil without any danger of washing out, because it there interacts with the humus and clay, and is converted into substances which are for the time insoluble. It should not, however, be used as a manure long before the plant is ready to take it up, because it is readily converted by the bacteria we have spoken of before into nitrates which do wash out of the soil. Sulphate of ammonia is therefore best employed as a top-dressing or for root crops, in which case it is put in the soil at the time of year when there is very little danger of any washing out. It is found by experience that when a concentrated nitrogenous fertiliser is needed, sulphate of ammonia is most suitable for shallow-rooted crops, like barley, swedes, turnips, potatoes. On chalky soils and on very heavy clays it is the most useful nitrogenous fertiliser, but it should not be used on light sands nor on peaty and other soils which have any tendency to get sour. Being such a concentrated fertiliser, only small quantities are, as a rule, required. It should be remembered also that when used as a top-dressing it will scorch and kill the foliage of any green plant on which it happens to rest. This is not because it is poisonous, but merely because any soluble salt in contact with the green leaf of a plant will draw water from the tissues, and eventually kill the leaf by so doing. For this reason sulphate of ammonia mixed with sand is often used to kill out weeds on lawns; when sprinkled over the lawn the soluble material lodges in the crowns and rests on the broad leaves of weeds like plantains, buttercups, and daisies, eventually killing them, whereas it does not touch the upright leaves of grasses but slips down to their roots and acts as a fertiliser. If a satisfactory result is to be obtained, however, the weather 
must remain dry; should rain come the sulphate of ammonia dissolves, washes down into the lawn, and fertilises weeds and grass alike. A more effective plan is to choose a fine morning and put a pinch of sulphate of ammonia into the crown of the plantains and other flat-leaved weeds.

Nitrate of soda is a substance obtained from certain extensive natural deposits in Chili, and has been brought to this country since about 1835 . It forms a grey or pinkish soluble salt which easily picks up water from damp air, and will even pass into a liquid state when left to itself. It is not retained in any way by the soil, and is most commonly employed as a top-dressing. Since it has to undergo no change but can feed the plant directly, it is the most active of all fertilisers, and is particularly effective in forcing on a plant into very rapid growth. Because of its immediate availability, it is also a specially valuable manure in early spring, when the natural processes producing ammonia and nitrates are so slowed down by the cold, that even in rich soils the plant is not obtaining sufficient nitrogenous food. Thus, nitrate of soda is particularly useful to the market gardener who needs to force on his crops rapidly or to get them growing specially early, and very large quantities are thus employed with profit. Nitrate of soda is particularly valuable as a top-dressing for wheat and maize, for grass land that is being laid up for hay, for mangolds, and for cabbages. On heavy soils it often forms an unsatisfactory manure, because it leaves the land in a state of bad tilth, very wet and sticky after rain, and then drying into hard clods. In such cases a mixture of equal parts of sulphate of ammonia and nitrate of soda is even more effective than either separately, and does not interfere with the texture of the soil. It is because of this bad effect upon the tilth that 
nitrate of soda gets called a stimulant or a scourge, and is considered to rob the land. This, however, is no more the case with nitrate of soda than with any other single manure. Whenever crops are grown with nitrate of soda alone, we are removing in the crop nitrogen, phosphoric acid, and potash, only one of which is being replaced, so that the land must inevitably become poorer in the other two constituents. But when nitrate of soda is employed with the potash and phosphoric acid that are equally required by the plant, the fertility of the land is maintained unimpaired, as may be seen from the Rothamsted experiments, where crops have been grown with such a mixture on the same land for nearly seventy years without showing any decline in the average yield. The other two fertilisers, nitrolim and nitrate of lime, are not so widely known. Nitrolim behaves in much the same way as sulphate of ammonia, but is slower in its action, and ought to be put on the land before a crop is sown. Nitrate of lime is very similar to nitrate of soda, though it has not the same injurious effect upon the texture of the soil. It should be mentioned that nitrate of soda is poisonous to stock, and deaths have been reported through animals licking the bags, or drinking water in which nitrate of soda had been dissolved.

Soot, the other manure which has been mentioned as containing nitrogen and no other fertilising ingredient, is chiefly used as a top-dressing for wheat in the spring. For this purpose it is very valuable, not only because of the fertilising effect of the small amount of nitrogen it contains, but also because it helps to protect the wheat from the attack of slugs and snails, which are very active at that time of the year. Moreover, the dark colour the soot imparts to the soil is of value, because it causes an increased 
absorption of the sun's rays, and on sunny days will raise the temperature of the soil by one or two degrees. Soot is very variable in composition, and cannot, as a rule, be purchased with any guarantee as to the amount of nitrogen it contains. "The best guide is its lightness. A good sample should be free from all admixture of cinders and similar refuse, and should not weigh more than $28 \mathrm{lb}$. per bushel.

The second of the great groups of fertilisers is made up of those which contain phosphoric acid as their valuable constituent. Of these, bones in various forms constitute the oldest and still among the most widely used of fertilisers. A bone consists of a mineral framework containing phosphate of lime mixed with a little carbonate. This mineral framework we can see left behind if we put an ordinary bone into the fire or in a muffle furnace. On the other hand, if we immerse a similar bone in dilute hydrochloric acid, after a day or two all the mineral matter will become dissolved in the acid, and there will be left behind the cartilaginous framework of the bone, consisting of material containing nitrogen, which will be converted into gelatine when heated up with water at high temperatures. At one time the bones were only roughly broken up, and then proved to be only a slow-acting, if effective, fertiliser. Nowadays it is customary to remove as much of the fat as possible, and then grind the bones to a fine powder, which is sold as "bone meal." Owing to the toughness of the organic matter contained in the bones, the bone meal is never really fine, and though it is highly valued on pastures and on some of the lighter arable soils, it is comparatively slow in its action and unremunerative in its results.

In addition to bone meal, various other manures are prepared from bones; sometimes they are treated with 
oil of vitriol, and yield a soluble acid phosphate, similar in its action to the superphosphate to be dealt with later. These dissolved bones or vitriolised bones, as they are called, form rather a damp mass, which is not very easily sown from a machine; they offer no special advantage over a mineral superphosphate which is cheaper, even after making allowance for the nitrogen the bone manure also contains. Again, the bones are sometimes submitted to the action of superheated steam before grinding, thus taking out of them most of the material containing nitrogen; the resulting steamed bone flour is a friable powder rich in phosphates but containing only about I per cent. of nitrogen, and forming a valuable manure on light soils. Bone manures, however, no longer possess their former importance when they were almost the only source of phosphates. For many years deposits of mineral phosphates of lime have been worked for manurial purposes. Sometimes these rock phosphates are ground to a very fine powder, which is practically insoluble in water but which does slowly become available to the plant in soils rich in organic matter and well provided with moisture. In the United Kingdom, however, such ground rock phosphates are rarely employed; as a rule, the mineral is treated with oil of vitriol and converted into the soluble phosphate known as superphosphate or acid phosphate. Superphosphate of lime, which, for manurial purposes, was invented by the late Sir J. B. Lawes, is the most widely employed of all the phosphatic manures. Being soluble in water, it becomes disseminated throughout the soil, and is there reprecipitated wherever it comes in contact with particles of carbonate of lime or humus. Thus the surface soil gets mixed with precipitated phosphate of lime in a very fine state of division, and it is to the fact 
that this precipitated material is so much finer and more thoroughly mixed with the soil than any ground insoluble material can be, that the activity of the superphosphate is due. Superphosphate is manufactured in several grades of concentration; it is adapted to all crops for which phosphatic manure is wanted, except for turnips on an acid soil where "finger-and-toe" occurs. Nowadays the great rival to superphosphate is a fertiliser called basic slag, which is obtained as a byproduct in the manufacture of steel from pig-iron, contaminated with phosphorus. As it occurs in commerce, basic slag is a very fine dark powder, insoluble in water, containing about 40 per cent. of phosphate of lime and also a certain amount of free lime. This free lime, together with an excess of loosely combined lime, gives the manure its basic character; it is alkaline in contradistinction to the acid nature of superphosphate, and it adds lime to the soil, whereas superphosphatic takes it away. The phosphates of basic slag are insoluble in water, but they are easily attacked by the carbon dioxide contained in the soil water, and it is found in practice that they are readily available to plants, especially upon soils that are damp and sour. Basic slag has proved of particular value as a fertiliser for all pastures on clay land, in which case the free lime that is also present adds greatly to the value of the manure. Its value as a fertiliser on arable land of a light and dry character has hardly been enough recognised in the United Kingdom. Basic slag is also sometimes known as Thomas's phosphate powder or basic cinder. It should be carefully distinguished from the ordinary slag of ironworks, which contains no phosphoric acid to make it valuable. Many of the compound fertilisers to be dealt with later also contain a considerable quantity of phosphoric acid; indeed some 
of the guanos contain so little else that they may be practically regarded as phosphatic manures, whose action is very similar to that of the steamed bone flour and bone meal mentioned above.

The third group of fertilisers are those which supply the element potash, but as this substance is naturally abundant in many soils, especially those containing much clay, the need for potassic fertilisers is not so much recognised, and they are less generally employed by farmers than either nitrogenous manures or phosphates. For a long time the only source of potash was the ashes of wood and other vegetable matter like kelp, but these sources have been entirely superseded by the opening up during the last half century of enormous mines of potash salts near Stassfurt, in Germany, whence the world's supply of potash is now almost wholly derived. Various grades of manures are put upon the market, the most common being an impure material containing about 12 per cent. of potash, which is called kainit, though nowadays it has little right to the title, since it consists almost entirely of chlorides of potash, soda, and magnesia. As a rule, kainit is just as valuable, potash for potash, as the more concentrated fertilisers, because the salt and other impurities wash out of the soil without doing any harm. In some cases, however, it is desirable to use pure materials, and sulphate of potash of two grades of purity, and muriate of potash, the most concentrated of all, can then be obtained. There is a general idea that with crops like potatoes, for which potash salts are largely employed, the sulphates give rise to better quality of the product than do the chlorides.

Of the compound fertilisers the oldest and still the most widely employed are the guanos, of which the Peruvian guanos, obtained from some of the rainless islands off the west coast of South America, are 
by far the most important. These guanos consist of the excrements of the sea-birds which frequent these islands in enormous numbers during the breeding season. Owing to the absence of rain, the material accumulates from year to year with very little change, and can be excavated and readily reduced to a fine powder. It, however, undergoes some slow process of decay and washing, so that while the recent deposits contain as much as 15 per cent. of nitrogen and only about 20 per cent. of phosphates, in the oldest deposits the nitrogen is reduced to less than 3 per cent., while the phosphates have risen to nearly 60 per cent. It is thus very important to purchase a guano according to its analysis, and not by its name alone. In any case these fertilisers will be found to be dearer than the same amount of nitrogen and phosphoric acid in other forms, the extra price representing the farmer's long experience of their kindly action upon his crops. The richer guanos, containing 6 per cent. of nitrogen and upwards, are extremely active fertilisers, the nitrogen being in forms which readily get converted into ammonia, and the phosphates being comparatively soluble in water. They are also very safe, well-balanced manures, containing nitrogen and phosphoric acid in much the same proportions as are required by plants, and also a little potash. Moreover, many different compounds of nitrogen are present which differ in the rate at which they will decay, so that the plant is fed continuously, and suffers from no excess of available nitrogen in the soil at any time. Such a fertiliser leads to a steady, equable growth, which is generally attended by superior quality in the product. Thus the Peruvian guanos become excellent fertilisers for crops where the quality is of importance, and where it is not necessary to cut down the expenditure on fertilisers to the lowest limit. 
Somewhat similar in their composition and in their action to the Peruvian guanos are a number of manures which are manufactured out of residues of meat and fish that accumulate in various processes of preserving, canning, and packing these articles for food. It is customary to extract as much as possible of the fat of these materials, and then reduce them to a very fine powder, which will contain nitrogen varying from 4 to Io per cent., and phosphates which lie between 10 and 50 per cent. These fertilisers decay in the soil, and yield ammonia in the same steady, continuous fashion as the nitrogen compounds of the Peruvian guano, and we may take it as a rule that the richer they are in nitrogen the more active will that nitrogen be. Meat and fish guanos, as they are called, form valuable fertilisers for perennial crops like fruit and hops, and may also be mixed in small quantities with purely mineral manures to form fertilisers for root crops. Rougher manures of this class are sometimes known as tankage, or as greaves, and are comparatively slow acting, some of them approach closely the bone meal described above. The nitrogen they contain should be reckoned as of less value than in the more concentrated fertilisers. Naturally all these classes of meat and fish residues can only be valued at the basis of their analysis. A meat guano, for instance, may be a highly nitrogenous fertiliser worth $£ 8$ or $£ 9$ a ton, or on the other hand, little better than a bone meal costing half the price.

Very similar in their actions to meat and fish residues are certain vegetable residues which from time to time can be purchased as fertilisers. The best known of them is rape dust, which consists of groundup residues of impure rape seed from which the oil has been extracted by chemical processes. As a rule, such seed residues from which oil has been extracted are 
employed as cattle food, but sometimes they contain substances injurious to stock, like the rape seed we have just mentioned and the cake which is derived from pressing castor-oil seeds, or they have become damaged in some way and are only utilisable as manure. Such materials contain, as a rule, about 5 per cent. of nitrogen and comparatively small quantities of phosphoric acid and potash, but when cheap they form very valuable manures, especially on light soils. Many other industrial residues get occasionally employed as fertilisers, in fact, anything of animal origin, like wool and silk, fur, hair, etc., contains nitrogen, and is thereby valuable as a fertiliser. Residues from the textile factories dealing with wool and silk, and fur or feathers, are sold in the United Kingdom under the general term of shoddies; they are extremely variable in composition, ranging from 3 to 13 per cent. of nitrogen, and they are always slow in their action, partly because the material itself is not readily attacked by bacteria, and partly because of the difficulty of getting the material finely divided and disseminated through the soil. But when they can be bought cheaply, such residues form valuable fertilisers for perennial crops. It should be kept in mind that vegetable fabrics like cotton, linen, and jute contain no nitrogen, so that their residues are valueless as manure.

In dealing with fertilisers it is necessary that the farmer should bear in mind the very different action of the three constituents upon the plant, for although all three substances-nitrogen, phosphoric acid, and potash -are equally necessary to the growth of the plant, as we have seen when considering water cultures, yet they possess very different functions in its development. Nitrogen is mainly concerned with the vegetative development of the plant, and increases the tendency to form leaf and stem; thus if a plant is given an excess 
of nitrogenous manure, the leaf system becomes excessive, a great number of shoots are formed, and the plant tends to go on growing rather than to turn to the production of flowers and fruit. Large quantities of nitrogen are thus valuable for leafy crops of fodder such as grass, kale, cabbages, etc. At the same time it is always found that the rapid growth promoted by excess of nitrogen is both soft and long-jointed, and is very susceptible to attacks of fungoid disease. Cereal crops grown with an excess of nitrogen are readily laid by wind or rain, and the susceptibility to disease of plants overdosed with nitrogen is often well seen under greenhouse conditions. If nitrogen promotes the vegetative side of the plant, phosphoric acid, on the other hand, hastens maturity and favours the reproductive side of its development, as, for instance, the production of fruit and seed. It is found by experience that the ripening of crops can be accelerated by a liberal use of phosphatic manures; perennial plants like fruit trees can be similarly induced to fruit rather than to grow. All these actions of phosphoric acid are most apparent on heavy soils and in wet seasons, when the natural conditions make for slow maturity. Phosphatic manures never give rise to the immediate burst of growth and the dark colour and look of vigour which follows the application of nitrogen; their effect is only to be seen at harvest time, and particularly in the proportion the fruit bears to the rest of the produce. In consequence, the use of phosphates is often ignored, while nitrogen has been too much employed because its effects are so manifest. Potash is particularly concerned in the manufacture of carbohydrates by the plant; it is therefore particularly valuable to crops which, like mangolds, contain a good deal of sugar or, like potatoes, a good deal of starch. Being so necessary to the assimilation 
by the plant, potash tends to keep them growing, especially on light soils and in dry climates, under which conditions it exerts its maximum effects. It is also found to help in stiffening the straw of cereals and grass, and it increases the disease-resisting powers of all plants.

But though we can thus distinguish between the effects of the different fertilising constituents, we are rarely able to argue from this knowledge as to the requirements of the particular plants. That we must ascertain by practical experiments, and as an outcome of our fifty years' experience with fertilisers, we now know pretty well the special requirements of our various farm crops. To some extent the manurial treatment of a crop is determined by the place it occupies in the rotation that is being followed. It is comparatively rare to find the same crop occupying the same land year after year, and under ordinary farming conditions the soil very often receives a fertiliser, the effect of which has to extend over several succeeding crops. Again, in considering the amount and nature of the fertilisers to be purchased, the farmer has to take into account the style of his farming, whether high or low. Wherever the land is not naturally rich and the markets are such that the farmer cannot obtain a large return per acre for his crops, he must cut his expenditure down to low limits, and only indulge in purchased fertilisers to a very limited extent. He must follow a conservative system of farming, being content with comparatively low yields, the material for which has in the main been derived from the soil. We should always remember that the first application of manure is the one which produces the largest increase in the crop, and that if we double the manure bill we shall not obtain a double yield or even a double increase over that which is given by onehalf the manure. In fact, if we go on increasing the 
amount of manure, we shall soon reach the stage when the last addition has no effect at all. This "law of diminishing returns," as it is called, means that a farmer cannot recoup himself for low prices by forcing big crops with the aid of fertilisers. The increase thus bought is the dearest part of the crop. For every farm there is a sort of level of expenditure on materials like fertilisers, and the more profitable and the richer the land, and the more valuable the crops that can be sold, the higher will this level become. Bearing this fact in mind, we find that in Britain the wheat crop rarely receives any fertiliser, except perhaps a small topdressing of nitrate of soda or soot in the early spring. Wheat has a long period of growth and an extensive root system, whereby it is able to forage for itself pretty thoroughly, and obtain all the phosphates and potash it requires from soil in ordinary good conditions. As, however, it makes its growth during the period of the year when the soil is comparatively cold, and as the soil has received very little cultivation before the wheat is sown, and none at all while it is growing, the processes which produce ammonia and nitrates out of the nitrogenous residues of the soil cannot be very active at the time the wheat chiefly requires its nitrogen. Hence the value of nitrogenous fertilisers to wheat in the spring, whereas phosphates and potash meet with very little response. If nitrogen is the dominant fertiliser for wheat, barley, on the other hand, chiefly demands phosphates. It is a comparatively shallow-rooted plant, and makes its growth in the late spring on land which has been much more thoroughly prepared than that on which the wheat crop is sown. In the United Kingdom barley is very often grown on land which is already comparatively rich because the ground has been previously occupied by the turnip crop, which may even have been 
consumed in situ by sheep. In such cases the land is already rich enough; in fact, it contains too much readily available nitrogen to give rise to the best quality of malting barley. But when barley follows wheat on some of the poor soils, a fertiliser is required, and this should be composed of a little nitrogen and a fair amount of phosphates. Oats can be treated in much the same way as barley, but they are often grown on land which has just been broken up from pasture and grass, in which case they are rarely likely to require much fertiliser. Of all the cereal crops, maize will respond most freely to fertilisers; to it should be given all the farmyard manure that is available, 200 or 300 1b. per acre of acid phosphate, and perhaps a later dressing of some active nitrogenous manure like nitrate of soda. Of the root crops, swedes are specially dependent upon phosphoric acid, and, whether this crop is grown by the help of farmyard manure or by artificial manures alone, it will be found necessary on all classes of land to use for it 4 or $5 \mathrm{cwt}$. to the acre of superphosphate or basic slag. Little nitrogen is wanted, because the crop is growing in the warmer period of the year and after a very thorough preparation of the soil, so that the production of available nitrogen compounds is going on actively in the soil. Mangolds, on the other hand, are more deeply rooted plants, and are sown at a cooler time of year; it is found by experience that they respond to very considerable quantities of nitrogen, and that they also pay for application of manures containing potash, though phosphatic manures are less necessary. Clovers, beans, lucerne or alfalfa, and other leguminous crops are rarely manured; they should not be given nitrogen, but they will respond to dressings of phosphates and potash, especially upon the lighter and sandier soils. 
The manuring of grass land is too big and complicated a subject to be dealt with here in any detail. Very often indeed the grass land receives no artificial manure at all; the farmer trusts to the fertilising effects of the cake and other foods consumed by stock on the land to maintain its fertility, even when he grazes it one year and lays it up for hay the next. It will, however, be found more profitable to hay the same land every year and keep up its fertility by manuring because in that way the growth of the stronger grasses which go to make a big hay crop is encouraged, whereas they are repressed by a summer's grazing and their place more or less taken by smaller bottom herbage which cannot figure largely in the hay crop. Speaking generally, when supplying manure for hay we want to remember that nitrogenous manures will promote the growth of grasses at the expense of the other constituents of the herbage, until, as we see on some of the Rothamsted grass plots, the continuance of a nitrogenous manure year after year for a long period will cause the whole herbage to be made up of grass alone. On the other hand, phosphates and potash without nitrogen stimulate the development of clovers and other leguminous plants. The herbage is not so bulky, but weight for weight is more valuable as food for stock. Thus a manure for hay should contain nitrogen in order to get bulk, but should also contain a due proportion of phosphates and especially of potash, to keep up the clovers and to give feeding value to the products. On pasture land we want chiefly to encourage the clovers, and therefore use fertilisers containing no nitrogen-either basic slag alone when the land is rich in potash which the lime in the basic slag will liberate, or basic slag and kainit on the lighter soils. If we can only encourage the growth of the clovers in the pastures 
sufficiently, the nitrogen they collect from the atmosphere, which mostly comes back to the land when the herbage is grazed off, will be sufficient to keep up the fertility of the soil.

As to the time of application of artificial manures, it has already been said that nitrates are not retained by the soil, so that nitrate of soda and sulphate of ammonia, which so readily changes into nitrate, can only be employed as top-dressings in the spring, when the crop already occupies the ground and is ready to utilise them. Practically there is very little danger of even the most soluble of quick-acting manures washing down beyond the reach of the plant in spring or summer. Consequently all kinds of fertilisers may be safely ploughed into the ground from the month of March onwards, except on the very lighest soils. The application of spring manures is often needlessly delayed from a mistaken apprehension that materials like superphosphate can be washed out of the land. Insoluble fertilisers like the shoddies amongst the nitrogenous manures, and basic slag amongst the phosphatic, should be put on as early as possible, and may be ploughed or dug into the soil in the autumn or early winter.

Table XXV. at the end of this chapter gives a number of analyses of the fertilisers with which a farmer is most likely to meet, but it should be borne in mind that many of these substances vary naturally in their composition, so that any particular sample can only be properly judged by the analysis of that actual parcel. In the United Kingdom, and indeed in all other civilised countries, the vendor must supply an analysis of the article he is offering for sale, which analysis has the force of a guarantee. Given such analyses of a series of suitable fertilisers, the farmer should then learn to value them one against another. The most ready way 
of doing this is by what is called the unit system, the unit being I per cent. of a ton of the fertilising constituents-nitrogen, phosphate of lime, and potash. The value of a unit of each of these constituents will vary with market fluctuations, and to a certain extent with the place of delivery. Thus the exact values prevailing at any moment can only be obtained by special calculations, but for purposes of comparing one fertiliser against another in the United Kingdom it will be sufficiently accurate to consider that the unit of nitrogen is worth I4S., the unit of phosphate of lime 2s. if it is soluble, and $15 \mathrm{~d}$. if insoluble, while the unit of potash may be reckoned as worth $4 \mathrm{~s}$. Working on these principles, fish guano containing $7 \frac{1}{2}$ per cent. of nitrogen and I 3 per cent. of phosphate, should be worth about I 2 Is., made up as follows :-

$$
\begin{gathered}
\begin{array}{c}
7 \frac{1}{2} \text { of nitrogen at I4s. } \\
+13 \text { of phosphate at Is. } 3 \mathrm{~d} . \\
\text { Total. }
\end{array} \\
\begin{array}{c}
\text {. } \\
\text {. }
\end{array}
\end{gathered}
$$

As this fertiliser was offered to a farmer at $146 \mathrm{~s}$., it must be regarded as dear when compared with the meat meal containing 7 per cent. of nitrogen and 30 per cent. of phosphate, which was offered at the same time at $127 \mathrm{~s}$. $6 \mathrm{~d}$. Valued on the same principle, this later manure is worth, 7 of nitrogen at $14 \mathrm{~s} .=98 \mathrm{~s} .+30$ of phosphate at Is. $3 \mathrm{~d}$. $=37 \mathrm{~s}$. $6 \mathrm{~d}$., or a total of $135 \mathrm{~s}$. $6 \mathrm{~d}$. By making valuations in this fashion of the manures on offer in the market, the farmer is often able to buy much more cheaply than he would if he stuck to the same kind of fertiliser year by year, independently of their fluctuations in market value. For some kinds of fertilisers which are subject to natural variations it is very necessary that the farmer should obtain an analysis after the delivery of the bulk, in order to compare it 
with the guarantee upon which he has bought. Such analyses are rarely necessary when dealing with reputable merchants for such standard articles as nitrate of soda, sulphate of ammonia, superphosphates, and potash salts, but all residual materials like meat and fish guanos and basic slag are subject to variations in composition which may not have been recognised by the vendor. When a farmer purchases large quantities of any of these articles it will always pay him to get the deliveries checked by analysis. However, as the material varies naturally, it is of the first importance that the farmer should sample the bulk very carefully so as to get a portion thoroughly representative of the whole.

TABLE XXV.-COMPOSITION OF VARIOUS FERTILISERS:

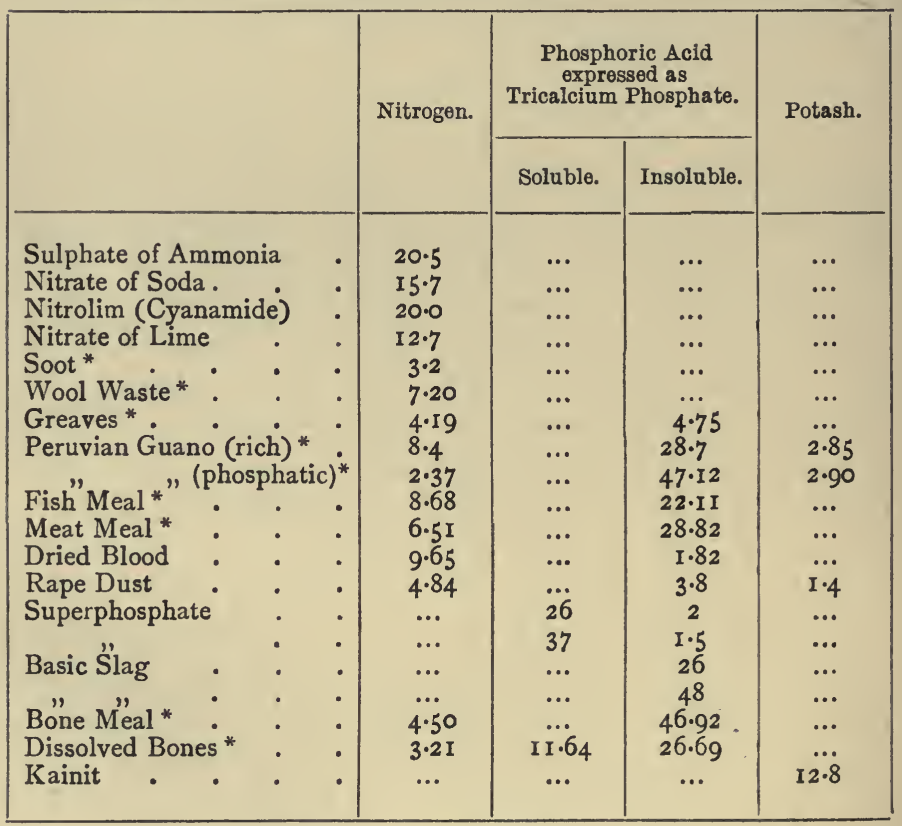

* Subject to considerable variation. 


\section{CHAPTER XIV}

\section{MILK, BUTTER, AND CHEESE}

Composition of Milk. Variations to which the Composition of Milk is subject. Effect of Individuality, Breed, Food, Time of Milking, Period of Lactation. Feeding for Milk. Composition of Butter. Nature of the Churning Process. Effect of various Foods upon the Quality of the Butter. Composition of Cheese. Changes taking place during the Cheese-making Process. The Ripening of Cheese. Importance of Cleanliness in all dealings with Milk.

MILK is not a simple substance, but a mixture of a large number of different bodies which are present in fairly definite quantities, though they are, subject to certain variations to be discussed later. By weighing out a small quantity of milk into a dish so that the milk only forms a thin layer over the bottom, and putting the whole into an oven to dry, we can show that the greater part of milk consists of water, 'there being, as a rule, not more than 12 per cent. of total solids in the milk. This important figure-the amount of total solids in the milk-can only be determined exactly by getting the milk spread out into a very thin layer before drying it, so readily does a skin form over the surface and cause the drying of the rest of the milk to proceed with difficulty. Among the milk solids at least three are characteristic. In the first place there is the fat, present to the extent of 3 per cent. or more; then proteins to the extent of about $3 \frac{1}{2}$ per cent., the greater part of which is commonly called casein; then lactose or 
[CHAP.

milk sugar forms another $4 \frac{1}{2}$ per cent. In addition to these three carbon compounds, the milk solids contain certain inorganic materials, chiefly phosphates and chlorides of calcium and potassium and sodium, some of which inorganic materials are, however, combined with the proteins.

Milk Fat.-The fat of milk is there present in a state of finely divided globules varying in size from $0.01 \mathrm{~mm}$. to $0.00 \mathrm{Im}$., i.e. from $\frac{1}{2500}$ of an inch to $\frac{1}{10}$ of that diameter. When examined under the microscope these minute globules appear to have a skin upon the surface, but this skin probably consists of nothing more than adhering particles of the casein, which also is not truly dissolved in the water of the milk. The fat globules vary in size, the milk of Jersey cows contain the largest, in the Guernseys and in the other Channel Island breeds they are almost as large, and they are also well above the average size in the milk of Kerrys. In the milk of the Shorthorns, globules of various sizes may be found, but the small predominate; the Welsh and South Devon, the Dutch and Holstein races, yield milk containing rather small globules. In these globules the fat is present in the liquid state, although the temperature of the milk may have cooled down below the temperature at which the fat solidifies in bulk. In such small particles, however, the fat remains liquid in a supercooled state, only assuming a solid condition when the globules are beaten together, as in the act of churning. The fat is lighter than water, possessing a specific gravity of 0.93 . In consequence, the globules tend to rise upwards through the heavier milk serum, and they are only hindered from rising rapidly by their smallness and the high viscosity of the milk serum. The larger the particles, however, the more quickly do they rise, as may be seen in the quicker 
and more thorough creaming of the milk from Jersey cows. When the milk fat is separated and examined it proves to be a complicated substance, consisting, like all fats, of a combination of glycerin with certain so-called fatty acids. In butter fats there are a large number of these fatty acids present, differing from one another in their physical constituents, some members being volatile and strongly smelling liquids, while others are solid substances, possessing little smell or taste. We can obtain an idea of these acids of butter fat by taking about a gramme of the clarified fat and warming it with 20 c.c. of a solution of potash in alcohol. If the fat is stirred up it will eventually dissolve, the glycerin being set free, while the acids combine with the potash to form a soap. The mixture is now dried up to get rid of the alcohol, and treated with dilute sulphuric acid, which decomposes the soap and sets free the fatty acids. These substances will then be found to possess a very powerful smell of rancid butter, the smell being due to butyric and one or two of the other volatile acids. As the liquid cools the non-volatile acids, which are also insoluble in water, will solidify to a cake on the surface of the liquid. The flavour of butter is due to the liberation of a very small trace of some of these volatile fatty acids through the action of bacteria upon the butter fat. If too much is liberated the smell and taste become too pronounced, and we call the butter rancid. The composition of the butter fat itself is not constant, but varies with the season of the year, the nature of the food, and the period of lactation. Hence follows a variability in the composition of pure butter fat which constitutes the chief difficulty in detecting adulterations of butter, for most of the methods of analysing butter depend upon determinations of the proportion of volatile and insoluble fatty acids. 
Protein.-Of the proteins of milk the chief is a body called casein, which is distinguished by its property of forming a firm curd when treated with the enzyme of rennet, or a flocculent curd when treated with acids. The casein is a compound of carbon containing 15.7 per cent. of nitrogen and about 8 per cent. of sulphur and phosphorus respectively. It is present in milk probably combined with calcium; the resulting salt is not soluble in water, but exists in normal milk in a finely divided state diffused through the serum, forming what is known as a colloidal suspension. Rennet, which consists of a solution of the enzyme which is present in the fourth stomach of a calf, causes the casein to coagulate and form a firm curd, in which are also enclosed the fat globules of the milk. The rapidity of the action of the rennet and the firmness of the resulting curd are increased at higher temperatures, but the presence of a soluble lime salt is necessary before the curd will form. For this reason, perfectly fresh milk will not curdle with rennet, a certain amount of acid must first have been developed, which formation of acid takes place naturally when the milk stands, by the action of certain bacteria, which always find their way into the milk and convert the milk sugar into lactic acid, the substance characterising sour milk. It will be seen later that the development of acidity and the establishment of a suitable temperature are very essential to obtain the curd of proper consistency for cheese-making. After the casein has been precipitated from milk by the action of rennet or acids, the milk still contains about 0.6 per cent. of other proteins, chiefly of albumen, which begins to coagulate when the whey is heated to temperatures above $70^{\circ}$.

Milk Sugar.-The solid body which is present in largest amount in milk is a particular sugar known as 
lactose, which differs from ordinary sugar in its lesser solubility and in its lack of sweetness. Milk sugar may be obtained by evaporating down the whey after the casein has been coagulated and the albumen removed by heating up to boiling-point. Milk sugar does not ferment with ordinary yeast, 'but can be fermented into alcohol and carbon dioxide by certain special yeasts such as those employed in making kephir and koumiss-fermented liquids used by the Mongol races. The most characteristic fermentation of milk sugar, however, is that brought about by the lactic acid bacteria, which are always about in cows' stalls, etc., and find their way into the milk; they multiply with great rapidity in the warm milk, and split up the sugar into lactic acid, while at the same time they oxidise some of it into carbon dioxide and water. These organisms are responsible for the usual natural souring of milk, in which the casein is precipitated as soon as the acidity reaches a certain degree. It is because the development of the lactic acid bacteria is so much accelerated by warmth, that it is important to cool milk down by the refrigerator immediately after it has been drawn from the cow, if the milk is to be sent any distance by rail and not used immediately.

Composition of Milk.-The average composition of milk in England is given by Droop Richmond as follows, the figures being the average of about 200,000 analyses:-

\begin{tabular}{|c|c|c|c|}
\hline Fat . & . & - & 3.90 \\
\hline Protein. & . & . & 3.50 \\
\hline Lactose & . & • & $4 \cdot 75$ \\
\hline Ash . & - & - & 0.75 \\
\hline \multirow[t]{2}{*}{ Water } & . & $\cdot$ & $87 \cdot 10$ \\
\hline & Total & . & 100.00 \\
\hline
\end{tabular}


Though this average composition is very well maintained when a large number of analyses are considered, the milk from a given cow may vary very widely from the average, and these variations are governed by the factors set out below. It will, however, be found that the chief variable is the amount of fat; though the solids also vary, the differences are never so great as those of the fat.

I. Individuality.-In the milk of the cows composing any given herd, although they may be all animals of the same age belonging to the same breed and all treated alike as regards food and housing, there will be found considerable variations in composition. In an ordinary mixed herd of Shorthorns, cattle not specially selected, it will generally be found that some of the cows habitually yield milk containing less than 3 per cent. of fat, while in others the percentage is well over 4. These differences are known to be hereditary, so that not only can the average composition of the mixed milk of the herd be considerably raised by weeding out the animals yielding poor milk, but by steadily breeding only from those cows which yield milk possessing a high percentage of fat, a very considerable and permanent improvement may be effected in the milk.

2. Breed.-It has already been mentioned that the Jerseys and other Channel Island cattle yield milk in which the fat globules are above the average size. It is also found that these races produce milk containing a higher proportion of fat. The following table shows the average analyses of the milk of a number of races of cows which are usually kept in milk in the British Isles. The effect of individuality must also be superimposed upon these average figures, so that single.cases occur in 
which the butter fat in the milk of Jerseys rises to 6 or 7 , and even IO, per cent.

Table XXVI.-Percentage of Fat in Milk of

DIFFERENT BREEDS.

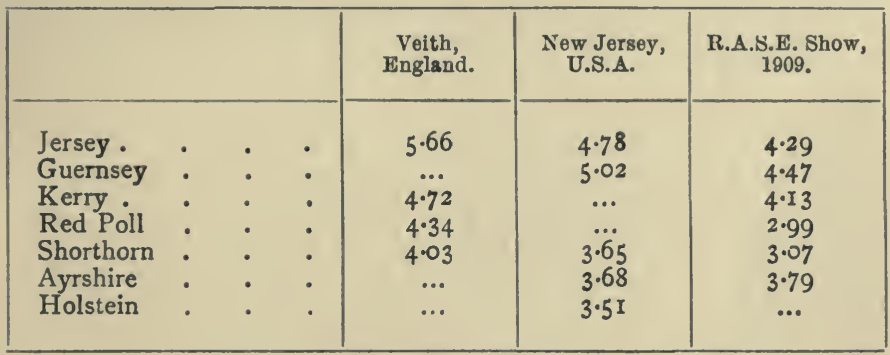

3. Food.-It is commonly supposed that the percentage of fat in the milk of a given herd can be raised by feeding concentrated foods rich in fat. Experiments, however, show that the difference which can be brought about in this way is very small; the proportion of fat contained in the milk yielded by a given cow being a physiological function of the cow itself, it is comparatively unaffected by the food. If the amount of food given be insufficient for the average requirements of the cow, the animal will begin to lose weight, and will draw the material from its own tissues in order to keep the yield of milk and the proportion of butter fat up to its normal percentage; only when the cow has lost an appreciable amount of weight will both the yield and the richness of the milk begin to fall off more markedly. On the other hand, an excess of rich food will cause the cow to put on fat, and as the cow gets very fat the milk will again begin to fall off both in quality and quantity. A high proportion of fat in the food does not make the milk any richer in fat. The chief effect of a liberal but not excessive diet appears to be to maintain the milk yield somewhat longer during the period of lactation 
than would otherwise be the case. Nor do particular foods have any permanent effect upon the richness of the milk. It is generally found that a slight change of food exerts a stimulating action for a short time upon the milk yield, though drastic changes may have the reverse effect and temporarily reduce the yield and quality of the milk; in any case the effect does not persist for many days. Certain classes of succulent foods which are very rich in $a$-proteins, such as brewer's grains, green fodder, and especially fresh grass at its first shoot in the spring, have an exciting effect in promoting the flow of milk. Particularly does the first grass, after the cows are turned out, give rise to an abundant production of comparatively poor milk. Lack of green food is also apt to result in a falling-off both in the yield and the quality of the milk, and a large quantity of watery foods eventually results in thin and poor milk.

The quality of the butter is, however, considerably affected by the nature of the food, because the composition of the butter fat varies with the material out of which it is manufactured by the cow; in some cases indeed the fatty acids contained in the food can again be identified in the butter fat. An excess of fibrous foods-hay and straw or over-ripe forage crops-gives rise to hard, tasteless butter; peas and beans and cottonseed meal or cake also harden the butter. On the other hand, linseed cake gives rise to a soft and oily butter, and maize and gluten feeds, oats and rice, also tend to soften the butter. The feeding of turnips and swedes, except some time before milking, communicates a characteristic and disagreeable flavour to the butter, while it is well known that the flavour of certain strongly smeiling plants like wild garlic is carried over to the butter. 
4. Period of Lactation.-Immediately after calving the cow yields milk of abnormal composition, the product being a thick yellowish liquid, which coagulates on boiling and is known as colostrum or beastings. The colostrum at first contains only about 70 per cent. of water and something like 20 per cent. of proteins, of which albumen is by far the most abundant, the casein being present in only about the normal proportion. After four or five days the colostrum, which is necessary for the first nutrition of the calf, passes into ordinary milk. During the first month or two after calving the yield of milk is at its greatest, and then gradually falls off until the cow becomes dry, after nine or ten months. During the first flush of milk the proportion of butter fat is at its lowest, it then reaches its average amount, and afterwards rises again as the cow begins to dry off. The influence of the period of lactation may be to some extent disguised by the time of year at which the cow calves down, and the effect of such changes as turning the cow out to grass.

5. Age.-While it is difficult to obtain strictly comparable results, there is evidence that the milk yield improves up to about eight years of age, after which a decided falling-off begins to set in about the twelfth year. The percentage of butter fat drops a little for the first few years, and then remains constant until the eleventh year or so, after which it begins to fall rapidly.

6. Time of Milking.-As a rule, in Great Britain cows are milked twice a day, at intervals separated by very unequal lengths of time. It is not uncommon, for example, to find cows milked at five or six o'clock in the morning and again about two o'clock in the afternoon, thus dividing the day into one period of sixteen and another of eight hours. It is always found that 
after a long interval, i.e., generally in the morning milk, the yield is larger, but there is a corresponding fallingoff of quality. The morning's milk very often contains less than 3 per cent. of fat, when the evening's milk may contain well over 4 , and the average milk of the herd is something like $3 \frac{1}{2}$ per cent. The following table will

TABIE XXVII.-VARIATION OF YiELD AND COMPOSITION OF MILK WITH INTERVAL OF MiLKING.

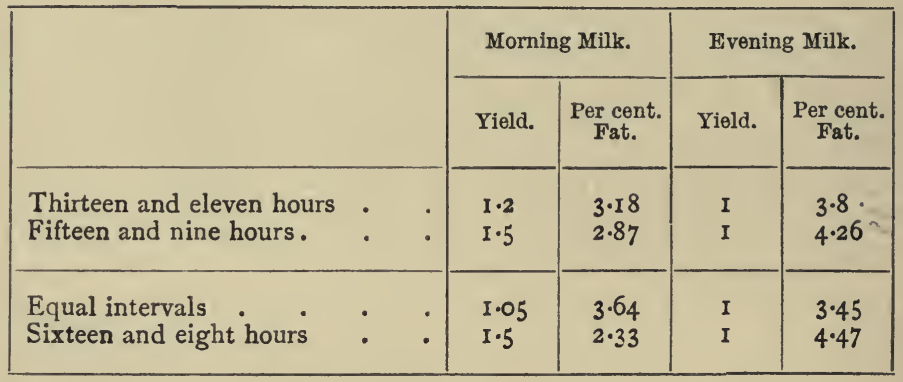

show an example in these variations in yield and composition. It is impossible to get over these variations by any alteration in the food of the animals, although, as a consequence, the morning's milk often falls below the legal standard of butter fat. In order to avoid trouble on this score it is necessary to milk at intervals of twelve hours, and hold back the evening's milk in a refrigerated condition for the morning delivery. Milking three times a day is sometimes resorted to, and there is some evidence that the secretion of milk is thereby stimulated.

The milk that is first drawn from the udder is always poorer than the last drawn, or the strippings. Consequently, the milker can seriously lower the average composition of the milk unless care is taken to thoroughly strip the cow and make her yield all the 
milk that is possible. Table XXVIII. shows the amount of butter fat in the successive portions of milk taken from the cow.

TABLE XXVIII.-COMPOSITION OF SUCCESSive PoRtions of MILK TAKEN FROM THE COW.

\begin{tabular}{|l|r|r|r|r|r|r|}
\hline Total solids : & $\begin{array}{r}\text { I0.47 } \\
\text { Fat. }\end{array}$ & $\begin{array}{r}\text { IC.75 } \\
\text { I.76 }\end{array}$ & $\begin{array}{r}\text { I0.85 } \\
2.10\end{array}$ & $\begin{array}{r}\text { II.23 } \\
2.54\end{array}$ & $\begin{array}{r}\text { II.63 } \\
3.14\end{array}$ & $\begin{array}{r}\text { I2.67 } \\
4.08\end{array}$ \\
\hline
\end{tabular}

7. Other causes of disturbance.-It is found that cows are extremely susceptible animals, easily disturbed both in the yield and composition of their milk by any external causes which excite the animals. Change of location into a new building, going out to grass, any sudden fright, a thunderstorm, or a marked change of temperature, will often be found to exert a considerable influence upon both the yield and the composition of milk. In fact, if the composition of the milk of a single cow be examined day by day, it will be found to show a number of irregular variations both in amount and composition, which are to be accounted for by minor disturbances of this kind. It is thus necessary, when one wishes to ascertain the average composition of the milk produced by a given cow, to make up a composite sample representing the milk yielded during at least one week. This should be done by putting aside after each milking a small quantity proportional to the yield on that occasion, a preservative being added to the mixed sample in order to retain it in a condition for analysis up to the end of the week.

From these particulars it will be seen that the farmer engaged in the production of milk should first of all pay attention to the yield and composition of the milk produced by each individual cow. By keeping his 
records of the milk yield of each cow from day to day, and by occasional analyses, he will be enabled to obtain the most profitable returns from his cows. Cases are on record where the milk yield of a herd has been raised by 100 or 200 gallons per cow per year by the keeping of careful records and the weeding out of the poorer animals. If the farmer is selling milk it will be sufficient for him to obtain occasional analyses of the mixed milk in order to see that it keeps above the legal standard; but if he finds it is falling too low, it may be necessary to examine into the composition of the milk of the single cows, in order to weed out those who are reducing the percentage of fat to a dangerous degree. When, however, a farmer is making butter from his milk he is less concerned with the total amount of milk yielded than with the amount of butter fat itself, and it is to such a farmer that a knowledge of the average composition of the milk yielded by each animal is of the first importance. As regards the feeding, we have seen that this should be liberal but not excessive, if either too high or too low the cow will begin to fall off in both yield and quality after a certain time. Perhaps the best test that the food is being maintained at a right level, is to weigh the cows from time to time. If they are slightly gaining in weight we may be sure that the food is at about the right level. Very often in this country cows are fed excessively and wastefully owing to the mistaken idea that the greater and richer the amount of food the better will be the production of milk. Perhaps the greatest economy in feeding cows can be effected by roughly adjusting the amount of food to the weight of the cow and the yield of milk. Properly speaking, a cow's rations should be made up of the amount of food required for maintenance, which will vary simply with the weight of the cow, together with the 
amount required for the production of the milk she yields, which may be taken to bear approximately the same relation to the food as the live weight increase does in the case of the fattening animals. For practical purposes considerable economy can be effected in the feeding of the herd if the cows are divided into three or four groups, according to their weight and their milk yield. The cows should have first a basal ration, supplying each with about $25 \mathrm{lb}$. of dry food per $1000 \mathrm{lb}$. live weight, this food to contain about I lb. of digestible protein and $\frac{1}{2} \mathrm{lb}$. digestible fat. Next, for each Io $\mathrm{lb}$. of milk, food with a starch equivalent of about $5 \frac{1}{2} \mathrm{lb}$. and containing about $\mathrm{I}_{2}^{\frac{1}{2}} \mathrm{lb}$. of protein, is necessary. The cows can easily be divided into three groups according to their milk yields (allowing also a little for their live weight), and given one, two, or three measures of concentrated food in addition to the basal ration which all receive alike.

\section{ButTER}

The essential feature of butter-making consists in agitating either the whole milk or the cream until the fat globules coalesce and form clots the size of shot, at which stage the butter is said to have "come." Whole milk is very rarely churned nowadays; instead, the milk is first of all set for twenty-four or forty-eight hours and the cream skimmed off, or the cream is separated by some mechanical separator, as in all modern dairies. In the old-fashioned methods of making butter, the milk, when still warm, is poured into shallow pans, which are left to stand in a cool dairy, whereupon the fat globules slowly rise to the surface, and the layer of cream is skimmed off. The separation, when effected in this way, is not very perfect, about 0.8 per cent. of the fat being left in the skimmed milk. Instead of shallow 
pans, deep metal vessels jacketed with ice were sometimes employed, by which means a very effective separation of cream was brought about, but an even larger quantity of fat, over I per cent., was left in the milk. The only real gain in this process was that the cream was protected from the influx of the harmful bacteria. Where any large quantity of butter is made, the mechanical separator is now invariably used. These instruments depend for their action upon bringing the milk into a violent whirling motion by making it flow into a bowl revolving at the rate of about 6000 revolutions per minute. Under these conditions the force of gravity, which tends to separate the lighter fat globules from the denser milk serum, is exchanged for a centrifugal force many times greater, which draws the heavier serum to the outside of the bowl and leaves the lighter cream at the centre, suitable ducts being arranged to take away the two liquids which have thus been separated. The cream which is obtained from the separator may contain anything from $\mathrm{I}_{5}$ to 50 per cent. of fat, according to the velocity at which the separator is run. The separated milk, which is the name given to the liquid from which the cream has been removed, contains as little as O.I 5 per cent. of fat when the separator is working properly; the rest of the serum possesses the same composition as it does in uncreamed milk. After the cream has been separated it may be churned at once, in which case the product is known as sweet-cream butter, but the flavour is then somewhat inferior and the yield of butter is lower. It is customary to put aside the cream for at least fortyeight hours in order to develop a certain amount of acidity before churning. While the cream is thus ripening it should stand in a warm place, as nearly as possible $65^{\circ} \mathrm{F}$. and should be stirred from time to time 
in order to aerate it. Unless the cream is kept aerated the bacteria making lactic acid may give place to others producing butyric acid, to the great detriment of the flavour of the resulting butter. When the cream is properly ripe it should be brought to an appropriate temperature before churning, this temperature being about $60^{\circ}$ in the winter and $55^{\circ}$ in the summer. The length of time occupied by churning will depend upon getting a proper proportion of cream and water and a correct adjustment of temperature. When the churning begins, it is necessary with sour milk in a closed churn to open the ventilator in the churn from time to time during the first five minutes of churning. The agitation of the cream liberates a certain amount of carbon dioxide which had been formed by the lactic acid bacteria and was dissolved in a supersaturated condition in the serum of the cream, and unless this carbon dioxide is liberated from the churn the whole of the cream will pass into a frothy or whipped condition. As soon as the granules of butter have reached the size of small shot the process is nowadays stopped, and the butter is washed to free it from all adhering milk serum before it is worked up into pats. Unless this washing is thorough the butter will not keep, because the small amount of casein and milk sugar left in when the washing is imperfect provides a very favourable nutrient medium for the development of bacteria, which will split up the butter fat and set free some of the disagreeably flavoured fatty acids. The resulting butter is not pure butter fat but contains a proportion of water depending on the velocity and the temperature of the churning, and also upon the method of working the butter afterwards. Rapid churning at high or at very low temperatures will give rise to a number of very finely divided globules of water inside the butter fat, and these cannot 
be removed by any subsequent working. What visible water there is in butter has been left in through imperfect work on the butter table. Well-made butter should not contain more than 15 per cent. of water, though as much as 18 may be not unfrequently found. In addition to the water a certain amount of curd, i.e., coagulated casein, and of lactose derived from the cream serum, are always present, together with whatever salt has been added to the butter in the process of making up. From this account it will be seen that no chemical action takes place during the making of butter; it is a mechanical process whereby the fat globules are made to coalesce by being beaten together until the surface layer which prevents them from uniting in milk, has been broken down. Success in churnirig depends upon obtaining the right degree of acidity at starting, and then working at the proper temperature. In the further treatment of butter, cleanliness is the chief essential.

\section{Cheese}

The process of cheese-making is much more elaborate than that of making butter. Moreover, from the very large number of different kinds of cheese whose characteristics are developed by special methods of making and curing, it would be beyond the scope of this book to discuss the working details of the processes which result in any particular cheese; instead, it will be sufficient to consider very broadly the principles involved in the making of one variety, Cheddar, because these principles apply to all other cheeses. Cheese-making may start with either whole milk, separated milk, or milk from which a portion of the cream has been removed; but it is desirable that the milk should be derived from Ayrshires, Shorthorns, or Dutch cows, which do not give rise to large globules of fat readily 
separating from the serum. It is necessary to begin with a certain degree of acidity in the milk. This is obtained by leaving the vats to stand at a proper temperature, stirring from time to time, both to introduce air and to keep the cream mixed with the milk. When the proper acidity has been attained-and this will vary with each kind of cheese, and must be determined by chemical means before the cheesemaking is embarked upon-the milk is then brought to a particular temperature and mixed with a certain quantity of rennet. Speaking generally, the more acid the milk, the higher the temperature at which the rennet is added; and the more rennet is added, the more quickly will the curd come and the firmer consistency will it attain. The necessary degrees of acidity, the most desirable temperature, and the proper strength of the rennet have been worked out for most of the cheeses made on a large scale. When the curd has formed the vat is left to stand until the curd begins to separate from the serum or whey. The curd consists of the casein, in which are entangled the globules of fat contained in the original milk; the whey contains the albumen of the original milk, all the lactose, and a certain proportion of the salts, some of the calcium phosphate being retained in the casein in the curd. The next stage in cheesemaking consists in getting up a suitable consistency in the curd. In the case of a hard cheese like Cheddar, the curd is allowed to contract or shrink in the whey. It is then cut up to facilitate the removal of whey, and the whole mass is raised in temperature to increase still further the consistency of the curd and expel the whey. Finally the curd is lifted out, allowed to drain, and put through the mill in order to reduce it to small pieces. During all these processes the lactic acid bacteria are actively at work, and the curd becomes more and more 
acid. In the making of softer cheeses like Stilton, the curd is formed at a lower temperature and is not allowed to contract so much in the whey, but is removed and placed in the cheese moulds when still in a soft condition and before it has developed much acidity. In all cases, however, the curd, when it has reached its appropriate consistency, is packed into tin vessels lined with a thin cloth, and perforated at the sides to allow of the expulsion of the whey. At this stage, too, a certain amount of salt is usually mixed with the curd. In making Cheddar cheese, a considerable pressure is then applied to the curd in the moulds, and this pressure is continued two or three days until the mass is thoroughly consolidated. In the softer cheeses no pressure is applied, and the mass of curd has to consolidate by its own weight. The cheese is now made and is a soft mass possessing a slightly sour flavour, the true cheese flavour is only developed during the ripening. The ripening processes which cheese undergoes are extremely various, thus giving rise to the special and very distinct flavours which the different kinds of cheese possess. We may distinguish three distinct processes going on. I. Certain enzymes contained in the original milk attack the casein and gradually soften or even liquefy it, breaking it down into a number of simpler nitrogen compounds of the amino-acid type, some of which are strongly flavoured.

2. Though the lactic acid bacteria die out, other bacteria develop, and some of them form highly characteristic flavouring products out of the casein or the butter fat. In some case special bacteria are introduced into the curd, as in the making of Gruyère, Dutch, and Roquefort cheeses. Sometimes the bacteria associated with the special flavour of the cheese also give rise to gas, and blow round holes in the cheese, as in Gruyère. 
3. Certain moulds, such as Penicillium, the blue mould of cheese, begin to grow in the curd, and these likewise split up the casein and the butter fat, forming from them bodies possessing strong flavour and smell. The particular set of organisms which will develop in any make of cheese depends entirely upon the processes of manufacture, and in many cases upon the actual place in which the manufacture is carried out. The walls and the vessels of dairies which have for a long time been devoted to the manufacture of a particular kind of cheese become impregnated with the organisms associated with that cheese and communicate them to the new curd. Furthermore, the many details in the management which experience alone has taught the cheesemaker, can be shown to bring about the encouragement or depression of particular groups of organisms which affect the flavour of the resulting cheese. The curing process is also accompanied by a gradual shrinking of the cheese and an expulsion of the whey which is still contained in the curd. For this reason it is necessary to change the cloths surrounding the cheese rather frequently at first, and to turn the cheeses constantly when they have been put into the storage-room. It is also necessary to maintain the storage-room at the constant temperature which experience has shown to be appropriate to the development of the special flavour of the cheese. As the manufacture of cheese is thus dependent upon the development of particular groups of organisms, it is clear that it may very easily be turned in a wrong direction, should any of the encroaching putrefactive or otherwise undesirable organisms, which are abundant in dust, dirt, foul water, etc., establish themselves in the curd. It is to these intrusive organisms that defects in the flavour or texture of cheese are usually due, and they 
can only be avoided by careful attention to cleanliness and to the purity of the materials employed. The wrong kind of organisms may have already obtained a hold in the milk itself at starting, generally through want of cleanliness in the milking. Next, they may be introduced by imperfect cleaning of the utensils in which the milk stands; the water used is also often a source of danger, and has frequently been found to be a cause of various troubles in the final product. When natural souring is trusted to, a not very satisfactory flora of the various lactic acid making, bacteria may become established in the dairy. For this reason it is sometimes customary both in cheese- and butter-making on a large scale to begin by pasteurising the milk; that is, by heating it up to a temperature of about $170^{\circ} \mathrm{F}$., which kills practically all the bacteria present. After cooling, the pasteurised milk is then mixed with a "starter," consisting either of a pure culture of the desired bacteria or of the good but mixed culture contained in the buttermilk or the sour whey derived from a previous churning, or from another dairy turning out products of an appropriate flavour. In this way the development of acidity in the milk can be controlled, and this is the first step towards obtaining a standard product.

In all the farmer's dealings with milk and its products it is important to remember that the milk itself provides an almost ideal feeding-ground for bacteria ; and as bacteria of all kinds are particularly prevalent in dust and dirt, specially in the organic dirt that collects in cow stalls and cattle sheds, or in a dairy which is not kept most scrupulously clean, milk will deteriorate more readily than almost any other natural product. The only way to overcome this difficulty is to exercise the most scrupulous cleanliness, and to keep the temperature as low as possible. In the case of milk and milk products, 
dirt does mean disease, sometimes even disease for those who consume the products; more often, perhaps, the dirt gives rise to defects lowering the value of those products. To ward off the growth of these foreign bacteria recourse should not be had to antiseptics which inhibit the development of bacteria. The proper remedy is cleanliness, and cleanliness alone is sufficient for practical purposes. 



\section{N D E X}

ACID, sap, 49 ; vegetable, 75 ; soils, $90,123,147$; manures, 147 ; soil water in peaty soils, 183 ; fatty, I71, 173

Adulteration of foods, 180

Air, required in germination, II ; carbon dioxide in, 22 ; in the soil, 152

Albumen, 272, 285

Albuminoid ratio, 206, 218

Albuminoids, 66, 70, 71, 125, 169, I 73, 177

Albumoses, I73

Alcohol, 75

Alfalfa, I38, 141, 168, 199

Alimentary canal, I 7 I

Alkali land, 139

Alluvial, soils, $86,97,166$; subsoils, 95

Alumina in soils, 94

Amides, 6, 170, 204

Amino-acids, I 70, 173, 204, 276, 286

Ammonia, absorbed by plants, $5 \mathrm{I}$; in soil, 93 ; in nitrification, 122 , I25; as a product of putrefaction, I25; sulphate of, 250

Analysis, of soil, mechanical, 88 ; of various arable soils, 96

Antiseptics, 289

$a$-proteins, 6 ; converted to protein, 66,70 ; proteins converted to, 71 , 177 ; in animal food, 175 ; in silage, 177 ; in root crops, 183 291
Artificial manures, 225, 248 ; nitrogenous, 250; phosphatic, 254; potassic, 257 ; valuation of, 267 ; composition of, 268

Ash, in plants, 2 ; of crops, composition of, 55 ; in foods, 169 ; digestion of, I75

Asparagin absorbed by plants, 51

Aspect of land, II7

Assimilation, 25 ; potash required for, $26 \mathrm{I}$

Available, plant food, I5I ; energy converted into mechanical work, I98; energy of various foods, 199

Azotobacter, I4I

BACTERIA, nitrifying, I22, I45 ; putrefactive, 125, I45; ammonia producing, 125, 145 ; denitrifying, I26, I46; aerobic, I29, 146; anaerobic, I30, I46; nodule, I 32 ; nitrogen fixing, I4I ; conditions necessary to growth of soil, 145; in intestinal tract, I72, I74; in farmyard manure, 228 ; in milk, 273 ; cheese, 286 ; in the dairy, 288

Barley, manurial requirements of, I62, 263 ; as food, 182

Barren soils, 99

Basalt, 78, 80

Basic slag, 256 
Bean, germination of, 7 ; root of the, 42 ; as a recuperative crop, $\mathrm{I} 38$; soya, 180 ; as food, 182

Biennials, food storage, 69

Bile, I7 I, I72, I76

Blood, the circulating medium, $17 \mathrm{I}$, I73, 202

Bone meal, 254

Bones, 254

Boussingault, carbon balance-sheet, $2 \mathrm{I}$; on leguminous crops, 135

Brick earth, 83

Bulbous plants, 59

Bullocks, on maintenance diet, I95, I 97 ; on fattening, I95; minimum protein requirements, 203

Butter, $28 \mathrm{I}$; fat, $27 \mathrm{I}, 276$

CAKES, oil, 178

Calf, composition of fat, 207

Calorie, 186

Capillarity, 104

Carbohydrates, in plants, 5 ; in foods, 169; digestion of, 172 ; proteins and fats in terms of, 183 ; dependence on potash, 26I

Carbon, in plants, 2 ; increased weight of plants largely made of, 20 ; drawn from the air, 21 ; in humus, 27

Carbon dioxide, evolved in germination of seeds, II ; in air, 22 ; split up by plants, 22 ; excreted by roots, 48,50 ; dissolved in rainwater, 79; in soil gases, I53; product of combustion in animal body, I72, I73, I74

Carbonate of lime, dissolved by soil water, 80 ; in soils, 90 ; in subsoil, 95 ; in heavy soils, beneficial effect of, 98,167 ; absence in soil inhibits bacterial action, I44, I47

Carcass weight, 208

Casein, 269, 272, 285

Castor cake, 260
Cellulose, in plants, 5 ; fermentation by soil bacteria, I29; digestion of, 172

Cereals, as foods, 182

Chaff, 64

Chalk, formations, 97 ; soils; 90, 167

Cheese, 284 ; ripening of, 286

Chewing of the cud, 172

Chlorine, in plants, 50 ; in soils, 94

Chlorophyll, assimilation, 24; iron necessary to formation of, 5 I

Churning, 28I

Citric acid as a soil solvent, I 54

Clay, derived from felspar and basalt, 80 ; obtained in mechanical analysis, 89 ; properties of, $9 \mathrm{I}$; soils, $97,106,108,166$

Clover, on succeeding crop, effect of growth of, I 35 ; manures for, 265 Colostrum, 277

Colour of soils, I 16

Combustion in animal body, I 73

Compensation for food-stuffs consumed, 243

Condition of the soil, 147, 239

Cooking does not increase digestibility, 177

Corm of colchicum, 60

Corn, place in diet, 194, 200

Cotton-seed cake, 169, 178, 180, I83, 192

Cotyledons, 7

Cows, breeds of, 270,274

Cream, 28I

Crocus, contractile root of, 44 ; autumn (colchicum), 60

Crops, water required by, 39 ; drying action of, 39 ; effect of catch, 40 ; composition of, 57

Cultivation, I07

Curd of milk, 272, 284

Cuticle, 37

Cuttings, 72

Cyanamide, 250 
Cytase, I72

DANDELION, contracted root of, 44

Decay of organic matter, I 29

Denitrification, I 26

Desiccation, 66

Dew, 38

Diastase, 16, 72 ; function in leaf, 28 ; in saliva, $\mathbf{I 7 2}$

Diet, in digestibility experiment, I 76 ; maintenance, 189

Digestibility, of foods, I75 ; experiments, I 76

Digestion, I70; work expended on, 190

Diminishing returns, law of, 263

Diphenylamine, test for nitrates, 93

Disease, susceptibility of plants to, 261

Dormant plant food, I 5 I

Drainage, II 5

Drift soils, 82 ; glacial, 84

Dry farming, I I 3

Dung, short and long, 226 ; London, 236

Dynamic energy, 192, I93

\section{EARLY soils, II6}

Earth-nut cake, I80

Embryo in seed, 7

Endosperm, 8, 64

Energy, stored by plants, 33 ; in a nimal body, r72, I 73, I85 ; transformed to heat and work, 185 ; available for work, I90, I99; dynamic, I90, I92 ; thermal, I88, I92 ; total, I87, 192

Enzymes, 16, 72, 76, I71, 203, 272, 286

Equivalents, starch, 184, 215

Essential oils, 6

Etching, action of roots, 4

Ether, in fat extraction, 169

Ethers, 75
Evaporation, cooling effect of, 109 ; loss of water by, I09, I IO; checked by hoeing, III; checked by wind breaks, II4

FAECES, I 7I, I 74, 226

Fallow on soil moisture, effect of, 40 , II 2

Farmyard manure, 158,224 ; composition, 234; use of, 238,242 ; duration of, 240 ; physical effects of, $24 \mathrm{I}$; cost of, 246

Fats, in plants, 5 ; in foods, 169 ; digestion of, I 7 I ; heat value of, I83; in terms of carbohydrates, 183 ; fuel value of, 187 ; in milk, 270

Fattening, animals, 195, 207 ; composition of increase in, 208

Fehling's solution, I 5

Felspar, 80

Fermentation, 75; aerobic, 128, I29; anaerobic, I29, I 30 ; of farmyard manure, 228

Ferments, 16

Fern, growing in air-tight bottle, $3 \mathrm{I}$ Fertilisers, 248 ; nitrogenous, 250 ; phosphatic, 254; potassic, 257 ; nitrogenous, effect of, 260 ; phosphatic, effect of, 26I ; potassic, effect of, 257 ; valuation of, 267 ; composition of, 268

Fertility, maintenance of, 158

Fibre, in plants, 5, 69; in foods, I69; digestion of, I72, I74

Film, in soils, the water, roI

Fine earth, 86

Finger-and-toe, 147,256

Fish manures, 259

Fixation of nitrogen, I 3 I

Flocculation, 92, 108, I I 5

Food, used as fuel, I72, I 74 ; more digestible than poor, rich, I77; valuation of, 183 ; as a source of energy, 185 ; fuel value of, 187 ; 
in relation to live weight increase, 210 ; rations, 217 ; manure value of, 243

Frost, distribution of plants by, 47 ; disintegration of rocks by, $8 \mathrm{I}$; valleys specially liable to, II 7

Fuel value of food, I 87

Fungi in the soil, 147

GASES, soil, I53

Gastric juice, I7I, I73

Gelatin from bones, 254

Germination, conditions necessary to, 9

Gluten, 6, 65; meal, 18I, 183

Glycerin, $27 \mathrm{I}$

Glycogen, I73

Grain, the filling of the, 63

Granite, 78, 80

Grass, composition of meadow, 4 ; land, manures for, 265 ; characteristic, $164,165,167$

Gravel, deposition of, 82, 83

Greaves, 259

Growth, elements necessary to plant, $5 \mathrm{I}$; changes of composition during, 59 ; temperature required for, II4 Guanos, 257

HAY, growth and ripening of meadow, 68 ; digestibility of, 177 ; composition of, 182 ; heat value of, 189; dynamic value of, I94, I99; place in diet, I94; values, Thaer, 217 ; manures for, 265

Heat value of foods, 188

Heating of soils, II4, II6

Heavy soils, 97, II 8

Hellriegel, on transpiration, 38 ; and Wilfarth on nitrogen fixation, 132

Hoeing, II 2

Hops, 74

Horse, fed upon straw, I9I ; on maintenance diet, 194, I97 ; a vail- able energy of various foods fed to the, I99; energy requirements of working, 200 ; minimum protein requirements, 203

Humus, 86 ; soluble in alkalis, 87 ; in subsoil, 95 ; product of cellulose fermentation, I 29, I30; value of, 24I

Hydrochloric acid, solvent action on soils, 94 ; in stomach, 175

Hydrogen, I 73, 187

ICE as a transporting agency, 84

Inoculation of nodule organisms, 132, 139

Intestines, I7 I, I76

Iron, in plants, 50 ; in rocks, 80 ; in soils, 94

\section{KAINIT, I 59, 257}

Kellner, on fuel values, I88, I $9 \mathrm{I}$; on the maintenance of store bullocks, 197; energy requirements of working horses, 200 ; standard rations, 223

Kelp, 257

Kephir, 273

Kidneys, I74, 202

King on transpiration, 38

Koumiss, 273

LACTATION, period of, 277

Lactic acid, 273, 283, 285

Lactose, 269, 272

Lawes and Gilbert, 255; on transpiration, 38 ; on the composition of farm animals, 207

Leaf, work of the, 19 ; starch formation in the, 26 ; removal of, 34 ; stomata in, 37 ; the fall of the, 73

Lean meat, $174,189,209$

Leguminous crops, 54, 132, I 35 ; plants and soils, $164,165,168$

Light, assimilation and, 24, 26; soils, 98, II 6, II 8 
Lime, in plants, 50,73 ; in ash of crops, 54 ; in soils, 94 ; nitrate of, 250,253 ; in basic slag, 250

Limestones, 97

Linseed cake, 176, I78, 181

Lipase, I6, I7 I

Litter, 228

Liver, 173

Loam, 107, 165

London dung, 236

Lucerne, 138, 141, 168, 199

Lymphatic system, I 7 I

MAGNESIA, in plants, 50 ; in soils, 94

Maintenance diet, 189,195

Maize, gluten meal, 182 ; as food, 182; dynamic value of, 199; manures for, 264

Malt, I6

Mangold, yield proportional to combined nitrogen supplied, 53 ; food storage, 69 ; composition of, 69,182 ; manures for, 264

Manure, farmyard, 224; artificial, 225,248 ; required by crops, 263 ; value of foods, 243

Manuring, theories of, $16 \mathrm{I}$

Marl, 98, I67

Marsh-gas, 127, 173, 187, 229

Meals, 178

Meat guanos, 259

Metabolism, of proteins, 66, 70, $7 \mathrm{I}$, I73, 202; of carbohydrates, 172 ; of fats, $17 \mathrm{I}$; of starch, $14,26,172$

Methane, $127,173,187$; in farmyard manure, 229

Mica, 80

Micropyle, 9

Migration of plant food, 60,63

Milk, fat in, I7I, 173 ; composition of, 269,273 ; souring of, 273 ; morning and evening, 278 ; analysis, 280

Moisture in foods, 169
Moulds in cheese, 287

Mulch, III ; soil, II3

Mummy wheat, I 3

Müntz on digestion, I9I

Muriate of potash, 257

Mustard seed in rape cake, 178

Nitrate, of soda, 250, 252; of lime, 250, 253

Nitrates, in water cultures, $5 \mathrm{I}$; in soil, 93, I 21 ; lost in denitrification, I 26

Nitre, 12I

Nitrification, 12 I

Nitrites formed in process of nitrification, 122

Nitrogen, in plants, 3 ; required in combined state by plants, 53 ; accumulation in black virgin soils, 54 ; in plant food, 66,70 ; in humus, 87 ; in soils, 95,149 ; cycle illustrated, 125 ; lost by denitrification, 127; fixation by bacteria, I3I; losses and gains during a four-course rotation, I59; excreted by kidneys, I74 ; losses of, in manure-making, 230 ; in fertilisers, $25^{\circ}$

Nitrolim, 250

Nodules, on roots of leguminous plants, 132 ; organisms, racial adaptation of, I 39

OATs, as food, 182, 199; manures required by, 264

Offal, weight of, 208

Oils, in plants, 5 ; cakes, 169,178 ; digestion of, I 7 I, I74

Organic matter, in soils, $86, \mathrm{II} 6$; promotes denitrification in soils, 126, I46

Oxen, composition of, 207

Oxygen evolved by plants, 23

PALM-NUT cake, 180 
Pancreatic juice, I7I, I72, I73

Papain, 16

Pastures, fattening, I95 ; manures for, 265

Peas as food, 182

Peat, I30; moss litter, 228 ; moss manure, 236 ; soils, $86,90,95$, I23, I 53, IE8

Pectins, 7I, 75, I82

Pepsin, 16,173

Peptone, I 24, I 73

Percolation, I05

Pericarp, 64

Peruvian guanos, 257

Phosphate of lime, as a food constituent, 175

Phosphoric acid, necessary to plant growth, 50; in soils, 94, I49; removed in four-course rotation, I59; deficient in clays, 167 ; in fertilisers, 254

Physical effects of farmyard manure, 24I

Pigs, composition of, 207

Plant, food, migration and storage of, 60,63 ; food, dormant and available in soil, I5I ; excretions, I 57

Ploughing, autumn, I07; spring, I08; work done by horses in, 200

Pore space, 104

Potash, in plants, 50,53 ; in soils, 94, 149; removed in four-course rotation, 158 ; abundant in clays, I67; manures, 257

Potato, 72 ; districts, early, II 8 ; composition of, 182 ; manures for, 257

Prairie soils, 144

Preservatives in dung-heaps, 233

Protease, I6

Protein, in plants, 6 ; and $a$-proteins, $66,70,71,177$; breakdown and reconstruction, 125 ; in foods, 169 ; digestion of, 173 ; in silage,
I77; heat value of, 188,201 ; in terms of carbohydrates, 183 ; fuel value of, 187 ; requirements, 174 , 201

Protozoa, 147

Puddled clay, 9I

Putrefaction, I 24

QUALITY in produce, 77

Quartz, 80

RAPE, cake, I78 ; dust, 259

Rations, construction of food, 217 ; for milch cows, $28 \mathrm{I}$

Rennet, 272, 285

Respiration, in plants, 29, 60, 63 ; of roots, 47 ; during storage of root crops, 7 I ; chamber, 2 II

Ripening, of grain, 66 ; of fruits, 57

Rock, 78 ; primitive, 80 ; volcanic, 80 ; phosphate, 255

Rolling, I IO

Root, 22 ; hairs, 43 ; adventitious, 44 ; source of water supply to plants, 46 ; effect of frost on, 47 ; absorbs soluble substances, 48 ; etching action of, 49 ; part played in weathering, 81 ; nodules, 132

Root crops during storage, changes in, 71 ; digestibility of, 178 ; composition of, 182

Rotations, value of, 156

Ruminants, I72, I74, I77

SAINFOIN, 138,168

Saliva, $\mathrm{I} 72$

Salt as a food constituent, I75

Sand, deposition of, 82,83 ; in mechanical analysis, 88 ; properties of, $9 \mathrm{r}$; in foods, 170

Sandy soils, $98,107,163$

Sap, 50 ; acidity, 49

Sea, temperature in proximity to, I1 8 
Seed, 6 ; "hard," 9 ; vitality of, 13 ; depth of sowing, I3 ; testing, 17

Seed-bed, I8, I08, II 3, 24 I

Separation of milk, 28I

Sheep, on maintenance diet, 195, 197; on fattening diet, I95; minimum protein requirements, 203 ; composition of, 207

Shoddy, 260

Silage, digestibility of, I77

Silica, in plants, 50, 54, 73; in soil, 94

Silt, deposition of, 83

Slag, basic, 256

Soda, in plants, 50 ; in soils, 94 ; nitrate of, 250, 252

Soil, origin of, 78 ; sedentary, 79 ; of transport, 82 ; motion of the, 84 ; chemical constituents of, 93 ; relation to subsoil, 95; water, movements of, 100; colour of, I16; inoculation, I39; chemical composition of the, I49; gases, 153

Soot, II6, 250, 253

Souring of milk, 273

Soya bean cake, I80, 18 I

Standard rations, 223

Starch, in plants, 5, 14, 26; iodine test, 14 ; digestion of, 172 ; heat value of, 188 ; equivalent, 184 , 215 ; use of, 219

Starters, milk, 288

Stassfurt potash deposit, 257

Steppe soils, 144

Stomach, I I I

Stomata, 37

Stones, growing on arable soils, 84 ; in soil samples, 86 ; check evaporation, II5

Storage, of plant food, 60 ; of fats in animal body, 173 ; of protein in animal body, 174

Store condition, 194, 197
Straw, digestibility of, I77; composition of, 65,182 ; food value, I9I, I99; as litter, 228

Strippings, milk, 278

Subsoil, 79, 95 ; packing, II 3

Sugars, in plants, 5 ; test for, 15 ; in mangolds and beet, 69 ; in turnips, $7 \mathrm{I}$; action of yeast on, 76 ; digestion of, I 7I, I 74

Sulphate of ammonia, 250 ; potash, 257

Sulphur, in plants, 50 ; in soil, 94

Sun, source of heat to soils, II4

Superphosphate, I 58, 255

Surface tension, 100; of soil particles, I05

Swede turnip, food storage, 69; composition of, $7 \mathrm{I}, \mathrm{I} 82$; manurial requirements of, 163,264

Symbiosis, $\mathrm{I} 33$

\section{TANKAGE, 259}

Tannins, 75

Temperature, soils, II4 ; dung-heap, 230; body, 196

Test, for starch, 14 ; for sugar, I5 ; seed, 17; for carbon dioxide, 24

Texture of soil, I08, II5, 24I 252

Thaer, 217

Thermal energy, 192

Thomas's phosphate powder, 256

Tillering, 44

Tilth, 108, 157,252

Transpiration, 36 ; devices to reduce, $4 \mathrm{I}$

Transport, soils of, 84

Trees, characteristic, $165,167,168$

Trypsin, 173

Turnips, food storage, 69 ; composition of, 182

UREA, 174, 187, 202, 229

Urine, I 74, 203, 225, 229 
Valuation, of feeding stuffs, 183 , 213 ; of fertilisers, 267

Vetches, 138

Virgin soils, 54, 144

WATER, in plants, 2 ; required by crops, 39,107 ; cultures, 45 ; as a weathering agency, 79 ; as a transporting agency, 82 ; in animal body, I7I, I72, I74

Waxes, 5

Weathering of soils, 79

Weeds, 34 ; seeds in oilcakes, I8 I

Wheat, root, 43 ; development of, 61 ; effect of wet autumn on, 62 ; "strong," 65,156 ; in wet and dry seasons, 67 ; manurial requirements of, 162,263 ; as food, 182
Whey, 273, 285

Wilting, 46

Wind, as a transporting agency, 82 ; breaks, II4

Wollny, 38

Wood ashes, 257

Wool, 203

Work, done in animal body, 172 , 173,189 ; energy converted to, 186 ; done in walking and trotting, 198

Worms, action of, 85

YEAST, 75

ZEIN, 204

Zuntz, 191, 197, 198 



THIS BOOK IS DUE ON THE LAST DATE STAMPED BELOW

\section{AN INITIAL FINE OF 25 CENTS} WILL BE ASSESSED FOR FAILURE TO RETURN THIS BOOK ON THE DATE DUE. THE PENALTY WILL INCREASE TO 50 CENTS ON THE FOURTH DAY AND TO \$1.00 ON THE SEVENTH DAY OVERDUE.

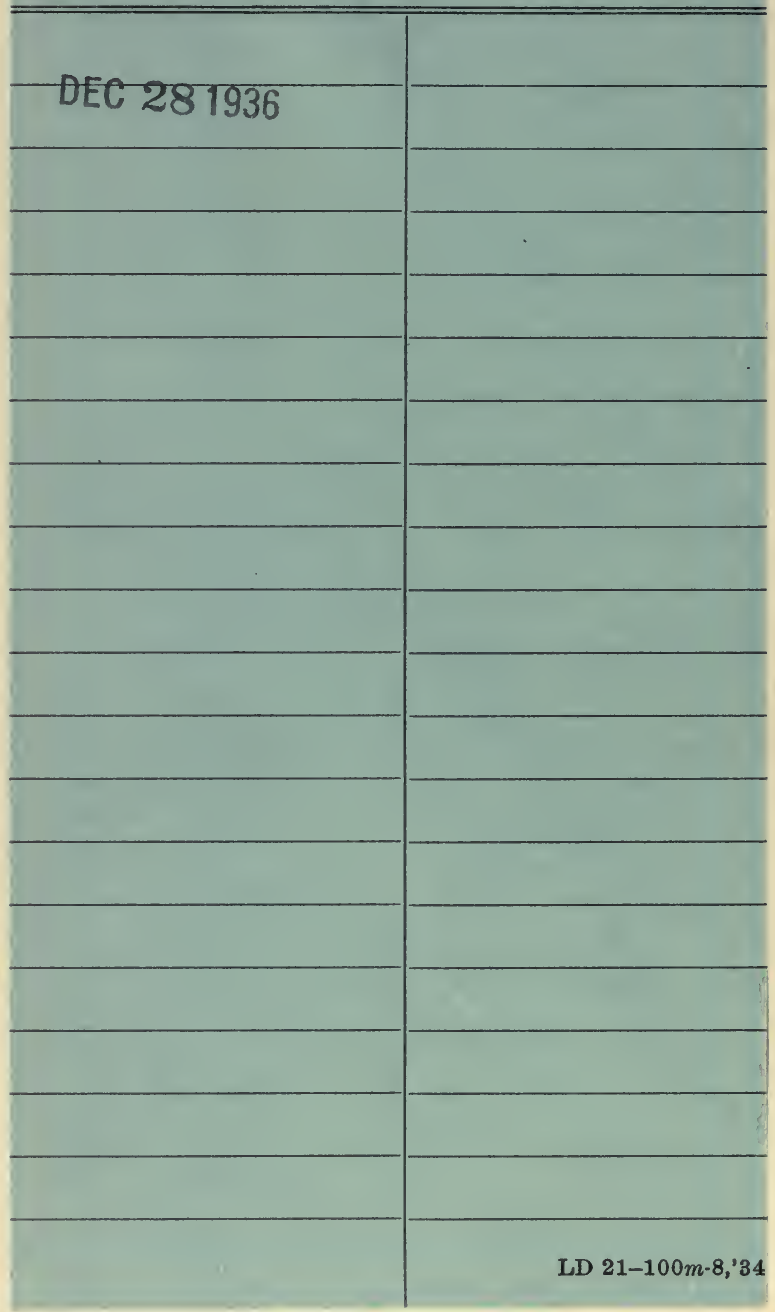



